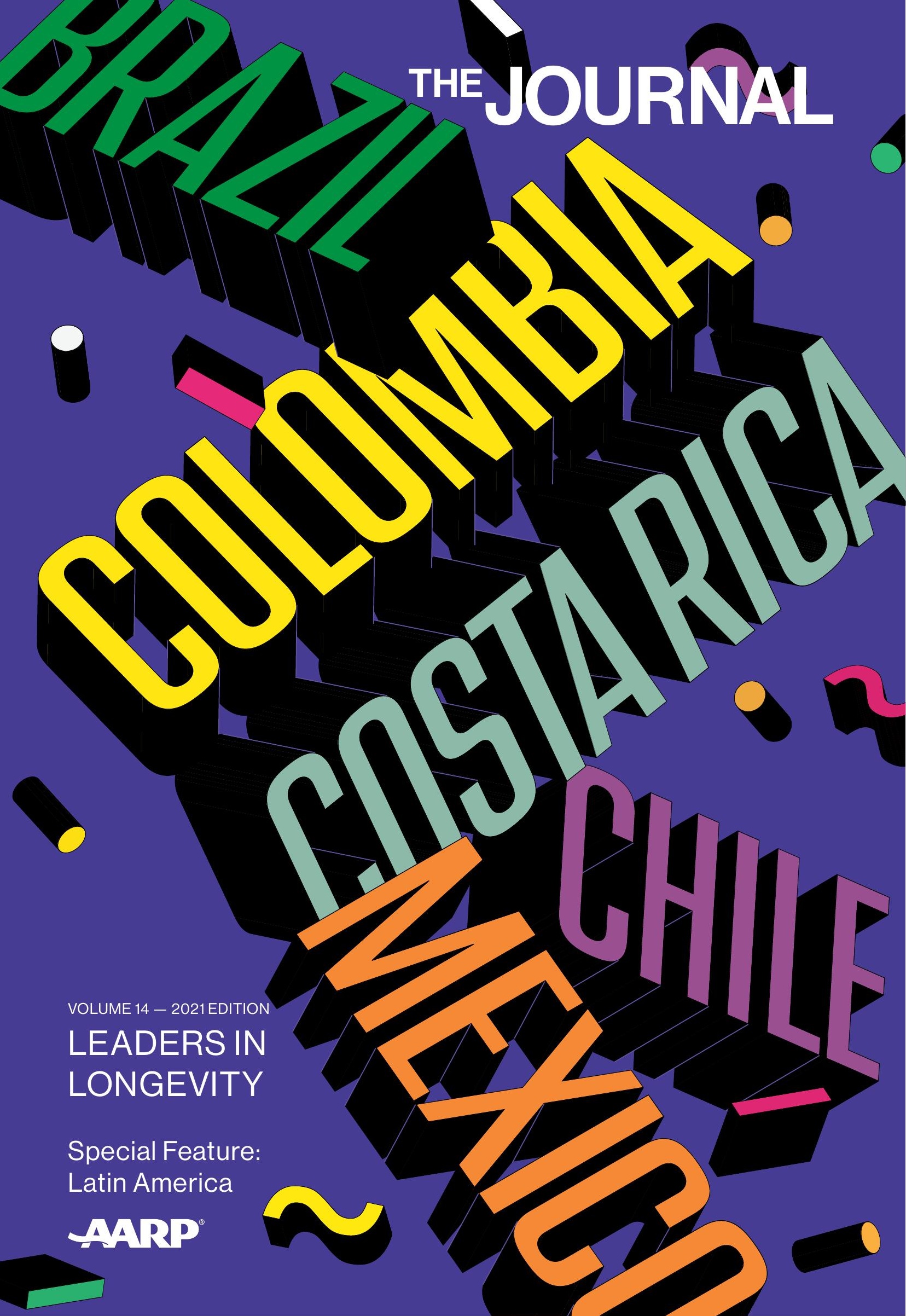




\section{F. Akosua Agyemang}

is a professional social worker and social gerontologist. Akosua is a Senior Lecturer at the University of Ghana, Legon. Akosua has a strong background in research, community development, gender, children, elderly care, adult education and other related issues. She has over 30 years working experience at different stages of her career. She has lectured and presented papers in Ghana and other foreign countries in Africa, Europe and America.

\section{Martha Boudreau}

is AARP's chief communications and marketing officer. She is responsible for setting enterprise brand and communications strategy and unifying AARP's voice throughout the organization's extensive channels: social, digital, earned media and paid media along with AARP's leading publications, AARP The Magazine and AARP Bulletin.

\section{Andrew Byrnes}

is Emeritus Professor of International Law and Human Rights, Faculty of Law \& Justice, University of New South Wales, Sydney, Australia. He is also a research associate of the Australian Human Rights Institute and the Ageing Futures Institute, both at UNSW.

\section{Emer Coveney}

is the National Programme Manager with Age Friendly Ireland, where she manages a team-based framework of 31 local Age Friendly Programme Managers assigned in each local authority in Ireland. Dr. Coveney contributes to the development of resources and guidance documents for the national programme as well as managing research links with external organizations.

\section{Julio Frenk}

became the sixth presidentof the University of Miami in August of 2015. He also holds academic appointments as professor of public health sciences at the Leonard M. Miller School of Medicine, professor of health sector management and policy at the Miami Herbert Business School, and professor of sociology at the College of Arts and Sciences. Prior to joining the University of Miami, he served for nearly seven years as dean of the Harvard T.H. Chan School of Public Health and T \& G Angelopoulos Professor of Public Health and International Development, a joint appointment with the Harvard Kennedy School of Government. Julio Frenk was the minister of health of Mexico from 2000 to 2006.

\section{Terry Fulmer}

is President of The John A. Hartford Foundation in New York City, a national philanthropy dedicated to improving the care of older adults. She serves as the chief strategist for the Foundation and her vision for better care of older adults is catalyzing the Age-Friendly Health Systems social movement. She is an elected member of the National Academy of Medicine and recently served on the independent Coronavirus Commission for Safety and Quality in Nursing Homes.

\section{Tedros Adhanom \\ Ghebreyesus}

was elected WHO Director-General

for a five-year term by WHO

Member States at the Seventieth World Health Assembly in May 2017. In doing so, he was the first WHO Director-General elected from among multiple candidates by the World Health Assembly, and was the first person from the WHO African Region to head the world's leading public health agency.

\section{David C. Grabowski}

is a professor of health care policy at Harvard Medical School. His research focuses on long-term care financing, organization, and delivery of services. He is a member of the Medicare Payment Advisory Commission, and he served on the CMS Coronavirus Nursing Home Commission.

\section{J. Nadine Gracia}

is the President and CEO of Trust for America's Health (TFAH), a nonprofit, nonpartisan public health policy, research and advocacy organization that promotes optimal health for every person and community. Dr. Gracia is a national health equity leader with extensive leadership and management experience in federal government, the nonprofit sector, academia, and professional associations.

\section{Stephen Johnston}

is the co-founder of Aging2.0, a global innovation platform with 125 city chapters in 27 countries addressing the 'Grand Challenges' in ageing. He is also founder of Fordcastle, a boutique consulting firm helping organizations at the intersection of impact and innovation. Stephen is the co-author of Growth Champions (Wiley) and serves on a number of non-profit boards, including Music \& Memory, a New York non-profit that uses music to improve the lives of those with dementia.

\section{Pablo lbarrarán}

is a principal social protection specialist at the Social Protection and Health Division at the IDB. His recent work has focused on aging and social protection and is involved in policy dialogue on the development of long-term care systems. 


\begin{abstract}
Aleš Kenda
works as a secretary at the Ministry of Labour, Family, Social Affairs and Equal Opportunities of the Republic of Slovenia. He has devoted nearly two decades of work to a wide variety of topics related to population aging, participating in the preparation and implementation of the latest two strategies on responses to demographic change. In 2012, he was the National Coordinator of the European Year for Active Ageing and Solidarity between Generations. Mr. Kenda is also a member of the Standing Working Group on Ageing at the United Nations Economic Commission for Europe (UNECE) in Geneva.
\end{abstract}

\section{Peter Lloyd-Sherlock}

is Professor of Social Policy and International Development at the University of East Anglia in the UK. He coordinates an expert network on older people and coronavirus in low and middle-income countries. His research focuses on health and social care interventions in Latin America, Asia and parts of Africa.

\section{Kim McCoy Wade}

is the Director of the California Department of Aging. She most recently served at the California Department of Social Services as the CalFresh \& Nutrition Branch Chief, where she led the expansion of CalFresh food benefits to older adults and people with disabilities, as well as several data and technology initiatives, including the GetCalFresh mobile application. She previously served as a consultant to multiple health and human services non-profits and as Executive Director of the California Association of Food Banks.

\section{Cecilia Morel Montes}

is a Family Counselor and currently the First Lady of Chile. In the first term of her husband, Sebastián Piñera, in addition to leading the Network of Foundations of the Presidency, she created the "Elige Vivir Sano" program, an initiative that seeks to promote healthy habits and fight obesity and sedentary lifestyles. In this second term of government, in addition to her role in the foundations, she has led "Better Ageing" Program, an initiative that seeks to promote a cultural change regarding older persons, strengthening their social integration and promoting positive and healthy aging.

\section{Déborah Oliviera}

holds BSc and MSc degrees in Nursing from the University of Campinas (Brazil), and a PhD from the University of Nottingham (United Kingdom). She works at the IDB's Social Protection and Health Division and has global experience working on the fields of long-term care, dementia, and public policy.

\section{Julieta Rodríguez Duarte} is President of Fundación Provida Colombia, an organization founded 47 years ago by her parents. Prior to joining this team, she studied fashion design. In her current work, she promotes innovation in education and wellness programs to create awareness about what it means to experience active and purposeful aging.

\section{Kenneth Roth}

is the executive director of Human Rights Watch, one of the world's leading international human rights organizations, which operates in more than 90 countries. Roth has conducted numerous human rights investigations and missions around the world. He has written extensively on a wide range of human rights abuses, devoting special attention to issues of international justice, counterterrorism, the foreign policies of the major powers, and the work of the United Nations.

\section{Marcia Scazufica}

is a Senior Researcher at the Institute of Psychiatry, University of São Paulo. Brazil. Her scientific interest is in epidemiology and mental health, with emphasis on research with older adults, pragmatic clinical trials in primary care, and the development of innovative treatment models for mental disorders.

\section{Matthias von}

\section{Schwanenflügel}

is the Director General of the Division of Demographic Change, Older People and Welfare in the Federal Ministry of Family Affairs, Senior Citizens, Women and Youth. From 2010 to 2014, he was Head of the Household, Legal and Telematics Division and, from 2005 to 2010, Head of the Nursing Care Sub-Division of the Federal Ministry of Health, where he had been working in various departments since 1991.

\section{Sofía Elena Segura}

is a professor at the School of Medicine of the University of Costa Rica. She also serves as Coordinator of the Programa Institucional para la Persona Adulta y Adulta Mayor of the University of Costa Rica. Ms. Segura holds a degree in Pharmacy from the University of Medical Sciences, a Master in Pharmacology and Drug Management from the University of Costa Rica, and is currently pursuing a Master in Social Management from UNINI. 


\section{The Format}

The Journal contains three main sections: Departments, Contributors, and Feature.

Departments provides exclusive articles, insights and interviews from AARP and the International team. The Contributors section contains thoughtful pieces from a wide range of experts, policymakers, and AARP's own in-house thought leaders. The Feature explores in depth the aging reality of a region, told through a multitude of stories and visual narratives.

\section{AMPP}

AARP International engages global stakeholders to spark solutions that strengthen communities, protect the vulnerable and enable people around the world to pursue their goals and dreams. Working with governments, civil society and the private sector, we are focused on enhancing the quality of life for people as they age. We serve as the global voice for AARP, a social change organization with a membership of more than 37 million.

\section{Departments}

From the Editor-in-Chief, Peter Rundlet

6

From the CEO, Jo Ann Jenkins:

Turning the Decade of Healthy Ageing into Action, in the U.S. and Across the World 10

From the Executive Editor, Jean Accius:

Aging: The Impact from Every Tailored Action

14

Newsmakers Interviews: AARP Speaks with Leading Advocates for Older Adults Around the World 18

\section{Julio Frenk}

Applying the Pandemic's Public Health Lessons Holds Promise for Latin America and the World

30

\section{Contributors}

\section{BIGPICTURE}

Tedros Adhanom Ghebreyesus The Decade of Healthy Ageing is an Investment in All of Our Futures 32

\section{AGE-FRIENDLY ENVIRONMENTS}

\section{Emer Coveney} Age Friendly Towns in Ireland 34

\section{Kim McCoy Wade}

Building a Better California for All Ages and Abilities

38

\section{COMBATTING AGEISM}

\section{Andrew Byrnes}

Protecting the Human Rights of Older Persons

40

\section{Martha Boudreau}

Combating Ageism in the Media and Marketing

42

\section{Kenneth Roth and Bridget Sleap}

A Turning Point for the Rights of Older People

44

\section{Aleš Kenda}

Response of the Republic of Slovenia to Population Aging 48 
Feature Story

LATIN AMERICA

\section{INTEGRATED CARE}

\section{Peter Lloyd-Sherlock, Karla Cristina Giacomin and Lucas Sempé \\ An Innovative Caregiving \\ Program Shows Promise \\ 52}

\section{Stephen Johnston \\ Global Innovations in Aging \\ and Longevity \\ 56}

\begin{abstract}
Nadine Gracia and Terry Fulmer Why We Need Age-Friendly

Public Health Systems

60
\end{abstract}

\section{LONG-TERM CARE}

\section{Déborah Oliveira, Natalia} Aranco, and Marco Stampini Long-Term Care Challenges and Opportunities in Latin America and the Caribbean 64

\section{David C. Grabowski}

Lessons from Abroad, Applied State-Side: The US Needs to Increase Investment in Home and Community-Based Services 68

\section{Matthias von Schwanenflïgel} Concerted Action for Nursing Germany's Strategy to Combat the Shortage of Nursing Professionals 70

\section{F. Akosua Agyemang} Long-Term Care and Caregiving for Older Adults in Africa

\section{Latin America and The Caribbean 78 \\ Regional Highlights \\ 84}

BRAZIL

90

\section{Marcia Scazufca}

Message Received, Loud and Clear: Pandemic Shows Society Falling Short of Statute's Vision 96

\section{Brazil: Day in the Life 100}

\section{Serving Up Tradition} 104

\section{CHILE}

118

\section{Cecilia Morel Montes}

Dignity and Quality of Life:

Prioritizing Aging Issues in Chile 124

Chile: Day in the Life 128

Tightly Woven Community 132

\section{COLOMBIA}

144

\section{Julieta Rodriguez and}

\section{Nancy Bohorquez}

How Colombia Uses Education to Drive Its Healthy Longevity Work 150

\section{Colombia: Day in the Life} 154

\section{Saving Salsa}

158

\section{COSTA RICA}

170

\section{Sofia Elena Segura}

The Aging Population in Costa

Rica and the Importance of

Lifelong Learning

176

\section{Costa Rica: Day in the Life} 180

In the Zone

184

\section{MEXICO}

196

Pablo Ibarrarán, Ana Mylena Aguilar, Fiorella Benedetti, Natalia Aranco

Turning Challenges into Opportunities: Accelerated Aging in Mexico

202

\section{Mexico: Day in the Life} 206

Guardians of Culinary Customs 210 
AARP

Jo Ann Jenkins

Chief Executive Officer

EDITOR-IN-CHIEF

Peter Rundlet

Vice President

International

\section{Debra Whitman}

Executive Vice President and

Chief Public Policy Officer

\section{EXECUTIVE EDITOR}

Jean Accius

Senior Vice President

Global Thought Leadership

\section{Jeff Gullo \\ Julia Elrod \\ Michael Epstein \\ Ian Hartman-O'Connell \\ Sarah Sampson}

CONTRIBUTING WRITERS

Carol Blymire

Boe Workman

\section{LATIN AMERICA}

Francisco Adriazola Santibañez

Boriana Benev Ode

Henri Carrières

Diana Catalina Davila Suarez

Ivonne Fernandez

Luis Miguel Gutiérrez-Robledo

Alex Juarez

Alexandre Kalache

Belen Mendoza

Yvette Peña

Carlos De Los Ramos

José Roberto Acarón

Luis Rosero-Bixby

Geneza Sorai Henry

Puru Trivedi

Octavio Vergara Andueza

Jorge Vindas

\section{THE JOURNAL ONLINE}

aarpinternational.org/journal

\section{AARP INTERNATIONAL ONLINE \\ aarpinternational.org \\ FACEBOOK \\ Colombia \\ Mariela Vallejos \\ Chile \\ facebook.com/aarpintl \\ TWITTER \\ Laura Avila
Fabrice Le Lous
Costa Rica}

CREATIVE + EDITORIAL

ultrastudio.co

Lauren Hassani

Editorial Director + Writer

Marco Javier

Creative Director

Carolina Marin

Research Assistant

Tim Fleschner

Research Assistant

Contributing Writers

Elisabeth Malkin

Mexico

Priscila Pacheco

Brazil

\section{Andrew J. Wight}

\section{CONTACT \\ AARP International \\ 601 E Street, NW \\ Washington, DC 20049 \\ United States \\ T +1 2024342398}




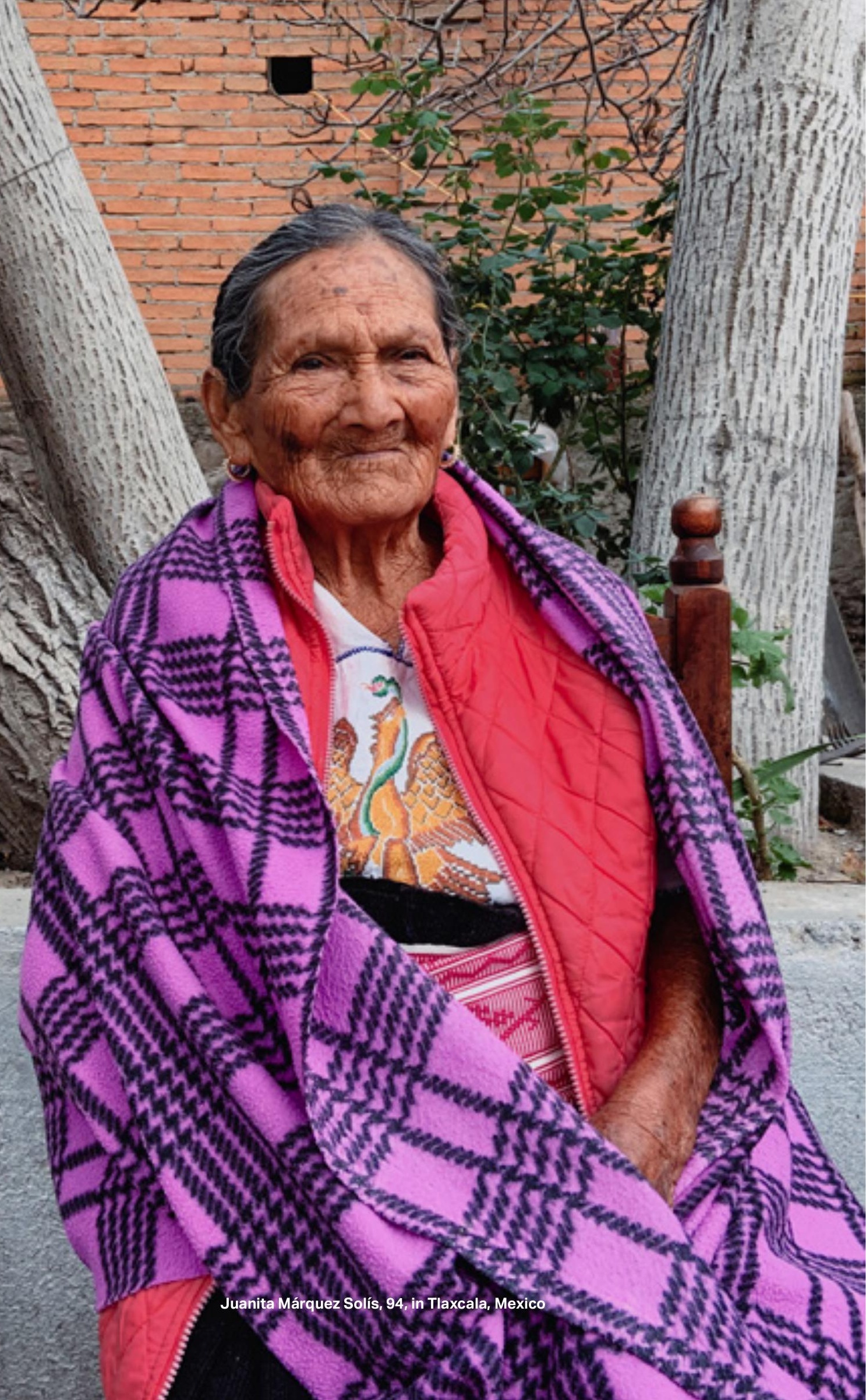




\section{The Journal, 2021 Edition} periods in history that are truly pivotal, those points during which virtually everything changes. They say that news articles are the first drafts of history; those of us living through these times know that something big is taking place, but we don't yet have the perspective to know how it will all settle.

That is the case today. We are floating through the rapids, enveloped by mist too thick for us to know where we are heading. And though each of us is living in our own turbulent world, the turbulence spans the globe: everyone, everywhere, is living or suffering through this storm in their own way.

Meanwhile, in seeming defiance of the present moment, more and more people are living past the age of 100, thanks to advances in health care and technology. There are people living today who were alive when women won the right to vote; when the Great Depression hit; during both World Wars, the Holocaust, and the dropping of the atomic bombs in Japan. These same people have also seen the rise and fall of Communism, the moon landings, and the creation of both the personal computer and the Internet. They have lived through the paradigm shift caused by $9 / 11$ as well as the Great Recession. And today we continue to face challenging times in America and around the world. We are witnessing increasing racial strife and political division, the resurgence of authoritarian governments, growing economic inequality, and the undeniable effects 


\section{The focus of our work at AARP this past year - and indeed in this 14th edition of The Journal - was on how to maximize the opportunity that healthy longevity affords us.}

of climate change. On top of all of that we have the seemingly unending COVID-19 pandemic.

The pandemic has been an almost unmitigated disaster. At the time of this writing, the United States had surpassed 800,000 deaths - and more than 5.3 million people have died of COVID globally. At both home and abroad the statistics are the same: approximately 75 percent of the people who have died were ages 65 years and older. And so, it seems, the pandemic does discriminate. Moreover, in the United States, the impact of Covid was devastatingly worse for Black people, indigenous communities, and other people of color.

But despite all of the tragedy, our collective resilience demonstrated that we could shift nearly everything in our lives to fight the virus and reduce harm. Seemingly overnight, we reordered our lives. Much of the workforce went home and did their jobs from there, all while caring for family members and teaching kids, often at the same time. And those essential workers who had to endanger themselves to do their jobs were recognized as everyday heroes. The world's scientists acted with remarkable speed to invent vaccines and create cures, and - though there was room for improvement - countries collaborated to share information, resources, and vaccines to stem the reach of the coronavirus.

In so many ways, the pandemic has been an exercise in empathy for us all. It's as if we've witnessed a collective epiphany, seemingly self-evident yet strikingly illusive: workers are human beings, with home lives and a multitude of responsibilities. As home became our workplaces, employers and colleagues became more flexible and adaptive, finally accommodating the reality that so many of us have others to care for, especially during COVID. And we proved we could do it. The economy of the United States in particular has rebounded, even surpassing where it was before the pandemic by the second quarter of 2021. Today, unemployment is down and employers are actively searching for workers. We succeeded with an adaptive work environment.

So, we will recover - perhaps with a new perspective and a renewed recognition of what is important: our health, our loved ones, our community, our time. And though COVID has dented our progress on life expectancy, collectively we are living longer, healthier lives (though it is critical to recognize that there are huge disparities in who is living longer; we are not aging equally).

Consequently, the focus of our work at AARP this past year - and indeed in this 14 th edition of The Journal - was on how to maximize the opportunity that healthy longevity affords us. At the end of last year, the UN General Assembly formally designated 2021-2030 as the Decade of Healthy Ageing, inviting stakeholders across the world to identify and amplify promising practices and policies that improve the lives of older people, their families, and their communities. In particular, the Decade focuses on four interconnected action areas: (1) promoting age-friendly environments; (2) combatting ageism and age discrimination; (3) delivering person-centered 


\section{We continue to be inspired by the novel thinkers, the builders, and the dreamers who are working to create a better world for older people everywhere.}

integrated care to older persons; and (4) improving access to long-term care.

Our readers will see that we dedicated a significant portion of this edition to sharing the insights of thoughtful experts on each of these areas. Jo Ann Jenkins, CEO of AARP, frames the issues and the critical work being done by AARP globally in her opening essay. And Dr. Tedros Adhanom Ghebreyesus, Director-General of the World Health Organization, builds on this by making the case for the Decade of Healthy Ageing. The subsections include thought-provoking articles from Kim McCoy Wade, Director of California's Department on Aging; Ken Roth, Executive Director of Human Rights Watch; Martha Boudreau, Chief Communications Officer at AARP; Terry Fulmer, President of the John A. Hartford Foundation; and several leading professors and policymakers from around the world, among others.

For the past several years, The Journal has included a deep exploration into the innovations of individual countries that have been particularly forward-looking with respect to their aging populations. The most recent issues have featured Japan, the Netherlands, and Singapore, all developed with the invaluable ingredient of visits to the featured countries that provided the opportunity to learn, engage, and build relationships. To be sure, these fact-finding trips have created extraordinarily rich exchanges between AARP and our foreign partners.

This year, however, like the rest of the world, we were forced to stay home. Yet within the newly established boundary lines we took inspiration to do something different. We decided to focus on developments in a region perhaps not as frequently discussed in the aging-issue context because it is not among the oldest - yet it is one that is among the fastest aging regions in the world: Latin America and the Caribbean (LAC). Though the aging of populations in Asia and Europe has been more widely recognized and studied, birth rates across Latin America have been consistently declining since the 1960s, and in 2015 , the average number of births across the region fell below the replacement rate of 2.1 children per mother for the first time. The Pan American Health Organization (PAHO) projects that the number of adults over age 65 in the region will outnumber the number of children under 15 by 2050 .

This edition describes some of the key dynamics for the aging populations in five LAC countries - Brazil, Chile, Costa Rica, Colombia, and Mexico - and includes key demographic data for seven more: Argentina, Barbados, Cuba, Dominican Republic, Jamaica, Peru, and Uruguay. We are pleased to share articles from thought leaders such as Cecilia Morel Montes, the First Lady of Chile; Dr. Julio Frenk, current President of the University of Miami and former Minister of Health in Mexico; as well as several experts from the Inter-American Development Bank, and others. We are excited about what we have found in the region - and, in fact, we expect to delve even more deeply into its issues and solutions as we go forward. 
Finally, we zoomed out to the global level so we could highlight some of the incredible small and feisty organizations around the world that are working hard and with limited resources to improve the lives of older adults. In a new feature we call "Newsmaker Interviews," we highlight the work of three of these organizations - from El Salvador, the Democratic Republic of Congo, and the Philippines. We hope you take a look - and let us know about the work of other great organizations around the world.

We end 2021 as we began it - under the cloak of COVID-19, but resilient and optimistic for the future. We celebrate the fact that, just as the pandemic is not confined to borders, neither are good ideas. This edition of The Journal reflects that truth on each page. We continue to be inspired by the novel thinkers, the builders, and the dreamers who are working to create a better world for older people everywhere. As we continue to go forward, we will seek these ideas and share them, both here and online at www.aarpinternational.org. We want the best ideas to spread and expand. Because when communities are better for older people, they are better for everyone.

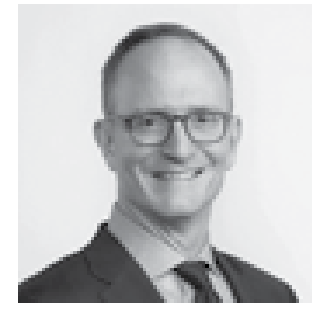

Peter Rundlet Vice President AARP International 


\section{Turning the Decade of Healthy Ageing into Action, in the U.S. and Across the World}

W hen the United Nations proclaimed 20212030 the "Decade of Healthy Ageing," they noted that health is central to our experience of older age and the opportunities that aging brings. They challenged governments, civil society, international agencies, professionals, academia, the media, and the private sector to come together to improve the lives of older people, their families, and the communities in which they live.

The "Decade of Healthy Ageing" recognizes that even though we know - and have known for many years - that the population is aging, and at an increasingly rapid pace, the world is not sufficiently prepared to secure the rights and respond to the needs of older people. At AARP, we believe that every person - in every country around the world - should have the opportunity to live a long and healthy life. Yet, our world has been turned upside down by the COVID-19 pandemic. And older people, and those with underlying health conditions, have been hit the hardest.

According to a recent study published in the International Journal of Epidemiology, the COVID-19 pandemic led to decreases in life expectancy in 27 of the 29 countries analyzed, reversing a decades-old trend of increased life expectancy. These losses were largely attributed to increased mortality in people over age 60 and linked officially to COVID-19 deaths. The pandemic also contributed to deaths from other causes - such as cancer and cardiovascular disease - because of a lack of treatment or a delay in getting treatment.

Paradoxically, the pandemic also has helped to open our eyes to ways we can redefine health as we think about how we live and age in the post-pandemic world. It's helped us better understand the expanding role technology can play in helping people maintain their health and in delivering health care - both the opportunities and the challenges. And it has also helped us understand that as we approach a time when the number of people 65 and older is expected to have doubled by 2050, we must not only focus on increasing the lifespan, but we must also increase the health span - the years we maintain good health.

Healthy aging is a lifelong pursuit. It doesn't begin at age 50 or 60 or 65 . Likewise, it doesn't just happen, and it's not something one can do alone. That's why at AARP we seek to create a society that supports healthy longevity across the life course:

-Where, for example, people have access to affordable health care at all ages,

-Where all people will be prepared to live longer, healthier lives,

-Where they will have more tools and knowledge to be proactive about their health and wellness,

-Where they will have access to a robust market of innovative health-related products and services that support longer, healthier lives, and

-Where we will all be better equipped to care for each other as we age.

In order to achieve that vision, people and societies across the globe must cast aside outdated attitudes and stereotypes about aging and understand that a healthy, engaged, and productive older population has the potential to be an economic boom, not an economic and social burden. It's time to recognize that as we extend healthy longevity, the growing number of older people is not a drain on society, but a key 
driver of economic growth, innovation, and new value creation.

In 2017, AARP decided to see how well prepared some of the world's major economies are for the challenges and opportunities their societies face as they age. We teamed with FP Analytics to take an in-depth look at how 12 countries ${ }^{1}$ are adapting their societies to an aging population. Together, these countries represent 61 percent of the global GDP and nearly half of the world's population of people ages 65 and older.

The resulting "Aging Readiness and Competitiveness Report" (the ARC Report) ${ }^{2}$ identified creative programs to promote volunteerism and entrepreneurship, lifelong learning in finance and technology, support for caregivers, and intergenerational communities.

In 2018, we did a second ARC Report ${ }^{3}$ focused on 10 smaller economies around the world ${ }^{4}$ - all of which have fewer than 25 million people - that are leaders in responding to demographic change. While all these countries face formidable challenges as a result of their aging populations - especially those related to housing, mobility, isolation, finance, and health care - we found that many of them are also coming up with innovative and flexible solutions to address many of these issues.

We need to empower societies around the world to both embrace the opportunities of aging to the fullest extent possible and address the attendant challenges. Healthy longevity requires societies to focus more on physical and mental fitness rather than diminishment alone - on preventing disease and improving well-being rather than simply treating ailments. Further, as we empower societies, we also need to empower individuals to become active partners in ensuring their own health and well-being.
If we prepare now, we can extend healthy longevity and productivity. As people live longer, healthier lives, they can stay in the workforce longer, whether motivated by desire or need. They can continue contributing to their families, communities, and society. They can delay or reduce admissions to hospitals and other care facilities and enjoy active, independent, and fulfilling lives while enriching their environments in many ways.

Achieving healthy longevity requires decisive, multisector action. In the past century, major breakthroughs have saved millions of lives that previously would have been lost to infectious diseases. However, not all these gains have been shared equally. And, again, this has become abundantly clear during the pandemic. We need a comprehensive global effort to guide the implementation of evidence-based strategies to advance healthy longevity among all people. We all have a role and a moral responsibility for this, from the personal to the private and public.

We need to explore innovative approaches to improve longer lives in practical and equitable ways. Toward that end, we recently convened a global conference of international experts and stakeholders focused on "Redefining Health: New Approaches for How We Live and Age." The conference explored how we can advance a global vision for healthy aging as a central strategy to reinvent, create, and build more resilient societies so people can live longer, healthier, and more productive lives.

At that conference, we also released ARC 3.0. Developed by Economist Impact and AARP, this report takes a thematic approach focused on innovations that promote healthy aging across four key areas: ensuring access to healthcare services for all older adults, strengthening the availability of long-term care and support for 


\section{As we all strive to put the pandemic behind us, we must also work to ensure that all people have access to the resources, services, and support that empower them to live a life of good health regardless of age, race, or income.}

caregivers, supporting aging in place through community-centered care, and caring for older adults in crisis situations.

We also work with our international NGO partners to advocate for the UN's Sustainable Development Goals (SDGs) in 2030 and to co-chair the Stakeholder Group on Ageing with our partner, HelpAge International. And we are engaged in several initiatives to help achieve healthy longevity. Since 2019, we have collaborated with the U.S. National Academy of Medicine to launch The Global Roadmap for Healthy Longevity, an initiative to bring together thought leaders from the full range of fields that touch on aging, "to identify the necessary priorities and directions for improving health, productivity, and quality of life for older adults worldwide."

Healthy longevity is not just about maintaining physical health, it's also about mental health. We have launched several initiatives to help people maintain and improve their brain health as they age, such as our Staying Sharp digital platform that provides users with tools and information that helps them protect and strengthen their brain. Through the AARP Brain Health Fund, we have invested $\$ 60$ million in the Dementia Discovery Fund, which in turn invests in research and development to identify cutting-edge therapeutic approaches that could lead to effective treatments and ultimately a cure for Alzheimer's and other types of dementia.

We have also convened the Global Council on Brain Health to bring together scientists, doctors, scholars and policy experts around the world to debate the latest in brain health science to reach consensus on what works and what doesn't and to translate critical scientific information on brain health into simple actions people can take every day to help stay sharp throughout their lives. And last year, we joined with Women Against Alzheimer's and Women's Alzheimer's Movement (founded by Maria Shriver) to release a landmark report, "The Role of Alzheimer's, Dementia and Caregiving on Women," which sets forth a strategy for improving women's brain-health research and policies over the next decade.

The key to helping people take advantage of generally longer and healthier lives in the coming years and decades is innovation. At AARP, we created AARP Innovation Labs to help shape the future of aging, promote healthy aging, support family caregivers, and help older Americans build financial resilience and combat social isolation. Our most recent innovation is the AgeTech Collaborative ${ }^{\mathrm{TM}}$. Through this platform, we're connecting leading AgeTech startups with investors, business services and industry experts and enterprises to address society's most pressing aging issues including caregiving, chronic illness management, social isolation, housing and more in order to generate big new ideas and send innovative new products into what is now an $\$ 8$ trillion economy.

Empowering innovators, and - just as crucially, establishing a medium where they can communicate with one another, and their consumers - is critical to ensuring that this inventive energy truly makes a difference in helping people live better as they age. We must all work together to harness the promises of 
technology to improve health and assistance through robotics, artificial intelligence, and access to information.

As we all strive to put the pandemic behind us, we must also work to ensure that all people have access to the resources, services, and support that empower them to live a life of good health regardless of age, race, or income.

The opportunity to live longer, healthier, more productive lives is one of humankind's greatest accomplishments. Capitalizing on such an unprecedented opportunity, however, will require new approaches to how we live and age and a commitment to innovation across all sectors of society, from the personal, private and public. Only then can we create the sort of healthy longevity that the UN Decade of Healthy Ageing hopes to promote and inspire for all.

\footnotetext{
${ }^{1}$ The countries are: Brazil, Canada, China, Germany, Israel, Japan, Korea, Mexico, South Africa, Turkey, the United Kingdom, and the United States.

${ }^{2}$ https://www.aarp.org/arc3

${ }^{3}$ https://arc2018.aarpinternational.org/

${ }^{4}$ The countries are Australia, Chile, Costa Rica, Lebanon, Mauritius, the Netherlands, New Zealand, Norway, Singapore, and Taiwan.
}

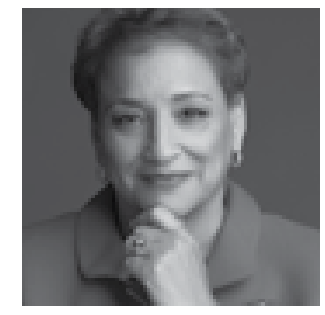

Jo Ann Jenkins CEO, AARP 


\section{Aging: The Impact from Every Tailored Action}

We are all in a drowning boat

Happened before at St. Domingue

We are the ones called boat people

We all died long ago

What else can frighten us

Let them call us boat people

We fight a long time with poverty

On our islands, the sea, everywhere

-From the poem "Boat People" by Felix Morisseau-Leroy

$H^{2}$ aitian writer and newspaper editor Felix Morisseau-Leroy was a man of the people. He grew up speaking French and English and developed a fascination with Creole while teaching in Port-au-Prince in the 1940s. He was the first to call for the language to take written form and be recorded, and he embraced its use in creative literature.

Morisseau-Leroy, through his love of language, was able to forge equity and inclusion in Haiti. He brought Creole up from what many called the "lower orders" into the mainstream. As a result, those who spoke Creole were no longer prey to marginalization. He was viewed as the father of the Creole Renaissance, the voice of Haiti, and his elevation of the Creole dialect helped it become the national language of Haiti in 1991.

Morisseau-Leroy fought for what he believed in, and wrote of his beliefs only in Creole, because he believed people can only understand and find solutions to their problems if they are communicated within their own language, not a language they didn't understand or was not their own. His work anchored the true spirit of Haitians in fyète - pronounced f-yet-tay which means pride.
I tell you this story of Morisseau-Leroy because his approach of meeting people where they are, in a language they understand, is something equally important as we begin to build anew and emerge from this pandemic.

COVID turned our worlds upside down and our collective future depends on the choices we make today. As we continue to navigate the uncertainties around the global pandemic, it is clear that we cannot and should not go back to our old normal. That "normal" excluded entire communities, income brackets, ages and races. The old normal deprived many people of life's basic necessities. We cannot let what has happened in the last two years pass in vain.

I fundamentally believe that we have the capacity to create a better and more inclusive future where everyone can age with dignity, purpose and independence. To achieve this, however, we must make a concerted effort to speak the language that is spoken, spend time in the communities, shift the way we think about those we serve, looking first at what they have rather than what they lack and then co-create solutions that meet their preferences, goals and aspirations in the ways that work best for them.

Rather than pushing a one-size-fits-all approach that we know doesn't work everywhere, we must continually adjust our strategies and elevate policies, programs and other innovative solutions that are local yet scalable. More importantly, we must recognize that there is no system that cannot be improved, no reality that cannot be bettered, no hope that cannot be made real. We at AARP have always been at the forefront of the fight to empower people to age as they choose. This fight requires that we address the accumulated impact of barriers, burdens, and hardships over the course of a life that makes aging different 


\section{Rather than pushing a one-size-fits-all approach that we know doesn't work everywhere, we must continually adjust our strategies and elevate policies, programs and other innovative solutions that are local yet scalable.}

for some, in both number and quality of years. We fight for each of us to help all of us.

In the following pages of this issue, you'll learn from some innovative examples that do just that, as we highlight unique solutions in some countries in Latin America and around the world.

This issue of our Journal, with a special focus on Latin America, is especially important to me. I was born in Haiti and spent my childhood there with my family. As a college student, I traveled to Panama on a study trip and learned about the culture and the people of that beautiful country. Today, as an executive at AARP, I look back on those times and experiences and can see how they influenced who I am today and, from a broader perspective, why the work we do matters.

At AARP, we help shape policies to increase healthy longevity, empower people and make systems equitable so everyone has the means to match their aspirations in health and life.
Things are changing fast. Rather than thinking about overcoming obstacles as a measure of success, we need to think about removing or preventing these obstacles in the first place. Our collaborations around the world can shift problem-solving strategies toward preventing age-related issues in the first place so that we have fewer problems to solve later, as people age.

Centered around aging across the lifespan in Latin America and highlighting the region's diverse populations, this issue of The Journal explores the successful strategies and innovations that are helping to provide people of all cultures in the region with access to health and high-quality and affordable long-term care.

All the world's countries have histories of surviving struggle and strife and all, in some way, continue to do so. It is up to us to set the stage for how we keep our nations moving forward and 


\section{We have an opportunity to construct a future that builds wealth, strengthens health, and ensures the same oppor- tunities that benefit the privileged also benefit those historically marginalized and everyone in between.}

ensuring we can all age with healthy longevity. Everyone at every age deserves the chance to grow old and see the influences of the generations to come.

In the photos on the opposite page, I am four years old in Haiti, 19 years old in Panama, and 42 years old in the United States. They are here for a reason. I encourage you, our readers, to find pictures of yourself at various ages and life stages, then line them up: Just watch yourself grow older. At each stage, think about the opportunities you had and the opportunities you needed. Think about those things that may have been in place during each of those stages to put you on a more secure path for the future-and think about those things that may not have been in place. Then, fast-forward to today, and imagine your four-year-old neighbor down the street and reflect on what needs to be in place now for them to age well across their lifespan. Think about your 18-year-old niece and what she needs to ensure economic stability and growth in her future. Then, think about the things you do today-and can do today-to build better systems and a better world so that when they are 42,52 , or 92 , they have what they need to fully participate in society and contribute to the generations that come after them.

None of us achieves success or feels fulfilled on our own. My grandmother was the one who raised me in Haiti. The images are clear in my mind, in spite of the decades that have passed: my grandmother, waking up well before the sun rose in Haiti, lifting up her basket of goods and placing it over her head, and heading off to the marketplace. In the evenings, I'd see her return, exhausted after a long day but visibly content - no doubt in knowing she was successful in providing her family with food. What she would say, often in those moments, also can shape the actions we take from the research on these pages.

"Pran swen lòt moun vle di pran swen avni w." 


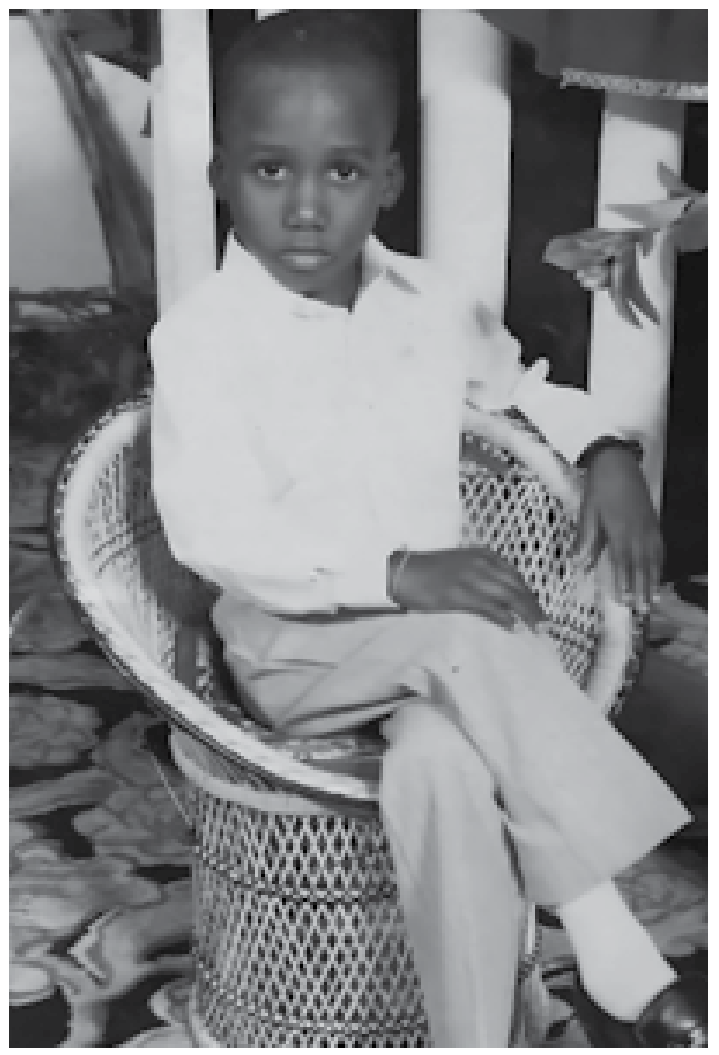

Caring for others means caring for your future. We have a very real chance to rewrite the script of a post-COVID society - a script where the sequel can be better than the original. In everything we do, and with everything we have, we have an opportunity to construct a future that builds wealth, strengthens health, and ensures the same opportunities that benefit the privileged also benefit those historically marginalized and everyone in between.

This is not just wishful thinking. Everything we do impacts real people living real lives. So, let's work together to make sure we're putting systems and policies into place that make those lives the very best they can possibly be. Let's write a new story, speak a common language and let's make the script so much better than the original.

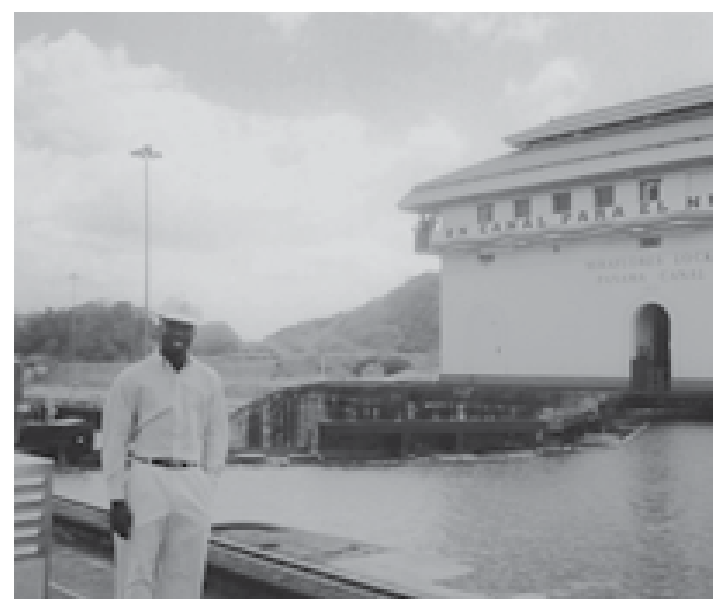

The author at age four in Haiti;

19 years old during a trip to

Panama; and below, at age 42.

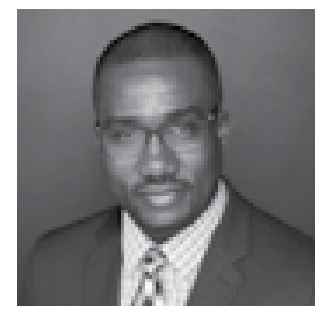

\section{Jean Accius}

Senior Vice President AARP Global Thought Leadership 
Newsmaker Interviews

\section{AARP Speaks with Leading Advocates for Older Adults Around the World}

\section{El Salvador}

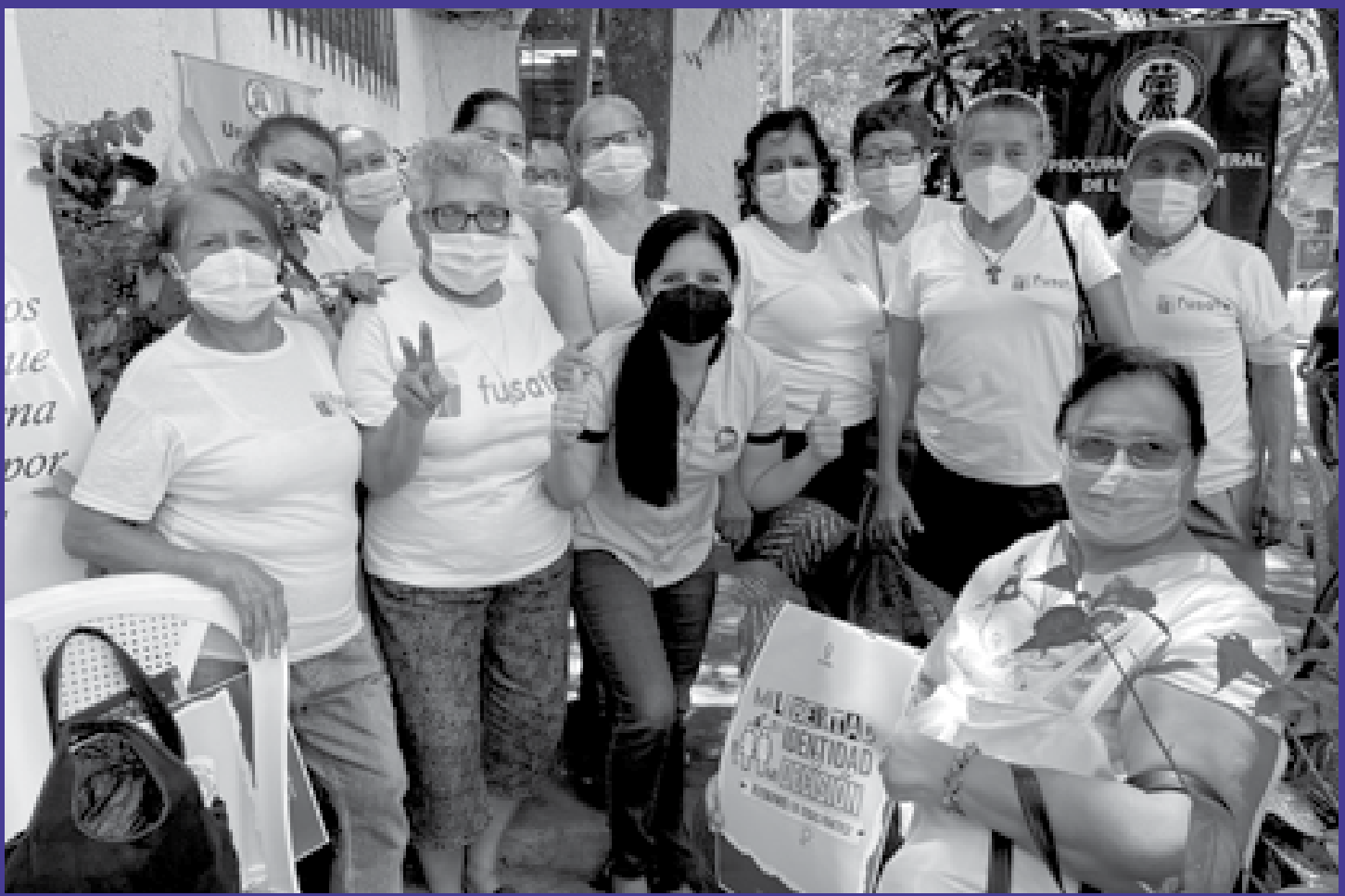

Fundación Salvadoreña de la Tercera Edad (FUSATE) is a non-profit, non-governmental organization founded in 1990 with the mission of helping to improve the quality of life for older adults in El Salvador. Across the country, FUSATE has touched the lives of over 110,000 individuals through the work of its network of leaders and affiliates. To learn more, AARP International spoke with its president, Olga Miranda. 
AARP What challenges do older people face in EI Salvador? How does your organization address those challenges?

Olga Miranda El Salvador is still a developing country, which makes things harder for older people. Most of our current aging population does not have a pension or social security benefits. Most have been affected by the emigration of their children or family to the United States or other countries. Few have their own home, and if they do, that home is in deplorable conditions. Of the almost 800,000 seniors in El Salvador, 75 percent live in some kind of poverty.

The government provides free general health care through local public hospitals or health clinics. But for people with chronic illnesses, it is very hard to get the care they need. Through FUSATE's nine comprehensive day centers, through home visits, and through adult clubs across the country, we provide primary health care. We are currently planning a larger initiative related to access to medication that we hope to implement in the future.

AARP How does your organization amplify the effects of any policies, laws, or community practices that are already making a difference in the lives of older people?

OM When our nonprofit foundation launched 31 years ago, we looked at what existed in terms of benefits for Salvadoran seniors. All that was offered at the time was related to direct benefit programs for employees covered by social security. There was also very little knowledge on the subject.

For years, we have worked with various entities to help develop policies to protect the rights and well-being of older adults. Laws and policies are now quite thorough and extensive, with provisions in place to ensure those commitments are not empty words. In 2021, the Special Law for the Protection of the Rights of Older Persons was passed which provides a detailed recognition of the rights guaranteed to older individuals in El Salvador. It also creates the Consejo Nacional Integral de la Persona Adulta Mayor (CONAIPAM), or the National Comprehensive Council for Older Persons, which will support the design, implementation, and evaluation of policies regarding the protection of the rights of older Salvadorans. ${ }^{1}$

Within the last year, our foundation began receiving government funding through the Ministry of Health. This funding supports operations at our nine comprehensive day centers, two overnight sleeping facilities, and 109 sub-affiliates at the departmental (state) level throughout the country; in addition, through our affiliates we provide direct nutritional support to 5,000 low-income people. Our work is complex and quite extensive, and we are constantly adapting to new circumstances.

AARP How has your work been affected by the COVID-19 pandemic?

OM The pandemic took the whole world by surprise. We had to move fast. We met with policy leaders and individuals who work directly with older people, and we made contingency plans for many scenarios, while taking stock of our human and financial resources. We knew we would be directly involved in, and heavily committed to, a COVID-19 response, given how much older adults depend on our adult day centers for their subsistence.

Our greatest concern at the time was that older persons might not have food. We quickly formed partnerships with private companies and other foundations to secure funding, and we stockpiled grains and basic provisions from various granaries before roads were closed and travel was restricted. We then shut down some of our facilities, such as the adult day centers, while our main office remained open through it all. 

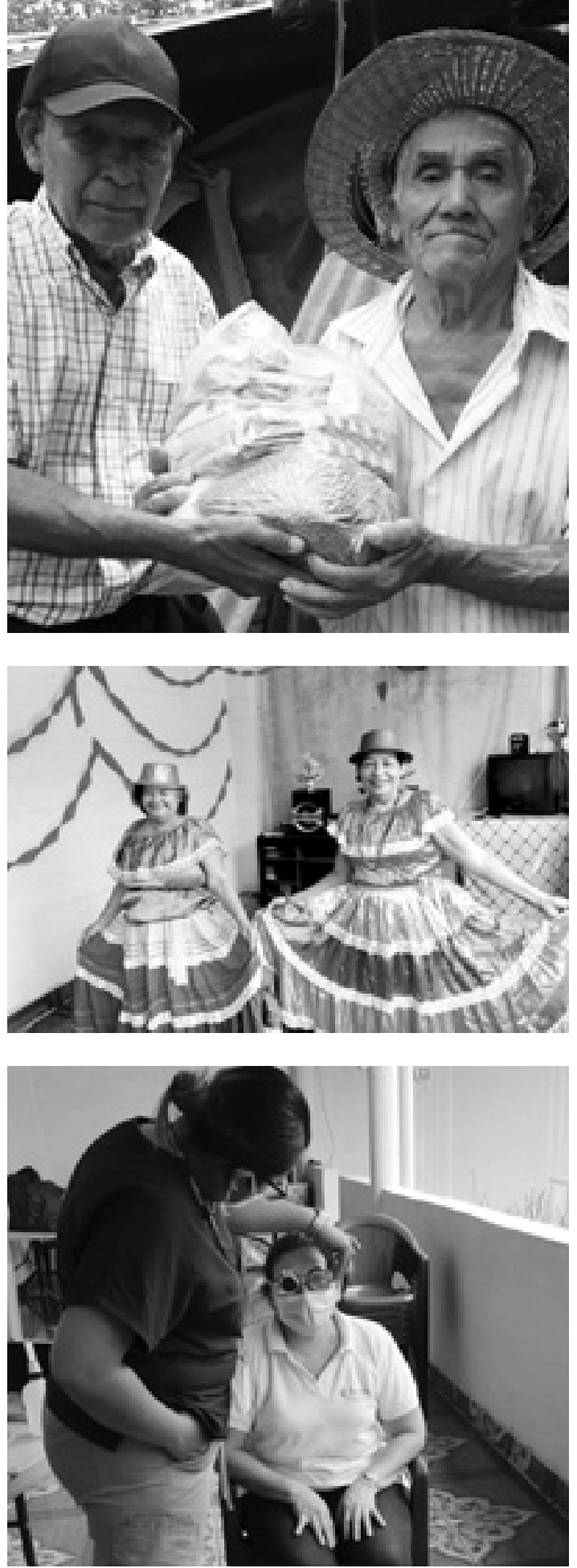

In our sleeping facilities, we opened temporary shelters where the municipal authorities brought indigent older adults. Before admitting individuals to these shelters, we placed them in quarantine in rooms that we rented and supplied with needed items as well as daily food. No one other than staff could enter or exit the shelters. Investments were made in all sorts of infrastructure: beds, fans, air conditioners, stoves, chairs, television sets, cable television, medications, bedding, etc. A wide variety of games and leisure items were purchased. Group activities were also developed, as would be done at the adult day centers in normal times.

Over time, the seniors became very unsettled. We rented buses to take them out for the day as if it were a holiday. We took them to our adult day centers, which were closed, to help them avoid becoming depressed as well as to avoid infection.

When we did have cases of COVID-19, we followed the protocol established by Dr. María Eugenia de Barrientos. She trained us via Zoom, we purchased oxygen tanks, and we learned how to isolate and treat patients.

AARP How do you motivate volunteers to work for your organization? On the other hand, how does your organization develop a relationship with the communities and individuals that could benefit from your assistance? What are your biggest challenges with outreach?

OM We travel to each departmental capital and additional cities, including in disadvantaged areas, to help local leaders form oversight boards for their initiatives and to provide guidance and training about how to respond to commitments, challenges, and new responsibilities.

The resulting sense of ownership was and continues to be our greatest success.

We started out with no infrastructure, instead using cultural and community centers, municipal or departmental government buildings, and even the private homes of board members for hosting activities. We meet with all our volunteers twice per year. Each time, attendees state their goals, responsibilities, and achievements, including how many seniors received ID cards from them to date. Most of our volunteers work with our affiliate and sub-affiliate organizations throughout 
El Salvador. We now have 109 sub-affiliates and 14 affiliates and 110,000 older adults have been provided with ID cards.

All our services are free, and our volunteers are unpaid; they are motivated by serving others.

Some volunteers join for specific events, including those organized during "Older Persons Awareness Month," as well as efforts to collect, pack and distribute food or social services throughout the year. Schools and universities are notable supporters of these initiatives.

Our involvement in each city begins by getting to know local leaders, particularly the mayors. We are non-political. Over the years we have worked with mayors of various political ideologies. For instance, during national disasters, we lend our facilities and personnel to support the emergency response operations of the municipal authorities. At times, we have had problems when people have tried to politicize our efforts. When this happens, we speak up and explain the purpose of our work.

Over the years we've started to face a serious problem: in many communities our personnel are exposed to the dangers posed by gangs. This is a social problem with no end in sight.

AARP Which of your organization's projects have been most successful? How does your organization define success? What challenges did you face during project implementation?

OM Everything is considered a success for us! We lasted 30 years with no steady government funding, and we have been able to advocate for and assist older people in El Salvador.

Aside from the economic aspect, almost no one thus far is keen on combatting the issues that face grandparents and older people. They would rather support programs related to children, women, roads, water, etc., especially in a country like ours, with so many needs. We've had to be extremely creative to find ways to gain a place in the arena, to raise funds, to figure out how to sell our work, and to persevere while always maintaining our mission and vision. Our biggest achievement has been to bring older people's concerns before the government which can implement policies like the provision of long-term benefits.
AARP We noticed from our research that you work in both rural and urban areas. How do you adapt your projects to be successful in both settings?

OM In adapting to different communities, nothing works better than being realistic. We start with what is there, or with what is possible, and then gradually expand our work as the budget allows, while striving to maximize quality of life.

AARP We are interested in hearing more about the shelters that you provide to make communities more livable for older individuals. Could you share more details with us about the day-to-day experience of both residents and volunteers?

OM We have always worked to ensure that older Salvadorans at any income level or familial background can go to our adult day centers to access multiple meals, receive basic food items for their household, obtain medications, and participate in therapies, workshops and recreational activities, completely free of charge. Our goal is to open as many centers in the country as possible to more easily serve the public's needs.

${ }^{1}$ https://www.diariooficial.gob.sv/diarios/do-2021/04abril/22-04-2021.pdf 


\section{Democratic Republic of the Congo}

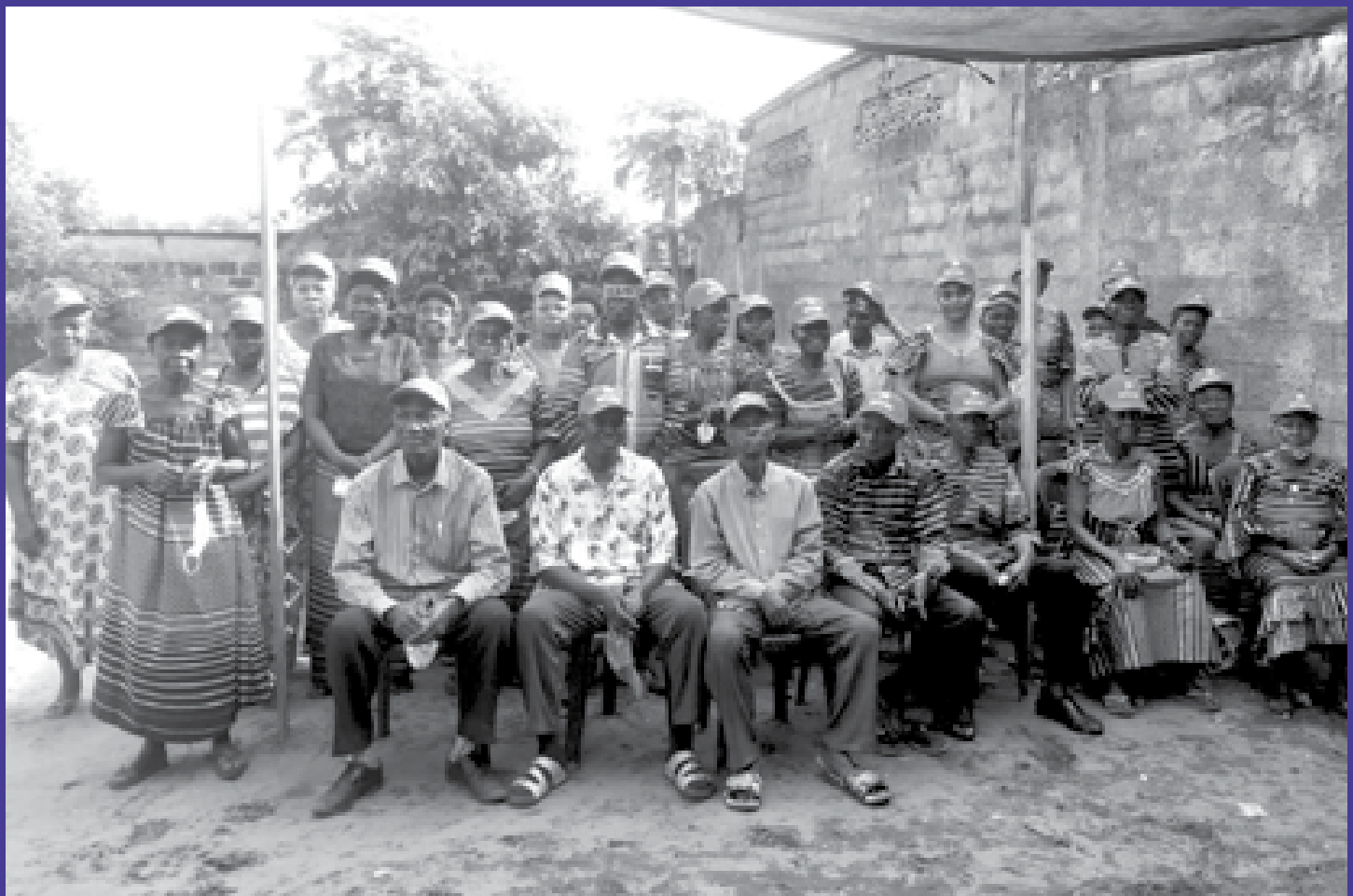

Association Amité Seniors et Jeunes aims to combat isolation and loneliness for older adults in Kinshasa, Democratic Republic of the Congo, by building lasting links between younger and older individuals. The group promotes the interaction of generations for the development of an open, inclusive, and united society. To learn more about their work, AARP International spoke with Association Amité Seniors et Jeunes President Triphon Mawete who has a master's degree in gerontology from the University of Montpellier. 
AARP What challenges do older persons face in the Democratic Republic of the Congo? How does your organization address these challenges?

Triphon Mawete The major challenges for older persons in the Democratic Republic of the Congo are:

- Poverty/economic insecurity

- Access to health care in general, an absence of gerontologists and geriatricians, and a lack of expertise in pathology

- Isolation, Ioneliness, and rejection by younger generations

- Accusations of witchcraft and the casting of harmful spells on the rest of the population

- Lack of social protection

As part of our efforts to address these challenges, our association established a home visiting program that decreases isolation and loneliness by encouraging intergenerational connections. Additionally, we organize monthly activities for older people, where they come together, help each other, and share their experiences. These activities include meal distribution events, birthday parties, dance and literacy classes, and intergenerational meetings where younger individuals can learn about their community's history as well as teach computer skills to older adults.

Our organization also hopes to shift the perceptions that younger generations have of older persons. To do so, we work to raise awareness about older persons' rights and social contributions by creating poster campaigns, hosting conferences and seminars, joining conversations on the radio, and leading one-on-one conversations with community members. We have been highlighted on TV and national radio several times, and we visit schools to describe our work and mission.
AARP How does your organization amplify the effects of any policies, laws or community practices that are already making a difference in the lives of older people?

TM Currently there are no laws that specifically protect the rights of older persons in the Democratic Republic of the Congo. In response to this lack of legal protection, our organization initiated a collaboration with members of the parliament to draft and pass such laws. We also collaborate with other organizations to achieve this goal. An example of a project that makes a difference in the lives of older people is our housing project, which provides welcoming homes for older persons.

AARP How has your work been affected by the COVID-19 pandemic?

TM The pandemic prevented us from holding our monthly meetings, depriving older persons of an opportunity to socialize with one another. The several-months long quarantine introduced in the Democratic Republic of the Congo also limited our ability to make home visits. As a result, isolation and loneliness among older persons has increased. The association was also affected by older persons and volunteers fearing COVID-19. Some volunteers no longer wanted to go to people's homes, and some seniors were afraid of contracting the virus.

AARP How do you motivate volunteers to work for your organization? On the other hand, how does your organization develop a relationship with the communities and individuals that could benefit from your assistance? What is your biggest challenge with outreach?

TM The association sets up training and awareness days to motivate volunteers. Additionally, volunteers are excited by the fact that Amité Seniors et Jeunes is a partner of a French 

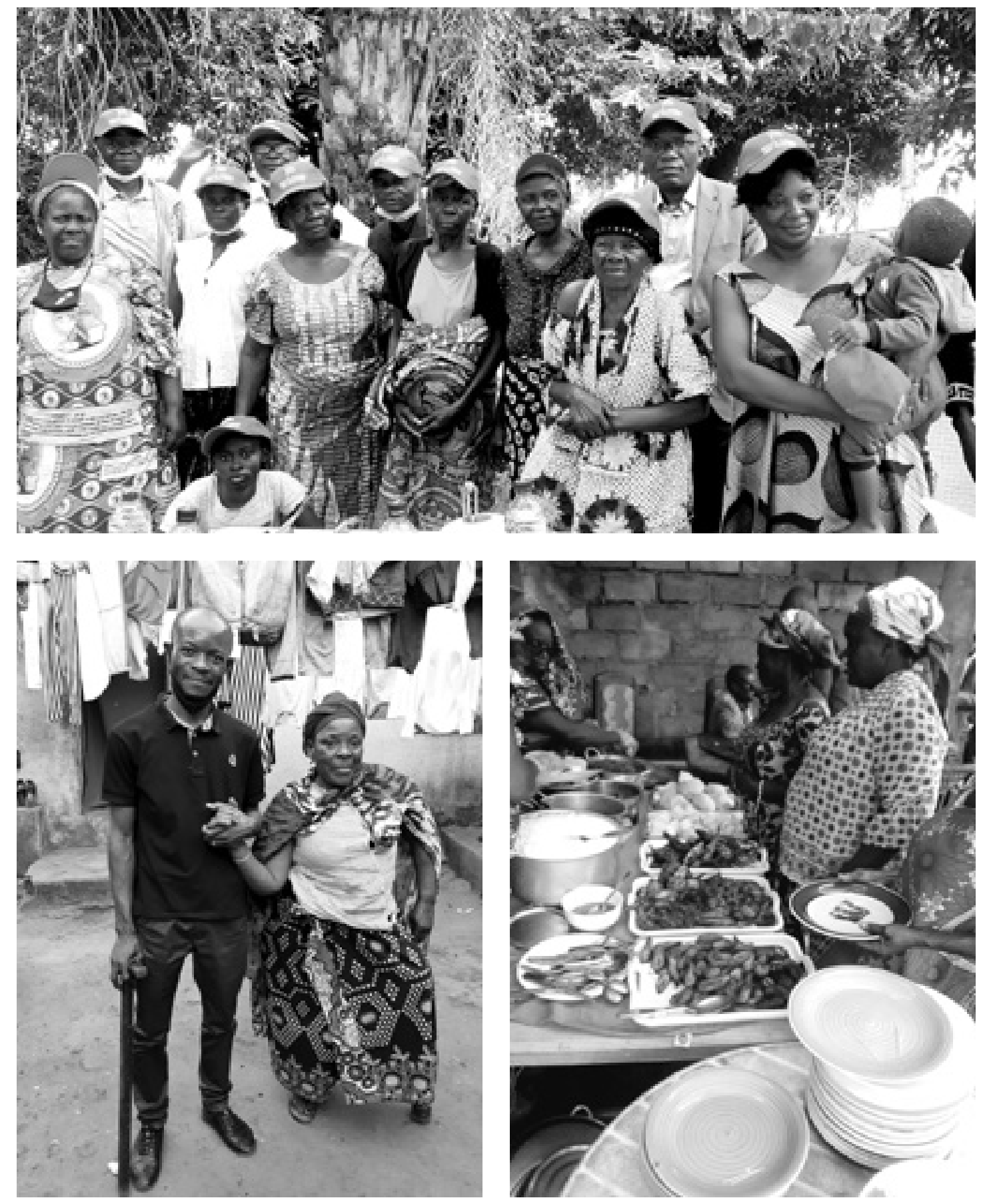
organization, Les Petits Frères des Pauvres, and other local host institutions.

To develop relationships with our community and the older population, volunteers work in local neighborhoods, which helps to promote and amplify the mission of our association.

The major challenge we face with respect to outreach is that older persons are often considered to be witches in the Democratic Republic of the Congo, and so they are often rejected and excluded from their communities, particularly by younger generations. For this reason, the association strives to involve young volunteers and calls itself "Amitié Séniors et Jeunes," which means Friendship Between Seniors and Young People.

AARP Which of your projects have been most successful? How does your organization define success? What challenges did you face during project implementation?

TM Our most successful events are:

- Monthly meetings

- Home visits

- October 1st celebration for the International Day of Older Persons

- End of the year community celebrations

Testimonies from older persons indicate that these activities create a sense of "togetherness" and help to combat isolation. Antoinette, a woman who joins various events, put it this way: "Since I started participating in the activities of the association, I have no more grief/sorrow and I feel young again. I regained a second family."

Furthermore, older persons are happy about the Christmas gifts, such as groceries and clothes, they receive from our team as well as the sense that they are being cared for.

The association's major challenges include a lack of financial resources to cover transportation costs for volunteers distributing food to older persons suffering from great poverty, and the size of the city of Kinshasa, which can make it difficult to get from one point to another.

Another challenge is that we do not have a specific space for hosting our activities. We have land at our disposal but do not have the financial means necessary to construct a building yet.
AARP How do you promote intergenerational friendships and the integration of older people into larger communities?

TM One of our organization's goals is to raise awareness of the challenges and realities facing older persons among young people so that they become volunteers with us. The association leads activities at primary schools to involve youth in efforts to integrate older persons into their community. The association also organizes community meals with activities arranged by young people. In the district of the association's headquarters, young people have mobilized, and we can now see that older people are meeting every month as a result of their support.

AARP Since aging is often associated with witchcraft or considered a "condition of concern," how does your organization combat negative perceptions of aging? Do these negative perceptions affect your work? What needs to be done to shift the public's perception of aging?

TM Older citizens are often accused of being sorcerers in the Democratic Republic of the Congo because poverty makes them a financial burden for their families. This phenomenon is growing in both urban and rural areas, as the country's economic and social situation deteriorates from year to year. Beyond the difficulties of setting up activities for the elderly, the association faces a lack of support from a public that does not understand why we look after "sorcerers," who some believe "should be left to die."

A shift in perceptions of older persons will only be possible through a communications campaign (posters, radio, TV) where volunteers can raise awareness and share their experiences. The status of older persons in Congolese society would also change if local politicians and stakeholders (organizations, civil society, schools) became involved in these efforts to fight against negative perception of old age by supporting the adoption of a law on the rights of older persons. 


\section{The Philippines}

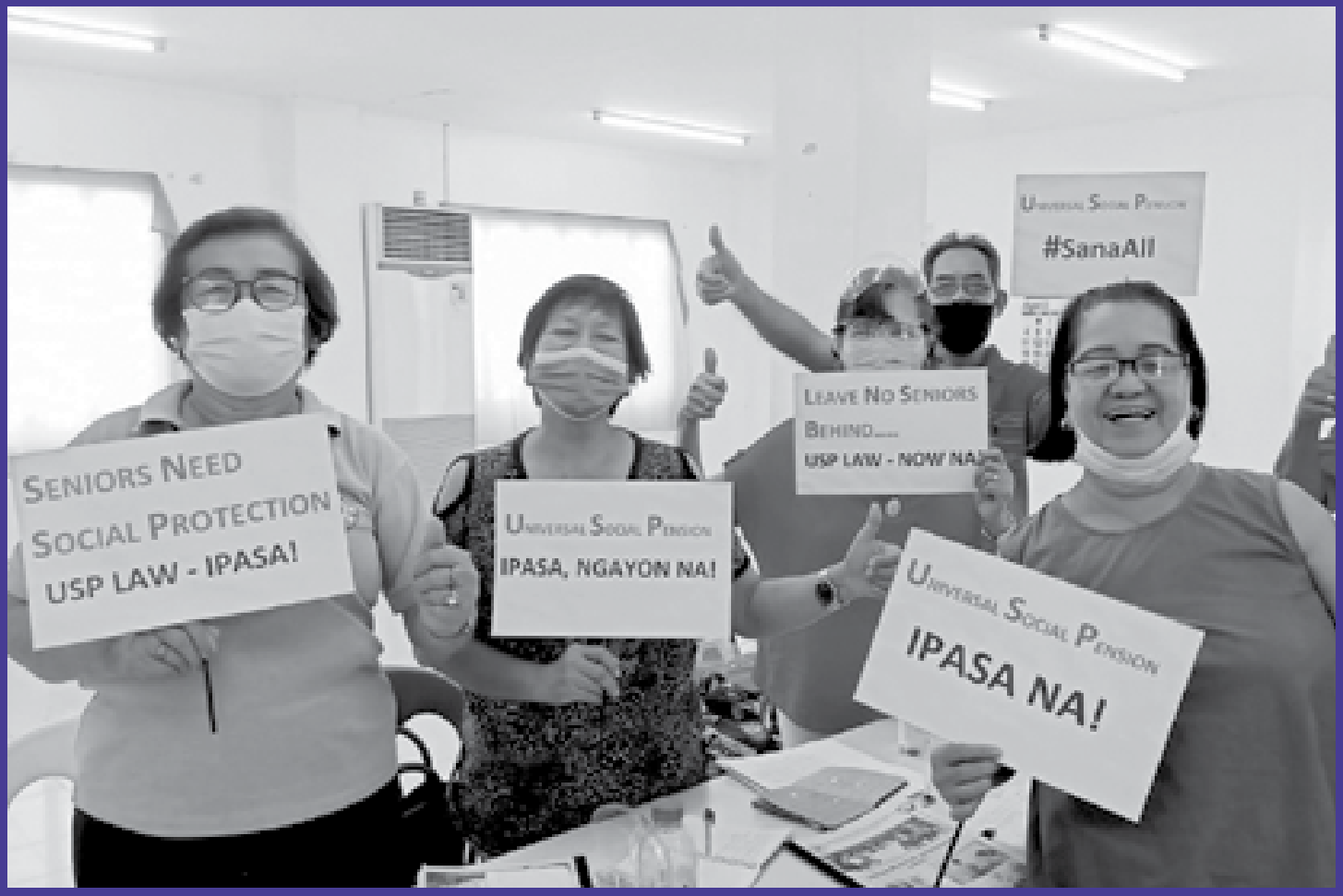

Advocacy campaign for a Universal Social Pension

The Coalition of Services of the Elderly, Inc. (COSE) is a non-governmental organization dedicated to working with older adults in the Philippines. Since 1989 COSE has sought to form and strengthen organizations aimed at helping older adults through building partnerships and advocacy. COSE considers older women and men as partners in the development of a better society for all ages - one where everyone can live with dignity and security. To learn more about this organization's work, AARP International spoke with COSE Executive Director Emily Beridico. 
AARP What challenges do older people face in the Philippines? How does your organization address those challenges?

Emily Beridico There are a number of challenges faced by older people in the Philippines, but the priorities are economic and health concerns. The situation was aggravated by the COVID-19 pandemic, as older people are particularly affected by the disease.

In 2018, 16.7 percent of the total Filipino population lived below the national poverty line, ${ }^{1}$ and almost a quarter of those individuals were older adults. ${ }^{2}$ Even before the COVID-19 pandemic, food insecurity was common. In a 2018 survey, 13 percent of older people's households experienced hunger in the preceding 3 months. ${ }^{3}$

More than in other countries in the region, older Filipinos rely on work to survive. ${ }^{4}$ In 2016 , 45 percent of older Filipinos worked outside the home to maintain their main source of income. Another 30 percent relied on their children's income, and only 20 percent relied primarily on a pension. ${ }^{5}$ Indeed, almost half of older Filipinos 57 percent of older men and 39 percent of older women - continue to be economically productive, while 28 percent of those aged $70-79$ work to earn an income. ${ }^{6}$

Many older persons are active in the informal economy, with over 70 percent of those who are economically active relying on these jobs, according to the 2012 Labour Force Survey. ${ }^{7}$ This workforce, which is dominated by women, is likely to be poorer than formally employed counterparts. They also work in sectors heavily affected by the pandemic (such as hospitality and tourism) and were therefore excluded from crisis-related short-term financial assistance programs for businesses. The International Labour Organisation predicts poverty amongst such informal workers will skyrocket everywhere. ${ }^{8}$

More than a third of older adults do not enjoy any form of pension in the Philippines. ${ }^{9}$ In contrast, China, Thailand, Mongolia, Brunei,
Timor-Leste, Vietnam, and Myanmar all guarantee basic income security in older age through universal social pensions. ${ }^{10}$ As a result, Filipinos, who worked most of their lives in the informal sector, age with very few savings and assets to draw from.

These challenges are being addressed by COSE through policy advocacy such as a campaign on the passage of a universal social pension; efforts to form and strengthen older persons' organizations; and the promotion and establishment of community-based programs benefiting older persons.

AARP How does your organization amplify the effects of any policies, laws or community practices that are already making a difference in the lives of older people?

EB COSE and our partner organizations advocate for enhancements of current policies/programs, like the social pension program. We proposed a yearly increase in the budget allocation and the number of beneficiaries. Since 2015, we have pushed for universal pension coverage for individuals age 60 and above and for doubling the amount distributed from Php500.00/month (\$10) to Php1,000.00 (\$20). Unfortunately, as of November 2021, the change has not yet been approved.

As a result of COSE's advocacy, there has been a significant increase in the number of individuals who benefit from existing programs. There were 139,000 beneficiaries in 2011 when the program started, and by 2021 , that number had increased to 3.7 million beneficiaries. Aside from the social pension program, we also lobby to enhance the benefits package of the PhilHealth program for older people.

On a smaller scale, COSE works to strengthen other organizations supporting older adults and promote the establishment of community-based programs, such as homecare assistance and mobile health care services, to address their health 

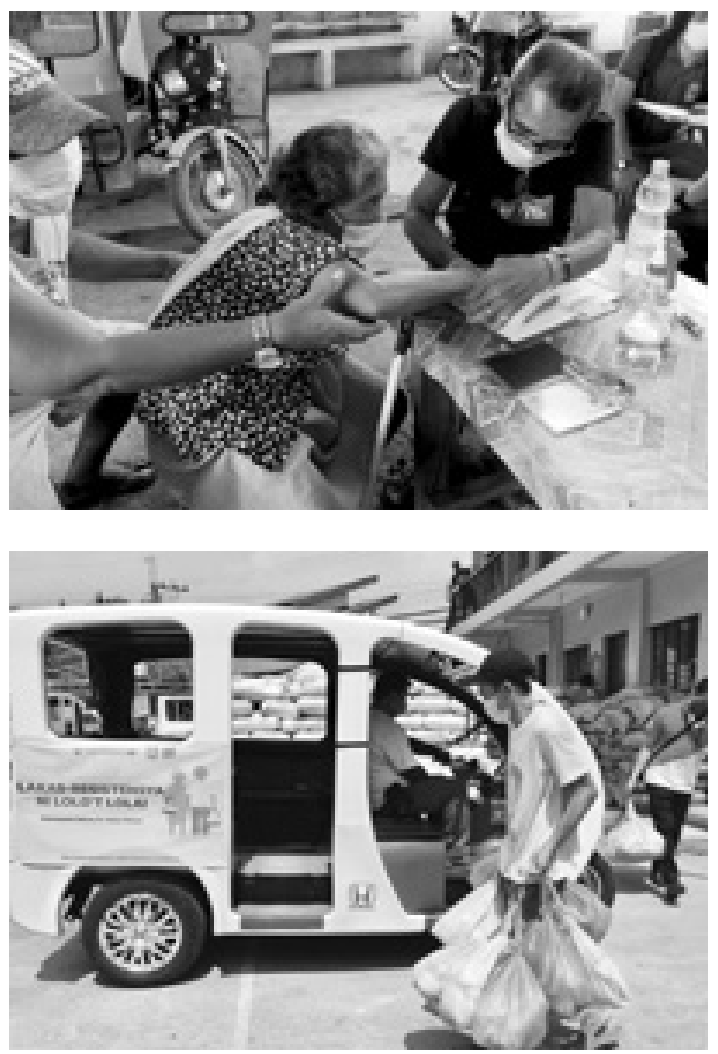

needs. These are necessary because of both the lack of health care systems and the inaccessibility of the few health services that are in place.

AARP How has your work been affected by the COVID-19 pandemic?

EB The COVID-19 pandemic greatly affects the work of COSE due to mobility restrictions. Face-to-face gatherings are prohibited all over the country. Even in the municipalities that allow some meetings, the number of participants must be reduced, and activities must be conducted in two sittings instead of one.

This also limits the lobbying activities of COSE and our partner organizations. Although mass mobilization and face-to-face meetings with legislators are not allowed, we continue our efforts through virtual meetings.

AARP How do you motivate volunteers to work for your organization? On the other hand, how

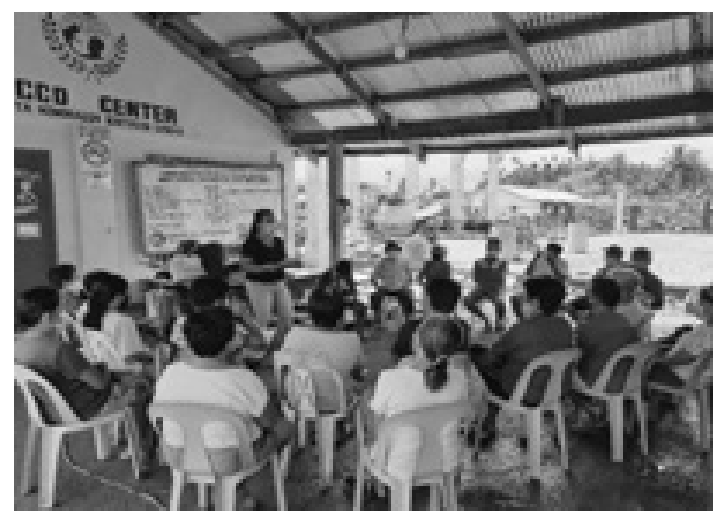

Clockwise: Provision of cash assistance to an older person affected by the COVID-19 pandemic; consultation meeting with the Older Persons' Organization; and distribution of Immunopacks to the houses of older persons.

does your organization develop a relationship with the communities and individuals that could benefit from your assistance? What is your biggest challenge with outreach?

EB We are amazed by how volunteers, particularly older volunteers, are motivated to support our organization. It may be, in part, because they are also directly affected by a lack of protection for older persons. Volunteers are motivated when they see the positive impact of their work in local communities, especially if they are able to help the most vulnerable.

Developing a relationship with communities and individuals has not been a challenge so far for COSE. We have community development officers or community mobilizers for each of our project areas. One of our strategies is to lead community organizing efforts in a way that substantively involves community members, particularly older persons, in all project processes, including planning, implementation, monitoring, 
and evaluation. We also build partnerships with local government officials during project implementation to ensure that the projects are supported by local policies.

Outreach is not challenging for COSE, or our partner organizations, because even local government officials request our presence in their localities for implementing projects that respond to older persons' needs. It only becomes a challenge if the request for COSE presence and projects is not supported by adequate financial and human resources.

AARP Which of your organization's projects have been most successful? How does your organization define success? What challenges did you face during project implementation?

\section{EB Some of COSE's successful projects are} community-based programs that respond directly to the socioeconomic and health needs of older persons. These include our homecare assistance program, mobile health care services, and our community-based residential care facility.

For COSE, success is evident if projects and programs are financially sustainable; if a large number of older persons benefit from our work; if new policies are adopted by the national agencies or local government units; and if our projects/programs are replicated by local government units or other organizations.

AARP Why do you think there is a disconnect between public rhetoric about respect for older women and men and the way that many older individuals face daily challenges to their wellbeing?

EB I believe that respect for older persons is highly valued in the Philippines, because close family ties are particularly protected here.

Nevertheless, there remain cases of elder abuse where perpetrators are family members, and older persons still face daily challenges in life. For me, this is partially a result of poverty. Children taking care of older persons still need to work to earn a living. They are stressed and experience boredom which can lead them to commit abuse. Cases of elder abuse also increased during the pandemic as children supporting older persons lost their jobs and faced additional struggles. This abuse is also related to how government officials respond to the challenges faced by the older persons, how they prioritize resources, and how they allocate funds for the programs protecting the rights of older persons.

AARP How does your organization distinguish between working with and working for older persons? Why is this differentiation so important?

EB We believe working for older persons is a one-sided approach where there is less participation of the older persons. Projects and activities are generally implemented without proper consultation with local communities. Most of the time, this way of working cannot be sustained. Despite this perspective, I do agree the working for approach could be used in some contexts, depending on the capacity of the people being affected by a particular project. For example, older persons who are frail, sick, and bedridden cannot fully participate in project design and will primarily be a beneficiary of our programs and services.

This differentiation is very important to understand in order to determine which approach should be used from the very start of an intervention.

\footnotetext{
${ }^{1}$ https://www.adb.org/countries/philippines/poverty\#

${ }^{2}$ https://www.jstor.org/stable/43486391
}

${ }^{3}$ https://www.eria.org/uploads/media/Books/2019-Dec-Ageingand-Health-Philippines/09-Ageing-and-Health-PhilippinesChapter-3.pdf

${ }^{4}$ https://www.ilo.org/secsoc/information-resources/publications-and-tools/policy-papers/WCMS_645692/lang--en/index.htm

${ }^{5}$ https://www.helpage.org/what-we-do/social-protection/ work-family-and-social-protection-in-asia/

${ }^{6}$ https://www.eria.org/uploads/media/Books/2019-Dec-Ageingand-Health-Philippines/09-Ageing-and-Health-PhilippinesChapter-3.pdf

${ }^{7}$ https://www.helpage.org/what-we-do/social-protection/ work-family-and-social-protection-in-asia/

${ }^{8}$ https://www.worldpoliticsreview.com/articles/28911/informalworkers-are-bearing-the-brunt-of-the-coronavirus-economicimpact

${ }^{9}$ https://www.onenews.ph/effective-pension-scheme-forphl-senior-citizens-sought

${ }^{10}$ https://www.philstar.com/headlines/2017/12/01/1764515/4-10filipino-elderly-without-pension-ilo 


\section{Applying the Pandemic's Public Health Lessons Holds Promise for Latin America and the World}

\begin{abstract}
O ver the past 18 months, for millions of individuals and families around the world, health care decisions have been complicated by a confluence of crises the enormity of which we had not previously experienced in our lifetimes. In Latin America, which is home to 8 percent of the world's population, but has witnessed nearly a third of deaths due to COVID, the grief and loss is palpable.

This is the sixth pandemic or public health emergency of international concern in which I have played some decision-making role. But this one is unlike any other. Bill Gates has called it a "once in a century pandemic." Its magnitude, its economic consequences, and the social unrest fueled by the disparities it has laid bare are unparalleled and have generated never-before-seen attention to our common frailty stemming from health risks.

While the current emergency is not yet over, we are all starting to imagine what a post-pandemic world could look like. In fact, there is much talk about a new normal. I would argue, however, that we have a once-in-a-generation opportunity to build a better normal. We owe it to all those who have suffered to apply the lessons we have learned thus far.
\end{abstract}

\section{Understanding the Impact}

As we do, there are two important facts we must keep in mind-here in the Americas and around the world. First, the impact of COVID-19 is far greater than imagined because it includes not only the direct death and disability toll caused by the pandemic, but also the indirect deaths and disability produced by delayed diagnosis and treatment of various diseases. Second, COVID-19 has not been so much a change agent as it has been a change accelerator, speeding up processes that were already under way. There are both luminous and gloomy facets of these shifts.

The right way to measure the full death-related impact of the pandemic is through what epidemiologists call 'excess mortality,' which is defined as "the number of deaths from all causes during a crisis above and beyond what we could have expected to see under 'normal' conditions." Because the number of deaths tends to be relatively stable from one year to another, any significant sudden increase can be attributed to the direct and indirect consequences of the crisis.
In the case of the ongoing pandemic, we can compare the number of deaths in a specific country during 2020 with the average number of deaths in the previous five years. The difference between these two figures is the excess mortality. Excess mortality gives a better idea of the real impact of the pandemic because it includes not only confirmed COVID-19 deaths but also the COVID-19 deaths that were incorrectly diagnosed and reported, as well as deaths from other causes that can be attributed to the overall crisis.

Several studies have measured excess mortality in 2020 in various countries. One of those studies shows that excess mortality in Mexico in 2020 reached 45 percent, one of the highest in the world. As more data become available, we may well see similarly high rates in other low- and middle-income countries across the region.

\section{Social Inequality Exposed}

Some of the trends accelerated by COVID-19 are especially troublesome. The first and most glaring is the persistence of social inequality - in this case, in the context of health and health care. In almost all countries, the COVID-19 pandemic has disproportionately affected low-income and marginalized groups. This is reflected both in infection and in mortality rates. Lack of access to health care, scarcity of critical resources, and subpar infrastructure limited the prevention and treatment efforts in communities the world over.

Alongside public policies to reduce disparities in access to high-quality health care services, this reality demands the design of specific interventions to deal with the social conditions that account for higher rates of COVID-19 infection and death among specific populations.

Efforts to respond to the pandemic have also exposed the structural weaknesses in health systems. Even in the wealthiest countries, such weaknesses include fragmented public health systems resulting in poor coordination among national, state, and local agencies, as well as insufficient investment in robust surveillance and preparedness programs.

These shortcomings at the national level were exacerbated by the weakness of global health security arrangements that left the world woefully unprepared. One of the distinctive elements of this pandemic is that the global alarm 
systems did not perform as expected, and there is consensus around the sources of this failure: prior to the pandemic, the calls by multilateral agencies, academic institutions, and philanthropic organizations to strengthen the global protection mechanisms against common threats simply were ignored. The irony is that a miniscule fraction of the costs to the global economy inflicted by COVID-19 could have financed a very robust alert and response system.

This cannot happen again. We should take advantage of the attention that public health is receiving to introduce not only marginal but structural adjustments in the global health system that can protect us all in an increasingly interdependent world.

\section{Capturing What We Got Right}

Gratefully, like any crisis, this pandemic has also revealed some bright spots, which we must seek to understand so they do not simply fade away after the acute phase of the emergency but rather become crucial components of the better normal that should follow.

The first sign of hope is the remarkable levels of scientific collaboration across sectors and countries, which led to the development of safe and efficacious vaccines in record time. That great victory shows the way forward as a model for addressing other global challenges.

Another bright facet of the pandemic is the way it has spurred innovation in health care delivery. Salient among such innovations is the dramatic expansion of telemedicine during the last year. In poor countries, and also in underserved communities of rich but unequal nations, telemedicine can allow leapfrogging current practices in a way that would vastly expand access to personalized treatments designed to improve outcomes while reducing costs.

The last and perhaps most encouraging sign of hope is the attention being paid to health risks and a new awareness of our interdependence and common frailty. Thanks to COVID-19, governments, businesses, communities, and individuals now know that no country is safe until every country is safe.

If we leverage these shifts in our understanding across the region, this pandemic can give way to the promise of a better future for aging populations and, as the impact resonates longer term, the generations to follow. $\bullet$

\section{Gratefully, like any crisis, this pandemic has also revealed some bright spots, which we must seek to understand so they do not simply fade away after the acute phase of the emergency but rather become crucial components of the better normal that should follow.}

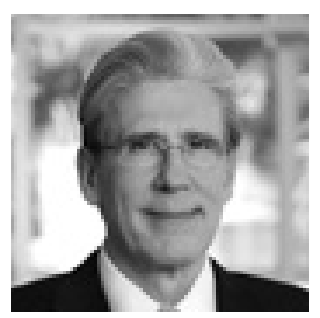

Julio Frenk

President

University of Miami and former Minister of Health Mexico 


\section{The Decade of Healthy Ageing is an Investment in All of Our Futures}

\begin{abstract}
The United Nations declared 2021-2030
the Decade of Healthy Ageing, so that everybody has the opportunity to live longer and healthier lives.

The World Health Organization has been tasked with leading the effort to turn that commitment into a reality, in concert with other UN agencies, governments, international organizations, civil society, the private sector, and academia.
\end{abstract}

\section{The Need to Act Now}

Turning that commitment into a reality is an imperative. More than one billion people are age 60 years or older, and most live in low- and middle-income countries. By 2030, the number of older people will have increased by an estimated 400 million people. Developing countries will experience the most rapid increases, with the number of people age 60 years and older growing fastest in Africa, followed by Latin America, the Caribbean, and Asia.

Many older people, more than 140 million, do not have access to even the basic resources, such as nutritious food, medicine, health and social care. Many more cannot fully participate in society due to issues such as poverty, social isolation, abuse, and lack of assistive products, appropriate housing, accessible transportation, and job opportunities.

The COVID-19 pandemic has highlighted the seriousness of existing gaps in policies, systems, and services for older persons. No country, city, or community has been spared; the crisis has laid bare the high degree of ageism in society and the stark weaknesses in almost every health and social care system. Across all countries we have witnessed how older persons in poor health have borne a disproportionate burden of infection and death. But the COVID-19 pandemic has also highlighted how much, as a global society, we must value health as a common good for humanity.

It is time to rewrite the narrative on population aging, which is often thought to have adverse effects on economic growth and is used as a justification for cost cutting. We often assume that increasing longevity is accompanied by an extended period of good health. But there is little evidence to support this belief. There are huge variations between countries; for example, a 65-year-old female in Slovakia could expect to live another four years in good health, whereas a 65-year-old female in Norway could expect another 16 years of healthy living. Approaches that advocate only for cost containment miss the opportunity to make sound investments to reduce the gap between health span and lifespan. It is time to change the paradigm, so that we are not just extending years, but making sure those added years are healthy, quality ones. We can avoid economic slowdowns by "adding life to years" through policy interventions supporting healthy aging, ${ }^{1}$ such as improving disease prevention, lifelong learning, increasing access to health care, social protection, and opportunities for decent work.

\section{How to Get There}

First, to change the narrative around age and aging, we have to take on the negative stereotypes and prejudice surrounding older people and stop discrimination based on age. Ageism can manifest in the workplace, in access to health care services, and in how products are developed and marketed. Ageism is bad for individuals and bad for society, but it is preventable. The UN Global report on ageism outlines strategies that work to prevent and respond to ageism, including education, intergenerational contact, and legal protections.

Second, we need to rethink health and long-term care. Many health systems are poorly equipped to respond to the needs of older people who have one or more chronic diseases. Health systems tend to value hospitals over primary health care while prioritizing treatment over prevention as well as the management of single diseases over integrated approaches. An effective shift, therefore, starts with primary health care. It must be responsive to older people, based around integrated care that provides comprehensive assessments and a single care plan that takes into account both acute and chronic conditions. This means moving away from acute hospitals towards community-based, planned and coordinated care.

Long-term care systems - that is, where they exist, for in many countries they do not - are often under-resourced, neglected, and poorly integrated with other parts of health and social care systems. The COVID-19 pandemic, specifically how it has disproportionately affected people living in long-term care facilities, has underscored long-term care's systemic flaws. 


\section{It is time to change the paradigm, so that we are not just extending years, but making sure those added years are healthy, quality ones.}

Concerted action is needed to improve the quality of long-term care, including increased emphasis on home- and community-based care. WHO has identified key action points to prevent and manage COVID-19 across long-term care, as part of a broader health and social-care guidance to help countries develop integrated services and pathways for the needs of older people.

The goals of the Decade of Healthy Ageing extend far beyond the health sector. They are focused on building communities that foster the abilities of older people in areas including labor, education, housing, social protection, transport, and technology. The WHO Global network for age-friendly cities and communities supports more than 1300 members from 51 countries covering over 260 million people. One example is Age-friendly Ireland. Established in 2014, it has embraced a vision of every county in the country being a great place in which to grow older, today having in place programs in all 33 local authorities.

Central to the mission of the Decade of Healthy Ageing is that older people must play a central role in the decisions that affect them. Older people, with the support of their families and communities, must have the opportunities to assume responsibility for their own health and well-being.

To achieve the promise of the Decade of Healthy Ageing, we have to work across countries, sectors, and disciplines. WHO, in collaboration with stakeholders from over 80 countries, has developed the Decade of Healthy Ageing Platform, an innovative multilingual knowledge exchange resource that will enable people to find, share, and produce knowledge on healthy ageing. The design of the Decade Platform recognizes that there are many types and sources of knowledge, including those derived from personal experience. To meet different knowledge needs, the platform contains voices and stories from older people, their families and communities, user guides, reports, databases, teaching resources, and research materials, as well as informal and face-to-face learning opportunities.

The Platform is designed for use by policymakers, practitioners, and all other stakeholders working to foster healthy ageing. To maximize the use of knowledge, the Platform also offers stakeholders training and opportunities to share successful initiatives and good practices.

\section{A Global Imperative}

During this Decade of Healthy Ageing and beyond, $\mathrm{WHO}$ is committed to working with older people and the organizations that represent them to foster good health, improved quality of life, and dignity for current and future generations. Improving the health and well-being of aging populations is not only a moral responsibility, it is a social and economic imperative. Our older generations have given us all so much. We now have the opportunity to give something back. Working together, we can build a healthier, fairer, and more dignified life for all. $\bullet$

${ }^{1}$ Health, an ageing labor force, and the economy: Does health moderate the relationship between population age-structure and economic growth? - ScienceDirect https://www.sciencedirect. com/science/article/pii/S0277953621006857

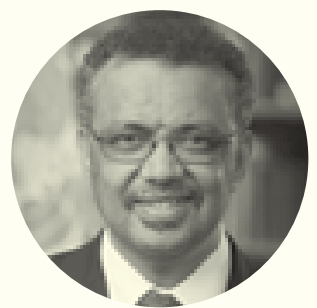

Tedros Adhanom Ghebreyesus

Director-General

World Health Organization 


\section{Age Friendly Towns in Ireland}

or more than a decade, the Age Friendly
Ireland Program has worked with local
governments to ensure their communities meet
the needs of all ages from the oldest to the
youngest. Hosted and run by Meath County
Council, the program was developed initially with
philanthropic funding, with local governments
taking the lead in developing multi-agency
alliance structures in each municipal area. ${ }^{1}$ Today
all 31 local authorities in Ireland lead age-friendly
programs, making Ireland the first country in the
world that has achieved full, country-wide mem-
bership in the World Health Organization's Global
Network of Age Friendly Cities and Communities.
This commitment by all local authorities was
critical to mainstreaming the program as a local
government shared service in 2018 . This service
is now anchored in four government departments,
in addition to the policing service, the Health
Service Executive, and the business community via Chamber of Commerce Ireland. The national government buy-in is cited as a critical success factor, supporting cross-departmental work to advance the age-friendly community agenda.

Local Age Friendly Alliance structures are the key delivery mechanism for initiatives to prepare for population aging, with their strength deriving from their inherent multi-sector nature. These alliances comprise senior representatives from the main public-sector agencies in each county and city, the business community, universities, transport companies and elected representatives, working together with representatives of Older People's Councils. This proven multisectoral partnership is highly effective and the program has gained significant traction in recent years, particularly in the development of Age Friendly Housing and the Public Realm, Age Friendly Towns, and integrated service delivery between local governments and health services.

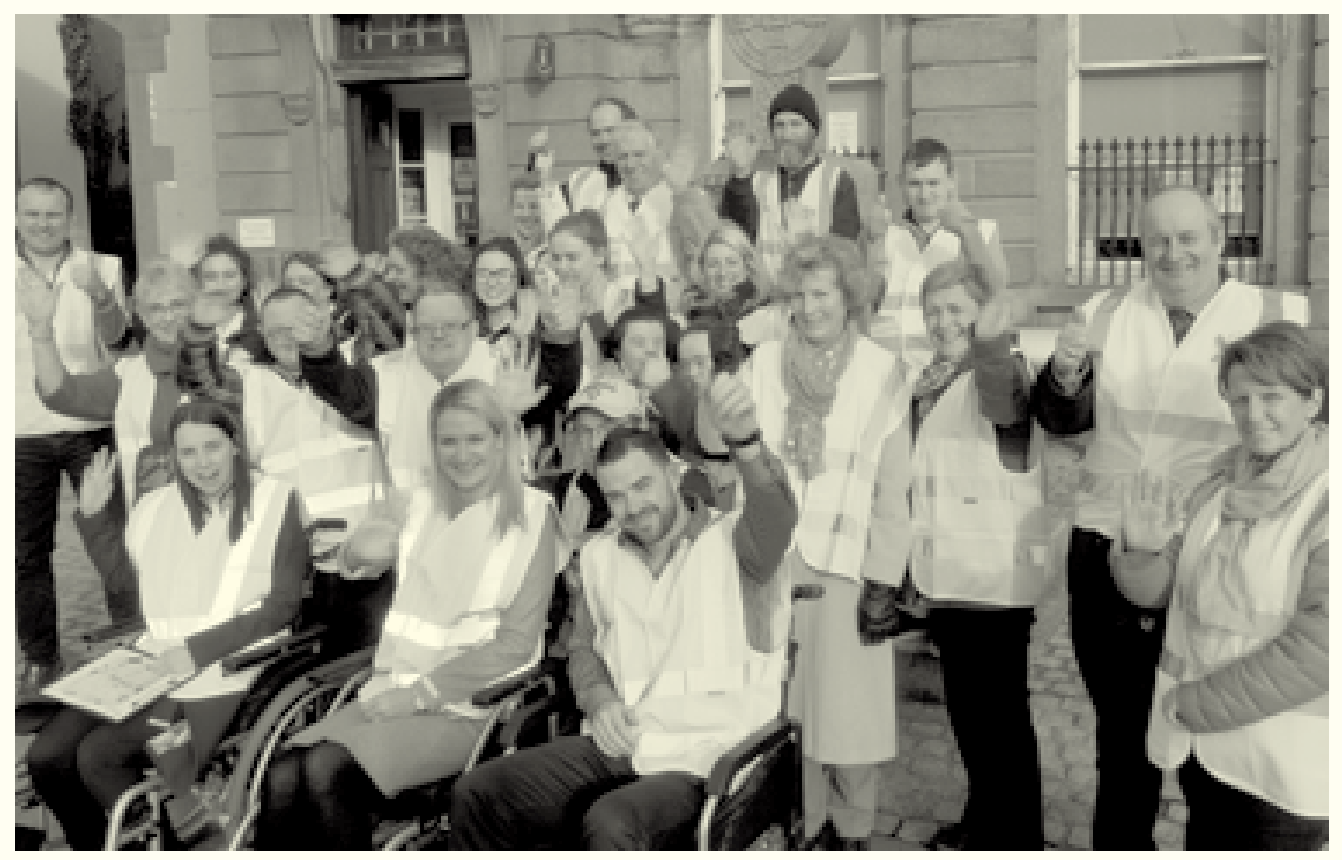

Walkability Audit in Kells town, County Meath as part of the Age friendly Town process. 


\section{Developing Age Friendly Towns revolves around the ethos that if you design for the young, you exclude the old, but if you design for the old, you include everyone.}

\section{Age Friendly Towns}

Developing Age Friendly Towns revolves around the ethos that if you design for the young, you exclude the old, but if you design for the old, you include everyone. A significant component of preparing for population aging is the development of Age Friendly Towns, which are smaller, discrete geographic areas such as a town, village, or a suburban community within a larger urban area. An Age Friendly Town plans for the older person's needs, supports active aging, and facilitates older adults to remain living in their own homes and communities.

Age Friendly Towns consider citizens' needs in a holistic way, focusing not just on the built environment but also on access to services, cultural opportunities, safety and security, and residents feeling connected to the community. There are about 60 Age Friendly towns in Ireland at various stages of development, with 29 having completed the process. Hosting Age Friendly Ireland in local government strengthens the ability to implement change, because it provides direct links with planning departments and decision-makers for public realm developments.

The shared service provides a suite of resources to support the development of Age Friendly Towns, including training programs, toolkits and other resources available online free of charge. The program's training module, 'Housing and the Public Realm,' is delivered to local government personnel, government departments, housing bodies and the construction industry. An Age Friendly Parking Guide and an Age Friendly Seating Guide also recently were published to help focus on specific areas for developing age inclusive features.

\section{Local Examples of Age Friendly Towns}

In the picturesque village of Thomastown, County Kilkenny, the Age Friendly Town process resulted in better street lighting for the town, footpath improvements, outdoor seating, community-based classes for older people, age friendly bus shelters, an Information Guide on older people's services, and a drop-in center in the town, among other things.

In the historic town of Trim, the Age Friendly Town improvements include a colorful sensory garden with plants selected to stimulate the senses (i.e., scent, touch, and sound), as well as chimes and a fairy garden. The sensory garden was developed with a disability group called Prosper Meath on local authority owned land, with support from the business community, the Office of Public Works, school children, and community groups such as Tidy Towns and the Men's Shed, which built furniture for the garden.

Joan Carroll, who works with the Age Friendly Program in Meath County Council, explains: "Becoming an Age Friendly Town takes work and 

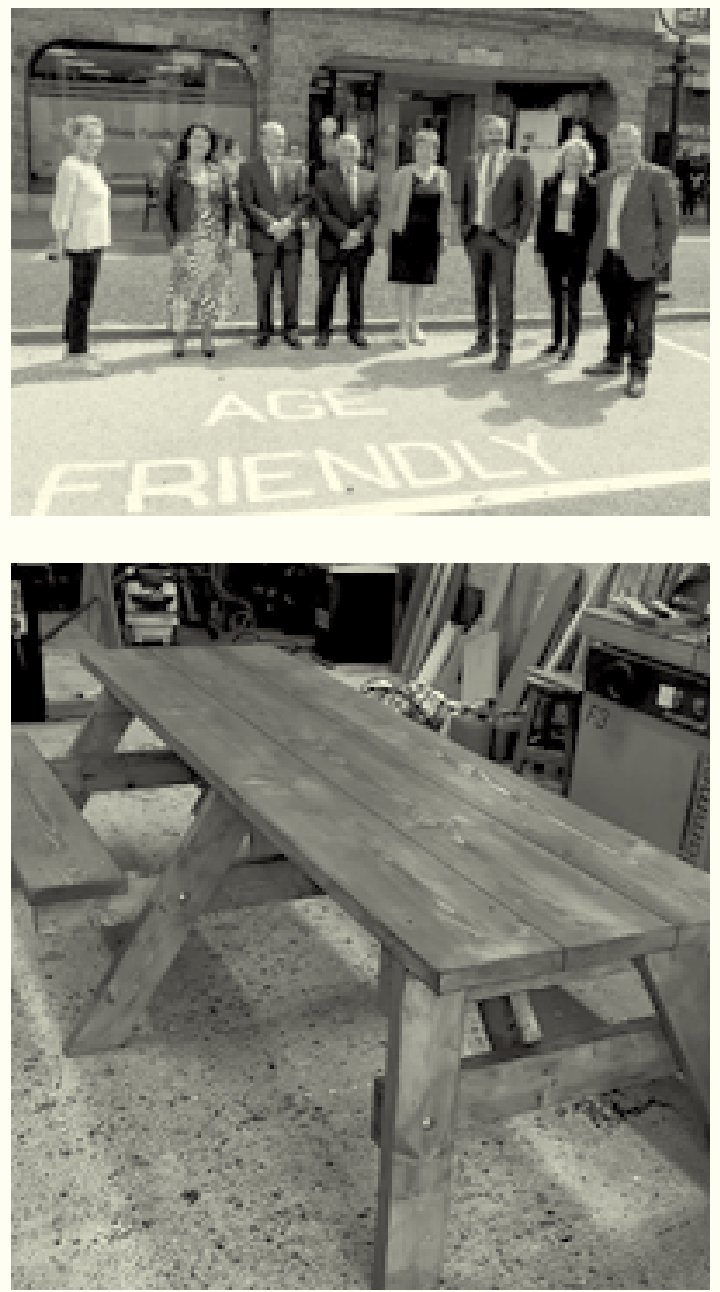

buy-in from the local community, the businesses and decision makers."

In Skerries in North County Dublin, the Age Friendly Town process led to the rollout of befriending services in the community. The community behind Age Friendly Roscrea, a town in County Tipperary, was described as a 'beacon of hope' during the pandemic, rallying volunteers to deliver goody bags to older people, and organizing regular check-ins and phone call networking with many older people living in the town.

Cork County took a proactive approach to developing Age Friendly Towns, with a significant program of work and dedicated budgets. For example, in the town of Middleton a talented

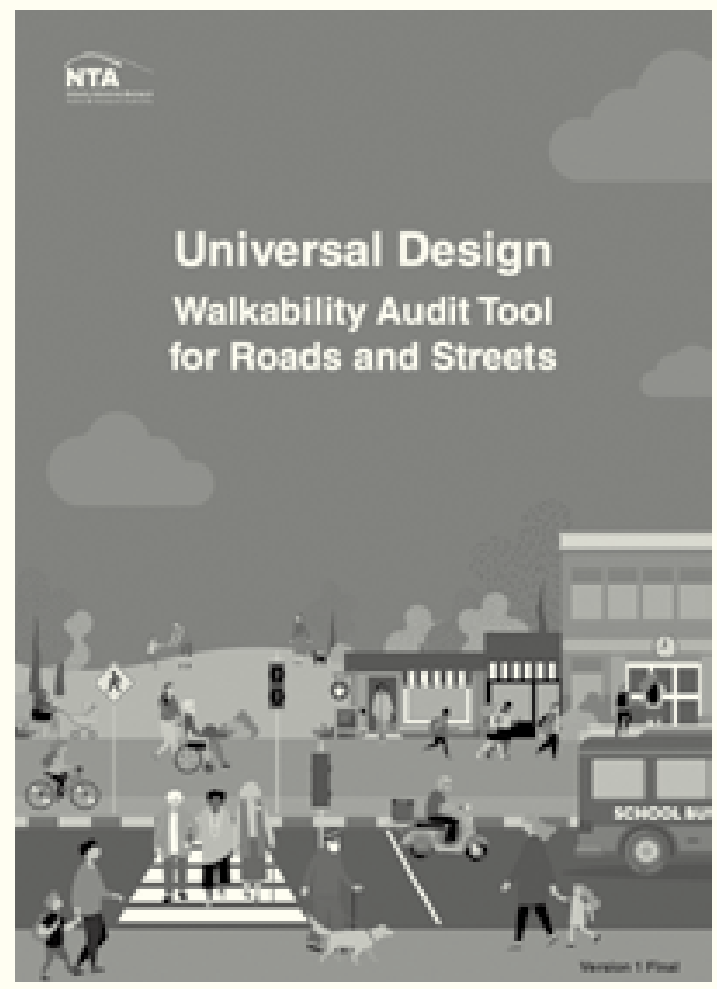

Clockwise: Installation of Age Friendly car parking; New Universal Design Walkability audit toolkit developed by the National Transport Authority with Age Friendly Ireland, An Taisce and the Centre for Excellence in Universal Design; and wheelchair accessible picnic table made by craftsman Paki O'Mahony for the Cork Age Friendly Programme.

local craftsman made two beautiful wheelchair-friendly benches that were accessible to people of all abilities. They are universally used by "a person with a wheelchair, or an older person with a walker, or even a mum with a buggy," explained Chairperson of Cork Older People's Council Liz Maddox.

\section{A Focus on Walkability}

Among the key tools for local government to modify public spaces so they are accessible for people of all ages is conducting a walkability audit. Reflecting a Universal Design approach, walkability audits are undertaken locally by a diverse group of participants, both young and old, 


\section{This work is helping Ireland to prepare for population aging in a very tangible way, with marked improvements in the built environment and structures to support the participation of older people in local decision-making about their communities.}

parents with buggies, and people with cognitive, sensory, and physical disabilities.

A number of walkability audits have been undertaken in County Meath in the east of Ireland, in the towns of Kells, Slane, Trim, Enfield, Summerhill and Athboy.

In 2019, the town of Athboy undertook a special Walkability Audit with an enhanced focus on dementia. The local Age Friendly Program partnered with the Health Service Executive's national dementia awareness campaign, called 'Dementia: Understand Together' to better understand how to serve its citizens with dementia. Representatives of the community worked with an architect who specializes in designing for dementia to identify issues presenting for people with physical, sensory, or cognitive impairment. In the aftermath of the audit, the local authority has secured significant funding to improve its public spaces. Capital projects are underway, including redesigned public seating, adding bollards to protect pedestrian spaces from vehicles, and resurfacing footpaths.

Walkability studies continue to play a critical role. The original Age Friendly Ireland walkability survey was developed further as a Universal Design audit tool in 2020 by the National Transport Authority. With input from Age Friendly Ireland, the Centre for Excellence in Universal Design, and An Taisce (the National Trust for Ireland), the updated tool takes an even broader, more age-inclusive view, including a focus on the walkability of the route to school for younger children.

As a result of walkability studies, the members of Comhairle na n'Óg (Youth Council) participated in dementia awareness training with the
Alzheimer's Association of Ireland, and this program will now be rolled out across the schools.

\section{Conclusion}

As the network of Age Friendly Towns develops across Ireland, older adults and generations to come all benefit from improvements. This work is helping Ireland to prepare for population aging in a very tangible way, with marked improvements in the built environment and structures to support the participation of older people in local decision-making about their communities. As the population ages, it is vital that our towns are sustainable and suitable for older people to flourish in their own communities for as long as possible. Joan Carroll from Meath County Council sums up the opportunity and impact of this work in this way: "Once a community understands the Age Friendly concept, the possibilities are endless." •

${ }^{1}$ In Ireland, each local government catchment area (based on county or city boundaries) is further subdivided into Municiple Districts.

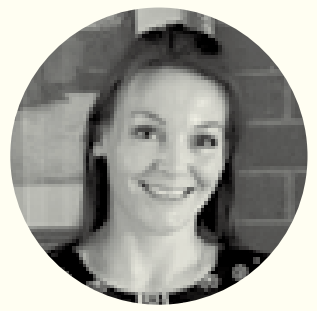

Emer Coveney

National Programme Manager

Age Friendly Ireland 


\section{Building a Better California for All Ages and Abilities}

$\mathbf{L}^{\mathrm{se}}$ ike elsewhere in communities around the world, California is aging. And with the leadership of Governor Gavin Newsom, it is embracing the opportunity to become the Golden State for the golden years. By 2030, nearly a quarter of California's population will be over the age of 65 , exceeding the 18 and under population for the first time. This extraordinary growth and diversity in the older adult population will change everything - the structure of our families, our communities, and our state.

To prepare California for the gifts and challenges of longevity, the governor issued an executive order in June 2019 that set in motion the creation of California's Master Plan for Aging (MPA). California for All Ages and Abilities is a blueprint to transform California, ensuring that all residents, families, and communities can thrive as we age. Crafting a blueprint of this magnitude requires the engagement and expertise of residents from across the state, in a range of inclusive and interactive ways. The MPA's development embraced this approach, spanning more than a year of public engagement, stakeholder outreach and work groups, webinars, community roundtables, and alignment with the Governor's Task Force on Alzheimer's Prevention, Preparedness \& Path Forward.

While we engaged a broad range of California stakeholders to develop the robust plan, California also drew inspiration from age-friendly communities worldwide. Innovative solutions in Japan, Singapore, and Taiwan to support an aging population influenced many aspects of California's MPA. Japan, known for being the global leader in this area, inspired California with its digital healthcare system which has improved the healthy longevity of its population. Singapore's anti-ageist vision for growth and development, community, and inclusion also had an impact on the development of the plan.
Finally, Taiwan's long-term care system has made a lasting impression on California with its ability to fully support the aging-in-place model by offering both robust home care and social services to those who choose to age at home. Plans are in motion to engage with the Chinese and Japanese consulates in San Francisco to compare innovations and solutions.

In early 2021, California launched its bold 10-year Master Plan for Aging. The Master Plan provides an inclusive and equitable framework for transforming aging for individuals, families, and communities as the changing demographics inevitably shape the future of California.

With the onset of COVID-19, the MPA became even more critical. Older adults experienced unprecedented death rates - particularly among Latino, Black, and Asian Pacific Islander communities and those living in nursing homes. Many have experienced increased feelings of isolation and loneliness, and struggled to access California's essential services.

\section{Five Bold Goals to Build Communities for All Ages and Abilities}

California's aging services and supports, like many in the United States, are far behind where they need to be. California's Master Plan for Aging provides a sense of optimism and urgency that will drive California's metamorphosis of services and supports, so Californians can live how and where we choose for the rest of our lives.

The Master Plan for Aging's goals lay the groundwork for all California communities to prepare for the current demographic shift. By prioritizing advances in housing, transportation, healthcare, workforce and volunteer opportunities, caregiver supports, and economic security, communities will be capable of improving the quality of life for Californians of all ages. 


\section{The Master Plan for Aging's goals lay the groundwork for all California communities to prepare for the current demographic shift.}

The Master Plan for Aging's five bold goals: housing for all ages and stages; health reimagined; inclusion and equity - not isolation; caregiving that works; and affordable aging are accompanied by 23 strategies, powered by over 100 catalytic and pragmatic two-year initiatives to advance our communities. The MPA addresses the most urgent and critical needs and gaps in systems for building age-friendly communities. But it is just a starting point with the goal that every county and city in California will have its very own Master Plan for Aging. California currently has three counties with their own Master Plans - San Francisco, Los Angeles, and San Diego - and 54 cities and counties are building age-friendly communities partnering with AARP's Network of Age-Friendly States and Communities.

\section{Making Your Community More Age-Friendly}

There is a lot to consider when planning for an aging community. The MPA is not only a statewide blueprint but also includes a local playbook that serves as a resource for local government, communities, and private and philanthropic organizations seeking to transform policies and services to promote age-friendly communities. The playbook outlines how to engage and work collaboratively with California's local aging champions - the county board of supervisors, city councils, university gerontology and aging experts, local aging and disability services, and beyond. It is designed to meet communities where they are and assist in determining the unique aging needs of California's diverse communities.

When building age-friendly communities, there is one remaining critical ingredient that binds it all together: the inclusion of older adults. Without the full participation of our older
Californians to provide their perspective, we would end up with half-baked plans with gaps and flaws in policies, programs, and services. Older adults must be at the table, listened to, and engaged with as the central architects of local aging plans. With aging comes great wisdom, life experience, and perspective that is critical to understanding what needs to change in our communities. To truly build a California for All Ages and Abilities, we must all be present and given the opportunity to contribute.

Looking ahead, we will continue to move our efforts not only locally but globally. California will continue to seek and build partnerships with the boldest and brightest minds around the globe. The stronger our network, the broader our toolkit to serve California's diverse older adults. We have a long way to go, but together we can build age-friendly communities we all deserve. Learn more about California's Master Plan for Aging and see how you can contribute to building age- and ability-friendly communities for all. $\bullet$

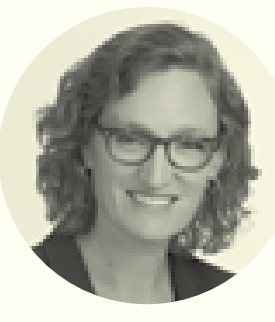

Kim McCoy Wade

Director

California Department of Aging 


\section{Protecting the Human Rights of Older Persons}

\begin{abstract}
$\mathrm{n}$ light of the devastating discrimination against older adults seen worldwide during the COVID-19 pandemic, it is time for the global community to respond using existing international protections of human rights while also considering new treaties. A new treaty on human rights addressing older age would provide a clear, coherent, and comprehensive statement to encourage reform and provide guidance for governments, policymakers, courts, and advocates. We must act to protect the human rights of older adults and provide the necessary resources for existing bodies to address the issue.
\end{abstract}

The COVID-19 pandemic shone a light on the ways in which older persons are marginalized, devalued, rendered invisible, and neglected. The staggering number of older adults who died of COVID-19 brought the issues of human rights for older adults to the forefront. Not only were older adults dying by the tens of thousands around the world, some were neglected in long-term care facilities, while others were isolated from their families and communities. Further, the emergence of ageist attitudes, and divisive discourses of intergenerational competition, were among the more pronounced features characterizing the responses in some countries. Finally, financially disadvantaged older adults were disproportionately harmed during the pandemic.

It's important to acknowledge that older adults, of course, were not the only group adversely impacted by the pandemic, and that it affected many other groups in different ways. Children, women, indigenous peoples and ethnic minorities, among other groups, also suffered in distinctive ways. In some cases we still do not fully understand the long-term implications of the pandemic on people's health. For instance, we don't know how long COVID will affect younger people as they age. Yet there is no doubt that the pandemic, and how governments responded to it, reinforced previous structures of ageism, while laying bare clear discrimination against older persons. This isn't to discount the affirming examples of intergenerational solidarity as communities, including many younger people, sought to support older relatives and community members during lockdowns and other restrictions. But those successes were not enough to undo longstanding ageist practices.

Given the disproportionate effect of the pandemic on older adults, there was - initially, at least - a new urgency to the discussions at the
United Nations regarding the necessity of a new treaty and what it should look like.

\section{A long history of human rights violations against older adults}

Human rights violations against older adults are numerous and widely documented around the world. These violations include the denial of legal capacity, restrictions on enjoyment of the right to live independently and in the community, elder abuse (including physical, psychological and financial abuse), and employment discrimination. Still another example includes older adults left financially unstable with an inadequate standard of living upon exiting the paid labor force. This comes in many forms, including having no pension or an inadequate one (government or private), and discrimination against women in the form of lack of retirement income. The list continues. A lack of access to lifelong learning and education, and capacity-building opportunities as well as technology accessibility issues in the context of digitization and online government, are among many other discriminatory practices facing older adults. These violations of human rights exist globally, in high-, low-, and middle-income countries.

In recognition of these persistent violations, calls for a new convention on human rights in older age began a decade ago. The general premise of these calls was to reaffirm that older persons hold rights under existing treaties. The goal was to provide detailed guidance on the steps states could take to ensure older persons fully enjoy their rights. International human rights law is no panacea, but such standards can provide a significant, focused stimulus to action.

\section{Existing human rights law}

Many continue to argue that the existing treaties and mechanisms for protecting human rights adequately extend to protect older adults and are reluctant to accept a new convention that explicitly prohibits discrimination on the basis of older age. These rights are guarantees against discrimination and affirm the right to life and freedom from torture; they are enjoyed by everyone by virtue of being human. The arguments for relying on existing law to protect older persons vary, but a recurrent one is that existing law is up to the task and that better implementation is the answer. 
These treaties exist at the United Nations, where the standards are potentially applicable to all countries in all regions of the world. Current treaties generally address civil, political, economic, social, and cultural rights (the International Covenants). Notably, others focus on particular types of violations, even toward specific groups: racial discrimination, discrimination against women, rights of the child, rights of persons with disabilities, rights of migrant workers, protection against torture and disappearances. Each of these thematic treaties addresses particular violations or protect specific groups.

Virtually none of these treaties mention older persons or discrimination on the basis of older age, though a number prohibit discrimination on the basis of "other status," which includes older age among a multitude of other characteristics. Some rights that apply to older adults, such as the right to social security, do appear in the treaties as a category of required social welfare supports. Because older people and their concerns are largely absent from the text of the treaties, they receive a relatively low priority in enforcement.

\section{The argument for a new treaty}

While existing treaties address sexism, ableism and racism, there is no explicit obligation to address ageism and ageist practices. Existing treaties do not provide any clear guarantee of a right to care and support to enable older persons to age in place, remaining in their own home and community (rather than being forced into a long-term care facility). Further, the treaties do not directly address many forms of elder abuse, including financial abuse, nor do they provide a clear guarantee of the right to palliative care as part of the right to health. Even among the treaty provisions that do relate to aging, there is a need to update them to better reflect current trends in longevity. For instance, provisions relating to work guarantees and "post-work" support are largely premised on a traditional three-stage life of education, work, and "traditional" retirement, ignoring the needs and protections of those who continue to work later into life. Additionally, rights to education and lifelong learning focus on younger people both in their formulation and implementation.

Given the obvious holes in the existing standards, I, along with other advocates, believe it is a necessity to strengthen current international policy with a new treaty specifically addressing ageism. The reasons for this are structural — that is, they involve the conceptual limitations and deficiencies of current standards, formulated without regard to the nature and today's realities of older age and its social meanings, and the operational limitations of existing mechanisms. We can make some progress with the tools that we have, but to complete the job we need a new set of tools in the form of a new convention.

The evidence showing the need for such action is now emerging. A 2021 study by the Office of the United Nations High Commissioner for Human Rights supports this approach. The study describes how the existing UN human rights system addresses human rights and older age as well as its limitations and deficiencies. The findings reveal a fragmented system that is generally not systematic or sustained. Missing from the existing norms is an understanding of the nature and social construction of older age and the implications of increased longevity for both individuals and larger populations, the study found.

Clearly, it is time for action. The current system lacks a comprehensive and coherent framework on human rights in older age comparable to those for women, children, and persons with disabilities, to underpin its work. Only a new treaty will be able to provide the push and focus that is needed.

Update to the 2012 Analytical Outcome Study prepared by the Office of the High Commissioner for Human Rights on the normative standards in international human rights law in relation to older persons, working paper prepared for the 11 th session of the United Nations General Assembly Open-Ended Working Group 2021, https://social.un.org/ageing-working-group/documents/ eleventh/OHCHR\%20HROP\%20working\%20paper\%2022\%20 Mar\%202021.pdf

Andrew Byrnes acted as a consultant to the UN OHCHR in the preparation of the updated study. The views expressed in this article are his own and do not necessarily represent those of the United Nations.

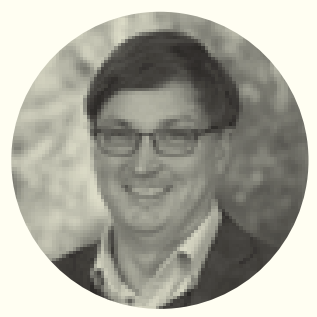

\section{Andrew Byrnes}

Emeritus Professor, International

Law and Human Rights, Faculty of

Law \& Justice

University of New South Wales,

Sydney, Australia 


\section{Combating Ageism in the Media and Marketing}

\begin{abstract}
C
onsumers' opinions of what constitutes

a desirable lifestyle are shaped by a continual stream of images and messaging from the mainstream media. Images, content and fashion models that surround consumers are central to driving the consumer belief system. Women have been programmed to believe that a beautiful body is thin and tanned. Women are led to believe that makeup is essential in order to be attractive. And, women are led to believe that youth is the only time in life when you are considered beautiful.

Luckily, times are changing and many (but not all) consumer health and beauty product manufacturers are embracing a much more diverse definition of beauty. Many of these health and beauty product companies, such as Dove, are creating advertisements that show women with different hair colors and textures, different body shapes and a multitude of skin colors. However, with the exception of L'Oreal, almost none have embraced age as a factor of diversity in their ads.

This lack of age representation in the media, marketing and advertising industries is shocking. Consider AARP's study on beauty and wellness: 81 percent of women said they would rather buy
\end{abstract}

a brand that shows a mix of ages in its ads, but 86 percent of women 50-plus felt underrepresented in ads and two-thirds said when they were represented, the images were selling old stereotypes.

Many marketers believe their strategy should be to attract consumers younger in their lives in order to create a multi-decade purchasing relationship. However, what's remarkable is that when those loyal consumers turn 50 years old, the companies that have enjoyed their brand loyalty for years turn their back on them, dropping them as a target audience purely because of age. Companies then, once again, pivot back to the younger demographic. This worn out strategy, of ignoring the older consumer, doesn't make good business sense.

Reaping the economic benefits of age-inclusive marketing starts with understanding the 50-plus lifestyle and then using images and messaging that connect with the reality of how people are aging today. Increasingly, that lifestyle includes employment, which is tied to consumption and spending patterns.

AARP research has shown that consumers over 50 are responsible for more than 8.3 trillion of the country's economic activity or 56 cents of ever dollar spent in 2018; and workers 50-plus

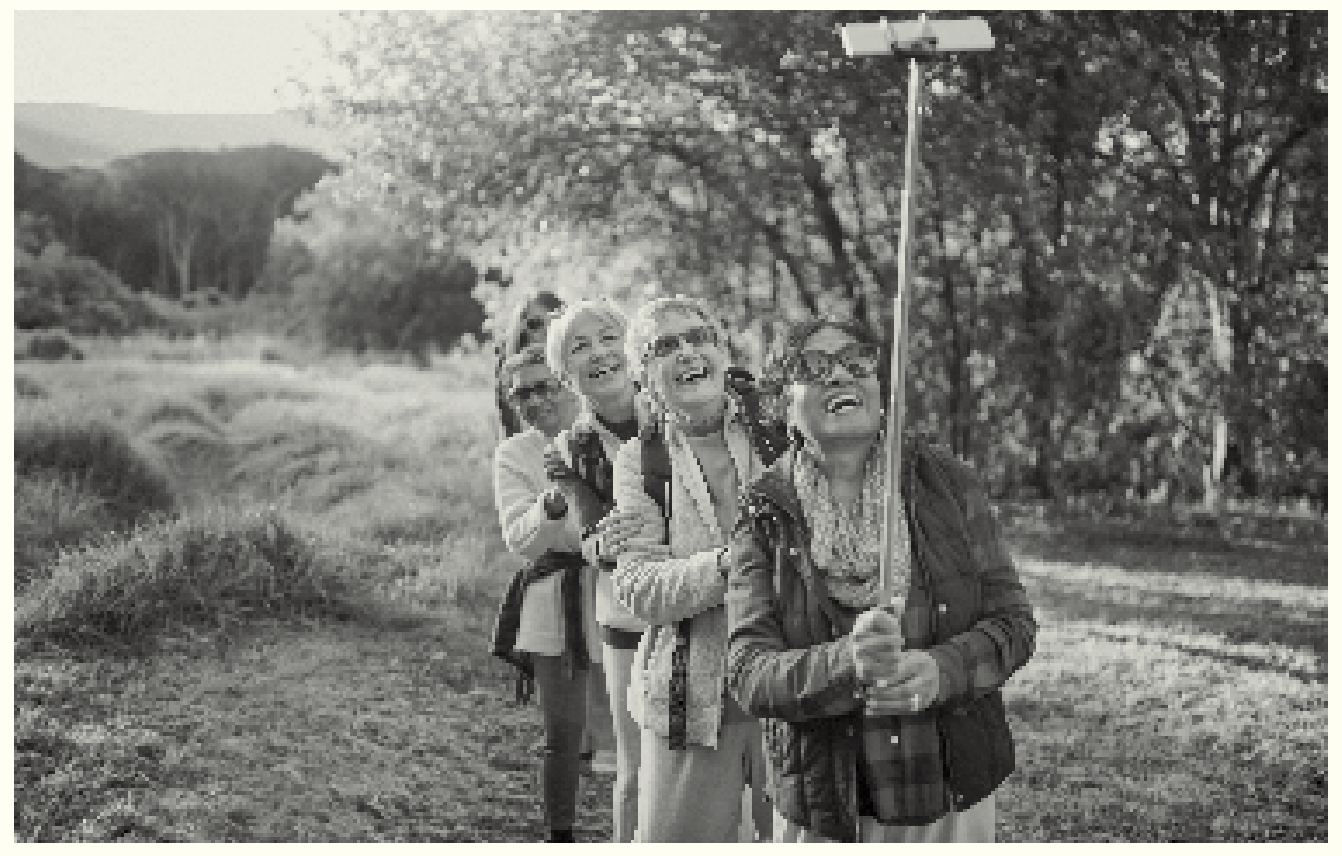




\section{Reaping the economic benefits of age-inclusive marketing starts with understanding the 50-plus lifestyle and then using images and messaging that connect with the reality of how people are aging today.}

make up over a third of the U.S. workplaces in key sectors such as technology, health and education. The 50-plus age group also strengthens communities across the U.S. by providing $\$ 745$ billion in unpaid activities such as volunteering and caregiving and $\$ 97$ billion in charitable donations.

How the 50-plus are spending their money also tells an important story for marketers. Adults 50-plus are responsible for $\$ 142$ billion of spending in the travel industry and $\$ 1.2$ trillion in the leisure industry, according to AARP research. These eye-popping stats should be interpreted as a call to action for consumer-goods companies and their marketing firms to reexamine stereotyped portrayals of older people, who often are shown only in health care settings or with a caregiver. Many images show older people in passive environments and rarely in the workplace, traveling, or socializing.

After witnessing too many of these typecast depictions, we at AARP knew it was time for a new image of aging to help marketers and the media accurately depict aging consumers. In 2019, we partnered with Getty Images to launch the Disrupt Aging ${ }^{\circledR}$ Collection of stock images. For two years now, advertisers and media have been empowered to present an accurate picture of aging.

Imagery in marketing is essential to product sales, but imagery in entertainment is what drives the broader societal discussion. At AARP we know the power of the entertainment industry. For more than two decades, through our Movies For Grownups awards program, we have recognized and awarded movie studios, actors and writers who create movies and television programming that taps the talent of the 50-plus and write stories that appeal to all generations. Afterall, entertainment is a top American export and all ages should be celebrated.

The UN's 2020 aging report said there were 727 million adults 65 and older in the world and over the next three decades, that number is expected to more than double to over 1.5 billion in 2050. That's a lot of people with substantial spending power. At AARP, our call is to the world's media, entertainment, and marketing industries to look at the data, shed outdated stereotypes, and embrace the reality that the future is about a global aging population. There is much to celebrate about this burgeoning consumer market. But the first step is recognition of this diverse and expansive market. And then comes a proper depiction of what it is: a market characterized by a vibrant, engaged and consumer-focused lifestyle, and one that can be tapped to transform economies around the world. $\bullet$

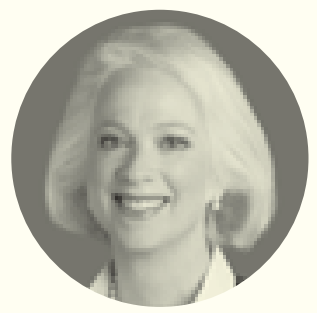

Martha Boudreau

Chief Communications and Marketing Officer AARP 


\section{A Turning Point for the Rights of Older People}

S usan Robinson, a 68-year-old resident of a United States nursing facility, spent months stressed and isolated during the COVID-19 pandemic. Weary from the confinement, she spoke to Human Rights Watch recently about the process of moving out of the nursing home and into a government-subsidized apartment.

"I can't wait," she said.

Thanks to a state program that helps older people and those with disabilities live in the community with adequate support, Robinson won't have to wait long. She spoke with eagerness about soon driving around her community with her fiancé and reconnecting with family members.

The impact of COVID-19 on older people is well documented. Older adults account for a substantial percentage of the deaths and were disproportionately impacted by the responses of many governments.

The question now is whether COVID-19 can serve as the wake-up call to the numerous accounts of ageism. If the issue is left unchecked, the rights of older people will continue to be denied and age discrimination will only grow. The unprecedented exposure of the failings in nursing homes should not be viewed as an isolated failure to protect the rights of older adults. For too long we have witnessed the impact of excluding older people in responses to climate change, conflict, and humanitarian disasters. Ageism must no longer be ignored.

Our goal should be to create an environment in which older people in Robinson's position have outcomes more like hers. That is, our goal should be to ensure that the aftermath of the devastating toll the COVID-19 pandemic had on older adults drives public support for a long-overdue global effort to better protect the human rights of older people.

\section{The Documented Human Rights Violations of COVID-19}

Millions of older people around the globe experience human rights violations every year. Most of these abuses go undocumented, and those responsible are not held to account. But the COVID-19 pandemic exposed deeply ingrained ageism and underscored that the failure to protect the rights of older people has serious consequences.

Between August and November 2020, before vaccines were available, approximately nine in ten deaths in Europe were among people age 60 or above. As of April 2021 in the United States, 95 percent of deaths were among people over age 50 .

Nowhere was the toll more severe than in congregate settings such as nursing homes. According to one analysis published by the International Long Term Care Policy Network, as of October 2020, long-term care residents made up an average of 46 percent of COVID-19 deaths in 20 countries for which there was data. In Australia, many outbreaks of COVID-19 in aged care facilities were "preventable," according to experts. Staffing shortages and lack of staff training in using personal protective equipment hampered an effective response.

In the United States, potential neglect and prolonged isolation exacerbated by visitor bans may have caused serious harm to many people in nursing homes. By March 2021, more than 1.4 million residents and long-term care employees were infected with the coronavirus and more than 178,000 had died, making up 34 to 40 percent of all U.S. deaths from COVID-19. Laws or executive orders in 32 states that shield nursing homes from civil liability during the pandemic have made it difficult for residents or their loved 
ones to seek legal recourse against facilities for alleged harm.

In his May 2020 report on the impact of COVID-19 on older people, UN Secretary General Antonio Guterres pointed out that the absence of both adequate legal protection of the rights of people in older age in many countries and a dedicated international legal framework may have contributed to inadequate responses to the COVID-19 crisis.

Nursing homes were not the only setting where older people's rights were denied during the pandemic. Arbitrary and discriminatory agebased restrictions on older people's movement to curb the spread of the virus curtailed the rights of older people to leave their homes, use public transport, and work. For example, in March 2020, the government of Bosnia and Herzegovina imposed strict bans on anyone over 65 from leaving their home for any reason, even to buy groceries or go to the pharmacy. The constitutional court determined the restrictions to be disproportionate and in violation of the right to freedom of movement.

Travel restrictions imposed in March 2020 by the Ukrainian government and Russia-backed armed groups on people who live in conflict-affected areas in eastern Ukraine made it hard for older people to gain access to their pensions, pushing many further into poverty as pensioners were forced to cut back on food, medication, and necessary hygiene products. HelpAge International estimates that in Sub-Saharan Africa alone the economic fallout of the pandemic will push 1.6 million to 2.3 million more older people into extreme poverty (those forced to live on US $\$ 1.90$ or less per person per day), as those who have no access to a public pension or other forms of social protection for older people fail to recover from the loss of livelihoods and income caused by COVID-19 lockdowns.

\section{For too long we have witnessed the impact of excluding older people in responses to climate change, conflict, and humanitarian disasters. Ageism must no longer be ignored.}




\section{All of us, whether from government, the UN, civil society, or the private sector, should ensure that all older people are treated with dignity and respect and enjoy their rights on an equal basis with others.}

\section{Other Documented Human Rights Violations in Older Age}

These threats to our human rights in older age are nothing new and existed well before the pandemic.

Human Rights Watch research in Australia shortly before the pandemic found that instead of providing support to older people with dementia, many aged care facilities use drugs to control their behavior, a practice known as chemical restraint. Many of these drugs are antipsychotics that are not approved in Australia for older people with dementia. In addition to the physical, social, and emotional harm that these drugs cause, their use in older people with dementia is also associated with an increased risk of death. Academic research in 2020 found that the prescribing of psychotropic drugs increased that year in nursing homes in Ontario, Canada and in the United Kingdom.

Older people also experience serious risks during armed conflict and humanitarian emergencies.

Our research has chronicled cases of older women arbitrarily detained, tortured, subjected to sexual violence, and killed, even burned alive, by government forces and non-state armed groups during armed conflicts in many countries including Armenia, Cameroon, the Central African Republic, Ethiopia, Guinea, Mali, Myanmar, and South Sudan.

We have documented human rights concerns for older people due to the serious humanitarian crisis in Venezuela, including insufficient access to food, medicines, basic supplies, and medical care. Many people have been unable to secure their pensions and other retirement benefits. And older people are among the more than 5.6 million Venezuelans to flee the country, potentially making it difficult to keep receiving their pensions. They also often find it harder than younger people to get jobs.

Older people also face human rights concerns stemming from climate change.

An April United Nations report on climate change and older people warned that older people are at higher risk of dying during conditions related to climate change. Recent climate change-exacerbated heat waves in the western Canadian province of British Columbia left hundreds dead. According to British Columbia's chief coroner, 79 percent of deaths between June 20 and July 29 were of people over 65, many of them living alone.

A December 2020 Lancet report on health and climate change found that in the past two decades heat-related deaths of older people in the United States almost doubled, reaching a record high of 19,000 deaths in 2018. In 2017, twelve older people in a Florida nursing home suffocated due to high temperatures after Hurricane Irma knocked out their air conditioning.

\section{Time to Respond}

In her April statement to the UN Open-ended Working Group on Ageing, the Independent Expert on the enjoyment of all human rights by older persons, Claudia Mahler, said: "The 
pandemic has had and continues to have a disproportionate impact on older persons and has magnified existing violations of their rights."

All of us, whether from government, the UN, civil society, or the private sector, should ensure that all older people are treated with dignity and respect and enjoy their rights on an equal basis with others. We need to explore alternatives to institutionalization by increasing and improving older people's access to home- and community-based support services so that no one is compelled to live in a residential institution for lack of choice.

We need to consult with and address the needs of older people in climate-change response plans and in conflict and humanitarian disasters. We should ensure that public pensions are adequate and do not become victim to budget cuts if governments look to tighten spending in the coming years. In short, we should ensure that human rights in older age are fully protected under both national and international law.

A life of dignity, free of fear and want in older age, is not a privilege for the few but a right for all. This year should and can be the point at which our collective record on the rights of older people improves.

Clearly, it is time for action. The current system lacks a comprehensive and coherent framework on human rights in older age comparable to those for women, children, and persons with disabilities, to underpin its work. Only a new treaty will be able to provide the push and focus that is needed.

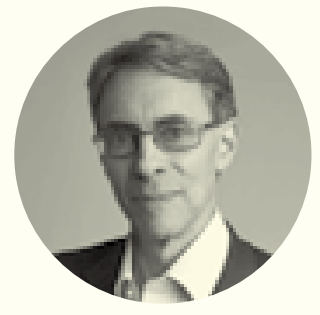

\section{Kenneth Roth}

Executive Director Human Rights Watch

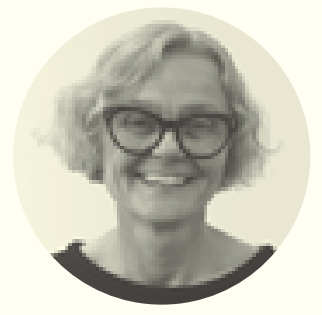

Bridget Sleap

Senior Researcher, Rights of Older People Human Rights Watch 


\section{Response of the Republic of Slovenia to Population Aging}

\begin{abstract}
- lovenia's population of about 2 million is aging rapidly, even faster than the European Union average. The aging of the population in Slovenia is mainly the result of longer life expectancy and a decrease in birth rates among younger generations. More than a fifth of the population (20.7 percent) is now age 65 or older, and by 2050 this proportion is projected to reach 31 percent, representing nearly a third of Slovenia's population.

To fully grasp the longer life expectancy in Slovenia, consider the number of centenarians (i.e., those ages 100 and older) living in the country. In 1991, when Slovenia became independent, there were 26 centenarians. Today there are 281. This occurred despite a stagnation, and slight decrease, in the number of centenarians between 2013 and 2019 due to the long-term consequences of World War I and World War II. On the other hand, we are faced with young generations that are fewer in number. At the time of baby boom, in the 1950s and 1960s, around 30,000 children were born in Slovenia every year. Today, the number of live births per year is only around 20,000 .

In response to population aging, the Government of the Republic of Slovenia has sought to emphasize an interministerial approach, promote aging as a human rights issue, encourage intergenerational responses and support, and take part in discussions in the international level. Since its independence, Slovenia has evolved its aging strategies to become broader and more integrated into the larger community.
\end{abstract}

\section{An Evolving Strategy for Addressing Demographic Change}

While Slovenia initially inherited a system of care that predominantly focused on state institutional care, the country began to better respond with the 1997 Programme of Care for the Older Population. Over the years it has updated its policies to look beyond the institutional options of supporting people as they age and better include the broader community.

The 1997 Programme's most important achievement was to develop services that enable older people to live in their homes or in facilities where they can maintain greater independence for longer (home help, care in the host family, sheltered housing). The Programme also established equality in the provision of social protection services between private and public providers and recognized the role of non-governmental organizations as a complement to the public services. Still, the approach at the time was too narrowly focused and failed to look beyond the field of social protection to include strategies for the society as a whole.

A new strategy emerged in 2006 that began to acknowledge the importance of an interministerial approach to addressing demographic change; moreover, it tackled the issue from an intergenerational perspective. This strategy came out of a document, developed by multiple ministries, aimed at linking the work of such ministries with the economy and civil society. Its purpose was also to increase solidarity and quality of coexistence between all generations. Although this strategy undoubtedly contributed to raising awareness among stakeholders about demographic change, its guidelines were not fully transferred into practice.

\section{Slovenia Adopts its Active Aging Strategy}

In 2017, Slovenia's government adopted the current Active Ageing Strategy with the goal of creating a society friendly to all generations. The strategy follows the concept of active aging, recognizes the heterogeneity of the older population, and shows an understanding of aging as a process and recognizes the need to age with purpose - in sum conveying a positive vision of extended life years. In seeking intergenerational cooperation and solidarity to address demographic change, the strategy's purpose is to spur various sectors to take action. In addition to 


\section{The strategy follows the concept of active aging, recognizes the heterogeneity of the older population, and shows an understanding of aging as a process and recognizes the need to age with purpose- in sum conveying a positive vision of extended life years.}

pursuing immediate solutions, the government is seeking to prepare for the future by focusing on the trends that will shape that future-including technological development and digitization of the society, a shifting understanding of the working life cycle, and changes in the labor market resulting from the increase in flexible forms of work.

The Active Ageing Strategy is divided into four clusters:

\section{Labor market and education}

2. Independent, healthy and safe living for all generations

3. Participation in society

4. Creating an environment that supports an active life throughout the life course

A key driver of the work within each cluster is a conscious effort to consider a broad range of actions, from creating provisions on immigration to addressing inequalities in health care. Efforts also include supporting active engagement in society through political engagement and volunteerism, especially with the support of technological solutions. Other aspects involve adjusting the labor markets and economy to the changed age structure of the population and reduced labor supply, improving housing and transportation systems, and creating social protections.

On the basis of the adopted Strategy, the Council for Active Ageing and Cooperation between Generations was established as a permanent expert consultative body of the Government of the Republic of Slovenia. The Council is responsible for the continuous and coordinated participation of the state, the profession, the economy and civil society representatives in the implementation of policies concerning long-lived society and intergenerational cooperation, as well as the monitoring and implementing of the Strategy and the well-being of older people. Key components of the Active Ageing Strategy among others include preventing ageism, addressing the personal safety of older people, and the protection and exercise of the human rights of older people. By actively raising awareness about ageism within the public and private sectors, the aim is to better identify discriminatory practices and create institutional cooperation to address it. To tackle ageism, the Strategy includes the establishment of a formal, high-level group composed of representatives of ministries, the human rights ombudsman, and non-governmental organizations focused on the human rights of the older population. This is still awaiting implementation. 


\section{By actively raising awareness about ageism within the public and private sectors, the aim is to better identify discriminatory practices and create institutional cooperation to address it.}

The action plans of different clusters are crucial for the implementation of the strategy and are monitored based on the indicators of the Active Ageing Index, a UNECE tool to measure the untapped potential of older people for active and healthy ageing across countries. This index includes four main criteria with different sub-criteria which are presented in brackets below:

1. Employment (employment rates for different age groups, also for those above 70 years)

2. Capacity for active ageing (voluntary activities, care to children and grandchildren, care to infirm and disabled, political participation)

3. Participation in society (physical exercise, access to health services, independent living, financial security, physical safety, lifelong learning)

4. Independent, healthy, and secure living (remaining life expectancy at age 55 , hare of healthy life expectancy at age 55 , mental well-being, use of ICT social connectedness, educational attainment)

In implementing the strategy and other activities related to aging, the ministries consult with various groups representing the older population, especially with the largest organization, the Slovenian Federation of Pensioners' Organisations (ZDUS). This is Slovenia's largest non-governmental, non-political and humanitarian organization of pensioners. They fight for older people's rights, better social legislation, housing standards for a good long-term care legislation, etc. Their main goal is that older people can stay at home for as long as possible. This is why they themselves, with the financial support of the state, implement the Older for the Older Program, where they make house visits to over-69-year-olds to check if they need any help. If needed, representatives of this organization inform the official institutions. Older people more easily share their problems with the representatives of the ZDUS, because they are their peers in whom they can trust.

\section{Response to the COVID-19 Pandemic}

Slovenia was heavily affected by the COVID-19 pandemic and, like other countries, adopted several measures to protect the most vulnerable groups, especially the older population. In the initial stages of the pandemic this included reserving early hours in shops for older people, relying on NGOs, neighbors, and other volunteers to bring supplies to older adults, and providing recipients of low pensions with a solidarity bonus twice. Physical distancing and quarantine measures, which effectively limited the spread of the virus, caused considerable feelings of loneliness, social exclusion and mental distress, especially in the older population.

In nursing homes, which were hit harder by infections in the first and second waves compared to the rest of the older population, the residents were additionally affected by restrictions on movement in their homes and visits. Virtual contact with family and friends could not replace genuine human contact, socializing, and walks, especially for residents suffering from dementia. 
The health, well-being, and physical abilities of many older people were undoubtedly affected by these measures. The current policies are much more friendly to older people, as they and their relatives are allowed more freedom and opportunities for contact. This was possible due to the high vaccination coverage of residents and the experience and good practices gained during the epidemic.

\section{The Slovenian Presidency of the Council of the European Union 2021, Conference on Ageism}

As part of its tenure as the Presidency of the Council of the EU, Slovenia hosted an international conference to shine a light on the link between ageism and human rights. Human Rights for all Ages: Promoting a Life-Course Perspective and Intergenerational Cooperation to Combat Ageism was hosted virtually on November 18, 2021.

Unfortunately, ageism is not always recognized on par with other forms of discrimination despite having persisted for a long time. The growing awareness of the implications of ageism on older people's lives and health, overall public health, individual wellbeing - and even the overall economy - must continue to be explored and discussed. Despite the fact that older people are a very heterogeneous group, they are losing their individual characteristics and becoming invisible members of the older people's group due to different forms of ageism. To tackle ageism, the Conference sought to spur intergenerational cooperation and activities (in accordance with the WHO guidelines), and highlight aging as an interconnected, lifelong process.

\section{Conclusion}

Slovenia has worked tirelessly to develop a comprehensive response to population aging. With the adoption of its Active Ageing Strategy, Slovenia has embraced the need to emphasize a broad understanding of aging - that is, aging is a lifelong process-and one that should be rooted in respect for human rights. By working with the international community to raise awareness of ageism as a form of discrimination, Slovenia is committed to tackling this issue at home, throughout the EU, and elsewhere.

The implementation of the Strategy's commitments remains high on the Slovenian policy agenda. Finally, development of such policies requires good cooperation on the national, regional and local level and the strong participation of older individuals and leading organizations that represent them.

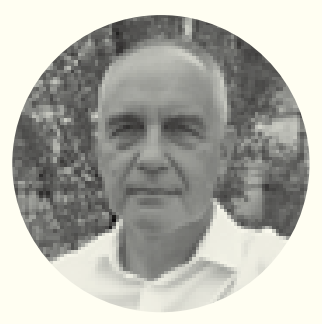

\section{Aleš Kenda}

Secretary, Ministry of Labour, Family, Social Affairs and Equal Opportunities of the Republic of Slovenia 


\section{An Innovative Caregiving Program Shows Promise}

y 2020, there were 290 million people aged

70 or older living in developing nations. As the older population grows in richer countries as well, calls are arising for new models of health and social care to support independent living at home and limit unnecessary hospital admissions. In countries such as the United Kingdom and the United States, belatedly merging services developed independently over decades has proved very challenging. In this short article, we look at a novel program operating in Brazil.

Even before the COVID-19 pandemic hit Brazil, there were concerns about the effects of population aging on health services, especially hospital care. Between 2000 and 2013, 31 percent of inpatient spending on people aged 60 years or older (amounting to $\$ 275$ million in U.S. dollars in 2013) was for conditions better suited to ambulatory treatment (Souza and Peixoto, 2017). The leading causes of admissions were urinary tract infections, falls, and poor management of chronic conditions - all of which are often avertable through effective home and outpatient care.

Wondering if the solution could be to integrate health and social care in the community, some local governments began to experiment. For example, in 2011 the city of Belo Horizonte set up Programa Maior Cuidado (PMC - Older Person's Care Programme), a program to support dependent older people in disadvantaged communities. PMC offers families support from trained caregivers who are recruited from similar communities and paid a basic wage. Each family gets between 10 and 40 hours of support a week, depending on the level of need of the individual and the family. PMC caregivers have uniforms and are jointly supervised by staff from the local health and social assistance centers.

Rather than replace family responsibility, PMC caregivers provide empowering support in a number of ways. They offer relatives some respite from what often is an exhausting 24/7 responsibility and also work with families to build their care skills and competence. Together with the older person, the PMC caregiver and relatives agree on a care plan, which receives a monthly review in joint meetings of health professionals and social workers.

Thus, given the program's promise, we decided to take a look at it more closely.

\section{Evaluation Reveals a Promising Program}

Since 2018, we have been running an evaluation of PMC. The work is ongoing and inevitably has been hampered by the COVID-19 pandemic. Our findings to date show PMC often helps to:

- manage health service use by older people;

- improve the care they get at home;

- relieve the pressures of daily caring felt by relatives (who are almost always women); and

- offer new skills and employment opportunities to local residents who become trained PMC caregivers.

This is an impressive array of positive effects effects supported by evidence, including statistical comparisons of older people in PMC and people of similar age, gender, and socio-economic profiles. PMC is associated with fewer unplanned health visits and more frequent use of health promotion services such as rehabilitation (Lloyd-Sherlock, Giacomin and Sempé, forthcoming). Interviews and discussions with people involved in PMC's day-to-day operation and with beneficiary families show how it can prevent acute health episodes, limiting the need for emergency hospital admission. For example, 


\section{Together with the older person, the PMC caregiver and relatives agree on a care plan, which receives a monthly review in joint meetings of health professionals and social workers.}

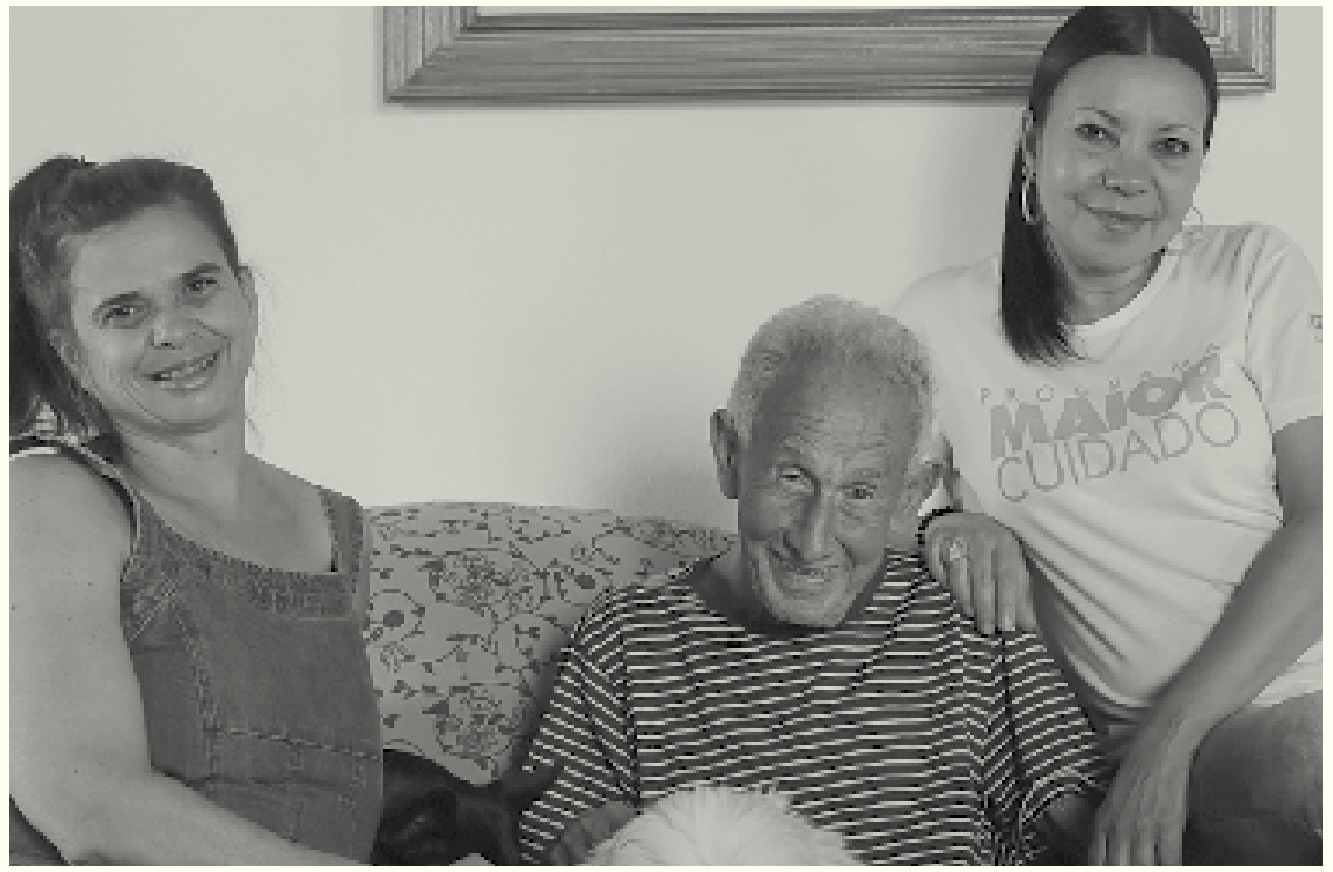




\section{Decent pay, training, and a professional identity enhance staff retention, account- ability, and quality assurance. In this way, PMC has become an empowering career option for women in neighborhoods where steady employment is very limited.}

the daughter of a 92-year-old man with multiple chronic health conditions hospitalized on several occasions for failing to manage them told us:

The PMC carer sets up his oxygen supply and stays with him chatting about this and that... She's always on the look-out in case there is anything different about him. She notices little things and then she'll tell me, "Look, there must be something going on with him. I'll have word with the people at the health centre."

Although the main goal of PMC is to improve the care older people receive from their families, it recognizes accomplishing that goal requires social workers and health professionals to work together to understand families' wider circumstances. In the poor communities where PMC operates, people of all ages face multiple problems, including addiction, unemployment, violence, and mental trauma. Acknowledging those challenges, PMC offers family caregivers respite and support so they can live their own lives, as well as provide loved ones the help they need. As one nurse put it:

The daughter of one older woman told me that now that they are in PMC she has time to wash her own clothes and do some things for herself. Before that, she didn't have time for anything.

Over the years, PMC has also provided training and a fair wage to thousands of local residentsmostly, although not entirely, women. This has been central to its success. These PMC caregivers are the lifeblood of the intervention. Decent pay, training, and a professional identity enhance staff retention, accountability, and quality assurance. In this way, PMC has become an empowering career option for women in neighborhoods where steady employment is very limited.

Notwithstanding these positive effects, PMC is not without flaws. Working with disadvantaged families in poor and sometimes violent neighborhoods is never easy, and not all families are predisposed to cooperate. PMC cannot cater to the needs of older people living alone, who require other forms of support. As with almost all interventions involving different government agencies, communication and coordination are not always perfect. These dynamics sometimes lead to confusion and misunderstandings between health staff and social workers and a degree of institutional disconnect at higher managerial levels (de Souza Aredes et al, 2021).

\section{Pandemic Presents Insights}

While, as mentioned, COVID-19 presented challenges, our evaluation of PMC was largely complete by the start of the pandemic. Nonetheless, the pandemic presented a chance to see PMC from another angle. As the number of infections in Belo Horizonte rose, we wanted to see how PMC would cope. To protect PMC caregivers, it was necessary to replace most home visits with telephone calls. Over time, a hybrid system was put in place with video calls and home visits resuming when COVID-19 was less prevalent. In this way, it was able to provide at least some support to 85 percent of families. Frustratingly, PMC 
caregivers were not categorized by public health agencies as front-line health professionals and, therefore, were not prioritized for vaccination.

It is always dangerous to promote models of "best practice" to resolve complex issues. Integrating social care and health for older people is a common-sense step towards meeting the needs of older people and their families. It is, however, much easier to do in theory than in practice. By the start of the pandemic, several Brazilian cities were developing programs modeled on PMC, but their plans were postponed as they faced the immediate challenges of keeping health systems afloat. In fact, the need for approaches like PMC has been greater than ever during the pandemic, and not just in Brazil. As the new U.S. administration looks to transform support for family care, it might consider a fact-finding visit to this unheralded city in Brazil.

\section{References}

J.de Souza Aredes, J.Billings, K.Giacomin, P.Lloyd-Sherlock and J.Oliveira Araújo Firmo (2021) Integrated care in the community: the case of the Programa Maior Cuidado (Older Adult Care Program) in Belo Horizonte-Minas Gerais, Brazil. International Journal of Integrated Care 21(2): 28, 1-12

Dias RD, Barros, JV. Burden of hospitalisation among older people in the Brazilian public health system: a big data analysis from 2009 to 2015 . J Epidemiol Community Health 2019; 73(6):537-543.

Lloyd-Sherlock P, Giacomin KC and Sempé L. The effects of an innovative integrated care intervention in Brazil on outpatient health service use by dependent older people. BMC Health Services Research (forthcoming).

Souza DK, Peixoto SV. Estudo descritivo da evolução dos gastos com internações hospitalares por condições sensiveis à atenção primária no Brasil, 2000-2013. Epidemiol e Serviços Saúde 2017;

The Kings Fund (2018). A year of integrated care systems: reviewing the journey so far, 2018. https://www.kingsfund.org.uk/ publications/year-integrated-care-systems

WHO (2015) The World Health Organization report on ageing and health, WHO, Geneva.

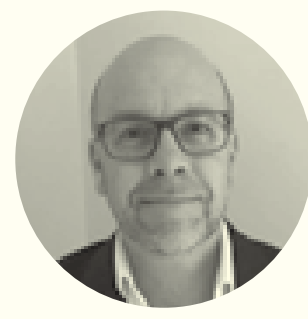

Peter Lloyd-Sherlock Professor of Social Policy and International Development University of East Anglia

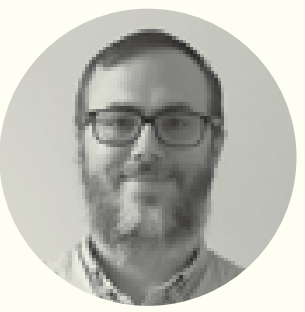

Lucas Sempé Research Fellow Institute for Global Health and Development Queen Margaret University, UK

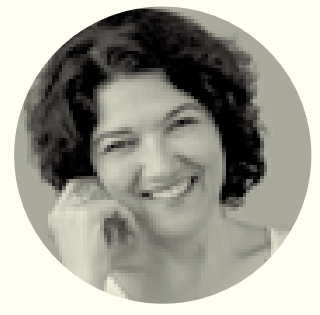

Karla Cristina Giacomin Senior Research Fellow Center for Studies in Public Health and Aging Fundação Oswaldo Cruz, Brazil, and Belo Horizonte Municipal Health Department 


\section{Global Innovations in Aging and Longevity}

$H^{2}$ umans have doubled their life expectancy over the past 100 years, but increasing inequality means the benefits of longevity aren't spread evenly. Only the richest are living their additional 30 years of life to the fullest, while for too many, chronic disease and frailty impact their quality of life. Spreading the benefits of healthy long lives to everyone, not just the lucky few is a defining mission of our time.

Three megatrends are shaping innovation in aging and longevity globally that will determine the success or failure of this mission: datafication of the individual; the home as the innovation battleground; and the return of social infrastructure. This article provides context for each as well as examples from around the world based on recent work by innovation consulting company Fordcastle and the Aging2.0 corporate innovation platform, The Collective.

\section{Datafication of the Individual}

Human activity is increasingly digital, and our data trails are powering countless business models. Healthcare has been a laggard so far, but is now catching up, propelled by the pandemic, venture funding, and ambitious moves by consumer tech giants into digital health.

Longevity on your wrist. If the Fourth Industrial revolution had a marketing tagline, it couldn't do better than Apple's "The future of healthcare is on your wrist." Consumer data is shifting power and insight from the doctor to the individual. We're seeing a convergence of longevity focused life extension and more quality-of-life centered healthspan maximization. Valencia, Spain-based Hearts Radiant is building
Human activity is increasingly digital, and our data trails are powering countless business models. Healthcare has been a laggard so far, but is now catching up, propelled by the pandemic, venture funding, and ambitious moves

by consumer tech giants into digital health. 

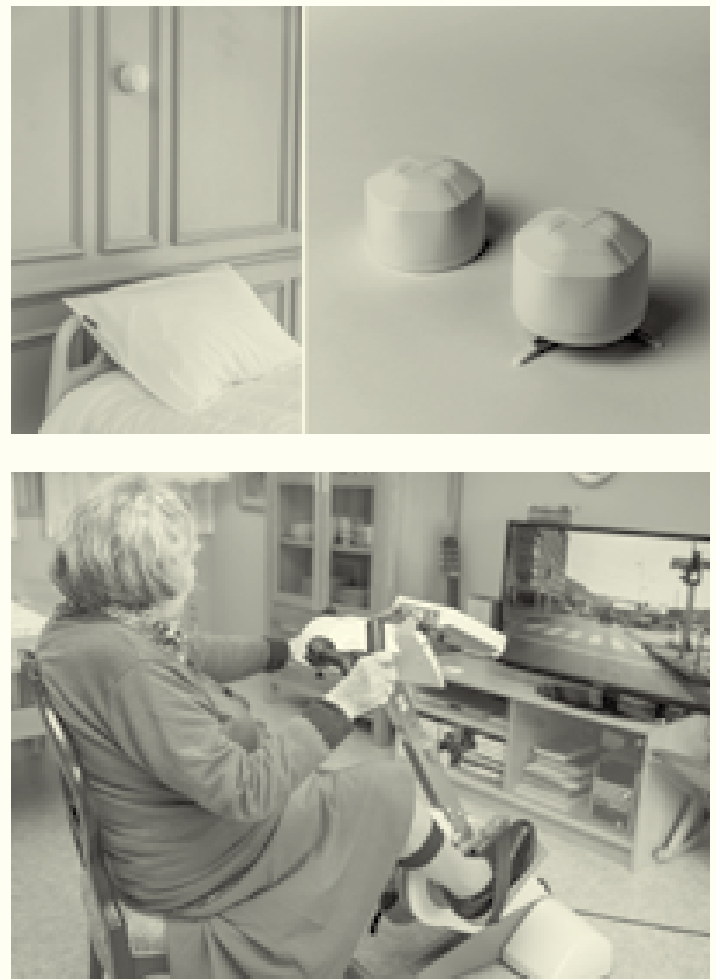

a digital community of people receiving expert longevity guidance, drawing on the founders' experience running a longevity spa. Other longevity-focused data-driven startups such as Humanity (U.K.) and China's iCarbonX are seeking to capture all types of body data and coach users towards longer, healthier lives. Finland's Elo Health, Zoe from the U.K. and Australia's myDNA are creating personalized longevity-focused nutrition plans.

Digital diagnostics. Digital tools are increasingly complementing and, in some cases, replacing human diagnostics. U.K.-based Babylon Health uses artificial intelligence-powered chatbots to triage and diagnose common health conditions, while Binah assesses vital signs in real time mobile video.The Israeli company SOLO has developed an app that can track and improve emotional well-being (think personalized tailored videos to improve moods) and U.K.-based Cognetivity has created a quicker and more effective dementia diagnostic. Italy's TeiaCare uses artificial intelligence and sensor networks to improve efficiency in European nursing homes, while South-Korean Kardian employs radar for vital sign monitoring. Canada's Winterlight Labs is a 'digital diagnostic', using speech to monitor potential cognitive impairment.

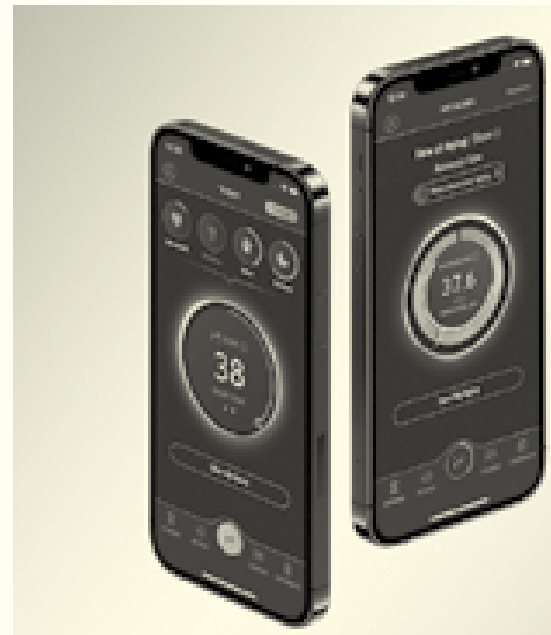

Clockwise from top left: Xandar

Kardian radar digital signal processing devices for health monitoring; UK-based Humanity launched the world's first-ever app designed to monitor, track, and slow the aging process; and Norway's Motitech offers a virtual cycling experience.

Movement is the killer app. Mobility is one of the most important markers of longevity and lends itself to digital analysis. Singapore's ConnectedLife has partnered with Johnson \& Johnson and FitBit, to improve outcomes of surgeries and track Parkinson's patients. Israel's Kemtai and Portugal's Sword use artificial intelligence computer vision to ensure home exercises or rehab are done accurately. Norway's Motitech offers an immersive virtual reality environment, allowing people to cycle on an exercise bike through the places where they've grown up, generating social, cognitive and physical benefits.

\section{Home is the Innovation Battleground}

The much-talked about shift of healthcare to the home has been accelerated by the pandemic, and more complicated procedures are now feasible at home. Sixty percent of health outcomes are driven by lifestyle activities-including diet, exercise, sleep, stress and socialization-and the home is the natural context for these. The remaining 40 percent of health outcomes are driven by 'traditional' medical services and genetics and the growth of 'hospitals without walls' programs globally is decentralizing these too. 


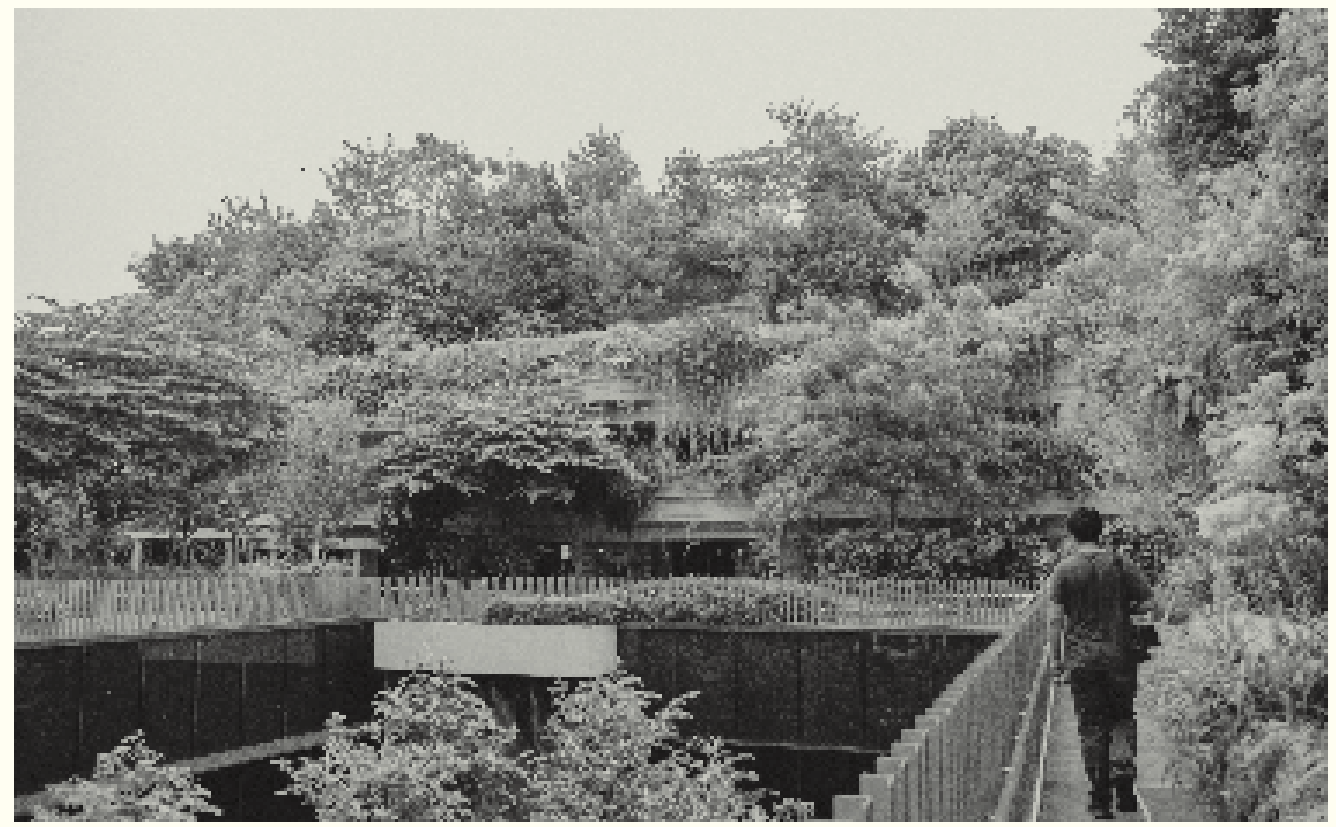

Singapore's Kampung Admiralty is an innovative example of an age-friendly community that seamlessly integrates green space and gardens throughout its award-winning design.

Internet of Things (loT) monitoring.

Connected devices are able to offer additional insight, particularly with respect to falls. Israel's Essence and Australia's Home Guardian among others, offer monitoring and alerts about falls or unusual activity, while Belgium's Nobi does this via a smart lamp.

Upgrading home care. The pandemic has given a boost to new hybrid care models that use in-person caregivers combined with telehealth connections to specialists. Singapore's Homage, Australia's Mable and Cera from the U.K. are catering to the growing market for helping people stay at home by building match-making marketplaces that connect families with caregivers. AXA Ventures-funded Birdie has found success building software to power home care providers.

Hospital at home. FocusCura from the Netherlands is bringing the hospital to the home, increasing the level of complexity and sophistication of medical interventions, while French company Qare allows residents abroad to access specialist doctors back in France.

\section{The Return of Social Infrastructure}

Social infrastructure can be defined as an environment that "fosters contact, mutual support, and collaboration among friends and neighbors." As the pandemic shut down cities and travel, social interaction has become more important, and many people got to know their neighbors, and voluntarily engaged in selfless acts of support. The pandemic forced many people to reevaluate their priorities and lifestyles and many have found solace in developing more meaningful connections with each other, with other generations, and with nature.

Purposeful connections. For isolated or lonely seniors living independently, France-based Famileo (a 2020 Aging2.0 Global Innovation Search winner) allows the family members to engage and share messages and media. Israel's Uniper Care improves engagement in real time with group video calls and activities. Other exciting developments are services that provide a platform for older people to share their perspective, knowledge and skills: Labora in Brazil offers a platform for knowledge, while Diaspo allows older amateur chefs to teach their culinary skills over Zoom.

Integrated living models. There are a variety of models that are starting to reimagine the role of senior housing, in particular becoming embedded into the local community. France's Village Landais has taken the dementia-focused 


\section{The pandemic forced many people to reevaluate their priorities and lifestyles and many have found solace in developing more meaningful connections with each other, with other generations, and with nature.}

Dutch Hogeweyk model, and a similar model has opened in Tasmania, Korongee, which has a cinema, cafe, beauty salon and gardens.

Biophilic cities. There are remarkable overlaps between societies that are built to be age-friendly and ones that are environmentally-friendly: highly walkable, dense environments, strong public transport and close social ties, among others. A 2019 Nature paper found that access to nature for just two hours per week resulted in a markedly improved sense of wellbeing, while other studies have shown a reduction in blood pressure and cancer. In Singapore, the Kampung Admiralty building combines high population density living with community and municipal services, with green space and gardens embedded throughout. While Future Solund in Copenhagen has created a futuristic, open-plan senior living environment, described as a 'nature integrated care center.'

\section{A Final Word on What's Missing}

A final word on innovations that we're not seeing: ambitious public policy measures that learn from other countries and ensure our systems are ready to adapt to longer lives. As someone noted in a recent innovator roundtable we hosted focused on the United States, startups in aging "are like Christmas tree ornaments without the Christmas tree." Startups alone can't deliver the necessary infrastructure and systems change to support populations to age on their own terms. Central to this is the question of paying for longer lives. Longevity brings with it the risk of running out of money, since pensions and Social Security are underfunded, real wages for the majority have fallen, and inequality has soared. A 2019 report by the U.S. Government Accountability Office (GAO) found that 48 percent of American households headed by someone 55 or older don't have any retirement savings. Other countries have stronger safety nets, but few countries can afford their pension commitments.

One startup focused on this topic, Dublinbased Tontine Trust, is reviving and reinventing the centuries' old concept of tontines-where a group of people put money in a shared pool paying dividends to surviving members; so those who live longest capture the most gains. Models like this that might address the question of how we will pay for longevity need to be considered in more detail.

One recent analysis ${ }^{1}$ has found the economic value of an extra year of healthy life for everyone would deliver $\$ 38$ trillion in benefit to the global economy. The opportunity here is for innovators and public policy makers to work together on bold new international and interdisciplinary ways to adapt society, prepare for longevity, and ensure the benefits of longer lives are shared with everyone. $\bullet$

${ }^{1}$ https://www.nature.com/articles/s43587-021-00080-0

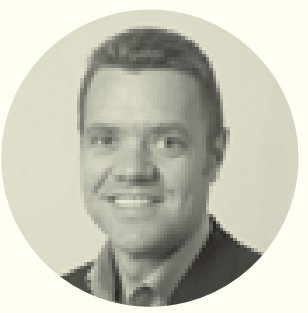

Stephen Johnston

Founder, Fordcastle and

Co-founder, Aging 2.0 


\section{Why We Need Age-Friendly Public Health Systems}

$\mathbf{D}^{\prime}$ riven by the Baby Boomer generation, the growth of the older adult population is unprecedented in U.S. history. The number of people ages 65 years and older is projected to nearly double between 2021 and 2060, rising from 54 million to 95 million, and increasing older adults' share of the total population from 16.5 to 23 percent. ${ }^{1}$ Eighty percent of older adults will experience at least one chronic condition such as heart disease, arthritis, diabetes, or depression $^{2}$ and over 60 percent will face at least two. ${ }^{3}$ A robust public health system focused on prevention, preparedness, and wellness could mitigate these health challenges and inform effective strategies to promote health and well-being and advance health equity for older adults. Yet chronic underfunding consistently hinders public health efforts, despite overwhelming evidence from programs that are successfully preventing disease and injury and effectively preparing for disasters and health emergencies with strategies specifically for older adults.

We can do better. An effective age-friendly ecosystem can be formed through collaboration among sectors and stakeholders so that the strength of public health systems can truly be realized. One particular organization, and the framework it developed as well as other efforts, are combining to help make that happen, and the impact is being felt in multiple states.

\section{Age-Friendly Public Health Systems}

Trust for America's Health (TFAH), a Washington, DC-based non-profit, nonpartisan public health policy, research, and advocacy organization, prioritizes older adult health and, in partnership with The John A. Hartford Foundation and others, developed a Framework for Creating
Age-Friendly Public Health Systems (AFPHS). ${ }^{4}$ This Framework is designed to create a culture of healthy aging within state and local public health departments and support the expansion of public health policies and programs to improve older adult health and well-being. It is not a prescriptive guide to action or a declaration of the public health sector's oversight of certain activities. There are many agencies and organizations in other sectors that are already actively engaged in healthy aging but are not leveraging the expertise of public health professionals. Public health departments can work in partnership with these organizations to promote healthy aging. These include AARP, with its focus on building livable communities, and Area Agencies on Aging, focused on service and program delivery to meet older adult needs. Additional roles for the public health sector include improving data systems to better identify crucial health interventions and adapting emergency preparedness plans to accommodate the health challenges of older adults and caregivers.

To test the Framework, TFAH conducted an 18-month pilot project in Florida in which it worked directly with two-thirds of the state's county health departments. Among the first steps of these public health practitioners was assessing the health status and needs of Florida's older adult population, as well as identifying opportunities for partnership and expansion of existing programs and services to include older adults. TFAH helped to facilitate the creation of Aging in Florida profiles for every Florida county that provide extensive data on the health, socioeconomic, and family status of those 65 and over. Many of these practitioners were not previously aware of the demographics of this population in their jurisdictions but have now been able to 
use this data to develop interventions to reduce the risk of falls, enhance emergency plans to accommodate older adults and their caregivers, and incorporate the views of older residents into planning processes. In some counties, the public health departments have led engagement with the Age-Friendly Communities movement, often serving as the convener of multi-sector coalitions to address the movement's eight domains of livability.

The success of the Florida pilot led to expansion of age-friendly public health efforts in other states, and further engagement with federal, state, and local policymakers. Efforts are now under way in Michigan, with funding from the Michigan Health Endowment Fund, to support AFPHS work at the local level, and to build a model for a seamless older adult care journey. Public health leaders in Colorado, Georgia, Mississippi, Washington, Wisconsin, New York, and other states are working to expand public health policies and programs to better meet the needs of people in those states who are living longer lives.

\section{AFPHS National Recognition Program}

TFAH continues to prioritize older adult health needs and is encouraging state and local public health departments to put these needs at the core of their work. The AFPHS Recognition Program was developed to provide guidance and support for the public health sector through a series of action steps that, if completed, will demonstrate meaningful and sustainable policy and practice changes to promote and support older adult health. The program's action steps include data collection, collaboration across age-friendly movements to improve older adult health, and listening directly to older adults to learn what matters to them. By completing the 10 foundational steps of this program, departments of health can expand the services they offer, build effective partnerships, and demonstrate a commitment to healthy aging. The New York State Department of Health received the first state-level recognition, and the Department of Health in Sarasota County, Florida was the first local health department to be recognized for this achievement. ${ }^{5}$

\section{COVID-19 Response}

State and local health departments have played a vital role in the pandemic response, working diligently to address the needs of all people, including older adults living in the community and those who reside in long-term care facilities. The pandemic has had a disproportionate impact on older adults in general and has posed an even greater burden on older adults of color. Data from the Centers for Disease Control and Prevention show that in 2020, race and ethnicity were strong predictors of increased risk of severe outcomes among older adults. ${ }^{6}$ Among adults 65 and older, the risk of COVID-19 hospitalization was two or more times higher among non-Hispanic American Indian or Alaska Native, non-Hispanic Black, and Hispanic or Latino populations 65 and older compared to non-Hispanic Asian or Pacific Islander or non-Hispanic White populations 65 and older. ${ }^{7}$ As of this writing, eight of ten deaths attributable to COVID-19 are still occurring in the 65 and over population. ${ }^{8}$

Multi-stakeholder coordination becomes all the more important in reaching such groups. One of the most significant outcomes of the AFPHS pilot in Florida was the value and significance of the partnerships formed between the county 


\section{The vision for an age-friendly ecosystem encompasses the lived environment, social determinants of health, the health care system, and a prevention-focused public health system.}

health departments and aging services organizations. The trust built among these stakeholders contributed to a more effective and efficient response to meeting the needs of isolated older adults during the pandemic's early days and beyond. Coordinated activities included meal and supply deliveries, identifying individuals who needed the COVID-19 vaccine administered in their homes, and helping to ensure access to health care, whether through transportation support or telehealth assistance. Public health departments also helped to coordinate other sectors to meet the needs of older adults, including emergency responders, home-based health care providers, and faith community leaders.

\section{In-Home Vaccinations Initiative}

In partnership with The John A. Hartford Foundation and the Cambia Health Foundation, TFAH facilitated an initiative to improve access to the COVID-19 vaccine for older adults who needed vaccines administered in their homes. TFAH engaged health care, public health, homebased care, emergency management and federal officials from multiple agencies to identify the challenges and barriers to in-home vaccines. TFAH then worked with these stakeholder groups to identify solutions and develop policy recommendations to expand access, including ensuring that appropriate reimbursements were available to cover all costs, allowing caregivers and other family members to benefit from at-home vaccinations, and engaging with community and faith leaders to overcome vaccine hesitancy. These efforts contributed to the adoption of new practices and policies to support older adults who need vaccines administered in their homes.

\section{Age-Friendly Ecosystem}

The Administration for Community Living (ACL) expects the number of older adults of color to rise by 217 percent in the coming decades. ${ }^{9}$ As the aging population grows and becomes more diverse, it will be crucial to embrace this demographic shift and develop policies and interventions that address the complex challenges and needs of a diverse aging population. Public health departments across the country are committed to eliminating disparities and ensuring all people have the opportunity for optimal health and well-being and that the public health sector is experienced in delivering services in a culturally and linguistically sensitive manner. Lessons learned from the successful AFPHS and in-home vaccine initiatives underscore the value of partnerships in improving the health and well-being of older adults, in large part with the expertise of public health in reaching diverse populations. Additionally, an integrated age-friendly ecosystem with collaboration and synergy between and among age-friendly initiatives can spur the necessary momentum for 
innovative change. The vision for an age-friendly ecosystem encompasses the lived environment, social determinants of health, the health care system, and a prevention-focused public health system. The opportunities associated with more people living longer lives can be harnessed and nurtured through an aligned age-friendly ecosystem that benefits from strong leadership, sustained commitment and investment, and national momentum.

Note: The authors would like to thank Megan Wolfe, Jane Carmody, Karon Phillips, and Katie Cunningham for contributing to this article.

\footnotetext{
${ }^{1}$ Vespa, Jonathan, Lauren Medina, and David M. Armstrong, "Demographic Turning Points for the United States: Population Projections for 2020 to 2060," Current Population Reports, P251144, U.S. Census Bureau, Washington, DC, 2020.

${ }^{2}$ Centers for Disease Control and Prevention. Healthy Aging at a Glance 2011. http://stacks.cdc.gov/view/cdc/22022
${ }^{3}$ Chronic Conditions Charts: 2015. Baltimore, MD: Centers for Medicare \& Medicaid Services. https://www.cms.gov/Research- Statistics-Data-and-Systems/Statistics-Trends-and-Reports/ ChronicConditions/Chartbook_Charts.html

${ }^{4}$ Anne De Biasi, MPH, Megan Wolfe, JD, Jane Carmody, DNP, MBA, $\mathrm{RN}$, Terry Fulmer, PhD, RN, FAAN, John Auerbach, MBA, Creating an Age-Friendly Public Health System, Innovation in Aging, Volume 4, Issue 1, 2020, igz044, https://doi.org/10.1093/geroni/ igz044
}

${ }^{5}$ https://www.johnahartford.org/dissemination-center/view/newyork-state-department-of-health-achieves-age-friendly-publichealth-systems-recognition

${ }^{6}$ Centers for Disease Control and Prevention. 2021. COVID-19 Racial and Ethnic Health Disparities. https://www.cdc.gov/coronavirus/2019-ncov/community/health-equity/racial-ethnic-disparities/index.html

${ }^{7}$ Rossen LM, Ahmad FB, Anderson RN, et al. Disparities in Excess Mortality Associated with COVID-19 - United States, 2020. MMWR Morb Mortal Wkly Rep 2021;70:1114-1119.

${ }^{8}$ Kaiser Family Foundation. 2020. https://www.kff.org/coronavirus-covid-19/press-release/8-in-10-people-who-have-died-ofcovid-19-were-age-65-or-older-but-the-share-varies-by-state/

${ }^{9} \mathrm{https} / / /$ acl.gov/programs/strengthening-aging-and-disabilitynetworks/diversity-and-cultural-competency

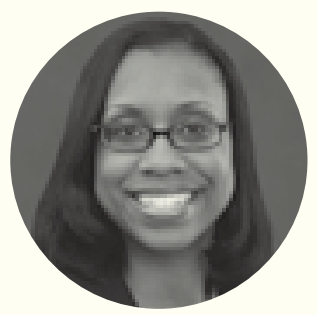

Nadine Gracia

President and CEO

Trust for America's Health (TFAH)

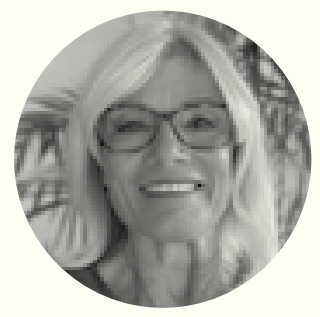

Terry Fulmer

President

The John A. Hartford

Foundation 


\section{Long-Term Care Challenges and Opportunities in Latin America and the Caribbean}

Poin opulation aging in Latin America and the Caribbean (LAC) has been one of the fastest in the world with the share of the population age 65 and older increasing from 5 percent in 1990 to 9 percent in 2019. And the trend will continue as that share is projected to double by 2050 . With age, levels of functional ability may become impaired due to a variety of internal and external factors. Ultimately this can reduce autonomy, compromise an individual's ability to meet dayto-day needs, and limit a person's capacity to learn, grow, make decisions, build and maintain relationships, and contribute to society. ${ }^{2}$ Already there are approximately 8 million older people in LAC who need to receive long-term care and support (also known as "long-term care") to perform at least one basic activity of daily living. This translates to 12 percent of the population age 60 and over, and 27 percent of the population over age 80, who need assistance with activities such as bathing or showering, eating, or moving around a room. By 2050, the number of older people with severe long-term care needs in LAC is projected to grow to 27 million, representing more than 3 percent of the total population and approximately 14 percent of people aged 60 and above in the region. ${ }^{3}$ As the population ages and more people require long-term services and supports, the promotion of healthy aging is essential for maximizing individual autonomy and preventing the long-term care systems from being overwhelmed.

The United Nations Decade of Healthy Ageing (2021-2030) is based on the premise that every person should have access to environments and opportunities that enable their right to live a long and healthy life. The initiative seeks to promote access to quality and timely long-term care services with the double objective of meeting current support needs and reducing the intensity of future needs through the preservation and recovery of older persons' functional capacities. ${ }^{4}$ The majority of long-term care in LAC is provided by family members - mostly women - who receive limited support from governments.' Along with being unfair to women, the situation is also unsustainable due to reductions in family size, increased participation of women in the formal job market, and the growing recognition of unpaid care provision as a key source of gender inequity. ${ }^{5,6}$ Governments can enhance access to affordable, quality services through the development of national care and support systems for older people experiencing or at risk of developing long-term care needs as well as for their unpaid caregivers. ${ }^{5}$

\section{The Case of Uruguay}

In 2015, Uruguay became the first country in LAC to establish a nationwide care policy. Known as the Uruguayan National Integrated Care System, this universal system aims to provide access to quality care to all individuals, regardless of income or place of residence. ${ }^{7}$ The target population includes older persons with long-term care needs, persons living with disabilities, children, and family caregivers. Projects and programming include the provision of subsidized home care assistants for individuals with severe impairment, telehealth, and the management of day centers for those with mild or moderate impairment. Support for caregivers is prioritized, including formalizing the position and training. Eligibility for care is based on age and levels of functional ability. For example, persons aged 80 and older with severe functional impairment are eligible to receive home-based, long-term care services. The system is financed through general revenues plus, in the case of home care and telehealth care, user co-payments. However, fewer than 15 percent of beneficiaries are required to pay 


\section{As the population ages and more people require long-term services and supports, the promotion of healthy aging is essential for maximizing individual autonomy and preventing the long-term care systems from being overwhelmed.}

because the obligation of a co-payment is based on household income.

Other countries, including Costa Rica, the Dominican Republic, and Peru, are now following Uruguay's program, fueled by long-term care garnering political attention.

\section{Financial Challenges}

Securing the necessary financial resources for a national long-term care system within contexts of strained budgets is a fundamental challenge. Even within the context of improving the social protection of older persons, long-term care needs compete with other priorities, such as improving the coverage and quality of pensions and health care. Depending on the target population and on the services to be provided, the estimated cost of a national long-term care system ranges between 0.3 percent and 1 percent of GDP. ${ }^{8}$ By contrast, Uruguay spends 0.04 percent of GDP on long-term care (2017) and Chile 0.02 percent (2019). ${ }^{9,10}$ The lack of financial resources allocated towards long-term care in these and other countries significantly limits the amount of services that can be provided and the number of people supported. For example, in Uruguay, only 11 percent of older persons with severe long-term care needs receive services from the government (including home care or teleassistance subsidies, day care, or residential care). In Chile, coverage is estimated to be 6 percent.i.

The financial costs of establishing a longterm care system should be considered jointly with the savings that system can potentially facilitate. In particular, long-term care services can reduce costs in the health care sector and can boost economic productivity by enabling family caregivers, who are primarily women, to increasingly participate in the labor market.

\section{Improving Care and Regulation}

The quality of services represents another important challenge. Most countries in LAC have set legal standards for residential and day care centers regarding their infrastructure, user-tostaff ratio, and the type of services that should be offered by authorized providers. However, 


\section{Investing in implementing and strengthening long- term care systems is key to providing the expansive care and support the aging population of LAC will require.}

compliance with these standards is low due to a lack of resources for monitoring. Data from Uruguay shows that in 2019, only 2 percent of residence centers had legal authorization to operate. ${ }^{9}$ In Argentina and Chile, the absence of a national registry of institutional service providers makes monitoring even harder..$^{10,11}$ As a result, the number of institutions that operate without legal authorization - and hence, unverified quality standards - remains high.

Compounding the regulatory issues is a long-term care workforce that is characterized by low levels of training, low salaries, and high levels of informality. The formalization of caregiving is key to ensuring service quality as well as the redistribution of the care work across genders. In Colombia, only 30 percent of care workers in the institutional sector has adequate training. ${ }^{12}$ In Mexico, a staggering figure of only 3 percent of workers are adequately trained. ${ }^{13}$ Uruguay sought to address the lack of training with a national care policy that explicitly invests in the training and formalization of paid caregivers. However, the country hasn't been able to keep pace with demand, as the strengthened educational system has been encumbered with long wait lists for training and accreditation courses.

\section{The Path Forward}

Investing in implementing and strengthening long-term care systems is key to providing the expansive care and support the aging population of LAC will require. Not only do LAC governments need to provide the necessary financial support but they must also find ways to improve their regulatory authority and help train a sufficient workforce and secure quality care. Making these investments will enhance access to affordable, quality services and supports at a critical time when the number of older people needing assistance is projected to grow with the overall aging of the population. 
1 United Nations. World Population Ageing 2019: Highlights [Internet]. Department of Economic and Social Affairs, Population Division; 2019 [cited 2021 Oct 13]. Available from: https://www. un.org/en/development/desa/population/publications/pdf/ageing/ WorldPopulationAgeing2019-Highlights.pdf

${ }^{2}$ World Health Organization. Decade of healthy ageing: baseline report [Internet]. Geneva, Switzerland; 2020 [cited 2020 Dec 28]. Available from: https://www.who.int/publications/m/item/ decade-of-healthy-ageing-baseline-report

${ }^{3}$ Aranco N, Stampini M, Ibarrarán P, Medellín N. Panorama de envejecimiento y dependencia en América Latina y el Caribe [Internet]. Inter-American Development Bank; 2018 Jan [cited 2021 Aug 13]. Available from: https://publications.iadb.org/ handle/11319/8757

${ }^{4}$ Curry N. Preventive Social Care: Is it cost effective? [Internet]. Kings Fund; 2006 [cited 2021 Sep 2]. Available from: https://www. kingsfund.org.uk/sites/default/files/preventive-social-care-wanless-background-paper-natasha-curry2006.pdf

${ }^{5}$ Cafagna G, Aranco N, Ibarrarán P, Medellín N, Oliveri ML, Stampini M. Envejecer con cuidado: Atención a la dependencia en América Latina y el Caribe [Internet]. Inter-American Development Bank; 2019 [cited 2021 Jul 22]. Available from: https://publications. iadb.org/es/envejecer-con-cuidado-atencion-la-dependencia-en-america-latina-y-el-caribe

${ }^{6}$ Chioda L. Work and Family : Latin American and Caribbean Women in Search of a New Balance [Internet]. Latin American Development Forum: World Bank; 2016 [cited 2021 Aug 3]. Available from: https://openknowledge.worldbank.org/ handle/10986/23748

${ }^{7}$ Aguirre R, Ferrari F. La construcción del sistema de cuidados en el Uruguay: En busca de consensos para una protección social más igualitaria [Internet]. CEPAL: United Nations; 2014 [cited 2021 Jul 21]. Available from: https://www.cepal.org/es/publicaciones/36721-la-construccion-sistema-cuidados-uruguay-busca-consensos-proteccion-social-mas

${ }^{8}$ Medellin N. Cost Simulation Tool for Long Term Care Systems [Internet]. Inter-American Development Bank; 2020 Sep [cited 2021 Jun 29]. Available from: https://publications.iadb.org/en/ node/28858/

${ }^{9}$ Aranco N, Sorio R. Envejecimiento y atención a la dependencia en Uruguay [Internet]. Inter-American Development Bank; 2019 Aug [cited $2021 \mathrm{Jul} 15]$ ]. Available from: https://publications.iadb.org/ es/envejecimiento-y-atencion-la-dependencia-en-uruguay

${ }^{10}$ Molina H, Sarmiento L, Aranco N, Jara P. Envejecimiento y atención a la dependencia en Chile [Internet]. Inter-American Development Bank; 2020 Sep [cited 2021 Jul 20]. Available from: https://publications.iadb.org/es/node/28903

${ }^{11}$ Oliveri ML. Envejecimiento y atención a la dependencia en Argentina [Internet]. Inter-American Development Bank; 2020 Nov [cited 2021 Jul 15]. Available from: https://publications.iadb.org/ es/node/29416

${ }^{12}$ Flórez CE, Martínez L, Aranco N. Envejecimiento y atención a la dependencia en Colombia | Publications [Internet]. 2019 [cited 2021 Aug 17]. Available from: https://publications.iadb.org/publications/spanish/document/Envejecimiento_y_atenci\%C3\%B3n_a_la_dependencia_en_Colombia_es.pdf

${ }^{13}$ López-Ortega M, Aranco N. Envejecimiento y atención a la dependencia en México [Internet]. InterAmerican Development Bank; 2019 Aug [cited 2021 Jul 15]. Available from: https://publications.iadb.org/es/ envejecimiento-y-atencion-la-dependencia-en-mexico

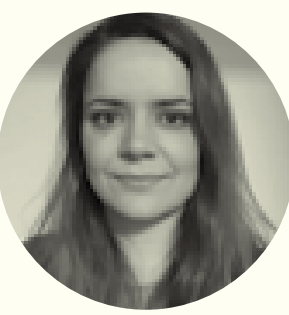

Déborah Oliveira

Social Protection and Health Division Interamerican Development Bank

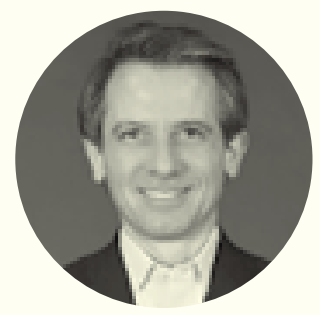

\section{Marco Stampini}

Social Protection and Health Division Interamerican Development Bank

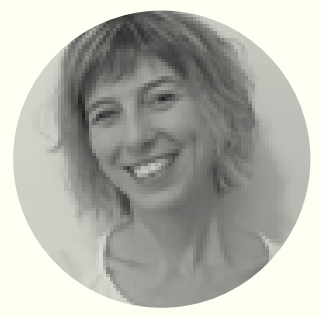

Natalia Aranco Social Protection and Health Division Interamerican Development Bank 


\section{Lessons from Abroad, Applied State-Side: The US Needs to Increase Investment in Home and Community-Based Services}

\begin{abstract}
he US needs to follow other countries like
Denmark and the Netherlands in transforming its spending on long-term care and medical services. The US currently buys too much low-value medical care and buys too little high-value long-term care - specifically, home and community-based services (HCBS).

As the Biden Administration considers an expansion of HCBS, several factors would make this investment most productive. First, the US should use this investment to improve care coordination across long-term care and medical services. Second, as part of this system of care, the US needs to invest in a navigating function such that families can learn about and access the services that best meet their needs. And finally, the US should invest in better pay and working conditions for caregivers.
\end{abstract}

\section{An Outlier in Medical Spending}

When it comes to medical services, the US is an outlier in spending far more of its gross domestic product (GDP) on health care services than any other country in the world. The US spends over 17 percent of its GDP on medical care, whereas the next highest country, Switzerland, devotes 12 percent of its GDP to medical spending. Out of every dollar of spending, the US devotes five cents more to medical care than its next closest counterpart. Much has been written about how this extra spending does not produce better health care outcomes in the US.

The opposite is true when it comes to long-term care spending, with the US spending significantly less relative to other countries. The US spends roughly 1.5 percent of its GDP on long-term care, similar to countries such as Iceland and New Zealand. By comparison, countries such as the Netherlands and Denmark spend over 3.5 percent of their GDP on longterm care. Out of every dollar of spending, the US devotes less than half as much on long-term care relative to these countries. Unfortunately, when it comes to long-term care, the US gets exactly what it pays for relative to its northern European counterparts.

\section{Significant Value of Long-term Care Spending}

What does the extra investment in long-term care buy in these other countries? Quite a lot.
Regardless of where they live, older adults prefer receiving care in the community rather than a facility. More HCBS also leads to less reliance and stress on family caregivers and a lower likelihood of entry to nursing homes.

In countries like the Netherlands and Denmark that invest far more in HCBS than the US, there are generally high levels of satisfaction with long-term care services. Conversely, satisfaction rates in the US are consistently low. Denmark has double the share of individuals receiving longterm care at home relative to the US.

The COVID-19 pandemic revealed another reason to support increased investment in HCBS. In a study of Connecticut long-term care settings, the rate of COVID cases and deaths were far lower for those receiving HCBS than in either nursing homes or assisted living facilities. During the five-month study period, more than one-third (37 percent) of nursing home residents and 14 percent of assisted living residents were COVID-positive, compared with 2-3 percent of HCBS recipients. The share of nursing home (11 percent) and assisted living (5 percent) residents who died from COVID-19 was considerably higher than the HCBS population ( $<1$ percent). Thus, HCBS is not only associated with better quality of life, it also likely saved lives during the pandemic relative to facility-based long-term care settings.

\section{Growing HCBS in the United States}

An influx of public dollars in HCBS is needed. The Biden Administration initially proposed a sizable investment in HCBS of $\$ 400$ billion over the next eight years. The Build Back Better Act included $\$ 150$ billion for Medicaid HCBS. Regardless of the level of funding that becomes available, a key question is how to spend it. Several years ago, I led a study that surveyed over 1,100 long-term care experts about HCBS. Not surprisingly, the experts expressed strong enthusiasm for increasing investment in HCBS. Experts supported system-based approaches for this expansion, including better care coordination, helping consumers make informed long-term care choices, and supporting paid caregivers. These elements are exactly what are found in countries that invest more heavily in HCBS.

Better Care Coordination. HCBS are just one of many long-term care and medical services that will be needed by older adults. Over time, 
HCBS recipients often require nursing home care. It is wrong to treat investment in HCBS and nursing homes as competing objectives. This is a false dichotomy. Instead, the US needs to encourage greater coordination in care between institutional settings and home-like settings.

Likewise, the goal in the US should not be to rebalance from nursing homes to HCBS but rebalance from institutional settings to more home-like settings. Other countries like the Netherlands not only invest more than the US in HCBS, but also invest more in home-like, less institutional nursing homes. These home-like models are associated with a better quality of life. The US needs to grow HCBS and transform its stock of nursing homes to build a true long-term care system.

In addition to reimagining long-term care, the US also needs to better connect long-term care with health care services. Several innovative models that integrate health and long-term care have been developed in recent years including the financial alignment initiative and the fully integrated dual eligible special needs plans. By coordinating health care for individuals living in the community with long-term care needs, the hope is that these models can allow individuals to age in place and avoid unnecessary, costly transfers to the hospital and nursing home.

Making Informed Long-Term Care Choices. Another important feature in growing HCBS is providing tools for older adults and their families to navigate the system and access the services that they need. Currently, care recipients in the US are often "flying blind" due to the complexity of long-term care choices and the lack of resources to help navigate the system. Older adults need a centralized community-based resource where they can get help quickly and easily. Moreover, they need to be able to find resources and guidance from advisers who are not beholden to private enterprise, and who can steer them toward the solutions that best meet their financial, care, and social needs. What is needed is a network of community-based healthy aging hubs across the country where families can go for resources, support, and advice - a one-stop shop for ongoing services and support needs.

Supporting the Workforce. The final piece in the expansion of HCBS is support of the workforce. In the US, many caregivers working in HCBS are underpaid and undervalued, often paid at or near minimum wage with few benefits. They are predominantly women. Many are persons of color and recent immigrants. The work can be difficult and isolating, and these challenges were magnified during the pandemic. There are a range of ideas for improving the support of this workforce, but it starts with improving wages and benefits for direct caregivers. As the US invests more public dollars in HCBS, the bulk of this investment needs to be directed to the individuals doing the care.

\section{Building a Better System}

By tapping elements of the successful long-term care systems from other countries like Denmark and the Netherlands, the US can transform its spending practices. Focusing on a rebalancing of long-term care from institutional setters to a more home-like model would go a long way to improving not only the cost of care, but patient satisfaction. With the Biden Administration's efforts to expand HCBS, there is an opportunity to improve care coordination, better assist families in navigating the complexities of long-term care and enhance the pay and working conditions of paid caregivers.

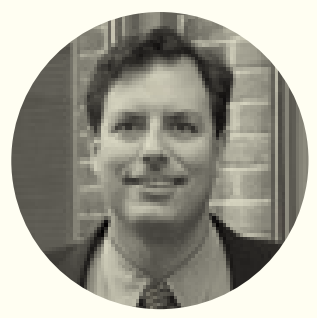

David C. Grabowski

Professor of Health Care Policy Harvard Medical School 


\section{Concerted Action for Nursing - Germany's Strategy to Combat the Shortage of Nursing Professionals}

$T^{\text {hec }}$ he Concerted Action for Nursing initiated a wide-scale process in Germany to win back, retain, and attract nursing professionals at all levels. Training and qualification play a key role in this effort, ensuring not only high quality of care, but also job satisfaction for nursing professionals taking on these demanding jobs.

The demand for nursing personnel is high. One of the most significant demographic changes facing German society is that people are living longer and enjoying a higher quality of life in old age than ever before. While this is a positive development, it requires ensuring access to long-term care for a growing number of people. By the end of 2019, approximately 4.1 million people in Germany needed long-term care. ${ }^{1}$ By 2050 , the number of those with care needs is projected to rise to 6.5 million. ${ }^{2}$ With more need, the demand for professional caregivers will also grow substantially.

Already a nationwide shortage of nursing professionals exists. In 2020, for every 100 unfilled positions there were only 26 professional caregivers in geriatric care and 47 in nursing care registered as jobseekers. ${ }^{3}$ Especially in geriatric nursing, demographic and social trends will continue to increase the demand for staff. It is estimated that the inpatient sector alone will need to fill an additional 71,000 full-time positions between now and $2030 .{ }^{4}$

Securing the staffing base to provide good professional nursing care is clearly one of the key social policy tasks in Germany. The COVID-19 pandemic cemented the importance of meeting the demands for nursing professionals. The frontline work of nurses during the pandemic demonstrated how their efforts save lives and reduce suffering. Nurses are essential not only in crisis response, but also in meeting the everyday needs of an aging society. Improving the structural framework conditions in nursing, achieving the appropriate financial valuation of the nursing professions, and increasing society's appreciation of professional caregivers are among the most important goals of German long-term care and health policy.

\section{Concerted Action for Nursing}

In 2018, the German federal government set up the Concerted Action for Nursing to meet the challenges caused by demographic changes in nursing and long-term care. The initiative is supported by a long list of partners, including government agencies and community organizations. Among those involved are the Federal Ministry of Health; the Federal Ministry for Family Affairs, Senior Citizens, Women and Youth; the Federal Ministry of Labour and Social Affairs; the Federal Laender; nurses' and nurse training associations; associations of LTC facilities and hospitals; churches; long-term care and health insurance funds; associations of affected persons; the occupational accident insurance funds; the Federal Employment Agency; and social partners.

In June 2019, the stakeholders agreed on binding goals and concrete measures to improve the working conditions of nursing professionals, enhance nursing training, and improve the remuneration of professional caregivers. Five different working groups specified goals and measures on topics such as training; personnel management; occupational health, safety, and health promotion; innovative approaches to care and digitalisation; recruitment of nursing professionals from abroad; and remuneration in nursing. ${ }^{5}$

Change is already underway. The second implementation report by The Concerted Action for Nursing, published in August 2021, ${ }^{6}$ highlights the creation of more nursing positions in 


\section{Improving the structural framework conditions in nursing, achieving the appropriate financial valuation of the nursing professions, and increasing society's appreciation of professional caregivers are among the most important goals of German long-term care and health policy.}

\section{1 million}

people in Germany in need of long-term care, end of 2019
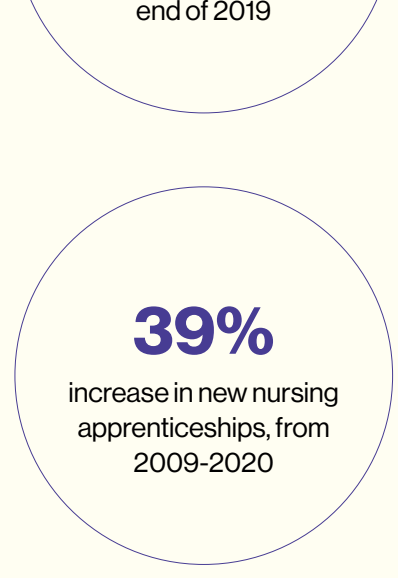

\section{5 million}

projected number of people with care needs by 2050

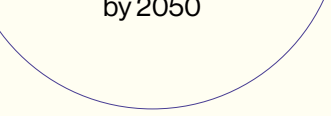

\section{7,309}

number of new geriatric nursing apprentices in vocational school, 2019

\section{1,000}

inpatient sector geriatric

nursing positions that need to be filled by 2030 


\section{By launching the nationwide campaign, "Make a career as a human being!" (2019-2021), the government aimed to attract young people and adults seeking a career change to nursing.}

inpatient and outpatient care. Additionally, critical steps are underway towards better payment and overall working conditions for care professionals and companion carers. The first-ever nationwide, uniform minimum wage for care professionals is being implemented $(€ 15.00$ per hour since July 2021). Starting in April 2022, the minimum wage for care professionals will rise to $€ 15.40$ per hour (increase of 2,67 percent). Also companion carers benefit from the new minimum wage. Since September 2021 the new minimum wage is $€ 12.00$ per hour. Starting in April 2022 the minimum wage for companion carers will rise to a nationwide minimum wage of $€ 12.55$ (increase of 4,58 percent). Furthermore, from September 2022 on, a long-term care facility's accreditation will depend on whether the care professionals and companion carers in its employ are paid at least the amount specified in one of the collective wage agreements in the field of care. ${ }^{7}$

\section{New Nursing Training in Germany}

To boost the popularity of the nursing profession and attract new recruits, Germany comprehensively reformed its new training program. The Act on Nursing Professions united previously separate and disjointed professional training programs for geriatric care, nursing care, and pediatric nursing into a uniform generalist nursing training program. Introduced in 2020, training is now for a "qualified caregiver" that seeks to cover comprehensive nursing care for all ages, in all areas of nursing practice. The vocational qualification is automatically recognized Europe-wide. In addition, after completing two-thirds of their program, trainees can opt for a special professional qualification in geriatric or pediatric nursing.

Not only was the framework for training overhauled, but so was the quality of the instruction. This included implementing new parameters for qualifying teachers and improving practical instruction. Finally, access to the program has improved. The nursing training program is free and trainees are entitled to an adequate training allowance. Alongside the professional nursing training programs, a primary qualifying nursing training program is being offered at universities for the first time.

\section{Inspiring Future Nurses}

With the goal of increasing both the number of trainees and training institutes by 10 percent by the end of 2023, the Vocational Training Initiative for the Care Sector launched in January 2019 as part of The Concerted Action for Nursing. Its aim is to support the introduction of the new nursing training program with over 100 agreements by the time the first year of training ends in 2023. Under the leadership of the Federal Ministry for Family Affairs, Senior Citizens, Women and Youth, 
the participants include all of the stakeholders involved in nursing from the federal government, the Laender, and the relevant associations.

By launching the nationwide campaign, "Make a career as a human being!" (2019-2021), the government aimed to attract young people and adults seeking a career change to nursing. The government financially backed this effort with a multi-year funding program of $€ 25$ million to the Laender for implementing long-term care reforms. To help transition to the new nursing training program, long-term care facilities and nursing schools are supported with diverse information and counselling opportunities. The website www. pflegeausbildung.net provides comprehensive information on the new nursing training program and the training initiative.

\section{Early Success Despite a Pandemic}

The Concerted Action for Nursing training program is already paying off with more people considering a job in nursing. A total of 57,294 trainees commenced the new training program in 2020. This came despite the negative impact the coronavirus pandemic has had on educational programs. Given the disruptions caused by the pandemic, it is possible that as we emerge from it the number of new trainees will continue to grow, outpacing the previous year.

Still, the coronavirus pandemic clearly demonstrated the role increased wages also plays. During the current legislative period of the Bundestag $(2018-2021)$, the increase in salaries in geriatric care amounted to 15.6 percent overall and 9.8 percent in nursing (by 2020). In this respect, the measures implemented by Concerted Action for Nursing led to positive developments overall. We now need to continue the successful implementation of the goals and measures specified within the framework of the Concerted Action for Nursing so that they can quickly bear fruit.
${ }^{1}$ Pflegestatistik - Pflege im Rahmen der Pflegeversicherung Deutschlandergebnisse - 2019, S.21. (Care statistics - Nursing in the Context of the LTC Insurance - Results for Germany - 2019, p. 21) (in German).

2 Siebter Bericht der Bundesregierung über die Entwicklung der Pflegeversicherung und den Stand der pflegerischen Versorgung in der Bundesrepublik Deutschland, Berichtszeitraum: 20162019, S.13. (Seventh Report by the Federal Government on the Development of the LTC Insurance and the State of Nursing Care in the Federal Republic of Germany: 2016-2019, p. 13) (in German).

${ }^{3}$ Bundesagentur für Arbeit Statistik/Arbeitsmarktberichterstattung Arbeitsmarktsituation im Pflegebereich, Mai 2021, S. 17 (Federal Employment Agency Statistics/Labour Market Reporting, Situation in Nursing, May 2021, p. 17) (in German).

${ }^{4}$ SOCIUM, IPP, iaw, KKSB (2020): Final report on project development and testing of an evidence-based procedure to uniformly measure the demand for personnel in long-term care institutions, based on the qualitative and quantitative standards stipulated in section $113 \mathrm{c}$ of the Social Code-Book XI (staffing requirements), p.369 (in German).

${ }^{5}$ https://www.bundesgesundheitsministerium.de/fileadmin/ Dateien/3_Downloads/K/Konzertierte_Aktion_Pflege/191129 KAP_Gesamttext_Stand_11.2019_3._Auflage.pdf (in German).

${ }^{6}$ https://www.bundesgesundheitsministerium.de/fileadmin/ Dateien/3_Downloads/K/Konzertierte_Aktion_Pflege/ KAP Zweiter Bericht zum Stand der_Umsetzung_der Vereinbarungen_der_Arbeitsgruppen_1_bis_5.pdf (Second report - Concerted Action for Nursing) (in German).

${ }^{7}$ Second report - Concerted Action for Nursing (Fn.6), p. $103 \mathrm{ff}$ (in German).

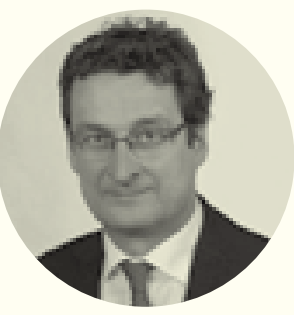

Matthias von Schwanenflügel

Head of Directorate-General 3 'Demographic Change, Senior Citizens, Non-statutory Welfare' Federal Ministry for Family Affairs, Senior Citizens, Women and Youth 


\section{Long-Term Care and Caregiving for Older Adults in Africa}

$T$ he current state of long-term care in Africa is rapidly changing, leaving critical gaps yet also offering an opportunity for bold, strategic change. While the African population, like the global population, continues to age, extended family supports are gradually eroding. It is therefore imperative that African governments design innovative measures to improve long-term care for older people. This work must be culturally sensitive and engage not only the government agencies, but also tap non-governmental organizations and social institutions including volunteer groups and other relevant stakeholders.

The rapid aging of the population - those persons ages 60 and older - has been long underway in many African countries. For example, in Ghana, the older population rose from 213,477 in 1960 to $1,643,381$ in 2010, with women making up 56 percent and men 44 percent of the population 60 and older (Ghana Statistical Service, 2013). In Uganda, older people comprise 4.5 percent of the total population (Uganda Bureau of Statistics, 2018). And in Nigeria - Africa's most populous nation and the seventh most populated country in the world - there are 10.9 million older people, according to 2020 data (He et al., 2020). Egypt, Ethiopia, and South Africa each boast elderly populations of more than 5 million.

With larger older populations come more care demands. In Ghana, for example, the World Health Organization (WHO, 2015) estimates more than half of those ages 65 to 75 require some help with daily activities. This development also comes at a time where kinship care for older persons is decreasing due to issues, such as insufficient financial resources, urbanization, and nucleation of the family (Dovie, 2019, Ofori-Dua, 2014). Consequently, governments, corporations, religious groups, and communities must establish long-term care programs to assist older people who are no longer able to care for themselves, including areas of health care, social engagement, housing, and other services. Long-term care aims to support those with any combination of physical, mental, or cognitive limitations. (Bodenheimer, 1999).

\section{A Culture of Family Caregiving}

In Africa, family members are primarily responsible for providing care and support to older adults (Essuman et al., 2018). This dependence is a reciprocated act, and one related to an African adage that roughly translates to: "Because you [i.e., one's older parent] have taken care of me [the child] to grow teeth, I will take care of you until your teeth fall out" (Apt, 1996; ScheilAdlung, 2015).

A study on such family involvement in urban Kenya and South Africa, suburban Ghana, and rural Tanzania found that relatives are actively involved in developing care plans with social service agencies such that they integrate their own roles and contributions. In some cases, families oversee both the implementation of the care plan and the performance of paid caregivers. The care recipients themselves likewise help to create their care plans, which ensures that their unique needs and preferences are considered (Ananias, 2012). 


\section{National efforts to develop long-term care systems exist only in three nations in the region with established middle-income economies: Mauritius, Seychelles, and South Africa.}

But dependence on families alone results in unreliable care quality and places economic, psychological, social, and physical burdens on the family caregivers, who tend to be women and girls (Kyomuhendo et al., 2020). Relatedly, family care inadequacies can result from poverty and vulnerable employment. Family caregivers often lack the resources to provide better care, or they are forced to either neglect their work, education/training, or other economic activities or neglect their dependent relative (Mudiare, 2013; Skovdal et al., 2009). Caretaking can often adversely affect the health of caregivers, who lack time to focus on their own well-being. Additionally, the financial costs of caregiving can be considerable (Nortey et al., 2017; Schatz \& Seeley, 2015).

Most family caregivers provide care with little or no guidance on how to address complex health issues. For example, few caregivers understand the nature of dementia, how it can influence behavior, and how they can improve the lives of older persons who have it. This lack of knowledge can increase the risk of elder abuse, either physical, or financial-from corrupt caregivers who help themselves to older people's assets (Pillemer et al., 2016).

\section{Developing Support Systems}

Given the challenges and complexities facing family caregivers, many sub-Sahara African researchers and policymakers believe it is no longer feasible to rely on extended families for long-term care of older persons. Rather, they have concluded, organized and paid long-term care services are needed to supplement and strengthen the care of older adults (Clausen et al., 2007; Obrist, 2012; Pype, 2016).

National efforts to develop long-term care systems exist only in three nations in the region with established middle-income economies: Mauritius, Seychelles, and South Africa (World Bank, 2017). These countries have established residential facilities for frail older people and provide some financial assistance to this population. In other African countries, there are piecemeal efforts to provide community supports, but they are often aimed at specific groups and do not serve all older people. For instance, some organizations tied to specific professions offer social support to retirees. Members of the Veterans Association of Ghana, HelpAge Ghana, Akrowa Aged Life Foundation (now Care for Aged Foundation), and Association of Ghana Elders occasionally meet to catch up and socialize (Essuman et al., 2018).

Access to health insurance also provides some older adults with health services, but this is far from universal. In Ghana, the registration fees, as well as the annual premium charges paid by beneficiaries of the National Health Insurance Scheme has been waived for older persons (aged 70 years and above); however, not all medical problems are covered by the scheme. Further, residents of rural areas are left to pay their own health expenses, which is especially difficult when it comes to seeking treatment for severe medical cases (Agyemang, 2014; Dake \& Van der Wielen, 2020). 


\section{Offering caregiver training programs, making improvements to health care, conducting aging-related research, and creating institutions for long-term care should be explored as opportunities for supporting family caregivers. This should be done in a manner that respects the long-existing roles of families embracing the responsibility of caring for the elderly.}

Offering caregiver training programs, making improvements to health care, conducting aging-related research, and creating institutions for long-term care should be explored as opportunities for supporting family caregivers. This should be done in a manner that respects the long-existing roles of families embracing the responsibility of caring for the elderly. Collaboration between government agencies in Africa and community organizations offer a way to include all stakeholders and support the physical, mental, and social needs of older Africans.

\section{Implementing Change}

There are four areas African countries need to focus on as policymakers and stakeholders consider improving the long-term care prospects for older adults: assessment, health, economic empowerment, and investment in youth. Each offer a way to not only clearly identify the specific needs facing a community, but also engage the elderly and their families in creating viable solutions.

Assessment. Government agencies should conduct periodic surveys on older residents especially in higher-poverty areas - to identify their major health, social, and economic challenges. Done well, an assessment can bring together government, families, volunteers, NGOs, professionals, and the private sector to collaborate for the betterment of older people (WHO, 2017).

Health. Health policies that address the needs of older persons - including the provision of health insurance, granting affordable access to medications, and the construction of health care clinic for older adults - should all be considered. If government makes caring for its older citizens a priority, then private-sector organizations will follow suit, seeing it as their corporate social responsibility, and help make it work.

Economic empowerment. Policies should help support older adults working longer. This can include vocational and technical educational programs and finding jobs that are older person-friendly. Employment provides financial security and keeps older adults cognitively sharp and engaged members of their community.

Investment in current youth. Today's youth will eventually grow old. Government programs aimed at educating younger generations on planning for old age and retirement ensure a better future for all. By planning for old age with information on healthy eating, financial savings, long-term housing needs, physical fitness, and more, younger generations can form the habits that will provide security and comfort in old age.

\section{Conclusion}

To effectively address the gaps in caring for an aging society, African governments must support the cohesive development of long-term care systems. While the tradition of relying on extended family to care for older adults should be respected, governments and community organizations need to consider ways to ease the burden with new policies and programs. Taking time to assess the unique needs of individual African countries and remembering to pay particular attention to 
the health and economic needs of older adults will help provide a path forward. Additionally, all efforts should include the long-term vision for the future that today's youth will eventually age and need care.

\footnotetext{
${ }^{1}$ Agyemang, F. A. (2014). Survival strategies of the elderly in rural Ghana. [Unpublished doctoral dissertation]. University of Ghana, Legon.

${ }^{2}$ Ananias, J. (2012, October 17-20). The relationship between informal caregiving, elder abuse and neglect in urban and rural areas of the Khomas Region in Namibia [Paper presented]. First IAGG Africa Region Conference on Gerontology and Geriatrics,
} Cape Town, South Africa.

${ }^{3}$ Apt, N. A. (1996). Coping with old age in a changing Africa: Social change and the elderly Ghanaian. Avebury.

${ }^{4}$ Bodenheimer, T. (1999). Long-term care for frail elderly peoplethe On Lok model. The New England Journal of Medicine, 341(17) $1324-1328$.

${ }^{5}$ Dake, F. A., \& Van der Wielen, N. (2020). Towards universal access to healthcare for older adults: An assessment of the old-age exemption policy under Ghana's National Health Insurance Scheme. International Journal for Equity in Health, 19(1), 1-10.

${ }^{6}$ Dovie, D.A. (2019). The status of older adult care in contemporary Ghana: A profile of some emerging issues. Frontiers in Sociology, 4(25), 1-12.

${ }^{7}$ Essuman, A., Agyemang, F. A., \& Mate-Kole, C. C. (2018). Longterm care for older adults in Africa: Whither now? JAMDA, 19(9), 728-730. https://doi.org/10.1016/j.jamda.2018.07.012

${ }^{8}$ Ghana Statistical Service. (2013). 2010 population \& housing census report: The elderly in Ghana. https://www2.statsghana. gov.gh/docfiles/publications/2010phc_the_elderly_in_Gh.pdf

${ }^{9}$ Gureje, O., Ogunniyi, A., Kola, L., \& Afolabi, E. (2006). Functional disability in elderly Nigerians: Results from the Ibadan Study of Aging. Journal of American Geriatrics Society, 54(11), 1784-1789. https://doi.org/10.1111/j.1532-5415.2006.00944.x

${ }^{10} \mathrm{He}$, W., Aboderin, l., \& Adjaye-Gbewonyo, D. (2020). Africa aging: 2020. International Population Reports.

${ }^{11}$ Kyomuhendo, C., Boateng, A., \& Agyemang, F. A. (2020). Experiences of elderly women caring for people living with HIV and AIDS in Masindi District, Uganda. AIDS Care, 33(8), 993-996. https://doi.org/10.1080/09540121.2020.1832191

${ }^{12}$ Mudiare, U. (2013). Abuse of the aged in Nigeria: Elders also cry. American International Journal of Contemporary Research, 3 79-87.

${ }^{12}$ Nortey, T., Aryeetey, C., Aikins, M., Amendah, D., \& Nonvignon, J. (2017). Economic burden of family caregiving for elderly population in southern Ghana: The case of a peri-urban district. International Journal for Equity in Health, 16(1), 1-9. https://doi. org/10.1186/s12939-016-0511-9

${ }^{13}$ Obrist, B. (2012, October 17-20). Who cares for frail older people? A rural-urban comparison from Tanzania [Paper presented]. First IAGG Africa Region Conference on Gerontology and Geriatrics, Cape Town, South Africa.

${ }^{14}$ Ofori-Dua, K. (2014). Extended family support and elderly care in Bamang, Ashanti Region of Ghana (Doctoral Dissertation). University of Ghana.
${ }^{15}$ Parmar, D., Williams, G., Dkhimi, F., Ndiaye, A., Asante, F. A., Arhinful, D. K., \& Mladovsky, P. (2014). Enrolment of older people in social health protection programs in West Africa-does social exclusion play a part? Social Science \& Medicine, 119, 36-44.

${ }^{16}$ Pillemer, K., Burnes, D., Riffin, C., \& Lachs, S. (2016). Elder abuse: Global situation, risk factors, and prevention strategies. Gerontologist, 56(2), 194-205. https://doi.org/10.1093/geront/ gnw004

${ }^{17}$ Pype, K. (2016). Caring for people with and without value: Kinshasa's retirement homes between the family, the state and the church. In J. Ho man \& K. Pype (Eds.), Ageing in sub-Saharan Africa: Spaces and practices of care (pp. 43-68). Policy Press.

${ }^{18}$ Schatz, E., \& Seeley, J. (2015). Gender, ageing and care work in East and Southern Africa: A review. Global Public Health 10(10), 1185-1200. https://dx.doi.org/10.1080\% 2F17441692.2015.1035664

${ }^{19}$ Scheil-Adlung, X. (2015). Long-term care protection for older persons: A review of coverage deficits in 46 countries. UNICEF. https://unece.org/fileadmin/DAM/pau/age/WG8/ Presentations/4b_Long_Term_Care_Working_Group_on_Ageing. pdf

${ }^{20}$ Skovdal, M., Ogutu, O., Aoro, C., \& Campbell, C. (2009). Young carers as social actors: Coping strategies of children caring for ailing or ageing guardians in Western Kenya. Social Science \& Medicine 69(4), 587-595. https://doi.org/10.1016/j.socscimed.2009.06.016

${ }^{21}$ Uganda Bureau of Statistics. (2018). Uganda national household survey 2016/2017. https://www.ubos.org/wp-content/uploads/ publications/03_20182016_UNHS_FINAL_REPORT.pdf

${ }^{22}$ World Bank. (2017). Country and lending groups. The World Bank Group.

${ }^{23}$ World Health Organization. (2015). World report on ageing and health. http://apps.who.int/iris/bitstream/handle/10665/186463/9789240694811_eng.pdf

${ }^{24}$ World Health Organization. (2017). Towards long-term care systems in sub-Saharan Africa. https://www.who.int/ageing/longterm-care/WHO-LTC-series-subsaharan-africa.pdf

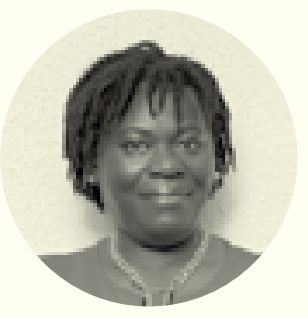

\section{F. Akosua Agyemang}

Senior Lecturer, Department of

Social Work

University of Ghana 
Feature Story

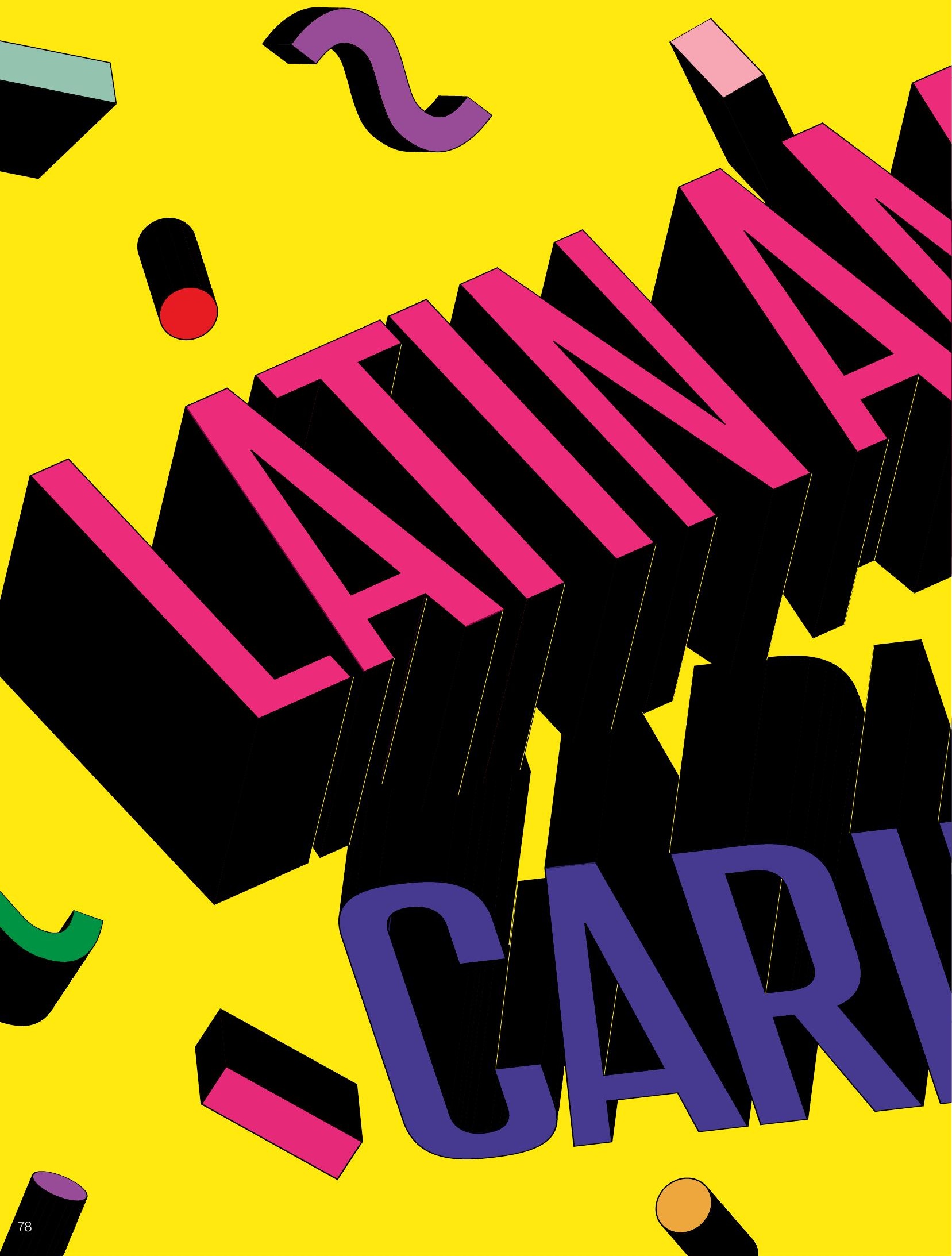




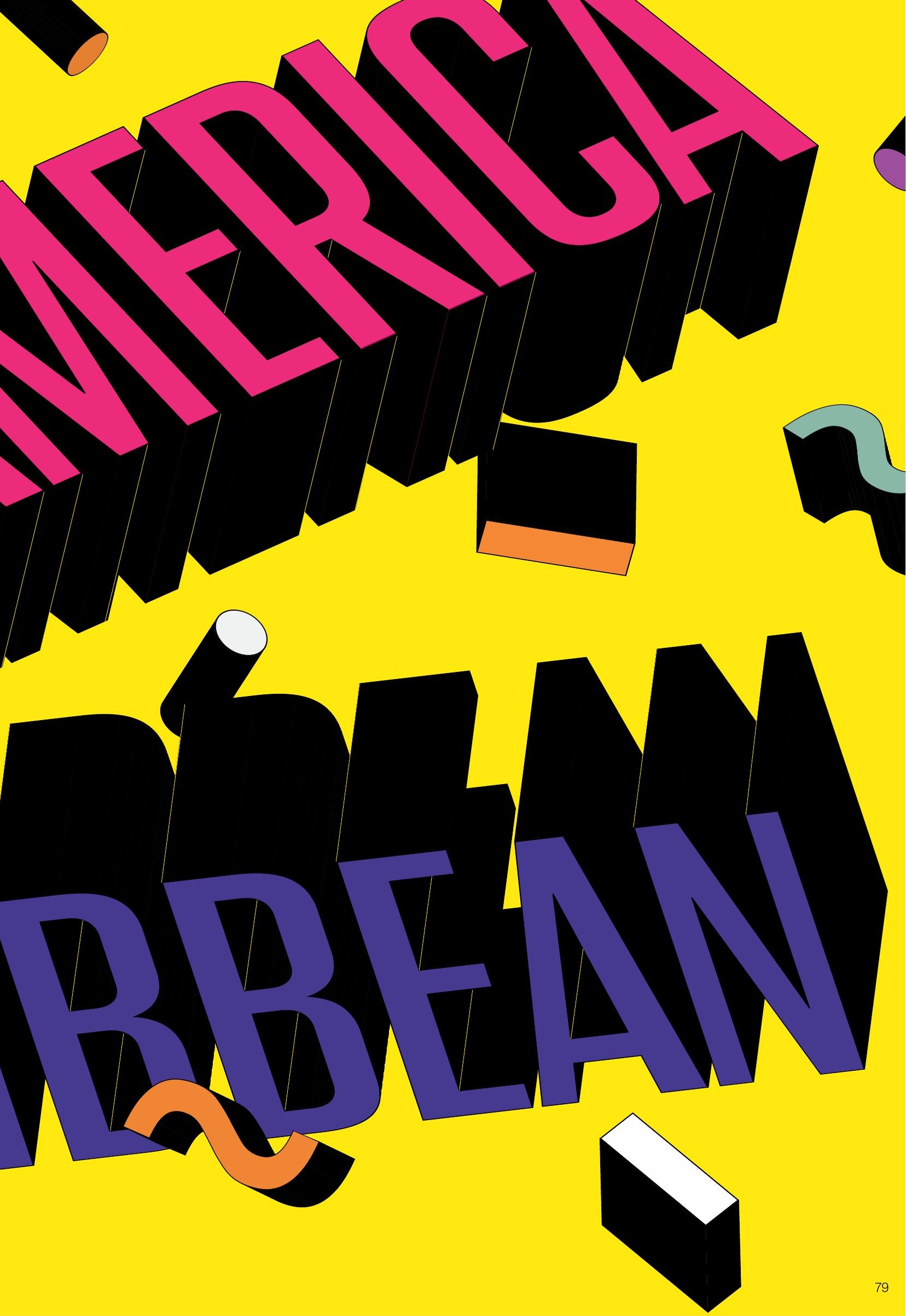


In 2020, nearly 58.5 million people over the age of 65

El Salvac

lived in Latin America and the

Caribbean (LAC), constituting

9 percent of the region's

population. The region

promises to soon be in the

thick of the global aging trend

that already is well underway

as this 65-plus population

is expected to double to

approximately 18 percent of

the region's residents by 2050 ,

according to the Organisation

for Economic Cooperation and

Development (OECD). 
$-)$

Thé Bahamas Dominican Republic

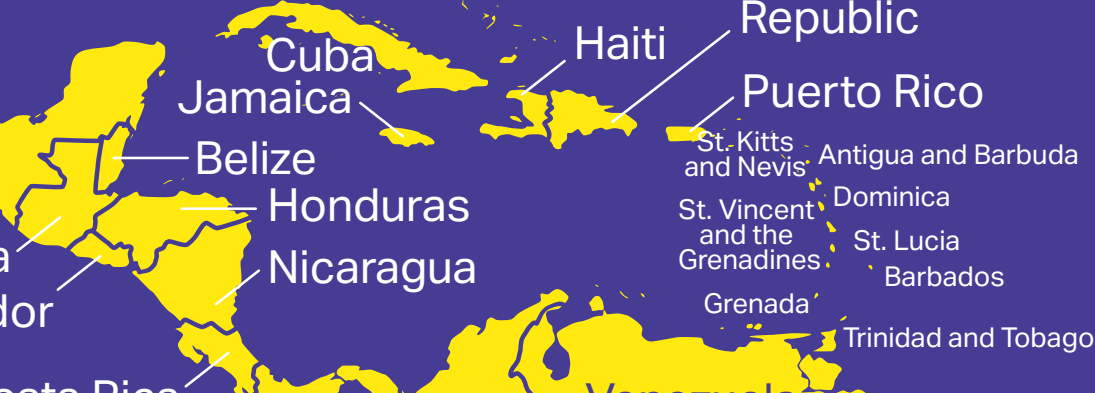

sta Rica

1..

Panama

Islands

Argentina

3 Trinidad and Tobago
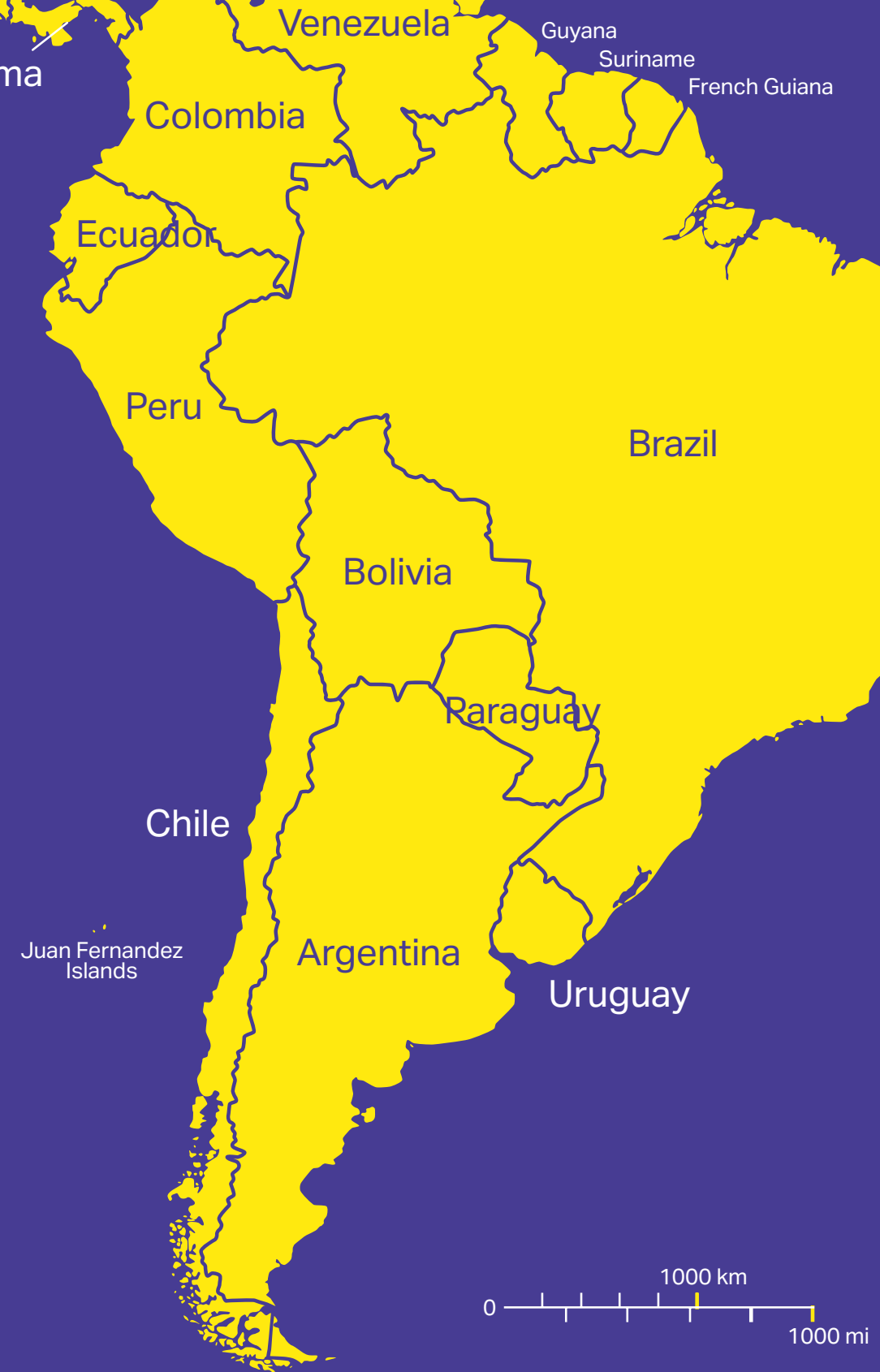


\title{
Population Aging in Latin America and the Caribbean
}

Percentage of population age $60+$

\author{
口 $2015 \square 2030 \square$
}

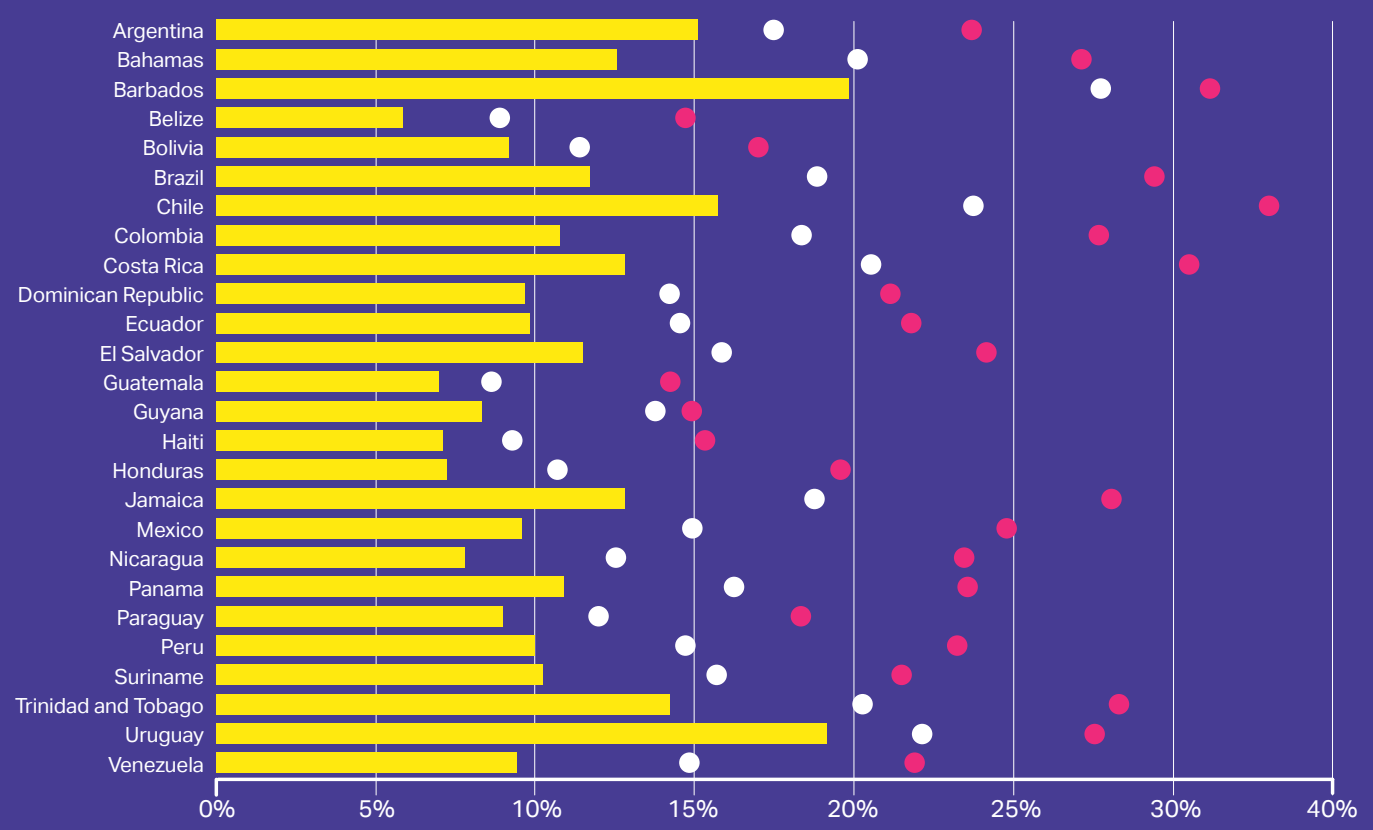

\section{Latin America \& the Caribbean vs. the World in 2100}

Median age by region, 1950 and 2100

$\square 1950 \square 2100$

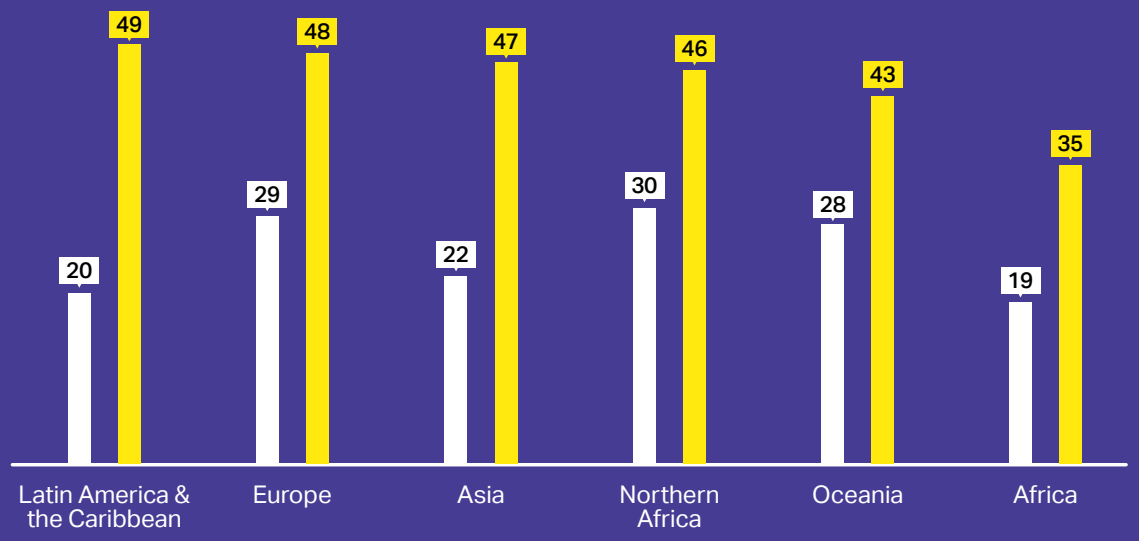


As with other regions across the globe, the aging trend in LAC translates into an increasingly urgent need to identify challenges, solutions, and opportunities. And while common factors affecting the well-being of older adults naturally span LAC's subregions and countries, those factors and dynamics come in different permutations and with a level of uniqueness within those subregions and countries. Over the past few years, protests over the adequacy of pension systems contributed to unrest in the Southern Cone countries of Argentina ${ }^{5}$ and Chile, ${ }^{6}$ while up north in the Central American country of Nicaragua, there were widespread protests about changes to the social security system. ${ }^{7}$ Regarding the Andean region, HelpAge International reported that the majority of older adults in Venezuela cannot afford to buy themselves food and medicine, ${ }^{8}$ and the Inter-American Development Bank estimated that 16 percent of Bolivia's 60-plus population lives in extreme poverty and 14 percent in moderate poverty. ${ }^{9}$ And, according to the World Economic Forum, in Brazil, over 80 percent ${ }^{10}$ of older adults rely on what America's Quarterly has described as an underfunded Brazilian National Health Service. ${ }^{11}$

Amid these dynamics, positive momentum has emerged on a range of aging issues. LAC took a leadership role in protecting the rights of older adults in 2015, when five countries signed the Inter-American Convention on the Rights of Older People. ${ }^{12}$ Meanwhile, 11 LAC countries developed Age-Friendly cities, demonstrating commitment and progress towards creating accessible living spaces, ${ }^{13}$ and the Nicoya peninsula of Costa Rica is considered a "blue zone"- a place where residents lead unusually long lifespans and health spans. ${ }^{14}$ Finally, LAC's policymakers, civil society leaders, and international organizations - such as the Pan-American Health Organization (PAHO), the UN Economic
Commission for Latin America (ECLAC, or CEPAL in Spanish), and the Inter-American Development Bank - as well as older adults themselves conduct lawmaking, advocacy, and research to bolster the protection of older persons' rights on local, national and international scales.

Thus, the aging challenges, solutions, and opportunities of Latin America and the Caribbean are fluid, compelling, and important to broader discourse on the global aging trend. Ideas and solutions developed for one location, while being tailored to the unique situation of a given place, can inspire ideas and solutions elsewhere. This section offers ground-level information about a dynamic region with an eye toward providing global takeaways. $\bullet$

\section{${ }^{1}$ https://data.worldbank.org/indicator/SP.POP.65UP. TO?locations $=\mathrm{ZJ}$}

${ }^{2}$ https://data.worldbank.org/indicator/SP.POP.65UP. TO.ZS?locations=ZJ

${ }^{3} \mathrm{https} / / /$ www.aarpinternational.org/arc3

${ }^{4} \mathrm{https} / / / \mathrm{www} .0 e c d-i l i b r a r y . o r g / s i t e s / 6 d e c c 105-e n / i n d e x$. $\mathrm{html}$ ?itemld=/content/component/6decc105-en

${ }^{5} \mathrm{https} / / /$ www.bbc.com/news/world-latin-america-42416195

${ }^{6} \mathrm{https} / / /$ www.reuters.com/article/us-chile-protests-pensions/ chiles-fiery-anger-fueled-by-fears-of-poverty-in-old-age-idUSKBN1XB3U8

${ }^{7}$ https://www.reuters.com/article/us-nicaragua-protests/ nicaraguans-take-to-streets-in-protest-over-social-security-changes-idUSKBN1HR02A

${ }^{8} \mathrm{https} / / /$ www.helpage.org/newsroom/press-room/press-releases/ humanitarian-response-to-venezuelan-crisis-must-stop-neglecting-the-needs-of-older-people/

${ }^{9} \mathrm{https} / / /$ publications.iadb.org/publications/english/document/ How_Do_Older_Adults_in_Latin_America_and_the_Caribbean_Live_ en_en.pdf

${ }^{10} \mathrm{https} / / /$ www.weforum.org/agenda/2020/11/ little-to-celebrate-for-older-brazilians/

"https://www.americasquarterly.org/ article/5-big-ideas-universal-health/

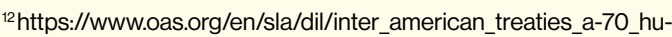
man_rights_older_persons_signatories.asp

${ }^{13} \mathrm{https} / / /$ extranet.who.int/agefriendlyworld/search-network/

${ }^{14} \mathrm{https}$ ///www.bbc.com/worklife/article/20200429-nicoya-the-costa-rican-peninsula-where-centenarians-thrive 


\section{ARGENTINA}

\section{COMMUNITY}

The Universidad para

Adultos Mayores Integrados

(University for Integrated

Older Adults or UPAMI)

offers free, continuing

education to older adults

age 60-plus. The program

is run with support from the

INSSJP (National Institute of Social Services for Retirees and Pensioners) and since 2009 has been offered at universities throughout Argentina. UPAMI promotes the personal growth of adults and, above all, allows them to continue contributing their experiences to society. Students can choose from a wide variety of courses, including digital literacy, health and wellness, history, dance, arts and culture, and psychology.

\section{HEALTHCARE}

RAFAM Internacional (Physical Activity Network for Older People International) facilitates the inclusion of physical activity in the daily lives of older adults. This organization hosts awareness campaigns, physical activity sessions, trainings for physical education professionals, and gatherings of older adults to highlight the importance of staying active while aging. Originally founded in 2010, RAFAM is now an international network that spans across 14 countries.

\section{TECHNOLOGY}

The +Simple tool was launched in 2018 with the aim of promoting digital literacy and the social inclusion of older adults. Through the government's Technology Inclusion Program, more than 100,000 tablets containing the "+Simple" platform were delivered to individuals age 60 and over. The platform is specifically designed for use by older persons. It gives them access to apps for newspapers, social media, games, radio shows, and web browsing in a safe and easy-to-navigate space.

\section{COMMUNITY}

Juegos de las Personas Mayores (the Older People Games) is an annual competition that was first held in 2018 by Argentina's Secretariat for Social Integration for Older People (SECISPM) to promote healthy aging. Participants must be age 60 and over and residents of the city of Buenos Aires. Previous activities of the games have included drawing, painting, photography, singing, comedy, and Buenos Aires trivia. Additional non-competitive, complementary activities, such as virtual yoga and tai chi classes, are also offered alongside the games.

\section{FINANCE}

Mayores Activos is an online financial education platform that strengthens the financial and digital inclusion of older adults in Argentina. The site, launched in 2021 as part of a cooperative agreement between Banco de la Nación Argentina (BNA) and the Latin American Development Bank - Andean Development Corporation (CAF), teaches users how to conduct online banking. The portal gives users access to banking services as well as modules informing them 
about how to use the ATM and BNA's virtual wallet. Users have access to a virtual support assistant and a chatbot to answer any questions. In addition, BNA trained 685 financial literacy educators at various branch locations to be able to help older persons learn to use the digital financial services.

\section{BARBADOS}

\section{COMMUNITY}

Centenarians of Barbados: The Foundation Builders is a project co-developed by the former National Committee on Ageing, the Barbados Museum and Historical Society, and the Barbados Government Information Service. The website showcases Barbadian centenarians through its digital archive of their individual stories. These online exhibitions celebrate the milestone of turning 100 while exploring how centenarians shaped the history of the island. An additional page highlights resources available for older adults in Barbados.

\section{COMMUNITY}

The "Fifty Plus" Radio

Show is hosted by the Barbados Association of Retired Persons (BARP), a non-profit, non-governmental organization dedicated to improving the wellbeing of people age 50-plus.

This 30-minute show airs on QFM 100.7 and VOB 92.9 FM and discusses issues pertinent to older adults in Barbados. Past topics of conversation have been consumer rights and protections as well as COVID-19 vaccines and the importance of getting vaccinated.

\section{BRAZIL}

\section{TECHNOLOGY}

Eu Vô offers door-to-door transportation and pickup services for older adults who need to go to medical appointments but who can no longer go on their own. This service is available in the cities of São Carlos and São Paulo, and it has continued to operate during the COVID-19 pandemic with a mask requirement.
Drivers also assist with errands such as trips to the supermarket. Passengers can request their ride through an app, similar in function to other ride-sharing services. Eu Vô drivers are trained in first aid, as well as in topics related to gerontology and psychology, to ensure the service is as safe as possible.

\section{COMMUNITY}

Programa Educativo is an innovative educational platform created by the Rede Bem Estar (Wellness Network) in partnership with the São Paulo State Council of the Elderly, the Tellus Institute and BrasilPrev. The platform highlights ways to strengthen social bonds among older adults, their caregivers and their surrounding communities. Programa Educativo offers a total of 30 hours of online workshops that were developed with the support of specialists in longevity for audiences with diverse connections to the aging population. 


\section{CHILE}

\section{COMMUNITY}

Acompañamiento Telefónico Mayor (ATM) is a telephone program, led by Fundación Amanoz since March 2020, that aims to create opportunities for isolated older adults to establish new social connections. Volunteers reach program participants by telephone or video call once or twice a week, depending on individual preferences. The organization has more than 450 volunteers throughout the country who provide social and emotional support to more than 500 older persons.

\section{TECHNOLOGY}

The NODO Emergency Platform is a mobile application that was created by the Chilean National Service for Older Persons (SENAMA) in collaboration with various UN agencies. It connects older adults to a network of trained professionals who can help them cope with isolation and loneliness during the COVID-19 pandemic. Since its launch in August 2020, the NODO Emergency Platform has aimed to expand older adults' ability access to resources regarding their health and well-being as well as to improve their sense of social inclusion.

\section{COLOMBIA}

\section{COMMUNITY}

The Consejo Distrital de Sabios y Sabias, or the District Council of Wise Men and Wise Women, of the City of Bogotá is a space for community leaders to help shape policies regarding social, economic, labor, environmental, educational and cultural concerns that particularly affect older people. The council is notably consulted by local political leaders on matters of public policy on aging. Councilmembers are elected from 14 different localities within the city of Bogotá.

\section{COMMUNITY}

Escuela Virtual de Historias en Yo Mayor is led by Fundación Saldarriaga Concha and Fundación Farenheit 451 with support from the newspaper
El Tiempo. The project originally launched in 2011, and its virtual nature during the COVID-19 pandemic has provided older adults with an outlet to explore their creative sides and to share their stories. During the 7-week project, participants utilize a series of pedagogical tools (in text, video and audio) to write their own and listen to each other's stories.

\section{COSTA RICA}

\section{COMMUNITY}

Contraticos is an online hiring platform that helps older adults to find job opportunities. The company serves as a liaison between older individuals and companies looking to hire experienced workers. Contraticos aims to break down myths around older workers, teaching employers about the benefits of having an age-inclusive workforce and providing guidelines on how to best utilize individual skills. The company's goal is to help everyone find employment 
opportunities, regardless of age, while helping to end discrimination against older people.

\section{COMMUNITY}

Proyecto Educativo para la Persona Adulta Mayor (PAMTEC), through the Instituto Tecnológico de Costa Rica (TEC), is a continuing education project aimed at people over 55 years of age. Students can choose from a range of course topics that includes computing and mobile devices, sustainable development, entrepreneurship and personal well-being. The goal for the program is to promote active aging and lifelong learning. Courses are taught by diverse academic experts from TEC as well as by volunteers.

\section{CUBA}

\section{COMMUNITY}

La Cátedra Universitaria del Adulto Mayor has been a wellknown educational program for older adults since its start at the Universidad de La Habana in 2000. What began with an initial cohort of 42 students has expanded to locations across the island with its total graduates numbering in the tens of thousands.

Students study a range of topics, including health and human development, arts and culture, and local history. For over 20 years, the program has aimed to foster a sense of belonging and improve the quality of life of participants.

\section{TECHNOLOGY}

Los GeroClub are initiatives led by Los Joven Club de Computación y Electrónica (JCCE, the Young Computer and Electronics Club) of Cuba. GeroClub groups, which started in 2007, are accessible at various locations throughout the country, and they provide intergenerational digital literacy workshops for people age 50 and over. The goal is to help older adults learn how to navigate an increasingly digital world.

\section{JAMAICA}

\section{COMMUNITY}

The "CCRP Update" radio show airs on Radio Jamaica
94FM and is sponsored by the Caribbean Community of Retired Persons (CCRP) Jamaica. CCRP Jamaica is a membership organization for people age 50-plus. Its over 11,000 members have access to benefits and discounts as well as numerous wellness and lifestyle activities, including social events and learning opportunities for retirement planning and personal safety. The CCRP Update radio show discusses a variety of topics relevant to the country's older population, such as ageism, mental health during the COVID-19 pandemic, nutrition, and establishing a healthy diet.

\section{MEXICO}

\section{TECHNOLOGY}

Alfabetización Digital Adulto Mayor is a digital literacy workshop originally created for older adults in 2015. The workshop's founder, Dr. Martínez-Alcalá, is an expert on information and communication technology at the Autonomous University of the Mexican 
State of Hidalgo (UAEH). Due to the ongoing COVID-19 pandemic, sessions are now taught entirely online using Zoom. Courses are generally organized at five levels, from basic through advanced, but some focus on more specific topics including cell phone use. The initiative's goal is to provide support for older adults who want to learn how to take advantage of changing technologies, enabling new opportunities for digital inclusion.

\section{COMMUNITY}

Una Cana al Arte offers people age 60 and over free, weekly tours of museums throughout Mexico. This program was created as the result of a partnership between the Instituto Estatal de la Cultura de Guanajuato (Guanajuato's State Institute of Culture) and Mexico's network of museums. After more than 20 years, the program generally expects about 30 to 50 older individuals attending each guided tour of permanent and temporary exhibits.

\section{PUERTO RICO}

\section{COMMUNITY}

La Juntilla 50+, a weekly radio program produced by AARP Puerto Rico, challenges the myths of life after 50 . The show airs on Thursdays at 7pm on Radio Isla 1320 AM. Topics discussed include current events, lifestyles, family, travel, finance, health, community, volunteering, and more. Recent shows have covered the effects of the hurricane season, COVID-19 and vaccine availability, and mental health during the pandemic.

\section{TECHNOLOGY}

Tecnoabuelos is a digital literacy project geared toward people of age 50-plus that was founded in 2013. Tecnoabuelos offers courses that help older people to maximize their use of the internet, applications, and devices like tablets and mobile phones. These courses promote the use of technology for staying connected, maintaining an active mind, and cultivating new interests. Individual and group courses are offered; during the pandemic all have been virtual.

\section{TRINIDAD AND}

\section{TOBAGO}

\section{HEALTHCARE}

My Senior Card, a program

led by the Trinidad and Tobago Association of Retired Persons (TTARP), provides an affordable medical insurance option for TTARP members. With the purchase of the plan, older adults receive one free annual medical exam, in addition to discounts on a range of other services, including dental work, laboratory testing, and diagnostic testing. TTARP is a membership organization for people age 50-plus in Trinidad and Tobago that provides aging-related resources, discounts, access to affordable medical services, and a range of social activities.

\section{URUGUAY}

\section{COMMUNITY}

The Festival Internacional de Cine sobre Envejecimiento 
(International Film Festival on Aging) was organized by el Centro Interdisciplinario de Envejecimiento at Universidad de la República and el Cine Universitario del Uruguay. This festival was the first of its kind in Latin America to center around the topic of aging. The goal was to generate spaces to reflect on and discuss how aging is represented around the world. During the inaugural event in September 2021, screenings of 66 short films took place alongside other events such as training workshops and talks. The topics highlighted by these films included the exploration of historical memory, intergenerational relationships, and the recognition of the rights of the elderly.

\section{COMMUNITY}

A collection of comic books centered around aging and older adults was co-created by Latin American and Scottish experts, including professors from the Universidad de la República in Uruguay and the University of Dundee in Scotland. Derechos de las personas mayores: Lecciones de la pandemia de COVID-19, or Older Person's Rights: Lessons from the COVID-19 Pandemic, was published in 2020, and the narrative highlights challenges faced by older people during the pandemic. Another comic titled La convención sobre los derechos de las personas mayores: Una guía gráfica, or The Convention on Older Person's Rights: A Graphic Guide, was released in late 2021. This one presents an overview of the InterAmerican Convention on Protecting the Human Rights of Older Persons, informing readers of the benefits of ratification as well as older adults' protected rights.

\section{TECHNOLOGY}

Plan Ibirapitá was launched in 2015 by the Uruguayan government to promote the digital inclusion of older adults. Under this initiative, older individuals with a monthly income below $\$ 800$ are eligible for a free internet-connected tablet and training workshops where they can learn to use that tablet's particular features. Others with higher incomes are also welcomed to join these activities if desired. As of 2021, around 230,000 tablets were reported to have been distributed. Each device and its specific applications were designed with older users in mind, and many have learned to use their tablets to access the news, social media, and video calls with their communities. 


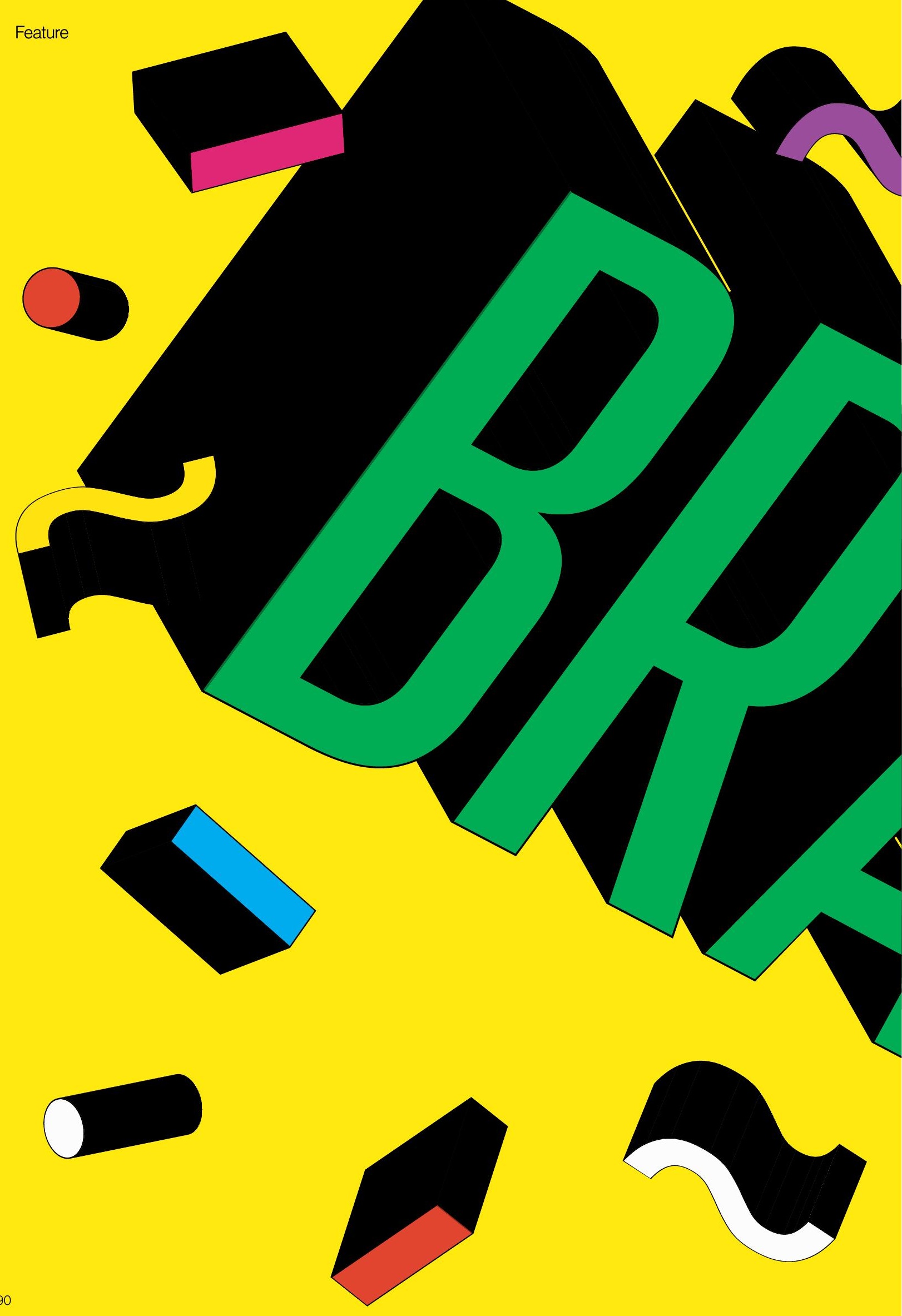




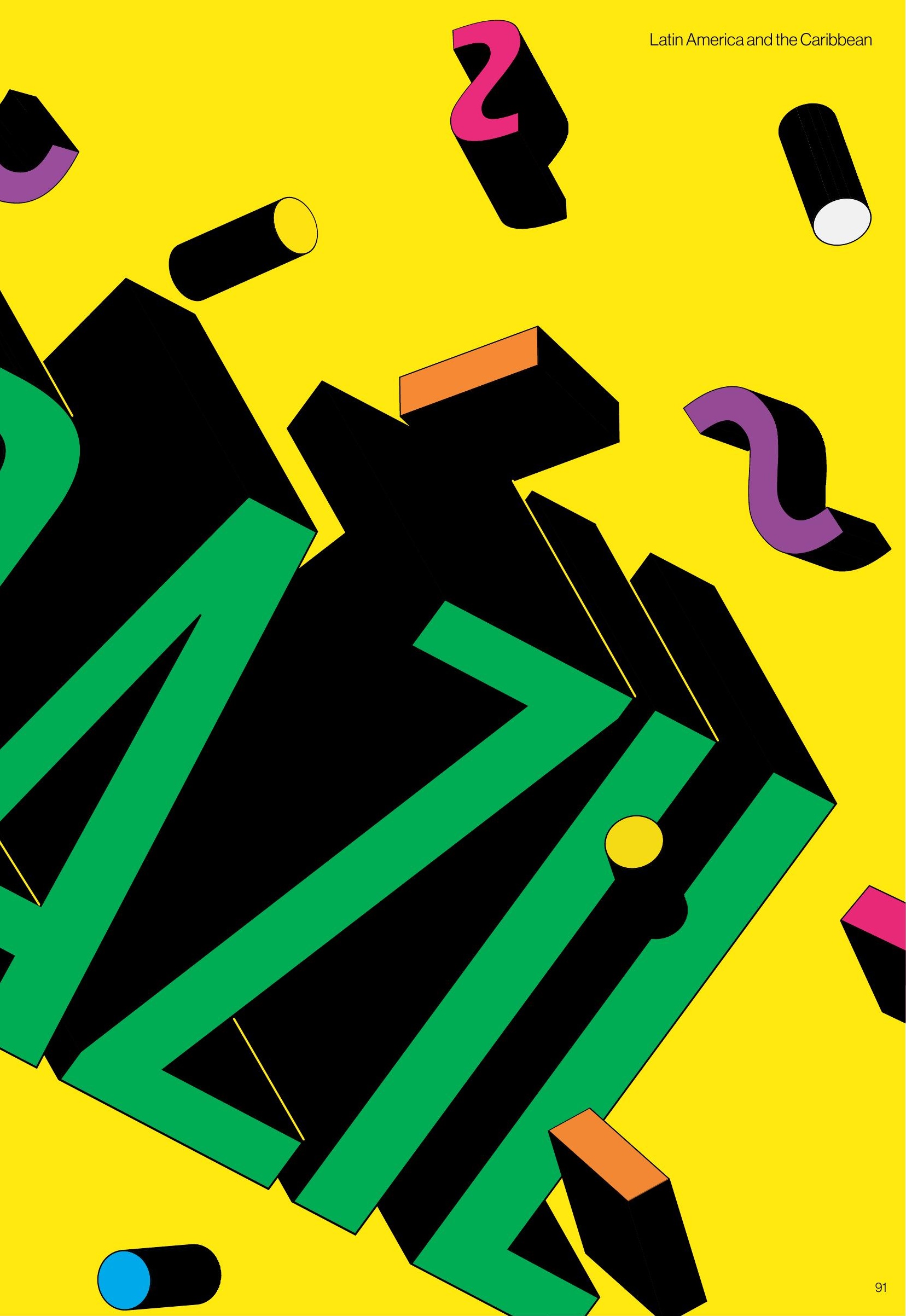


Despite being designated an "aging society" just a decade ago, Brazil is on track to boasting the fifth largest population of seniors in the world by 2030, according to its Ministry of Health. This rapid rate of aging, one of the fastest in Latin America, is driven largely by improved life expectancy and declining fertility rates. Although a series of policies were instituted starting in the 1980 s to protect the rights of older adults, Brazil's relatively youthful demographics have made aging a lower priority for the government in the intervening years. However, with the massive 
demographic shift looming, Brazil is starting to focus more attention on the older population, expanding the scope of public policies in areas such as health, education, employment, and housing. Local governments, such as the state of São Paulo, and NGOs, are championing the creation of age-friendly cities and the concept of "active aging." Public and private sectors are rushing to serve the needs of this growing demographic, particularly in the realm of information and communication technology. 


\section{Aging in Brazil}

\section{Demographic Profile}

1980

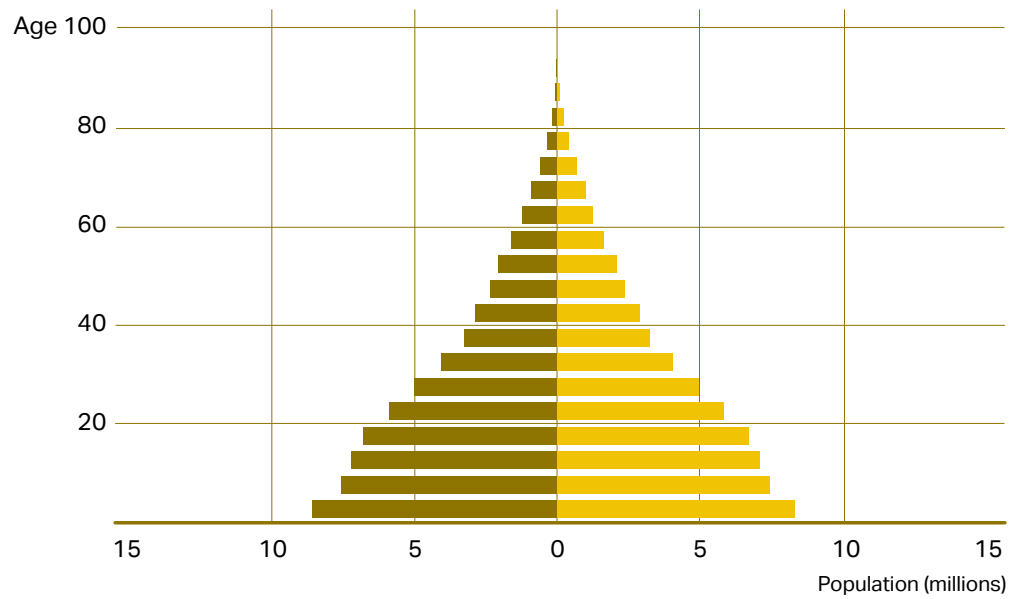

2020

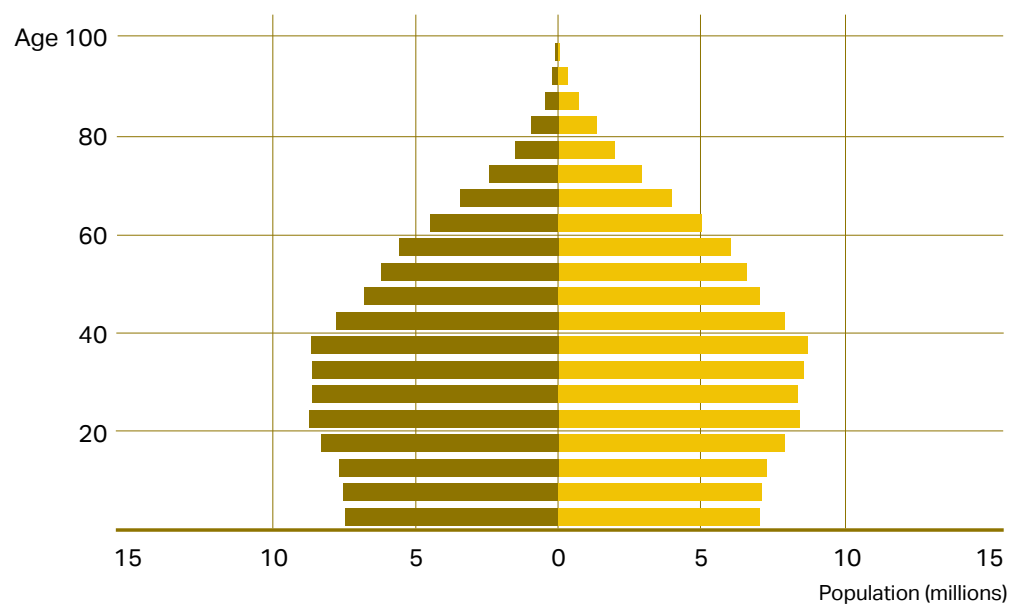

2060

Male

- Female

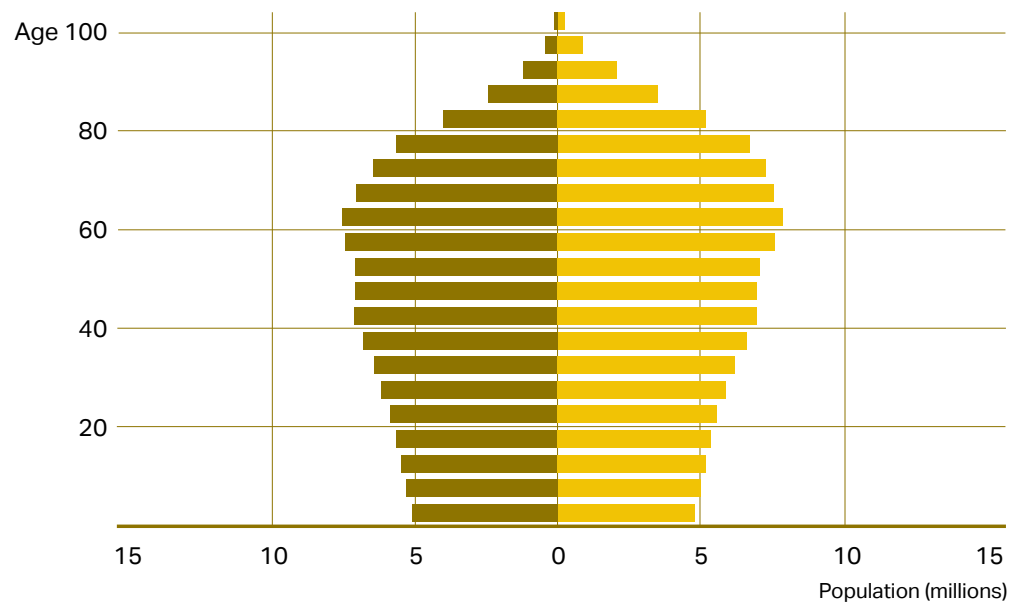



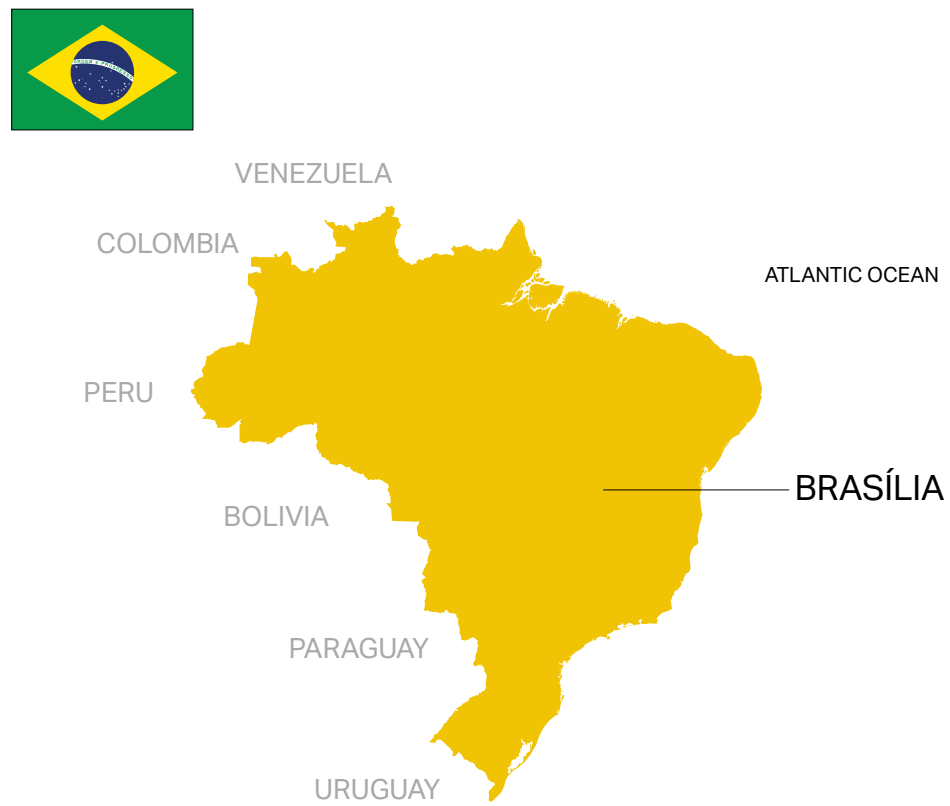

RELIGION

Roman Catholic 64.6\%, other

Catholic 0.4\%, Protestant 22.2\%, other Christian $0.7 \%$, Spiritist $2.2 \%$, other $1.4 \%$, none $8 \%$, unspecified $0.4 \%$ (2010 est.)

NET MIGRATION RATE

-0.13 migrant(s)/1,000 population (2021 est.)

LIFE EXPECTANCY AT BIRTH

Total population: 74.98 years $\left(129^{\text {th }}\right)$

Male: 71.49 years

Female: 78.65 years (2021 est.)

BIRTH RATE

13.44 births/1,000 population (2021 est.)

POPULATION GROWTH RATE

0.65\% (2021 est.)

URBAN POPULATION

$87.3 \%$ of total population (2021)

AGE STRUCTURE

0-14 years: $21.11 \%$

15-24 years: $16.06 \%$

25-54 years: $43.83 \%$

55-64 years: $9.78 \%$

65 years and over: $9.21 \%$

UNEMPLOYMENT RATE

$11.93 \%$ (2019 est.)
GINI INCOME INEQUALITY INDEX (2018) $53.9\left(7^{\text {TH }}\right)$

GENDER INEQUALITY INDEX (2019) 0.408

HEALTH EXPENDITURES

$9.5 \%(2018)$

$22.1 \%(2016)$

LITERACY RATE

93.2\% (2018)

LABOR FORCE BY OCCUPATION

Agriculture: $9.4 \%$

Industry: $32.1 \%$

Services: $58.5 \%$ (2017 est.)

RESIDENT LABOR FORCE

PARTICIPATION RATE

70.9\% (2019 est.)

EXPORTS (US DOLLARS)

$\$ 291.452$ billion (2019 est.)

IMPORTS (US DOLLARS)

$\$ 271.257$ billion (2019 est.)

LANGUAGE

Portuguese (official and most widely spoken language)

*Note: less common languages include Spanish (border areas and schools), German, Italian, Japanese, English, and a large number of minor Amerindian languages
OBESITY RATE
BRAZIL

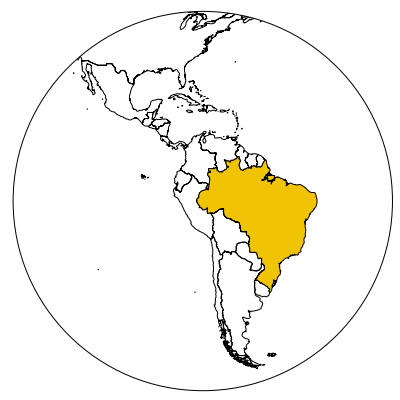

COUNTRY

Brazil

CONVENTIONAL LONGFORM NAME

Federative Republic of Brazil

TOTAL AREA

$8,515,770 \mathrm{sq} \mathrm{km}$

$(3,287,957.2$ sq miles $)$

POPULATION (WORLD RANK) $213,445,417\left(7^{\text {TH }}\right)$

POPULATION DENSITY (WORLD RANK) 26 per sq. $\mathrm{km}\left(188^{\mathrm{TH}}\right)$

DEMONYM

Brazilian

BUDGET (US DOLLARS)

Revenues: $\$ 733.7$ billion

Expenditures: $\$ 756.3$ billion (2017 est.)

GDP NOMINAL (US DOLLARS) $\$ 1.88$ trillion (2019 est.)

MAIN INDUSTRIES

Textiles, shoes, chemicals,

cement, lumber, iron ore, tin, steel, aircraft, motor vehicles and parts, other machinery and equipment

NATURAL RESOURCES

Alumina, bauxite, beryllium, gold, iron ore, manganese, nickel, niobium, phosphates, platinum, tantalum, tin, rare earth elements, uranium, petroleum, hydropower, timber

GOVERNMENT TYPE

Federal presidential republic

ETHNIC GROUPS

White $47.7 \%$, Mulatto (mixed White and Black) $43.1 \%$, Black $7.6 \%$, Asian $1.1 \%$, Indigenous $0.4 \%$ (2010 est.) 


\section{Message Received, Loud and Clear: Pandemic Shows Society Falling Short}

of Statute's Vision

October 1, 2021, marked the 18th anniversary of the enactment of Brazil's Statute of the Elderly, which provides specific rights for those over 60 years old. Development and enactment of the statute is a great achievement of Brazilian society. Its existence is particularly relevant for individuals who were born at a time when aging with dignity, respect, and social protection was a privilege of the few and was not considered to be an important part of the social agenda.

Particularly given that Brazil is home to over 30 million people age 60 and older, ${ }^{1}$ the 18th anniversary of the Statute of the Elderly should be a cause exclusively for pride, celebration, and discussion. However, that is not the current situation. NGOs, politicians, and the media commemorated the date while also warning about the setbacks facing Brazil's social policies for supporting older adults. Senator Paulo Paim, who proposed the law that created the Statute of the Elderly, even noted, "We have to make [the Statute] a reality effectively. It needs to be fully implemented in every municipality in the country." ${ }^{2}$
The pandemic has only exacerbated perennial challenges. As the pandemic continues to send lessons and messages that have long needed to be heard, it is time to ensure that the statute truly becomes a way of Brazilians' everyday life.

\section{System Strain: Hidden Cracks Revealed} Approximately 75 percent of older Brazilians are dependent on the Sistema Único de Saúde (SUS, the National Health Service). ${ }^{3}$ SUS was created by the 1988 Constitution to offer health services to all Brazilians free of charge. This system is also responsible for 


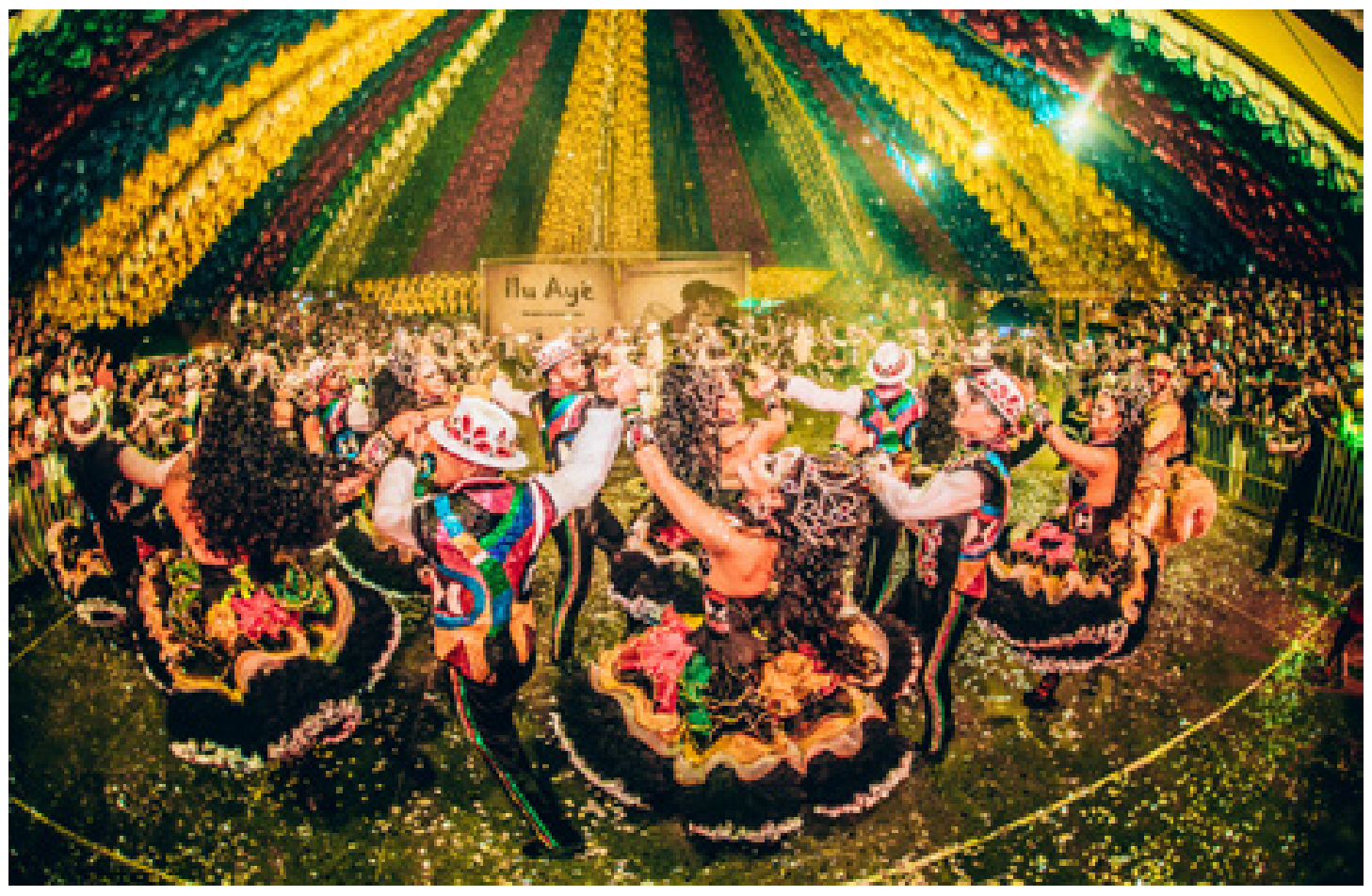

monitoring and improving the health of older adults. When the pandemic struck, its flaws became evident. The SUS could not effectively handle the crisis, nor could it monitor the pandemic on a national level. The public hospital system collapsed in several parts of the country ${ }^{4}$ because of hospital overcrowding, a lack of ICU beds, and a lack of available technicians, nurses, and doctors. ${ }^{5}$ Many previously scheduled in-person surgeries and other medical appointments were cancelled, hindering the treatment of older individuals with chronic health conditions. ${ }^{6}$ Furthermore, most of Brazil's approximately
400,000 Community Health Workers ${ }^{7}$ did not feel adequately trained nor protected to continue working in a pandemic. ${ }^{8}$

Thus, rather than celebrate an anniversary in October 2021, the country did quite the opposite: that month it reached the milestone of 600,000 COVID-19 deaths. ${ }^{9}$ The spatial distribution of COVID-19 deaths was notably impacted by socioeconomic determinants of mortality and the lack of protections for Brazil's most vulnerable older adults. Since the onset of the pandemic, urban communities with lower household incomes, overcrowding, an inability to access 


\section{The cohort of older Brazilians who} transformed the country from a young, rural, agrarian economy to one of the biggest urban and most diversified economies in the world was born roughly midway through the last century, and it plays an important role in Brazilian society today. Around a quarter of
older Brazilians are still working.

work remotely, and limited access to quality health services saw a disproportionate number of deaths. In Manaus, the capital of Amazonas state, the COVID-19 mortality rate for people over 60 years old was approximately three times higher than in São Paulo, the country's wealthiest and most populous city. ${ }^{10}$ As the Thematic Group on Ageing and Public Health from Associação Brasiliera de Saúde Coletiva (ABRASCO, the Brazilian Association of Collective Health) noted, these deaths show how Brazil has never had policies that can effectively protect the wellbeing of older persons in practice. ${ }^{11}$

As deaths from COVID-19 increased among young people, public manifestations of discrimination against older adults became more frequent, despite being illegal. In March 2021, at the height of the COVID-19 crisis in Brazil (approximately 3,500 deaths per day), a popular deputy in the Parliament of the State of São Paulo tweeted, "I care about all lives! But the lives of those who have lived less concern me more. In fact, I think it is time to clearly establish rules to prioritize the use of available resources: beds, respirators, etc. It is not a decision we take lightly, but it is necessary." 12

During the pandemic, reports of physical, psychological and financial abuse of older adults have also increased. In 2019, there were about 48,500 reports of violence against older adults, which accounted for 30 percent of the complaints received by the helpline Disque 100 - a platform run by the federal government that receives reports of human rights abuses. In 2020, reports of aggression against older individuals almost doubled, and in 2021 those reports have continued to grow. ${ }^{13}$

All this comes despite the powerful contributions older individuals have made, and continue to make, to society. In Brazil, economic prejudice against older adults is not only ethically wrong, it is baseless and even in direct contrast to reality. The cohort of older Brazilians who transformed the country from a young, rural, agrarian economy to one 
of the biggest urban and most diversified economies in the world was born roughly midway through the last century, and it plays an important role in Brazilian society today. Around a quarter of older Brazilians are still working. ${ }^{14}$ Almost half of these individuals are also key family breadwinners who support and care for children and grandchildren. ${ }^{15}$

Older adults in Brazil deserve more respect and recognition than they have been given to date. It is their legal entitlement and their human right. The Statue of the Elderly provided hope that the nation could achieve great progress. The 20th Anniversary will arrive in 2023. To make that two-decade milestone truly meaningful, we can listen to what the pandemic told us in blaring volume. We can put the statute's tenets into practice in everyday life.

\footnotetext{
${ }^{1}$ https://agenciadenoticias.ibge.gov.br/ agencia-noticias/2012-agencia-de-noticias/ noticias/20980-numero-de-idosos-cresce-18-em-5anos-e-ultrapassa-30-milhoes-em-2017

${ }^{2}$ https://pt.org.br/paim-estatuto-do-idoso-trouxe-luz-a-populacao-esquecida/ ${ }^{3} \mathrm{https} / / /$ portal.fiocruz.br/noticia/estudo-aponta-que-
75-dos-idosos-usam-apenas-o-sus

${ }^{4}$ https://portal.fiocruz.br/sites/portal.fiocruz.br/files/ documentos/boletim_extraordinario_2021-marco-03.pdf

${ }^{5} \mathrm{https} / / / \mathrm{www}$.nexojornal.com.br/expresso/2021/03/16/Como-a-precariedade-hospitalarimpulsiona-as-mortes-por-covid
}

\footnotetext{
${ }^{6} \mathrm{https} / / /$ www.gov.br/cnpq/pt-br/assuntos/noticias/ destaque-em-cti/pesquisas-apoiadas-pelo-cnpqestudam-a-saude-fisica-e-mental-dos-idosos-emtempos-de-pandemia
}

${ }^{8} \mathrm{https} / / /$ portal.fiocruz.br/sites/portal.fiocruz. br/files/documentos/os_agentes_comunitarios_de_saude_e_a_pandemia_da_covid-19_nas_favelas_do_brasil.pdf

${ }^{9}$ https://covid.saude.gov.br/

${ }^{10} \mathrm{https}: / /$ www.scielo.br/j/csp/a/

BSdNnmSRWRxf9hZsx7CWB5Q/

"https://www.scielo.br/j/rbgg/a/ pQvWz8j4JZx8B7PL984MHrQ/?lang=en\#

${ }^{12} \mathrm{https} / / /$ twitter.com/janainadobrasil/status/13758834 84271624192?lang=en

${ }^{13} \mathrm{https}$ ///agenciabrasil.ebc.com.br/direitos-humanos/ noticia/2021-06/aumentam-casos-de-violencia-contra-pessoas-idosas-no-brasil

${ }^{14}$ https://www.icict.fiocruz.br/content/ pesquisa-aponta-que-mais-da-metade-dos-idosos-sem-v\%C3\%ADnculo-empregat\%C3\%ADcio-perdeu-renda-durante

${ }^{15} \mathrm{https} / / /$ www.ipea.gov.br/portal/index. php?option=com_content\&id $=36188$

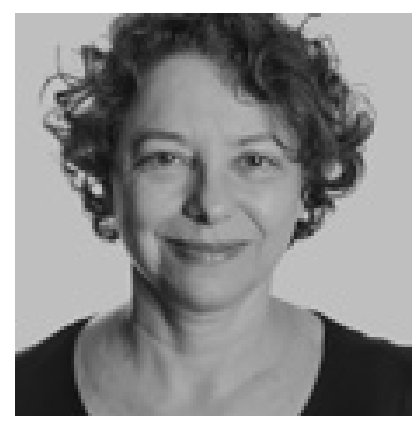

MARCIA SCAZUFCA

Scientific Researcher, Instituto de Psiquiatria Universidade de São Paulo 


\section{Day in the Life}

\section{Sheila Christina Monte Santo de Pinho Cardoso}

\section{Salvador}

68 years old

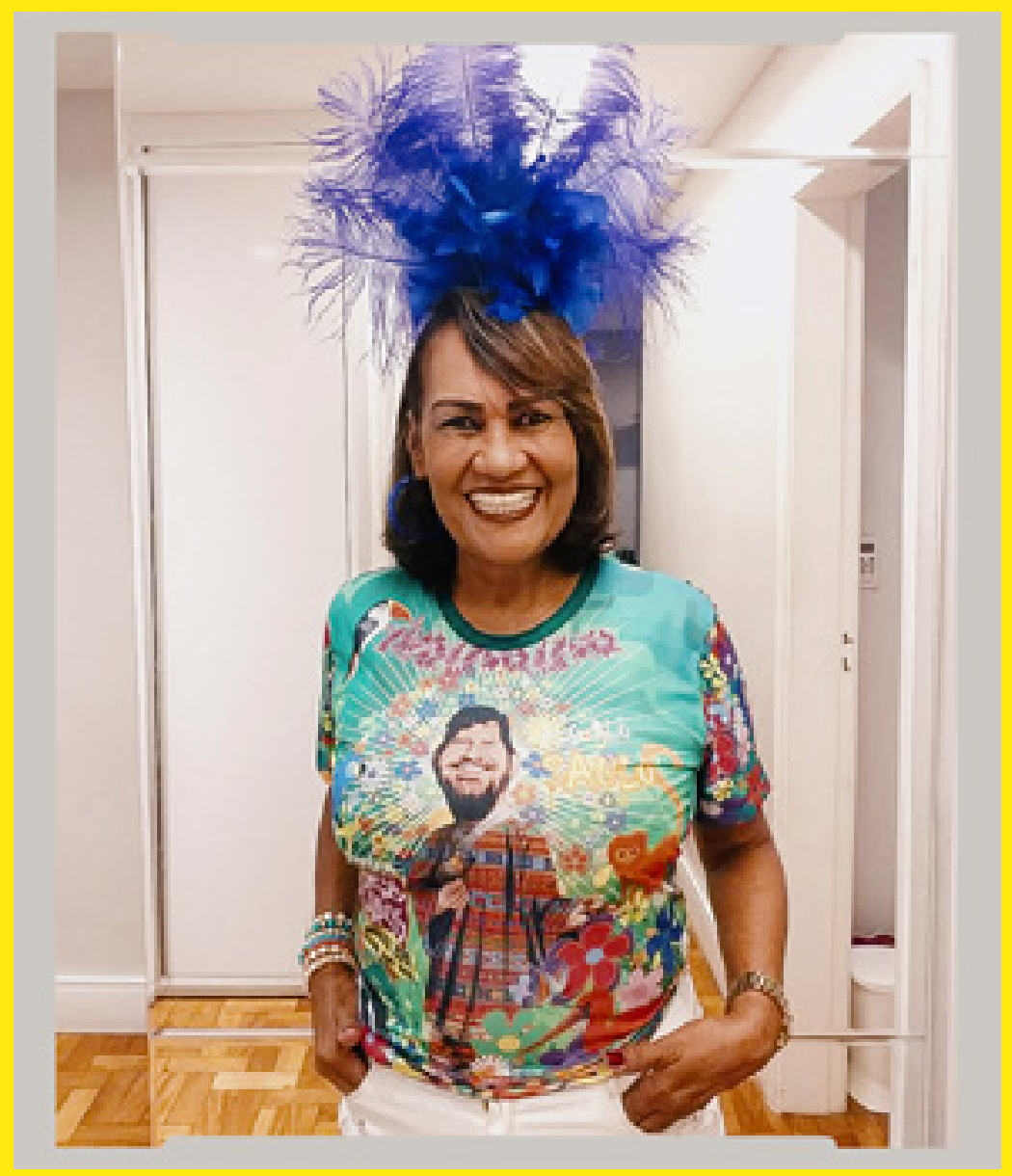

Sheila is a Public Service Administrative Technician in Salvador, the capital city of the state of Bahia in northeastern Brazil. She lives alone, but fills her free time with volunteer work, cooking, meditation, and visiting with friends and family. 


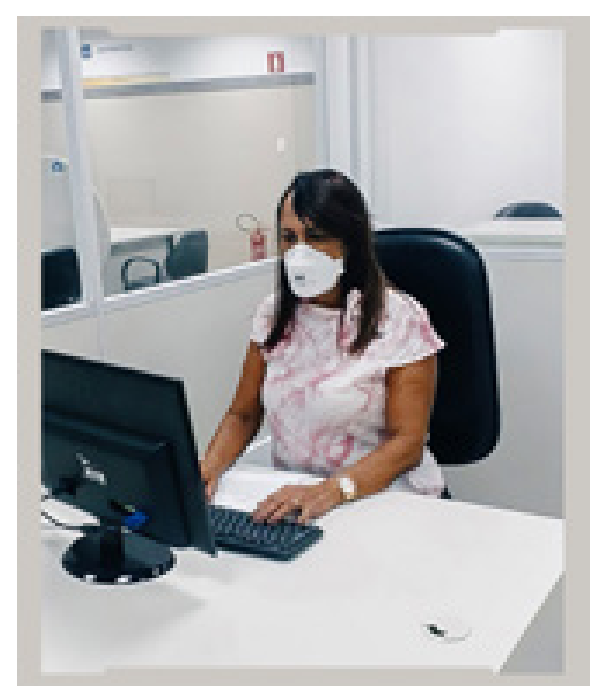

In the office

\section{What is your typical day like?}

I wake up at 6 in the morning and the first thing I do is thank God for granting me another day. Next, I take the first shower of the day, which gives me more energy to complete my daily activities. After I get dressed, I head straight to the kitchen where I have breakfast and then go to work. I always get to work at 8 a.m. and start performing my activities together with my team. I finish at 5 p.m.

Due to the quarantine, activities that were part of my daily life, such as having lunch with colleagues, going to the gym, or happy hour on Fridays were no longer possible, forcing me to change these habits.

In the evening, when I get home, I make lunch for the next day, watch Jornal Nacional to see what's going on around the world, call the kids, get on social media and read before going to bed. I always go to bed at 10 p.m. while listening to relaxing music. On Saturdays I go to the supermarket and beauty salon, chat with friends, spend time with family, et cetera. Sundays are all reserved for me, too!
Describe your living arrangements. Do you live alone or with family?

I live alone. One of the biggest advantages of living alone is the freedom to wake up and go to bed whenever you want, to go out and come home whenever you want, and to have friends over, among other things. All of this gives you an indescribable feeling of freedom. One thing that bothers me about living alone is the loneliness and not having anyone to talk to.

\section{How do you stay physically active?}

In a variety of ways: cleaning the house, organizing my drawers, preparing meals, walking up the stairs at work three times a day. I take the bus and subway from home to work and vice versa on weekdays and I attend religious services in the evening.

How do you stay mentally and socially active? Social isolation does not define me. Life is a series of changes. Therefore, we need to rely on our resilience at various stages of life. I keep my self-esteem up, think positive thoughts, and the joy of having my children and grandchildren keeps me moving forward.

\section{What do you find most challenging about growing older?}

Getting older also means changes and often losses, as well as gains, such as: retirement, widowhood, an empty nest, assuming roles like being a grandparent, as well as having to live with losing your independence and suffering from certain illnesses. With the support of family members, the elderly will feel more loved and willing to face their daily lives. 
Sheila Christina Monte Santo de Pinho Cardoso

Salvador

68 years old

"Social isolation does not define me. Life is a series of changes. Therefore, we need to rely on our resilience at various stages of life. I keep my self-esteem up, think positive thoughts, and the joy of having my children and grandchildren keeps me moving forward."

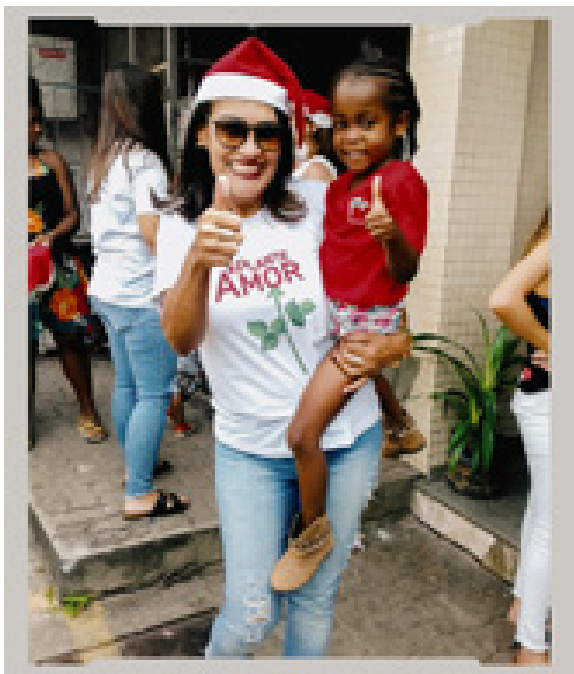

At a volunteer event with Brazilian NGO Seja Semente

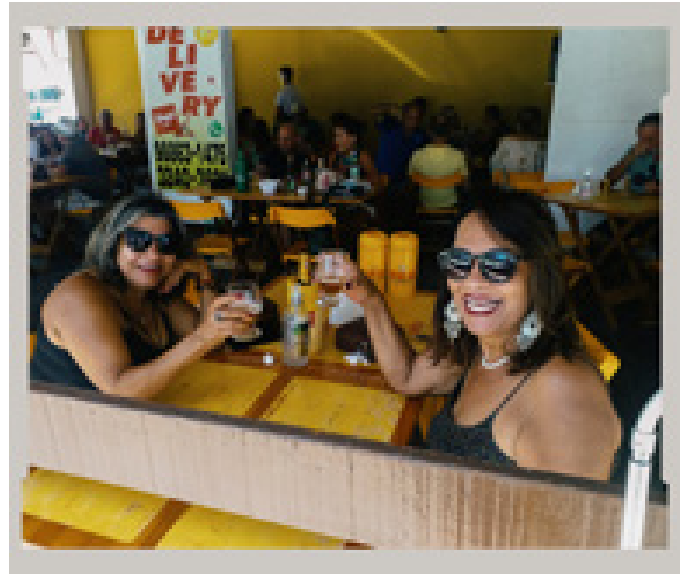

Out for drinks with a friend

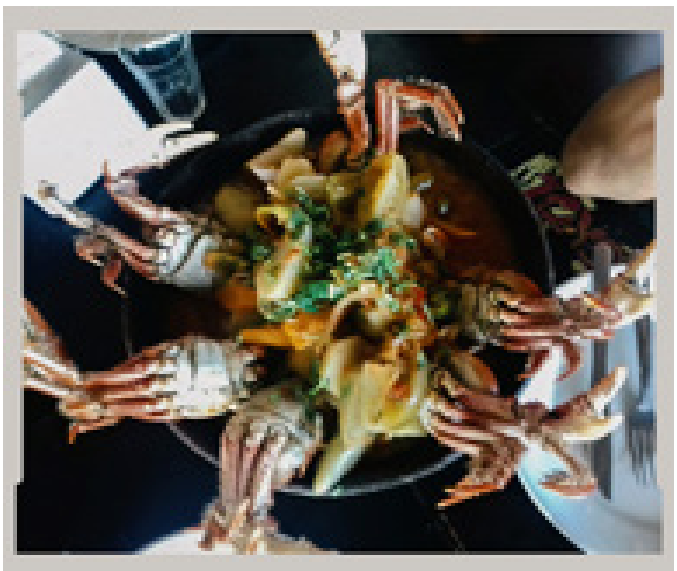

Crab stew, a traditional Brazilian dish, prepared by Sheila

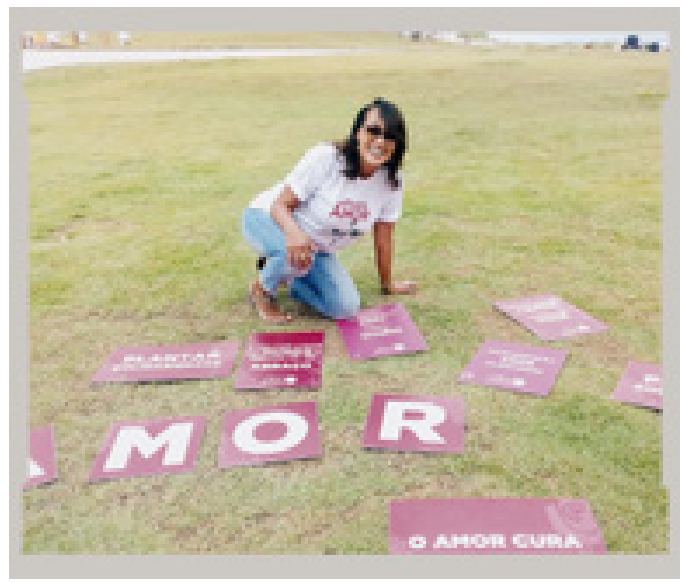

At a volunteer event 


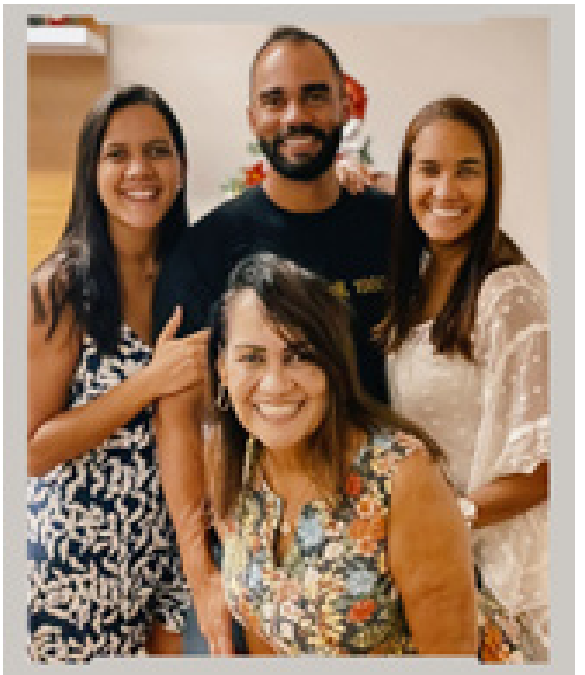

Sheila surrounded by her children

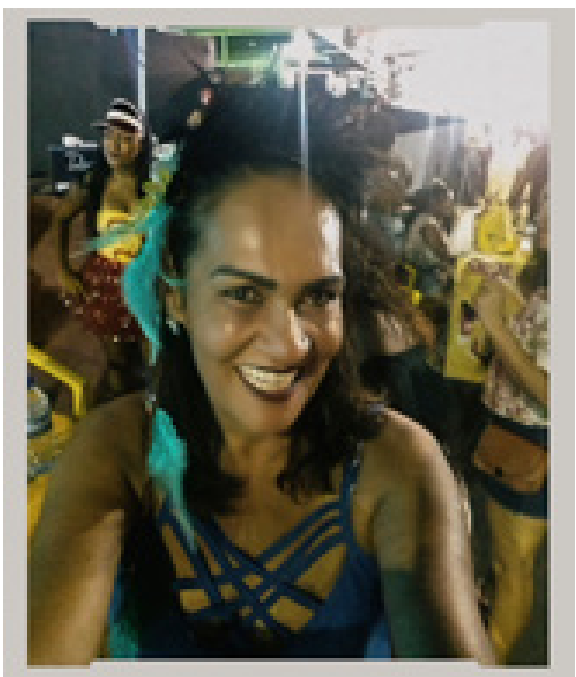

Attending a Carnival street party

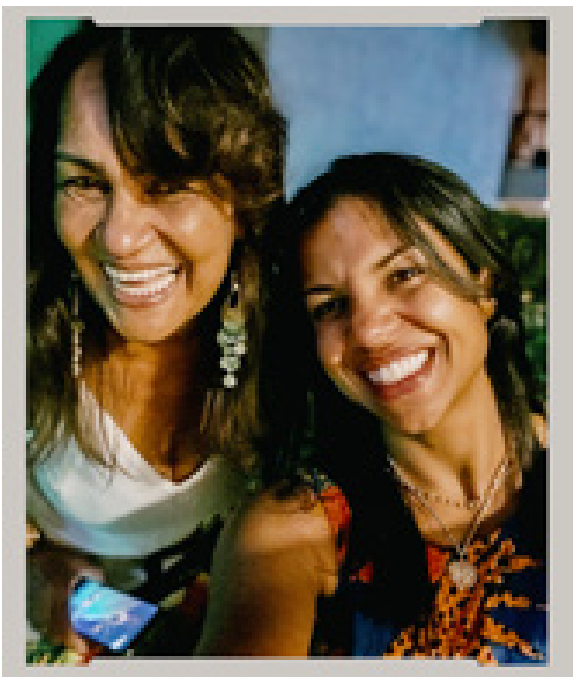

Sheila and her niece, Geneza

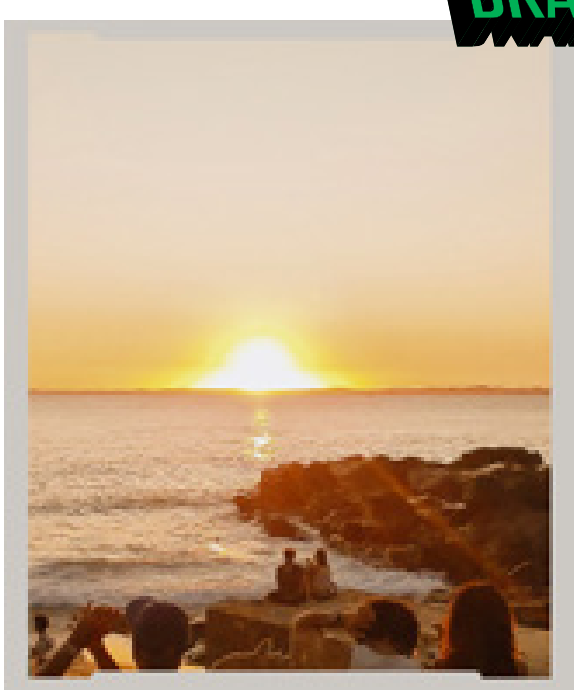

Sunset at the beach where Sheila often goes

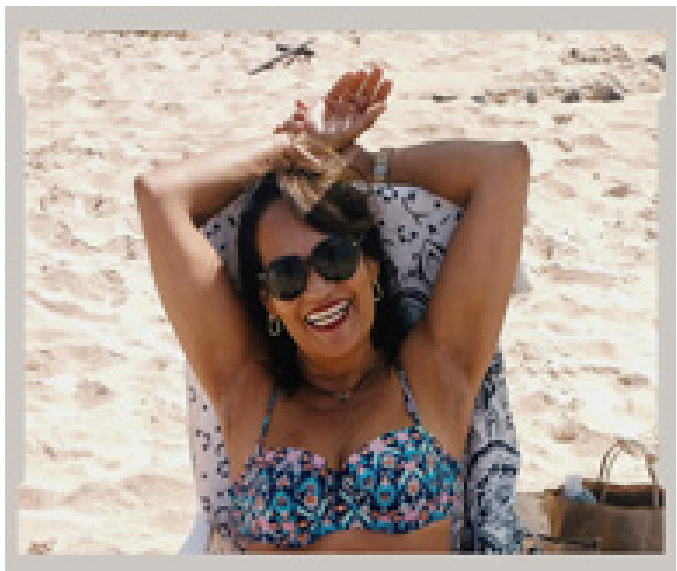

Enjoying the sunny weather at a beach near her home

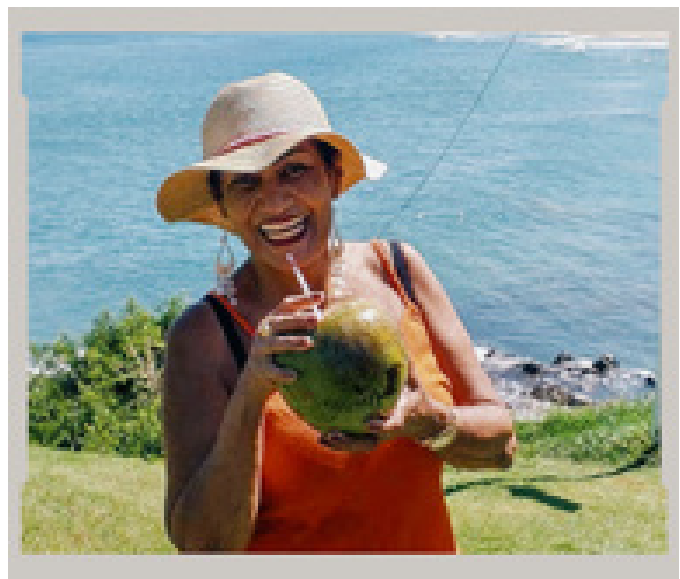

Drinking coconut water after a walk 


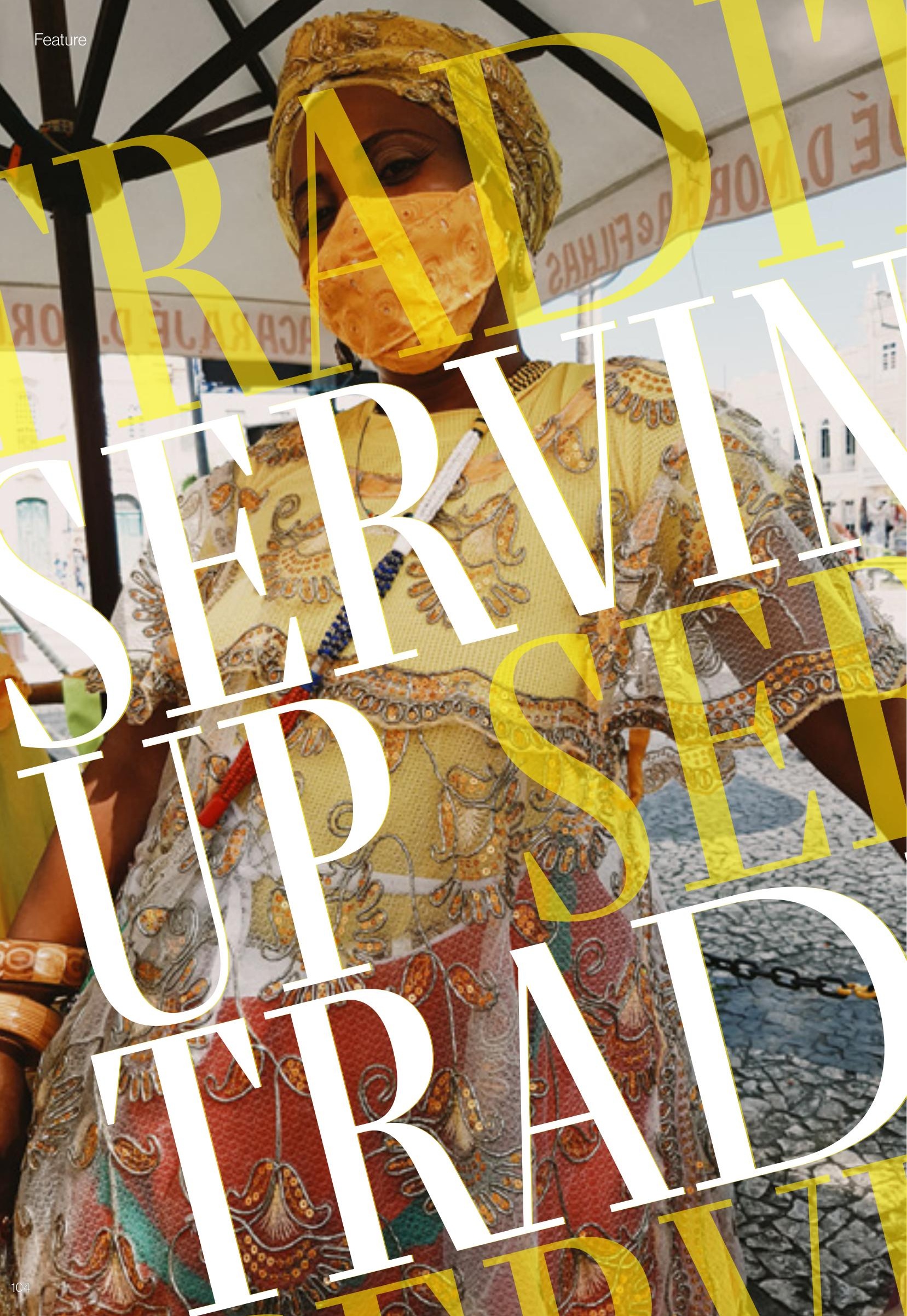





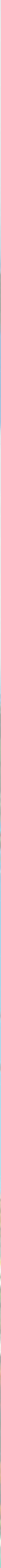


The aroma of palm oil attracts those who walk around Salvador, the capital of Bahia, a state located in Northeastern Brazil. It is the ingredient used to fry acarajés-black-eyed bean and onion fritters that have been sold on the streets by women known as the Baianas de Acarajé for centuries. The number of Baianas de Acarajé is not clear, as official statistics are inconsistent. Estimates put the number around 7,000 Baianas living in Bahia, most of whiom are over 50 years old and are based the the tourist city of Salvador.
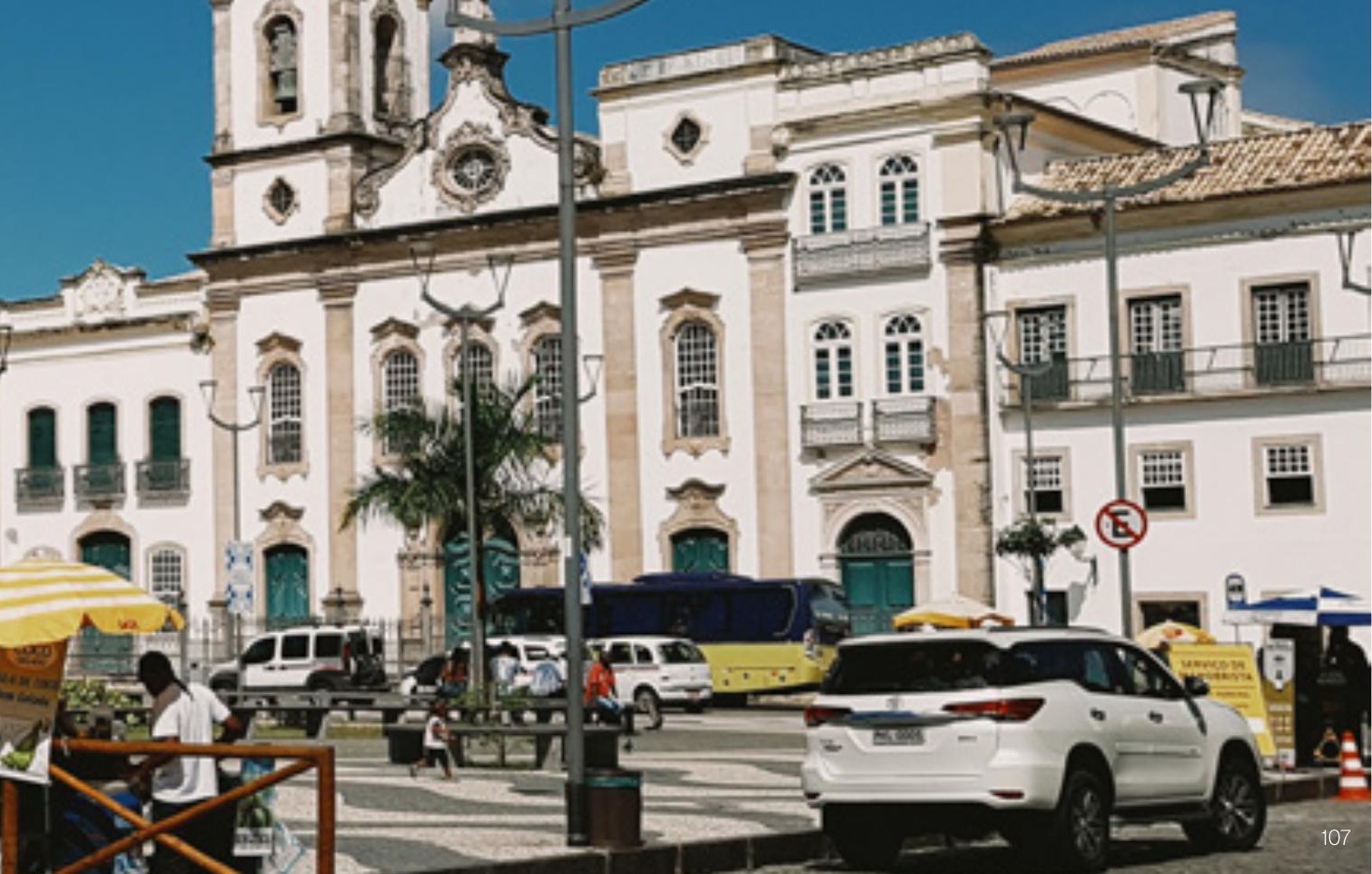
These women usually wear voluminous skirts, smocks, turbans, and colorful, beaded necklaces and are portrayed in sculptures throughout Salvador. Their craft was designated a cultural heritage of Brazil in 2005 by IPHAN (National Historical and Artistic Heritage Institute). Seven years later, the IPAC (Institute of Artistic and Cultural Heritage of Bahia) registered the work of the Baianas de Acarajé as an intangible heritage of Bahia.

The financially tenuous nature of the job (made worse by the ongoing COVID-19 pandemic), combined with an aging workforce, makes the future of the Baianas de Acarajé uncertain. However, intergenerational knowledge sharing, some government-funded initiatives, and the work of the Baianas de Acarajé Association have helped to strengthen and preserve this unique example of Brazilian culture.

West African slaves first brought acarajés to Brazil between the 16th and 19th centuries. In the new country, enslaved and manumitted women walked the streets selling acarajé. The name acarajé is composed of two words from the African Yoruba language - "akará," meaning fireball, and "je," to eat. In the Afro-Brazilian Candomblé religion, acarajé is a sacred food offered to lansã, Xangô's wife, both Candomblé deities known as orixás.

The Baianas' craft is usually taught at home. An example is Dulce Mary de Jesus, age 50. The great-granddaughter of a Baiana de Acarajé, who displays her delicacies on social media, proudly says that she started going to the stand in "mainha's belly," "mainha" being an affectionate nickname given to mothers in Bahia.

De Jesus learned to cook by helping her mother, but since 1992 she has had her own tent in Praça da Sé, a square located in the

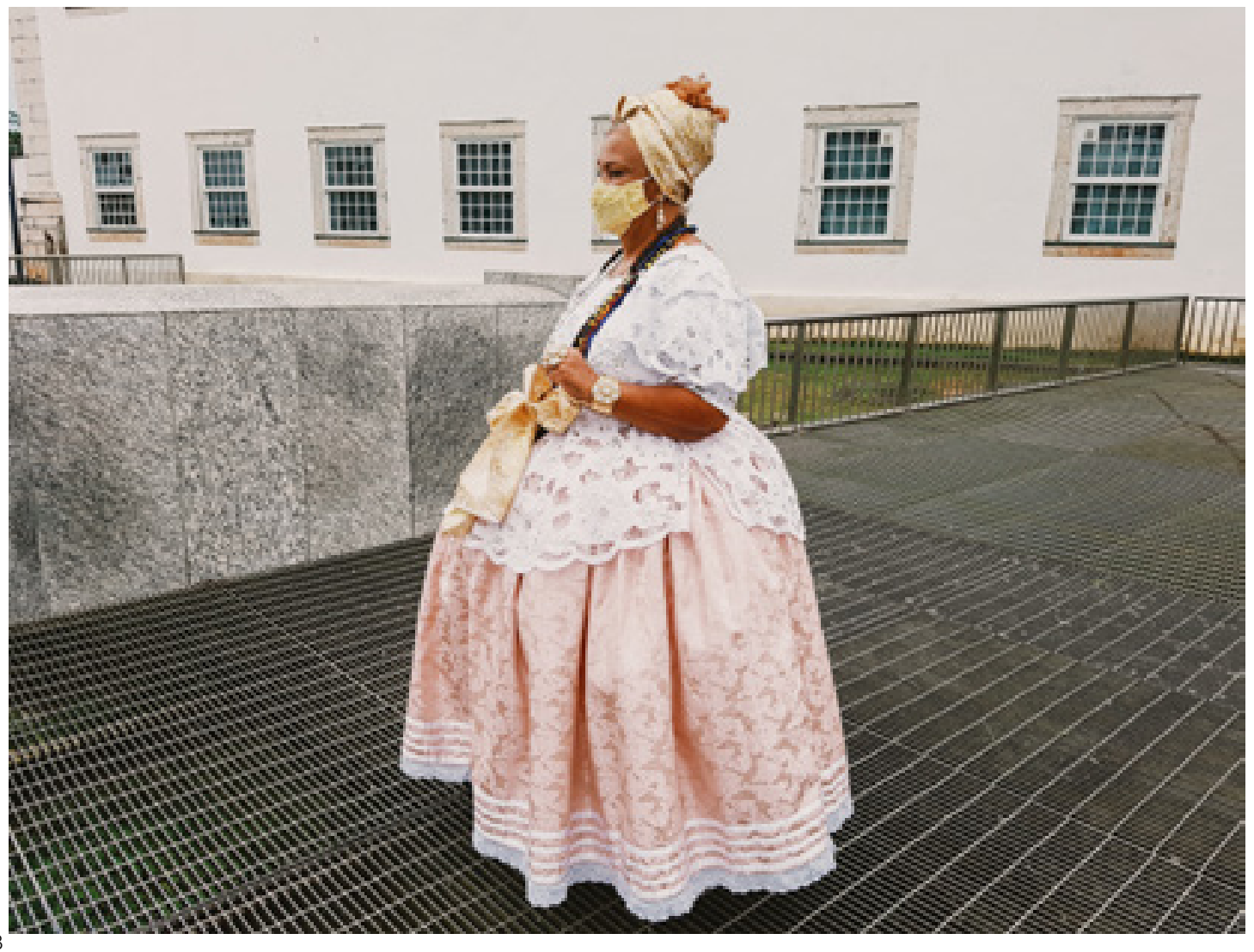


historic center of Salvador. "I love to be a Baiana. I think our culture is beautiful," says Jesus. De Jesus's mother is 72 years old and works alongside her daughter. Currently, she doesn't go to the stand but cooks from home. In de Jesus' tent, decorated with pictures of herself with famous Brazilians, she also sells other typical delicacies. Besides acarajé there are abará (another offering for orixás); cocada, a coconut and sugar candy; and bolinho de estudante ("student cake"), a sweet made with coconut and a starch extracted from cassava called tapioca, fried in oil, and sprinkled with sugar and cinnamon. It is said that the candy received this name because the smell attracted many students to the Baianas tents. Other Baianas also sell tamarind sweets, fried fish, and passarinha (bovine spleen).

Cristiane Santos, 47, is another Baiana de Acarajé who is proud to continue the family tradition. "When I'm preparing my goods, I feel so happy. I feel great pride in being a Baiana de Acarajé," says Santos.

Santos works with two sisters in Terreiro de Jesus, another square in the historical center. They learned the craft from their mother Norma, 83. Santos says that her grandmother Irene, who is now 108 years old, started working with acarajé back when women walked the streets selling food from a basket on their heads. Santos does not know the exact period, but it was during the time when acarajés were served with only a chili pepper sauce and palm oil.

It is said that the first stuffed acarajé dates back to the 1950s in Salvador. Today, acarajé is stuffed with vatapá, a puree whose main ingredients are ginger, peanuts, and palm oil; caruru, an okra stew with dried shrimp and palm oil; whole dried shrimp; and tomato salad.

A view looking out at Bay of All Saints, with Elevador Lacerda on the left, a public elevator that carries people between the upper city and lower city.

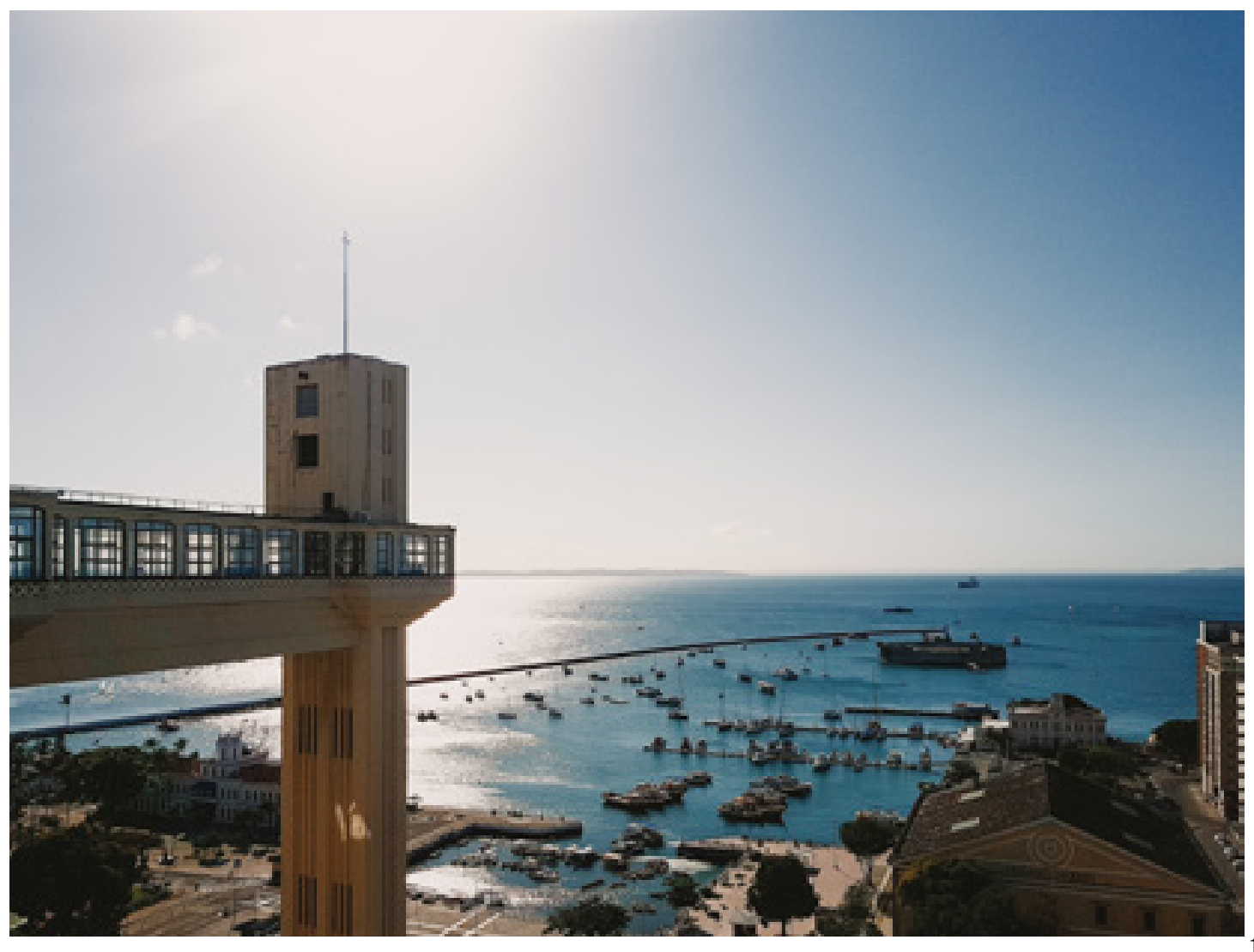


Feature

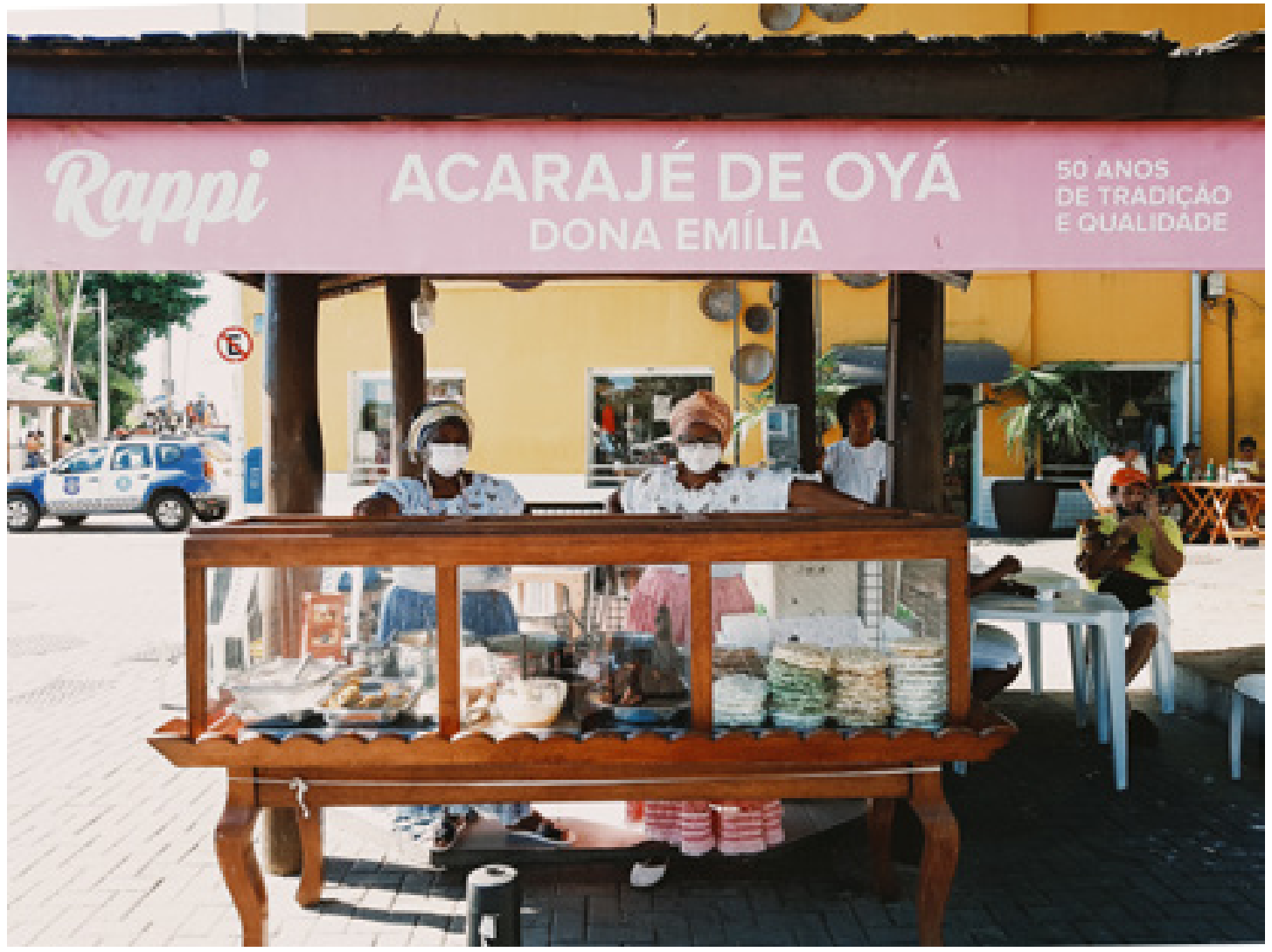

Maria Emília Bittencourt (left) selling acarajé with one of her daughters in the Barra neighborhood of Salvador 



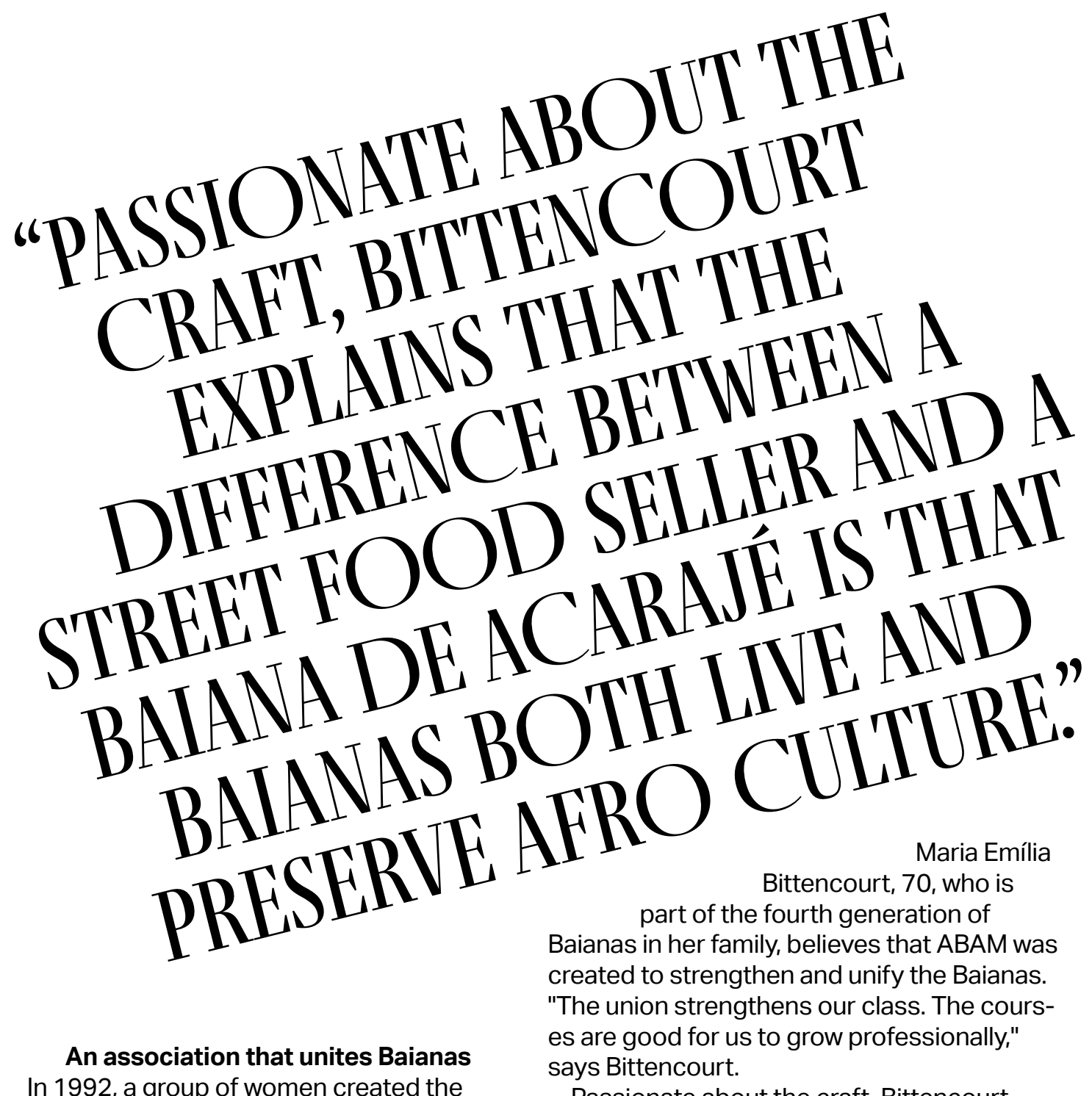

In 1992, a group of women created the Association of Baianas de Acarajé and Mingau (ABAM) to train Baianas, advocate for their rights, and preserve their traditions. The organization, for example, enforces traditional standards. They have resisted the demands of a small subset of evangelical women to change the name of the acarajé to "Jesus fritters," arguing that the name runs counter to the Candomblé origins of the delicacy. In 2014, ABAM went head-to-head with FIFA (International Football Federation) to insist that Baianas be allowed to sell acarajé inside the Fonte Nova stadium like other vendors during the World Cup that took place in Brazil. And the organization also advocates for training opportunities to help the Baianas learn to manage their own businesses.

Passionate about the craft, Bittencourt explains that the difference between a street food seller and a Baiana de Acarajé is that Baianas both live and preserve Afro culture. A mother of seven children, she taught everyone how to cook acarajé. Two of her daughters have since become Baianas de Acarajé and work in the tent located in Barra, Salvador's touristic neighborhood.

In addition to uniting women like Bittencourt, ABAM created the Memorial das Baianas, a museum dedicated to preserving the history of the Baianas. During the COVID-19 pandemic, the organization partnered with the cultural group Ska Reggae to carry out the project "Stories, Memories and Collections of the Memorial 
of Baianas de Acarajé." This project received nearly $\$ 76,500$ in funding as a result of the Adir Blanc Law, which granted emergency financial aid from the Brazilian Federal Government to protect the cultural sector during the pandemic.

The organization also used the funding to create a course called "Reproduction of Knowledge, Practices, and Identity." According to cultural producer Luana Oswaldo, 51, the course, which demands both physical attendance and online involvement, has benefited 300 Baianas de Acarajé aged 23 to 85 years old in more than 20 cities in Bahia. Participants took classes on topics including cultural heritage, logistics, customer service, food management, tourism, and women's empowerment.

Claudete de Souza, 63, resident of Vera
Cruz, a city near Salvador, participated in the course. She particularly enjoyed learning how to cater to tourists. "I have always served my clients very well, but with the course, I could improve more," says Souza, who learned how to cook acarajé with her aunt and has a 31-year-old daughter who follows the same career.

Another Vera Cruz resident benefiting from the project is former teacher Jucelia da Silva, 56 . She learned how to make acarajé with her mother-in-law and with her sisters-in-law. Silva's mother-in-law comes from a family that has been selling acarajé for five generations. Silva believes that constant learning is important. A frequent participant in ABAM courses, she learned a lot about logistics in this most recent course.

The project financed by the Adir Blanc

Maria Emília Bittencourt, 70, a fourth generation Baiana de Acarajé

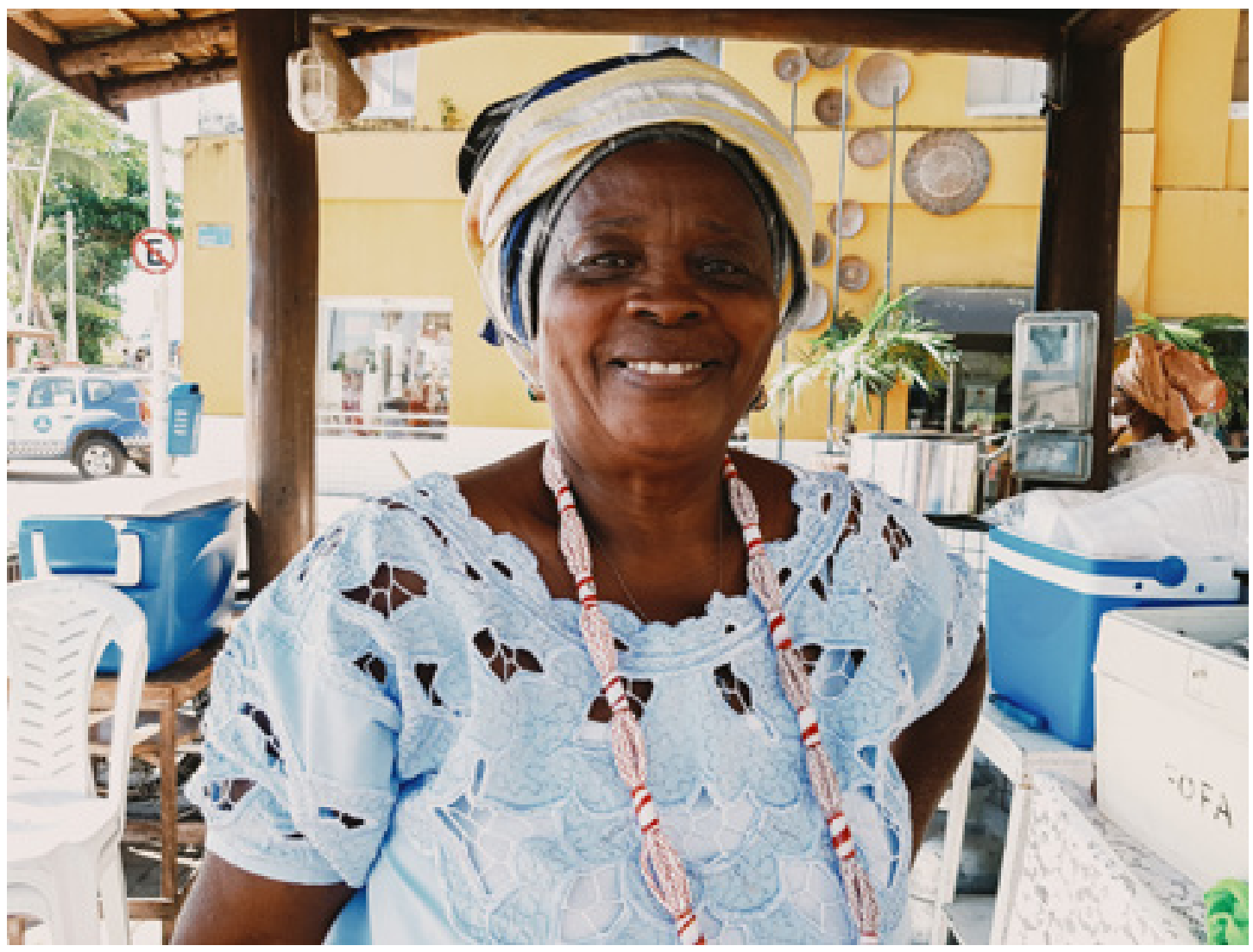


Law has also enabled the construction of a virtual museum and the production of a documentary on palm oil. The movie highlights the lack of government investment to modernize palm oil plantations, which has reduced the product's supply in the market and made it more expensive. Rita Santos, 64 , current president of the ABAM, points out that without palm oil there is no acarajé.

For Vanessa Castanheda, a postdoctoral fellow in

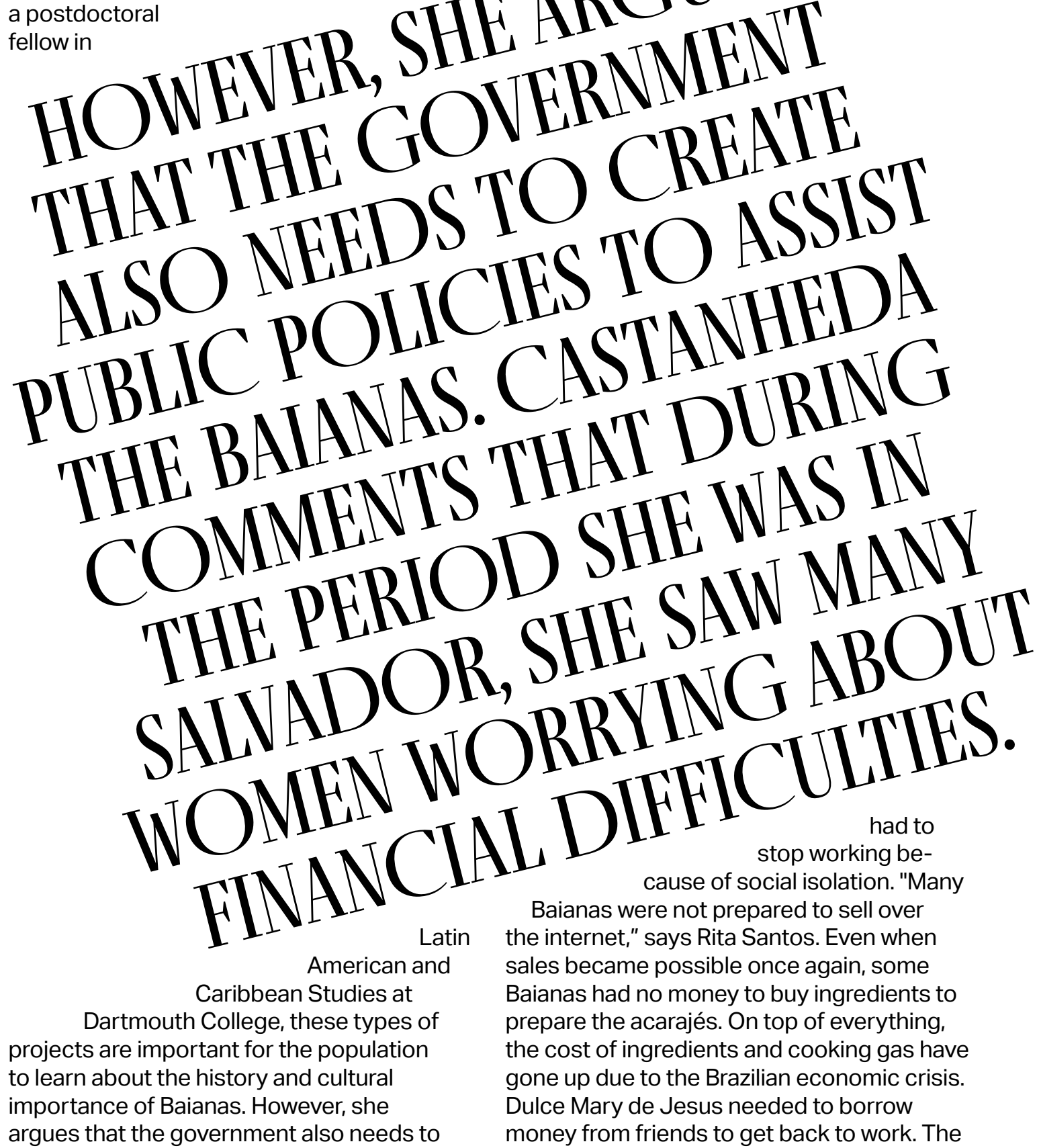

create public policies to assist the Baianas. Castanheda comments that during the period she was in Salvador, she saw many women worrying about financial difficulties.

The problems were reinforced during the pandemic when vendors 


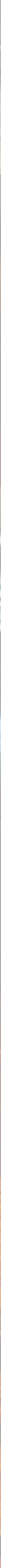


financial aid granted by the local government was insufficient and did not benefit all Baianas.

According to the press office of the mayor of Salvador, 120 Baianas de Acarajé were able to receive the "SOS Cultura," a municipal financial benefit created during the pandemic to help professionals in the cultural area. One of the rules for receiving the funding (equivalent to approximately $\$ 200$ USD) was to work in the historic center and be registered with the Municipal Department of Culture and Tourism.

Given the problems faced by this aging working-class, the question arises as to whether the craft of Baianas de Acarajé will survive. However, Vagner Rocha, a doctoral student in Ethnic and African Studies at the Federal University of Bahia, believes that it is impossible for such a culture to vanish. According to Rocha, the entire family nucleus is involved in the production of acarajés, which ensures that there is always someone with the knowledge to continue the tradition. In addition, there is a demand for acarajés, not only from tourists but from the local population too.

"We cannot forget our African roots. Besides, acarajé is a source of income for us matriarchs," says Jucelia da Silva, who reports feeling like a queen on her throne when she sells her acarajés on Duro beach in Vera Cruz.•

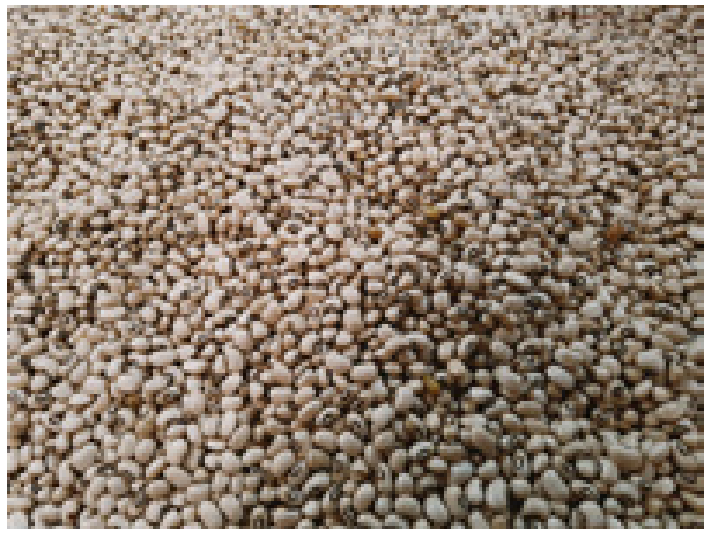

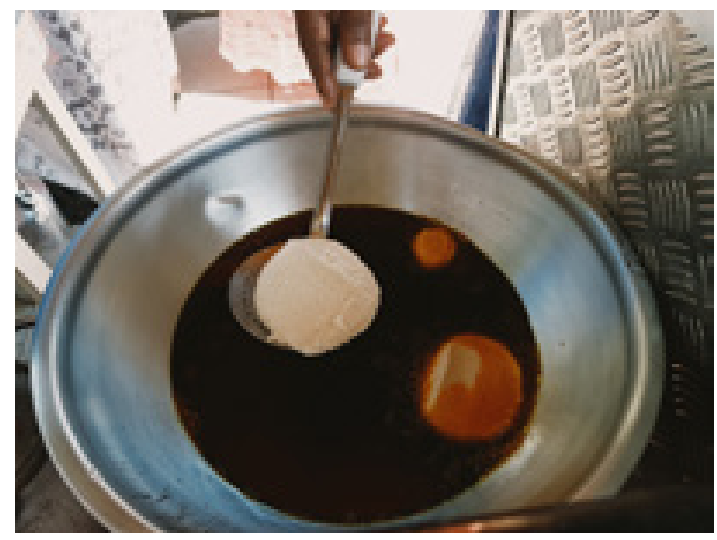
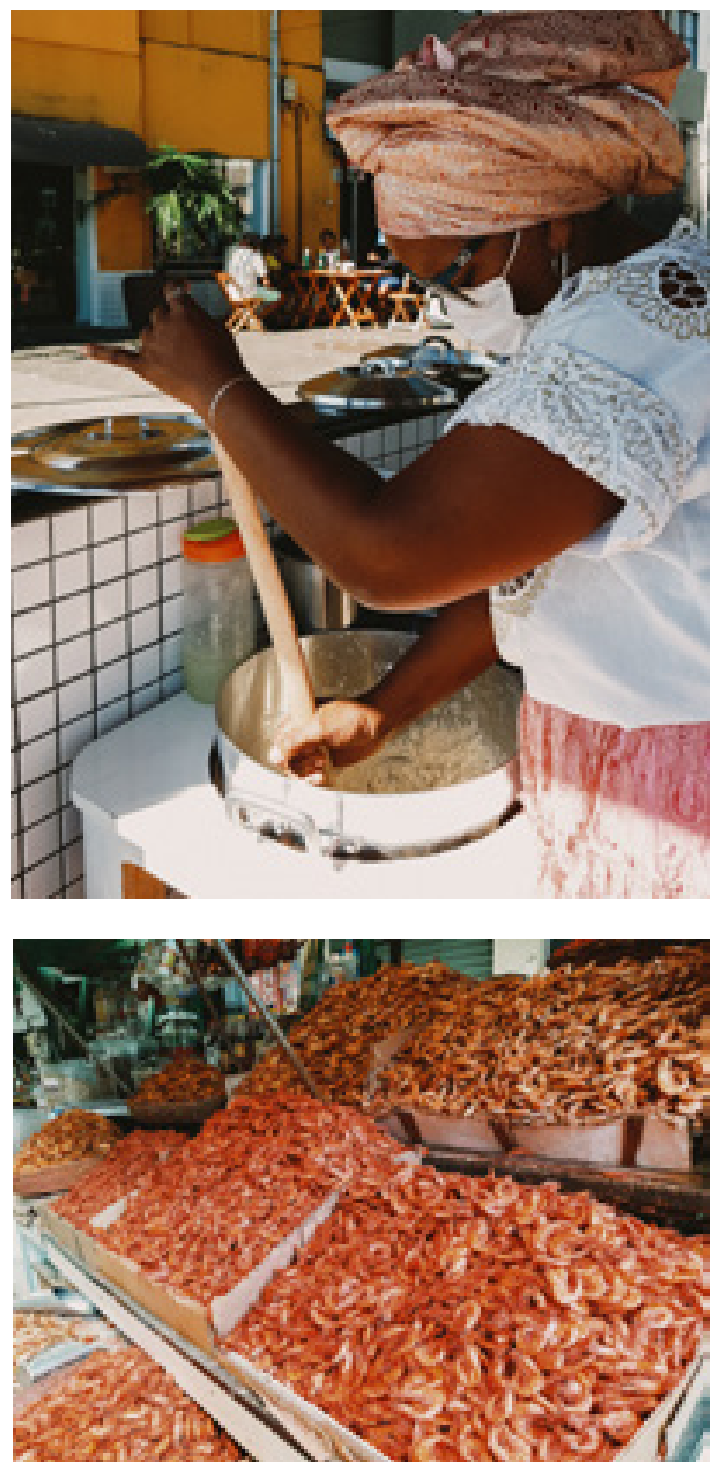

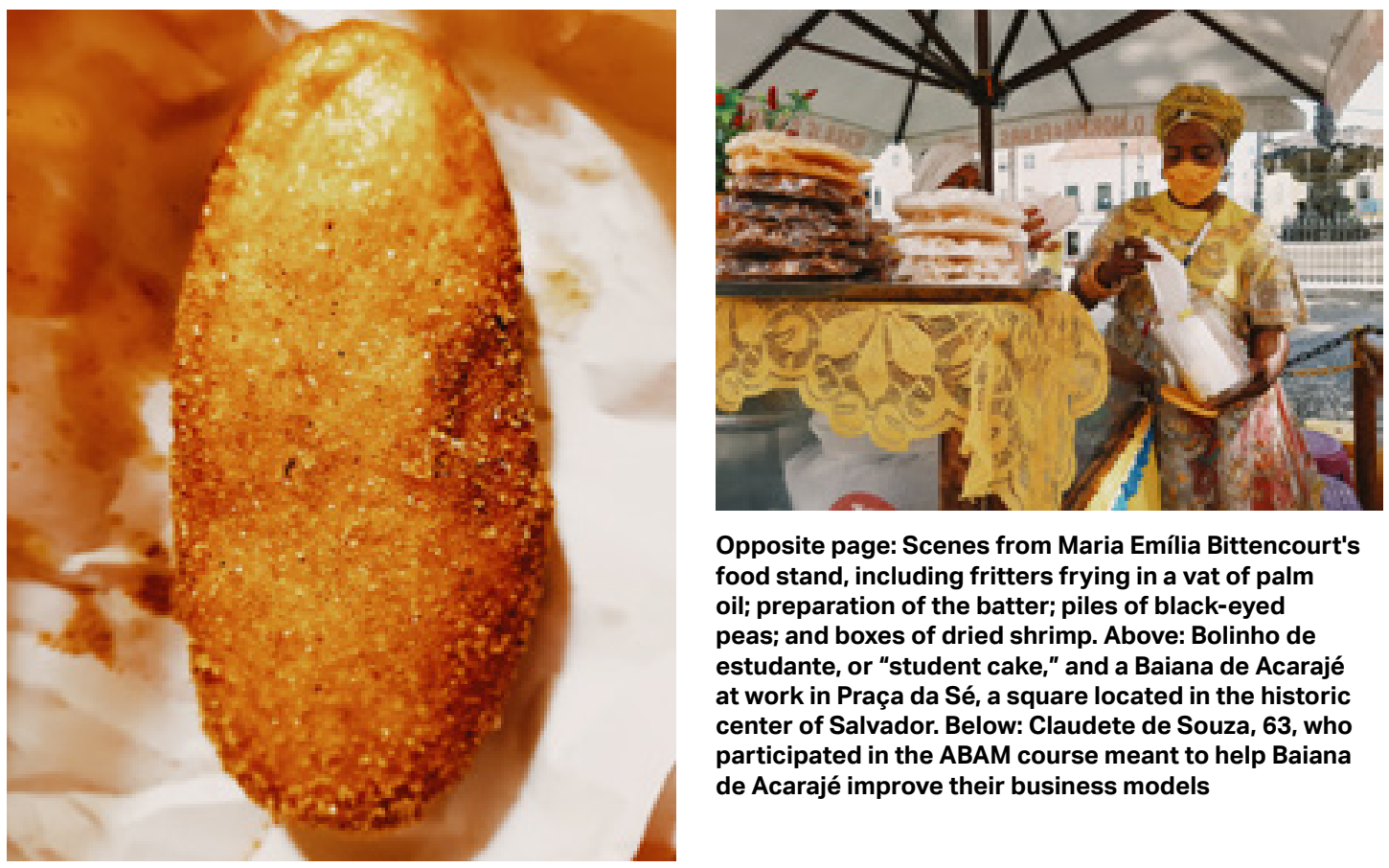

Opposite page: Scenes from Maria Emília Bittencourt's food stand, including fritters frying in a vat of palm oil; preparation of the batter; piles of black-eyed peas; and boxes of dried shrimp. Above: Bolinho de estudante, or "student cake," and a Baiana de Acarajé at work in Praça da Sé, a square located in the historic center of Salvador. Below: Claudete de Souza, 63, who participated in the ABAM course meant to help Baiana de Acarajé improve their business models

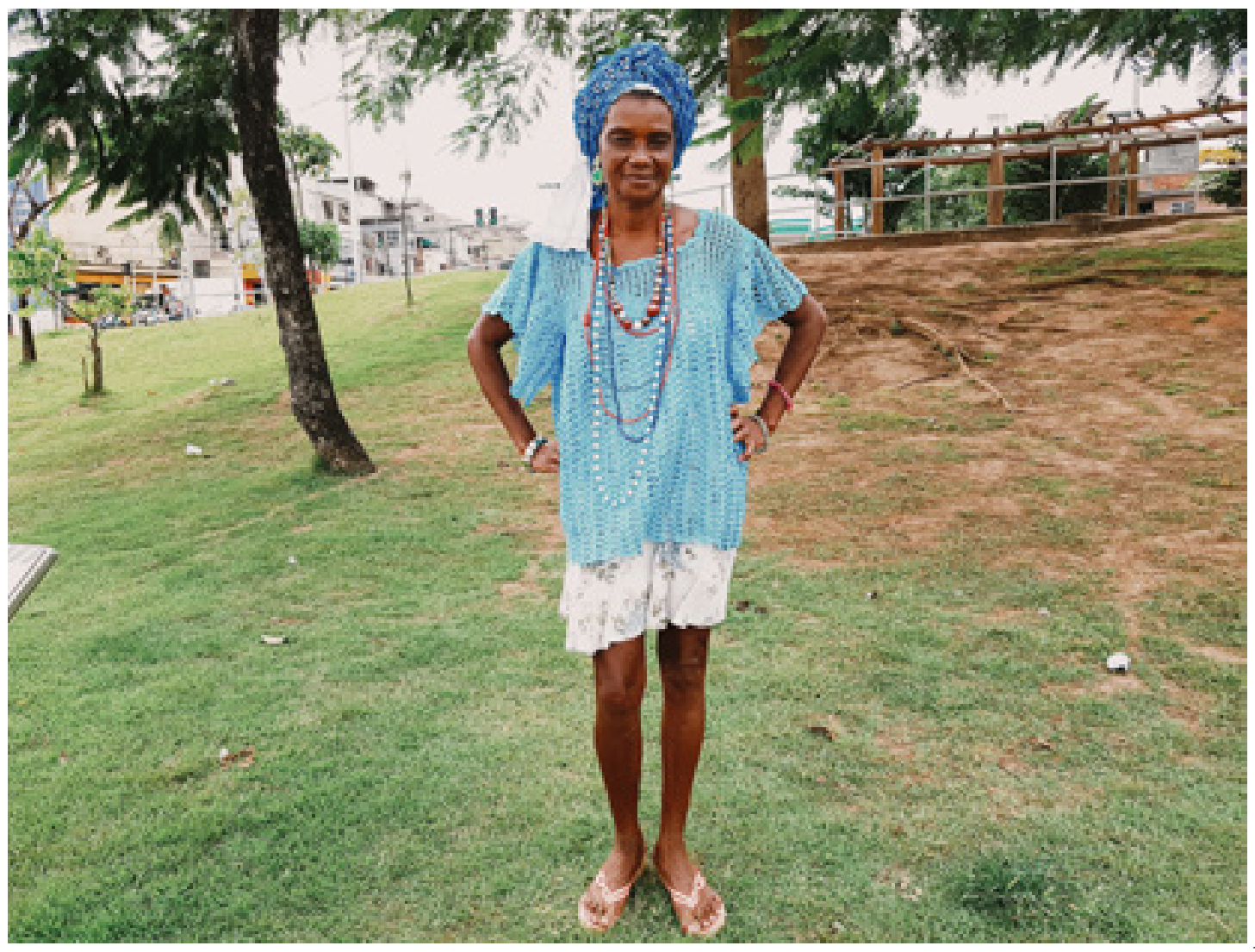




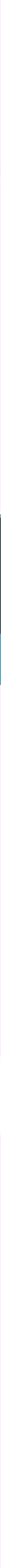


Chile, a nation of 19.2 million, is one of the oldest in Latin America. The United Nations projects that by 2050, its share of older people will rise to $\mathbf{3 1 . 7}$ percent (from $\mathbf{1 7 . 4}$ percent in 2020), meaning that nearly one out of every three people will be over the age of 60 . The national government has increasingly made this massive population shift a priority; its primary agency dedicated to the needs of seniors, the National Service for Older People (SENAMA), focuses on policy change, as well as building a variety of age-friendly initiatives and partnerships. The vastness and diversity of Chile's geographic makeup 
oftentimes requires more grassroots, community-focused solutions to meet the needs of aging residents, and municipalities are afforded a high degree of autonomy to develop and implement their own programs. There are 161 locations across the country that are members of WHO's Global Network of Age-Friendly Cities and Communities, the most in Latin America. With a high rate of internet penetration and connectivity (the highest in the region), Chile continues to leverage its well-developed ICT infrastructure to enhance the lives of its older population, particularly during the pandemic. 


\section{Aging in Chile}

\section{Demographic Profile}

1980

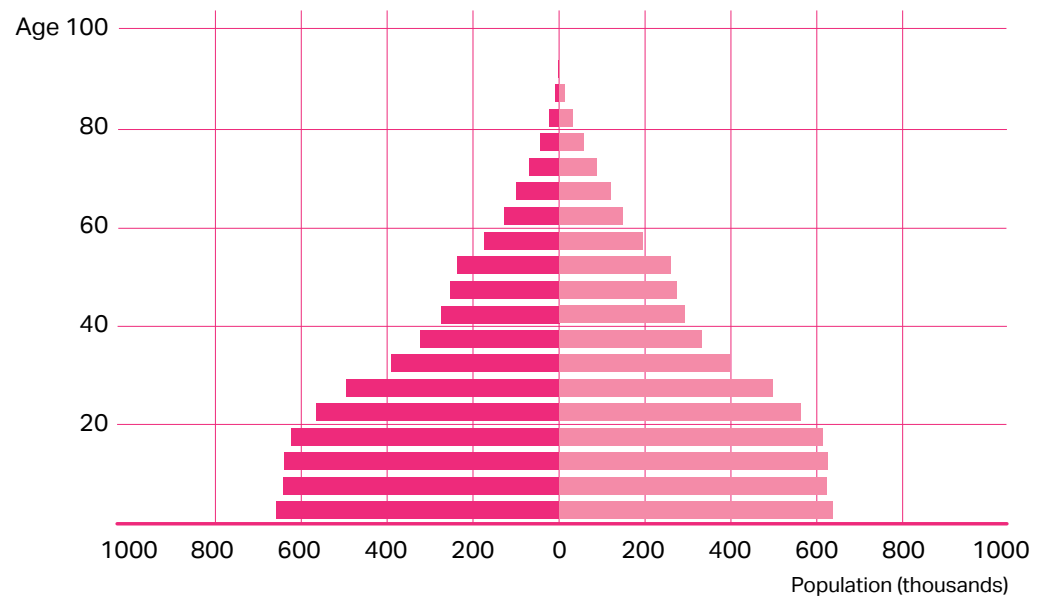

2020

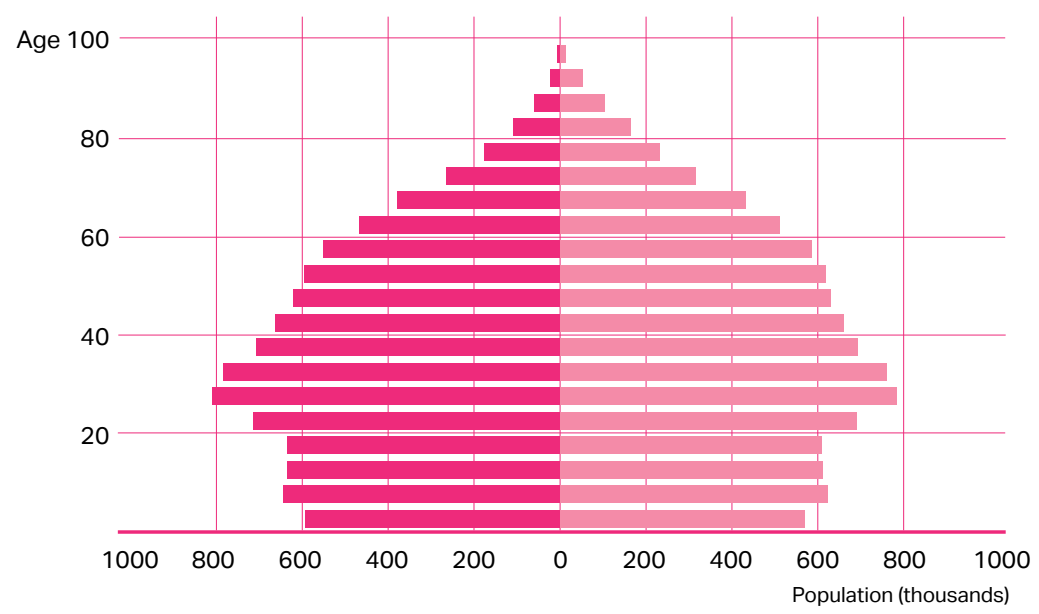

2060

Male

- Female

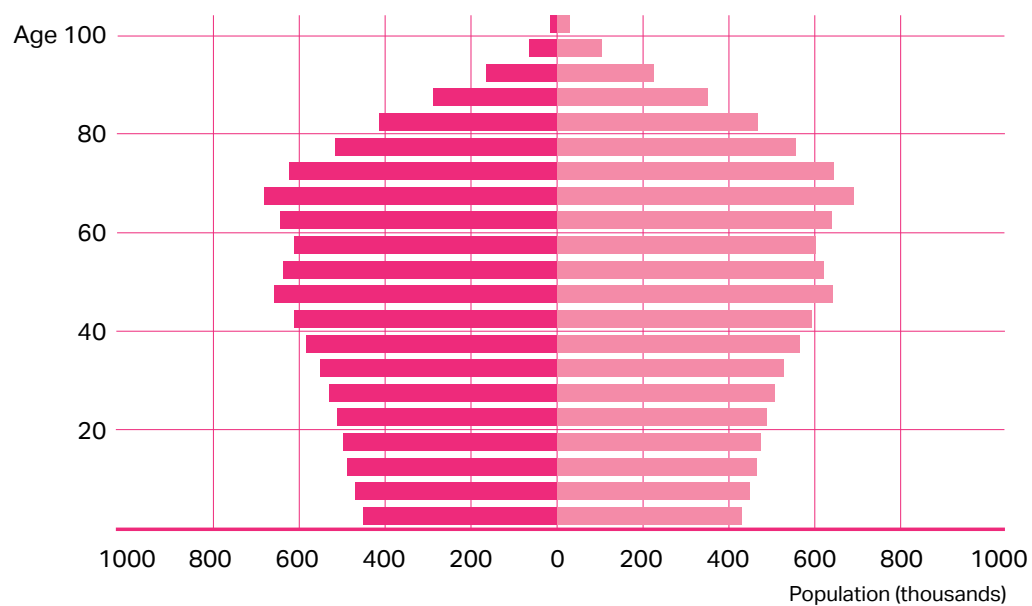



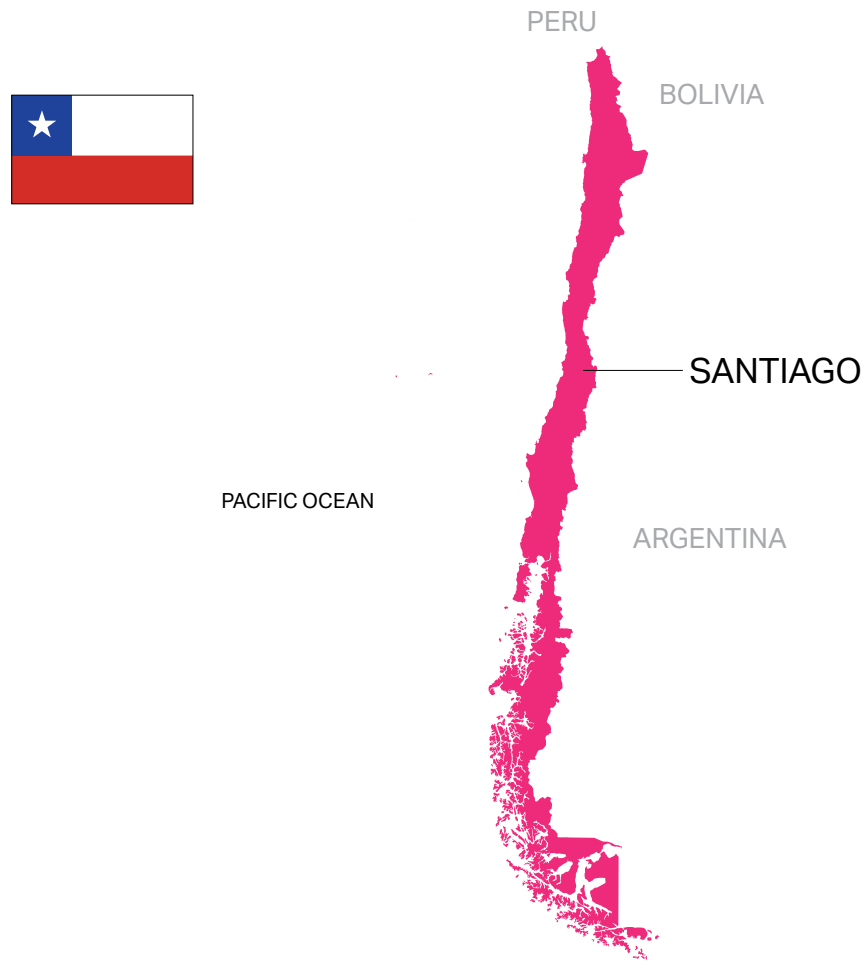

RELIGION

Roman Catholic 66.7\%, Evangelical or Protestant $16.4 \%$, Jehovah's Witness $1 \%$, other $3.4 \%$, none $11.5 \%$, unspecified $1.1 \%$ (2012 est.)

NET MIGRATION RATE

0.33 migrant(s)/1,000 population (2021 est.)

LIFE EXPECTANCY AT BIRTH Total population: 79.57 years $\left(54^{\mathrm{TH}}\right)$

Male: 76.55 years

Female: 82.71 years (2021 est.)

BIRTH RATE

12.92 births $/ 1,000$ population (2021 est.)

POPULATION GROWTH RATE

$0.86 \%$ (2020 est.)

URBAN POPULATION

$87.8 \%$ of total population (2021)

AGE STRUCTURE

0-14 years: $19.79 \%$

15-24 years: $13.84 \%$

25-54 years: $42.58 \%$

55-64 years: $11.98 \%$

65 years and over: $11.81 \%$

UNEMPLOYMENT RATE

$7.22 \%$ (2019 est.)
GINI INCOME INEQUALITY INDEX (2018) 44.4 (33 $\left.{ }^{\mathrm{RD}}\right)$

GENDER INEQUALITY INDEX (2019)

0.247

HEALTH EXPENDITURES

$9.1 \%(2018)$

OBESITY RATE

$22.3 \%(2016)$

LITERACY RATE

$95.1 \%$

LABOR FORCE BY OCCUPATION

Agriculture: $9.2 \%$

Industry: $23.7 \%$

Services: $67.1 \%$ (2013)

RESIDENT LABOR FORCE

PARTICIPATION RATE

$68.9 \%$ (2019 est.)

EXPORTS (US DOLLARS)

$\$ 90.626$ billion (2019 est.)

IMPORTS (US DOLLARS)

$\$ 87.505$ billion (2019 est.)

LANGUAGE

Spanish 99.5\% (official), English $10.2 \%$, indigenous $1 \%$ (includes Mapudungun, Aymara, Quechua, Rapa Nui), other $2.3 \%$, unspecified $0.2 \%$ (2012 est.)

\section{CHILE}

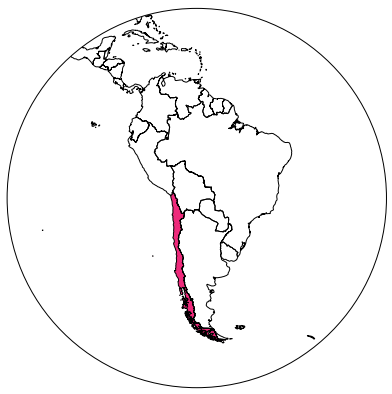

COUNTRY

Chile

CONVENTIONAL LONGFORM NAME

Republic of Chile

TOTAL AREA

$8,515,770 \mathrm{sq} \mathrm{km}$

$(3,287,957.2$ sq miles $)$

POPULATION (WORLD RANK) $18,307,925\left(166^{\text {TH }}\right)$

POPULATION DENSITY (WORLD RANK) 25.71 per sq. $\mathrm{km}\left(187^{\mathrm{TH}}\right)$

DEMONYM

Chilean

BUDGET (US DOLLARS)

Revenues: $\$ 57.75$ billion

Expenditures: $\$ 65.38$ billion (2017 est.)

GDP NOMINAL (US DOLLARS) \$282.655 billion (2019 est.)

MAIN INDUSTRIES

Copper, lithium, other minerals, foodstuffs, fish processing, iron and steel, wood and wood products, transport equipment, cement, textiles

NATURAL RESOURCES

Copper, timber, iron ore, nitrates, precious metals, hydropower

GOVERNMENT TYPE

Presidential republic

ETHNIC GROUPS

White and non-Indigenous $88.9 \%$, Mapuche $9.1 \%$, Aymara $0.7 \%$, other indigenous groups $1 \%$ (includes Rapa Nui, Likan Antai, Quechua, Colla, Diaguita, Kawesqar, Yagan or Yamana), unspecified $0.3 \%$ (2012 est.) 


\section{Dignity and Quality of Life: Prioritizing Aging Issues in Chile}

Chile is experiencing profound demographic changes. We find ourselves at an advanced stage of the population aging process. With a life expectancy of 80.7 years in our country, older persons now represent almost 20 percent of the population. But this reality will affect us even more in the coming decades, as it is expected that by 2050, our country's percentage of older persons will rise to become the second highest in Latin America, comprising 32 percent of the population.

Nowadays, population aging does not just mean an increased number of older adults compared to the past, but also that people are living longer. It is the so-called "aging of the elderly." In Chile, 15 percent of older persons are over 80-an important age when considering life changes: Although 86 percent of older persons are independent, this drops to 60 percent for those over 80 . This enormous demographic change is without a doubt generating a profound social, economic, and cultural impact, affecting areas like health, pensions, work, the design of cities, care, social integration, and community life, among other aspects.
A Challenge Both Societal and Concrete Despite sustained population growth of this segment in recent years, and the systematic increase of older persons' participation in different areas of society, today we face a problem of social exclusion based on misconceived perceptions, stigmas, and prejudice regarding older persons and aging. Positive traits associated with aging are underestimated while negative ones are exaggerated which can lead to the exclusion of older people from participation in society.

The Fifth Older People Inclusion and Exclusion Survey in Chile in 2017, conducted by the University of Chile and the 


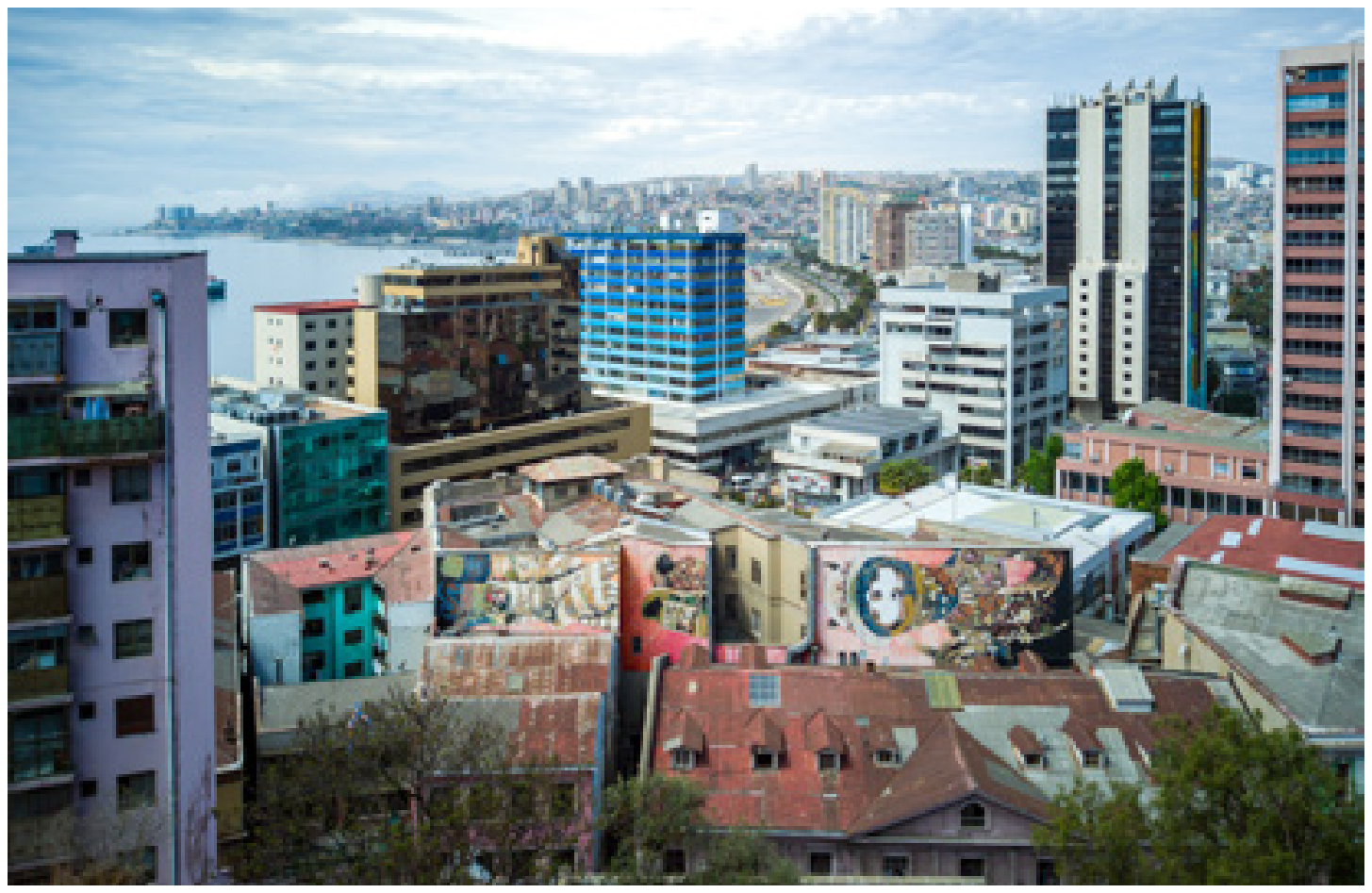

National Agency for Older Persons, shows this pessimistic and dispiriting perception of aging in Chile, which without a doubt is distant from reality. The survey found that 73 percent of people consider older persons to be socially marginalized, and 68 percent believe they cannot fend for themselves, when in reality, older persons have low levels of functional dependency, with only 14.2 percent having some degree of this.

A negative connotation to aging does not just exclude older individuals from the social setting, it also causes people to not want to accept that they themselves are aging, leading to lack of preparation for this stage of life. If we want to reverse this situation, a cultural change, a change of paradigm on how we see aging and older persons needs to be instilled. We have to change the negative vision of aging, so as to fully integrate older persons into the broader world, releasing them from stereotypes and thus creating all the conditions needed for people to thrive in later years. This change in vision entails seeing aging as a process that has no connection to impairment and dependence, but one of new possibilities for participation, development, and autonomy.

Older persons have much to learn and even more to give. We need to foster and 


\section{While we have made progress, we still have a long way to go. There are seemingly infinite challenges and changes to implement to achieve a new reality: that we, the older members of society, have a place in it, and have the quality of life we deserve.}

make visible their contribution to the social, family, economic, and cultural life of countries, showing that they are not a problem but rather an asset.

\section{A Commitment Now Visible}

Facing the reality of the aging of our population, and in supporting the commitment of the government of my husband, the President, Sebastián Piñera, to place older persons at the heart of public policy, I have focused on leading initiatives that support those people later in life. In 2018, we created the "Better Ageing" Program, where we worked together with the National Agency for Older Persons to strengthen older persons' social integration and foster positive and healthy aging. With this goal, we raised up and highlighted a set of concrete initiatives and actions provided by each one of the different ministries and public services in our country.

We are also adjusting and attuning all our internal policies and regulations to the guidelines and goals of the 2030 Sustainable Development Goals, the InterAmerican Convention on Protecting the Human Rights of Older Persons, and WHO's 2021-2030 Decade of Health Ageing, where, as a country, we have been working hard.

Since the end of 2018, we have been working hard on WHO's Age Friendly Cities program, with a community approach so that localities can become more age-friendly by encouraging active aging, participation, and safety. In 2018, when we started this program as a Government, fewer than 10 communities formed part of WHO's Network. Today, we have 180 communities involved.

Alongside this, we have developed different initiatives that promote greater mobility and participation for older people, such as a 50 percent reduction for older persons in the cost of public transportation, the reduction in real estate taxes, and free access to national parks, among other benefits.

Likewise, I would like to highlight the work done to strengthen the socio-legal defense of older persons in our country. In order for older adults to receive prompt and specialized attention regarding their legal needs, we created a program called Senior Citizen Defense Counsel, which secures lawyers throughout the country to provide free, specialized legal advice to older persons (or the community) who may be facing situations 
of abuse, mistreatment, violence, and/or infringement of their rights.

Also key has been the work done in the creation of a socio-health model, developed to foster older adult's functional ability and independence through the integration of Chile's social and health systems. As we know, it is possible to prevent dependence if certain conditions associated with a reduction of intrinsic capacity are diagnosed and addressed quickly.

Along this line, we have implemented Acute Geriatric Units for older people in Chile's hospitals, an initiative that uses an integrated attention model to promptly and effectively treat the acute clinical condition they are admitted for, enabling their initial functional recovery and helping to prevent dependence. This goes hand in hand with a 50 percent increase in the number of Geriatric specialists in our country; while the number of such specialists remains very low, the growth gives reason for hope that the trend will continue.

One of the main pillars of this sociohealth network are our country's Day Centers. These are spaces that promote and strengthen the autonomy of older people, contributing towards delaying their loss of functionality. In just three years, we have gone from 18 centers to almost 100 , and we hope to reach one per community over the next six years. Part of this network is a group of condominiums that allow older people to live independently while also sharing in community with others of a similar age.

Many of the actions to implement the socio-health model in our country will be developed through Chile's Integrated Health Plan for Older Persons of the Ministry of Health. This work is an extension of the public policies for aging, safeguarding the functional health of older persons.

\section{An Ongoing Commitment Means Ongoing Work}

All of this is the result of a commitment that, as a country, we develop and implement strong policies and solutions for older persons. We are focused on this and I am convinced that we will continue implementing actions and policies that allow us to achieve healthy, active, and participatory aging.

But I have to mention that while we have made progress, we still have a long way to go. There are seemingly infinite challenges and changes to implement to achieve a new reality: that we, the older members of society, have a place in it, and have the quality of life we deserve.

As we keep saying, what's important is not just living longer, but that any additional years are ones lived with dignity and a good quality of life.

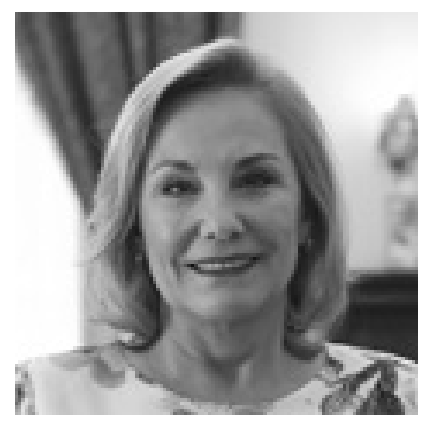

CECILIA MOREL MONTES

First Lady of Chile 


\section{Day in the Life}

\section{Claudia Ortega}

Santiago

50 years old

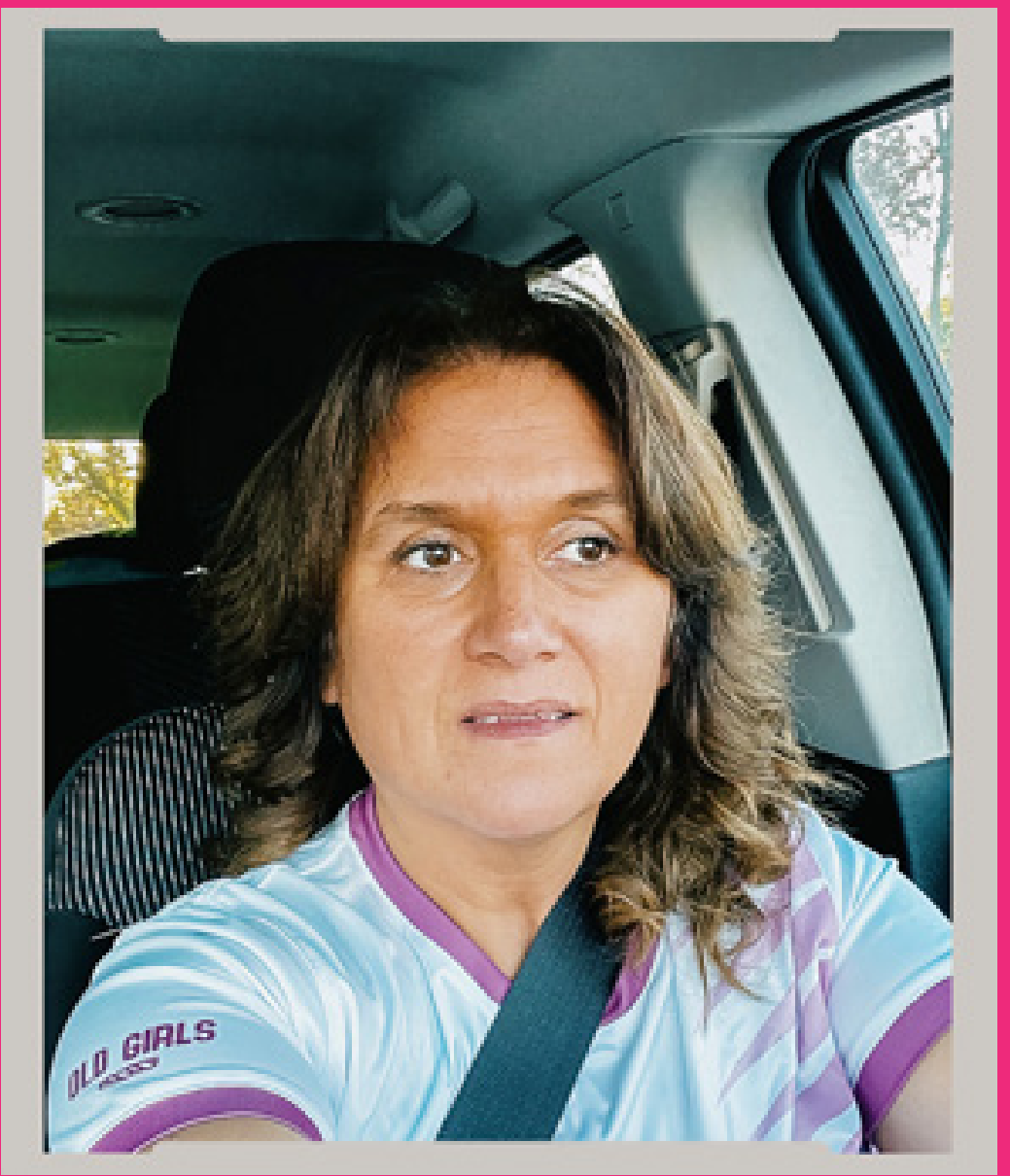

Claudia lives in Santiago with her husband and two children, a daughter, 22, and son, 20, both of whom are university students. She works full-time as a lawyer and in her spare time is training with Hockey Chile Masters Damas + 50 — and will participate in the Master's World Cup representing Chile in 2022. 


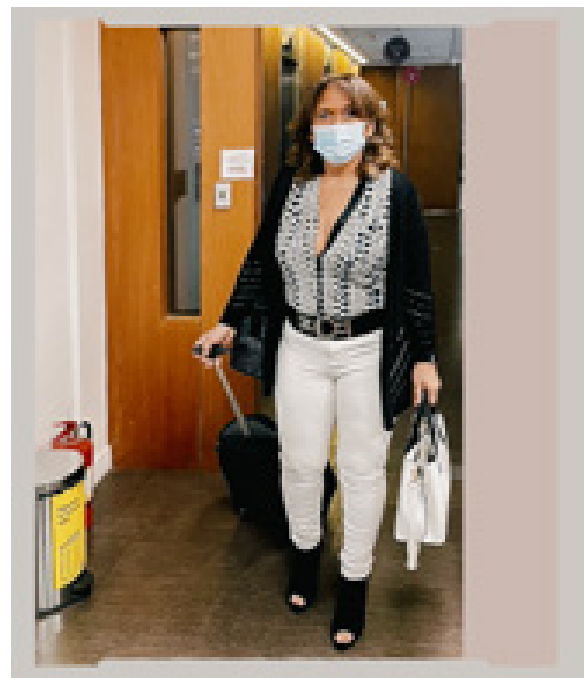

Ready for a day at the office

\section{What is your typical day like?}

A typical weekday includes working, either at home or at the office from 8:30 a.m. to 6 p.m. I am a lawyer and work involves mainly being on my computer and attending meetings. When working at home, I cook lunch and breakfast for my kids and husband, since almost everyone is at home because of COVID measures. When I go to the office, I have to cook in advance and I eat alone because of COVID restrictions.

After work, I go to field hockey training three times a week. I also take care of things at home, such as buying groceries (always online), laundry, cleaning and cooking. At night, when I don't go field hockey training, I have dinner with my family. After dinner, I watch the news, read a book or watch tv. Sometimes, I also do some knitting while watching TV. Sometimes, I go out to dinner or drinks with my husband and other times with friends.

Weekends are for spare time, which always includes cooking. I go out to buy some things that I may need, such as clothes or other items for the house. Most of the times I do some sports, such as riding the indoor bike and sometimes outdoor cycling or walking. Some weekends we go to our flat at the beach, and there I try to read, sleep and walk. My husband is a vineyard manager, and we like drinking good
How do you stay mentally and socially active? I try to read as much as I can, mostly novels, but sometimes history too. I have different groups of friends from school, university, the office, sports teams, and common friends with my husband. We regularly meet for drinks, dinner, dancing, and sometimes we travel together, with and without kids.

\section{What do you find most challenging about growing older?}

Growing older is challenging because of health problems. Your body doesn't always act according to your mental age. I've had surgery in one of my hips and will probably have to go through a new surgery in the coming years. You don't have as much energy as before and that's frustrating.

\section{What are your thoughts on aging in Chile?} Healthcare is very expensive in Chile, and when retirement comes incomes decrease, so it's necessary to have a lot of savings to face health problems when you get old. You need to have good health insurance and life insurance. Fortunately, I don't need to worry too much, however that's not the reality for the majority in Chile. The pandemic, together with the political situation, changed the reality of life in Chile, and there's a lot of uncertainties around what will happen in the future. I try to live one day at a time, trying to make the most of it all the time. 


\section{Day in the Life}

\section{Claudia Ortega}

\section{Santiago}

50 years old

\section{"Healthcare is very} expensive in Chile, and when retirement comes incomes decrease, so it's necessary to have a lot of savings to face health problems when you get old. You need to have good health insurance and life insurance."

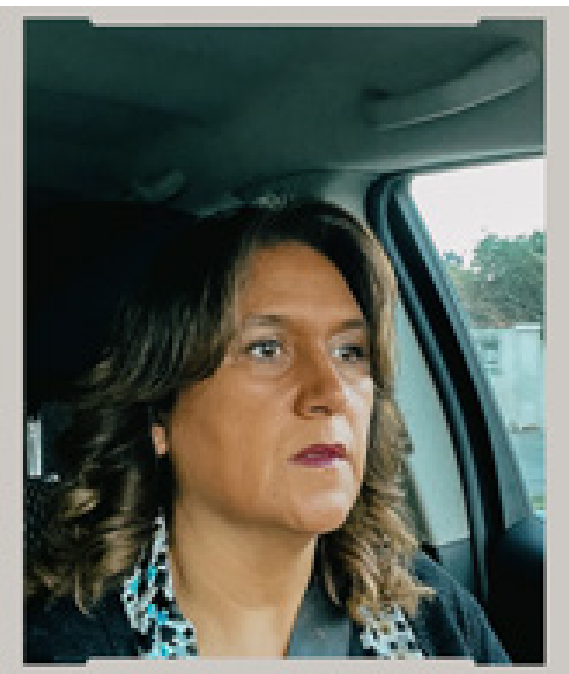

Driving to work at 8 a.m.

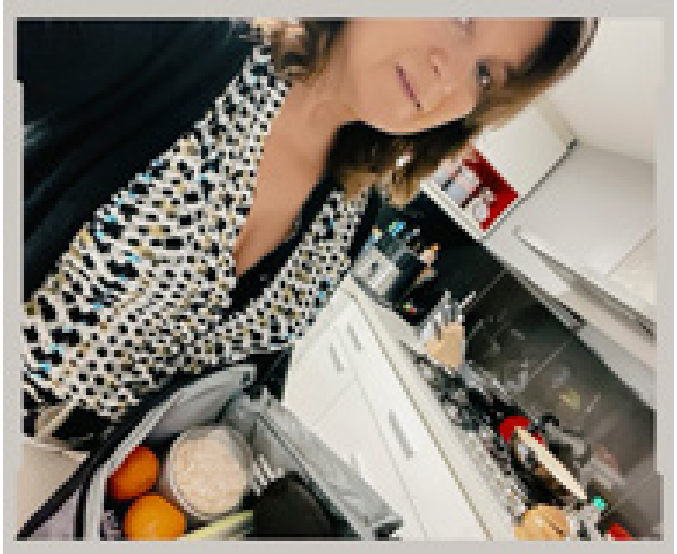

Preparing breakfast and lunch for herself and her family, who are all home because of the pandemic

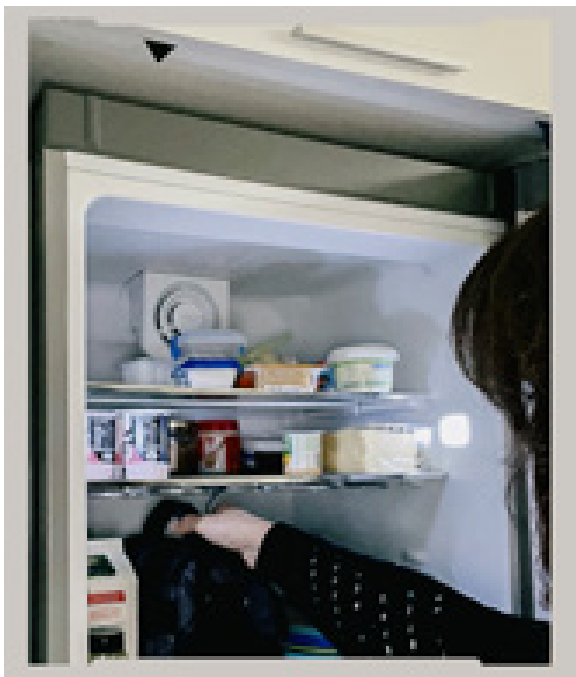

Preparing breakfast and lunch

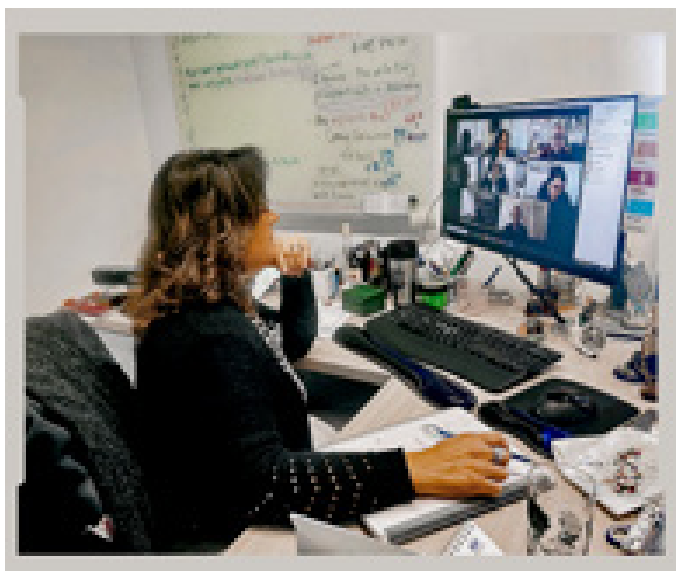

Claudia in her office 


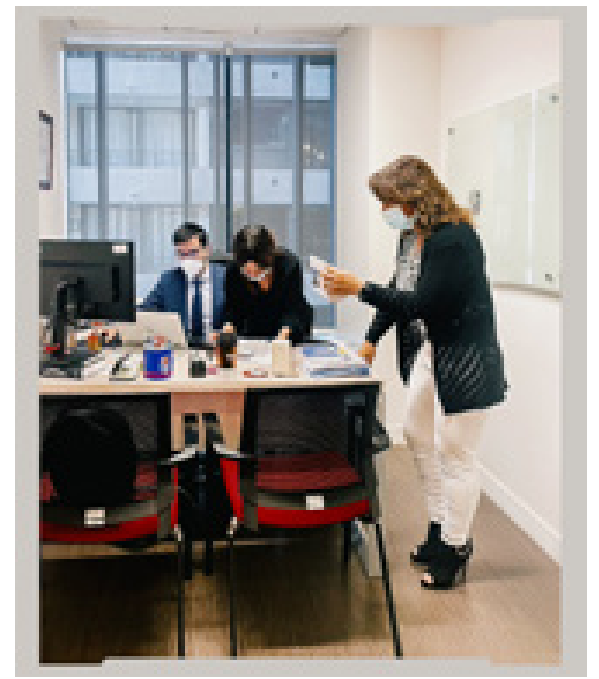

Meeting with colleagues

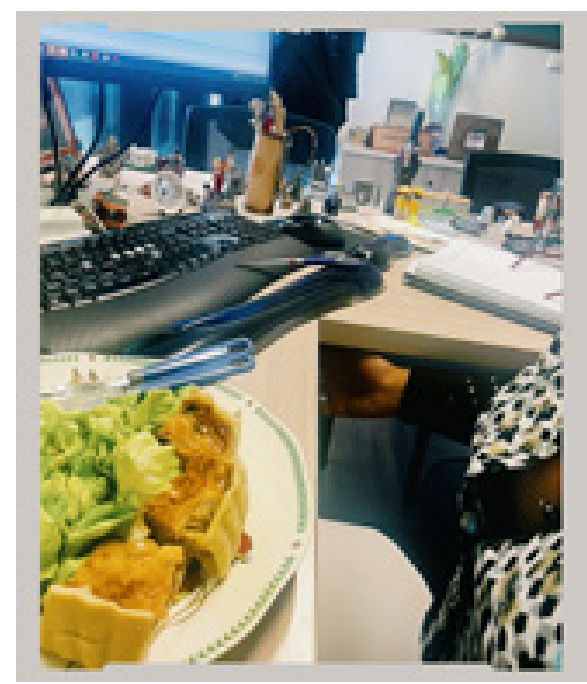

Lunch break, eating alone because of COVID-19 restrictions

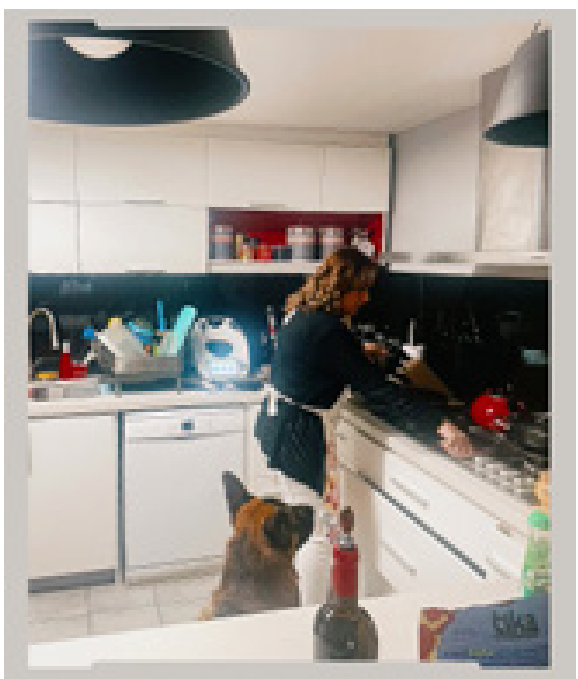

In the kitchen, preparing a meal for her husband and children

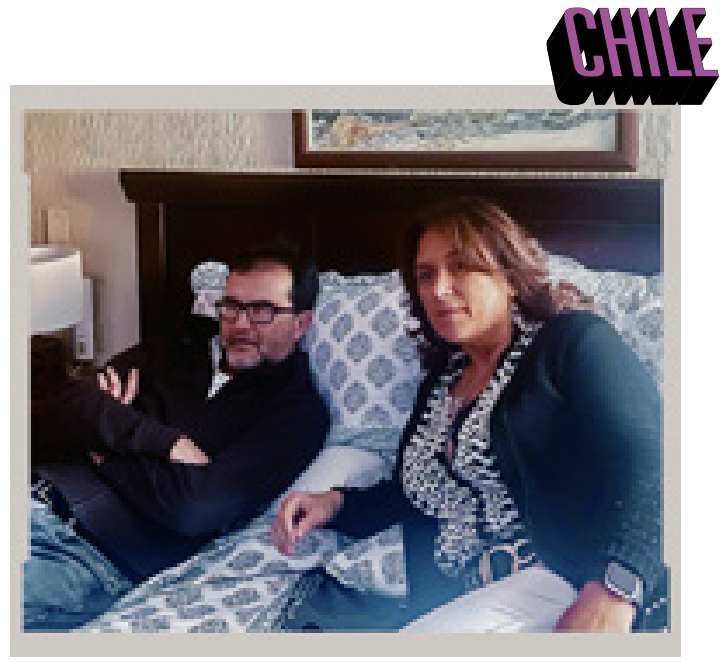

Taking a break to watch TV with her husband

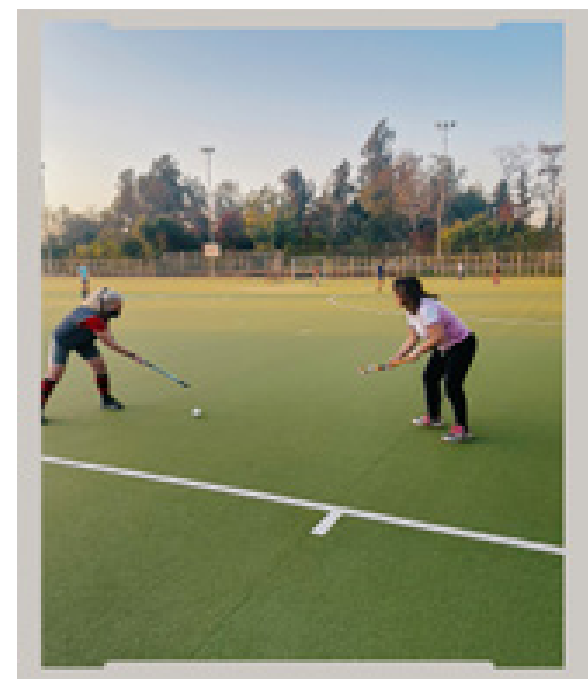

At field hockey practice with her team, comprised of women over age $\mathbf{5 0}$

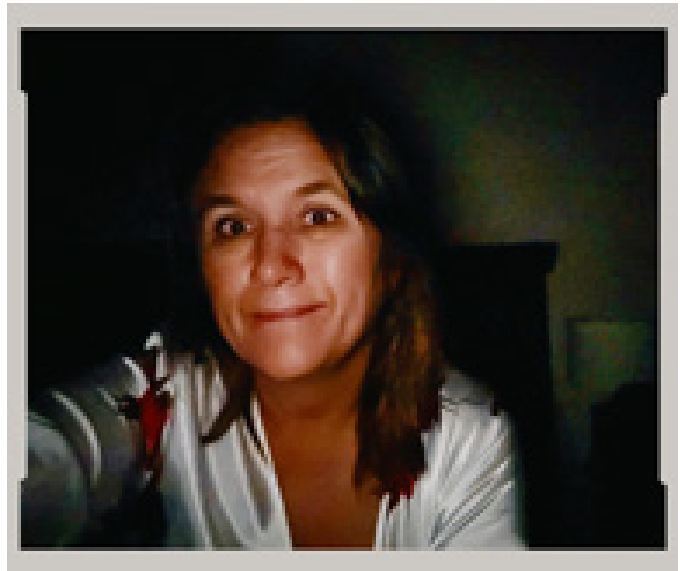

Claudia at the end of the day, just before going to sleep 


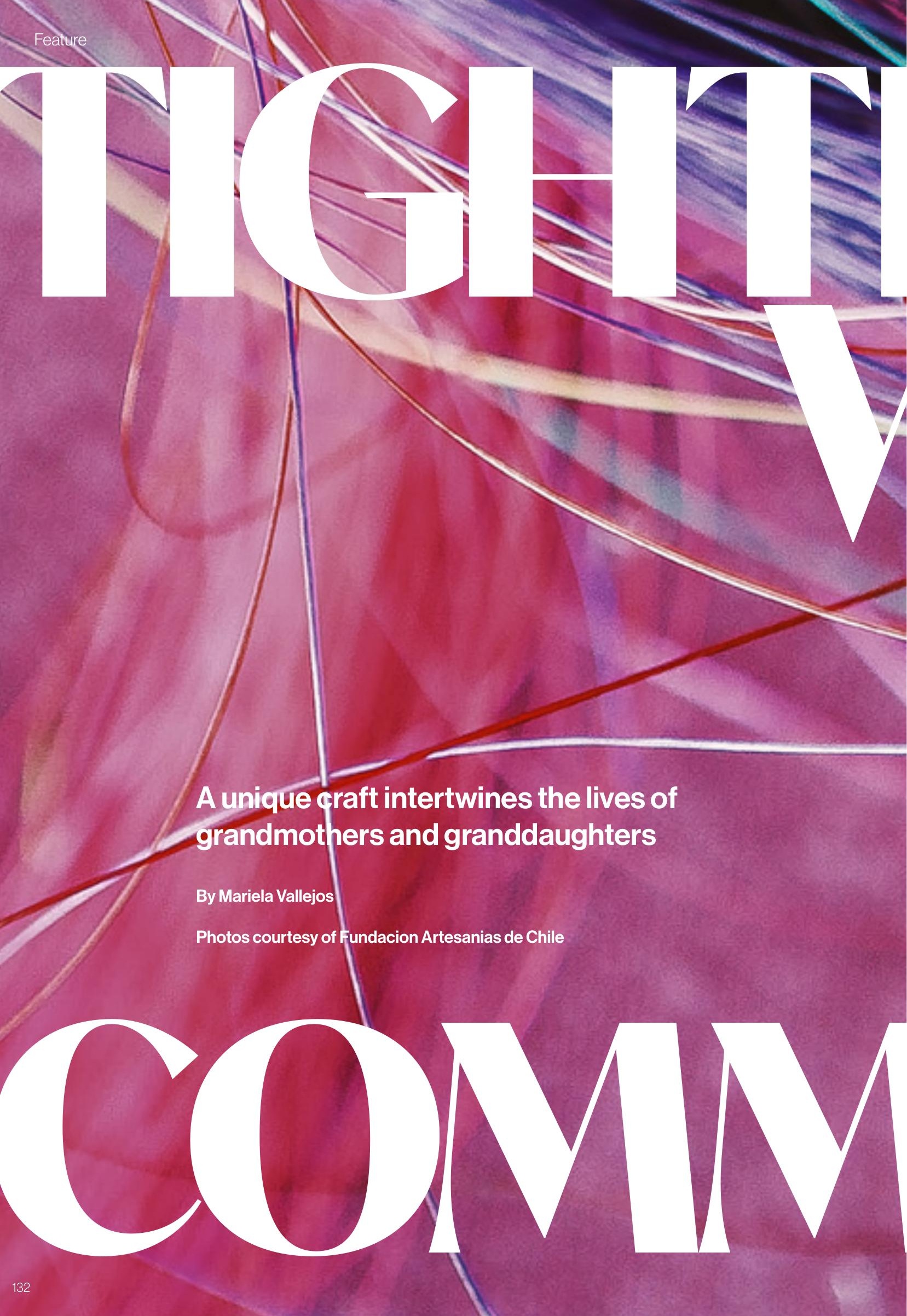




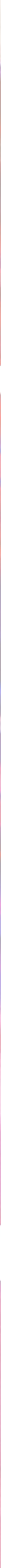




\section{rtisans from a remote rural area of Chile make the most stunning handicrafts: miniature flowers,} animals, butterflies, birds, angels, and witches, woven out of crin de caballo, dyed or natural-colored horsehair. Their delicate creations are unique to this part of the world, largely due to their geographic and historical isolation.

Horsehair weaving uses strands from the horses' tails - thicker, longer and sturdier than that of their manes - combined with the imported vegetable fiber ixtle to keep the structure more firm and durable. The decorative pieces come almost exclusively from two neighboring rural villages, Rari and Panimavida, located 22 kilometers east of the town of Linares in the Andean foothills, roughly 300 kilometers south of Santiago. 


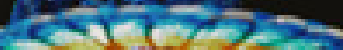

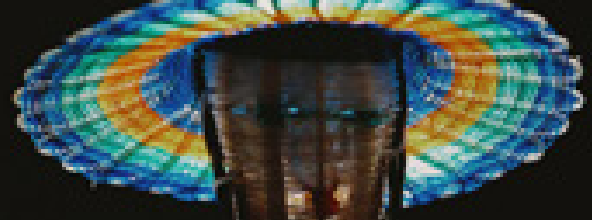

설

ing,

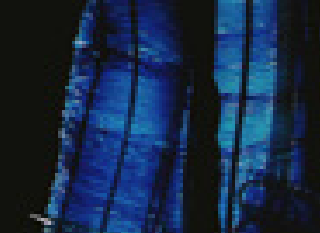

$1-3$
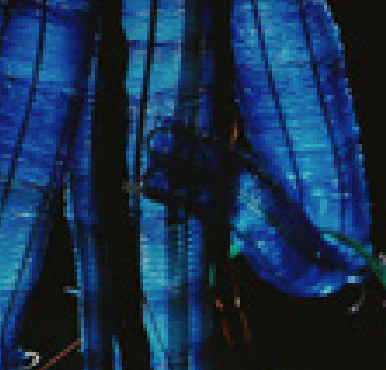

3 I I 
Sitting in their doorways or under a tree, during the evening or between domestic tasks, some 150 women carry out the intricate labor of weaving the horsehair, a tradition that has been passed down for over two hundred years, using only their hands demonstrates the power of transferring skills from one generation to the next and the benefits to both young and old during the process.

According to historians, the origins of woven crafts are closely linked to pre-

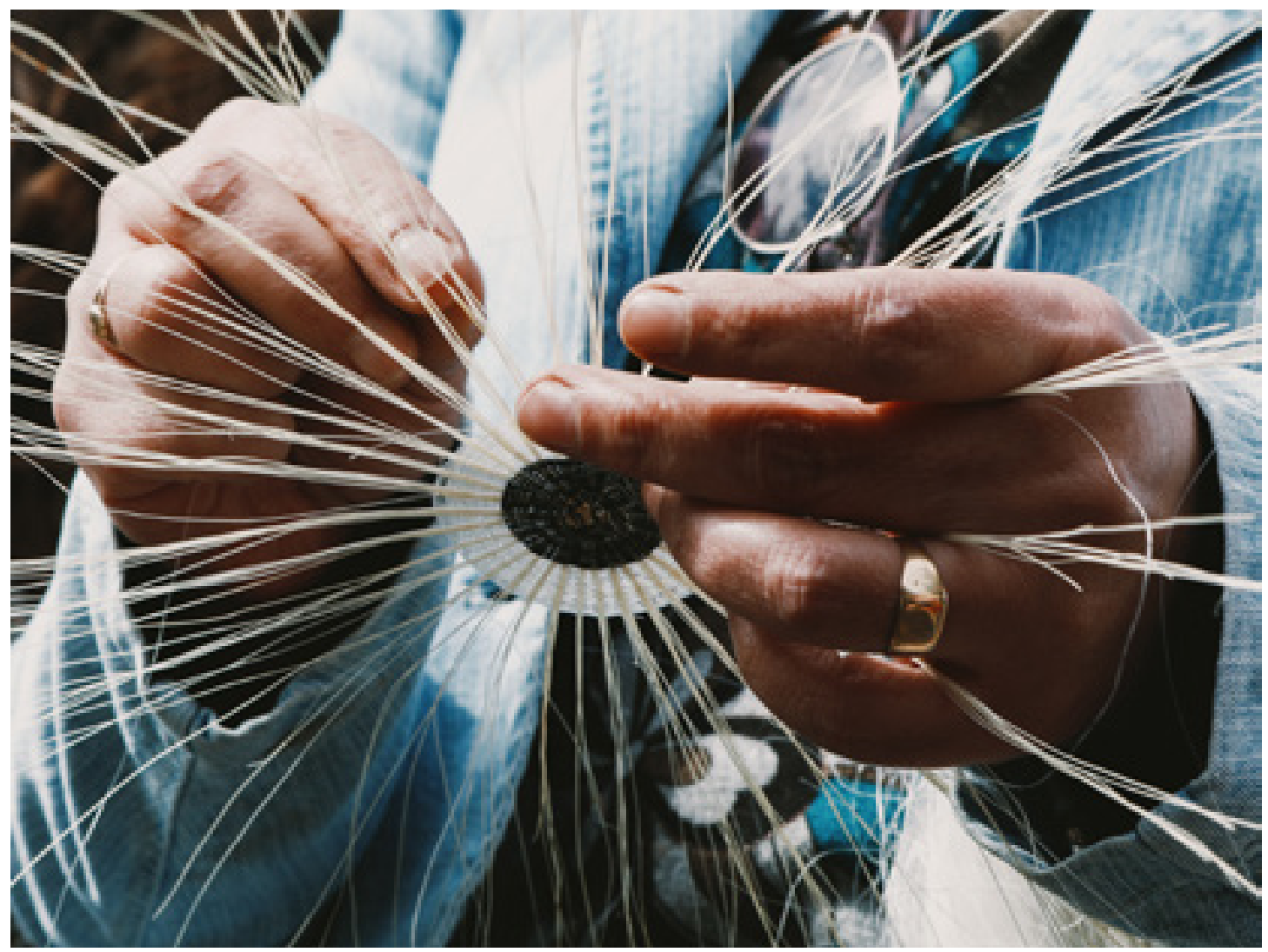

Weaving horse hair by hand

and a needle to finish off their creations. The results are delicate ornaments-often made into necklaces, bracelets, earrings-and decorative pieces inspired by nature and legend.

Rari-Panimavida exemplifies Chile's efforts to safeguard its folk arts, and by extension, the artisans who carry forth the traditions. Although the future of such crafts is uncertain, the community in these villages
Columbian basketry in the area. The tradition of making miniatures began, however, at the end of the 19th century when the village of Panimavida, famous for its hot springs, began to attract wealthy tourists and personalities from the cities. These visitors were always eager to buy a unique souvenir. Local women began using fine poplar roots to braid into small figures to sell. When poplar roots 
became scarce, they tried the natural fiber ixtle, already widely used to make brushes, and combined it with horsehair from the animals' tails. These materials woven together produced a new tradition.

For several decades, selling horsehair horsehair weaving and knitted with sticks and on a loom. She was also a seamstress and the midwife around here, too. There was no doctor, no electricity. Life was hard."

In the late 1960s, agricultural development and public policies brought progress to the

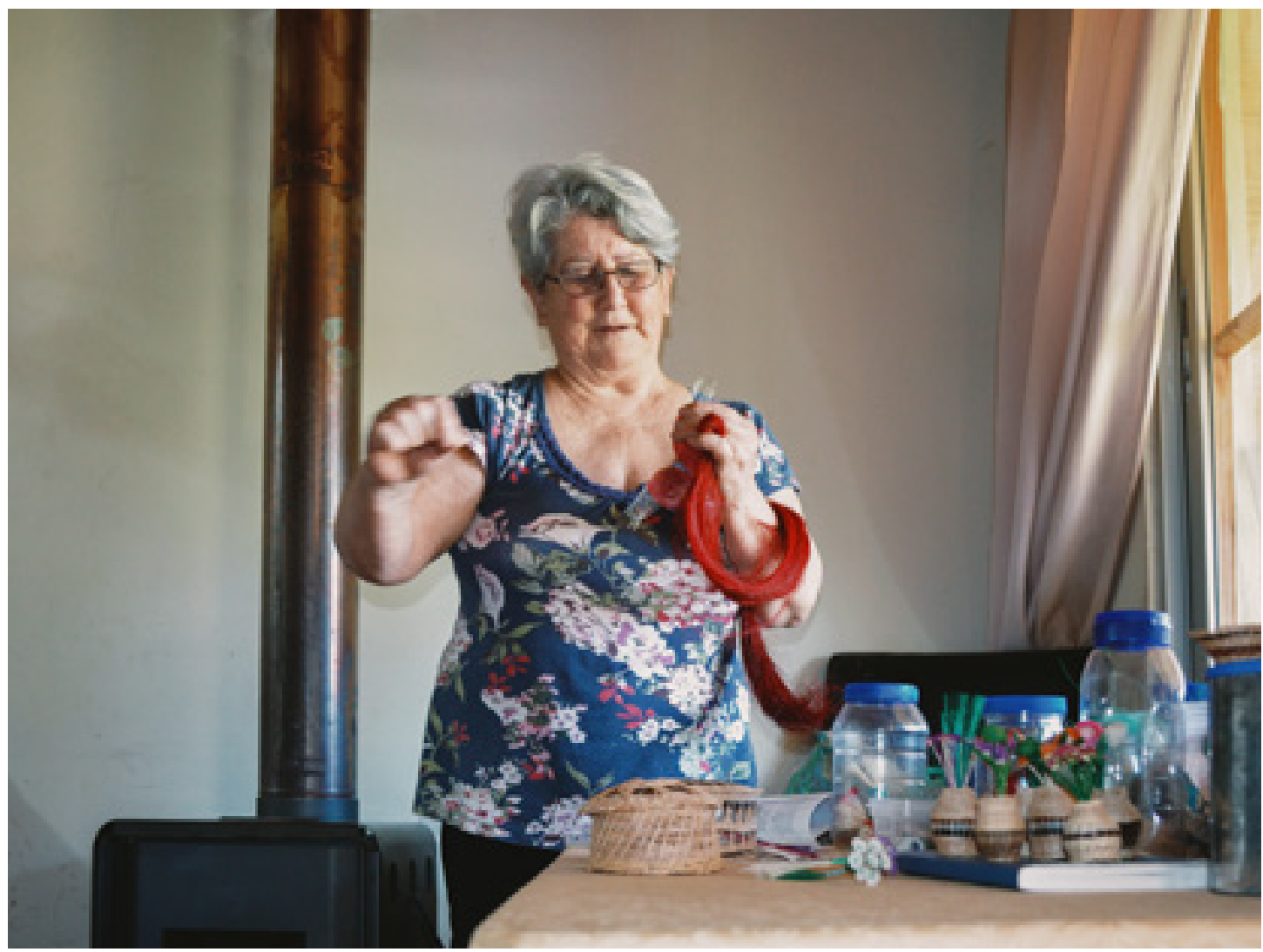

Artisan Guadalupe Sepulveda, 84, demonstrating some of the techniques she has learned over the years

souvenirs was an essential contribution to families' subsistence. "In the 1950s, when I was young," remembers artisan Guadalupe Sepúlveda, 84, "there was a lot of poverty here, and crafts were traded for food. Our dad worked all day in the field. We children had to help our mother weave." Sepúlveda had 10 siblings. "My mother was already too busy. She did domestic work. She did region. Children began to attend school regularly and the girls (mostly) took to weaving in their free time, regarding it as a profitable hobby. In the 1990s, with the support of various government entities and NGOs, a generation of artisans began to organize their work. "From weaving alone in our homes, trying to obtain raw materials and selling our products individually, we switched 



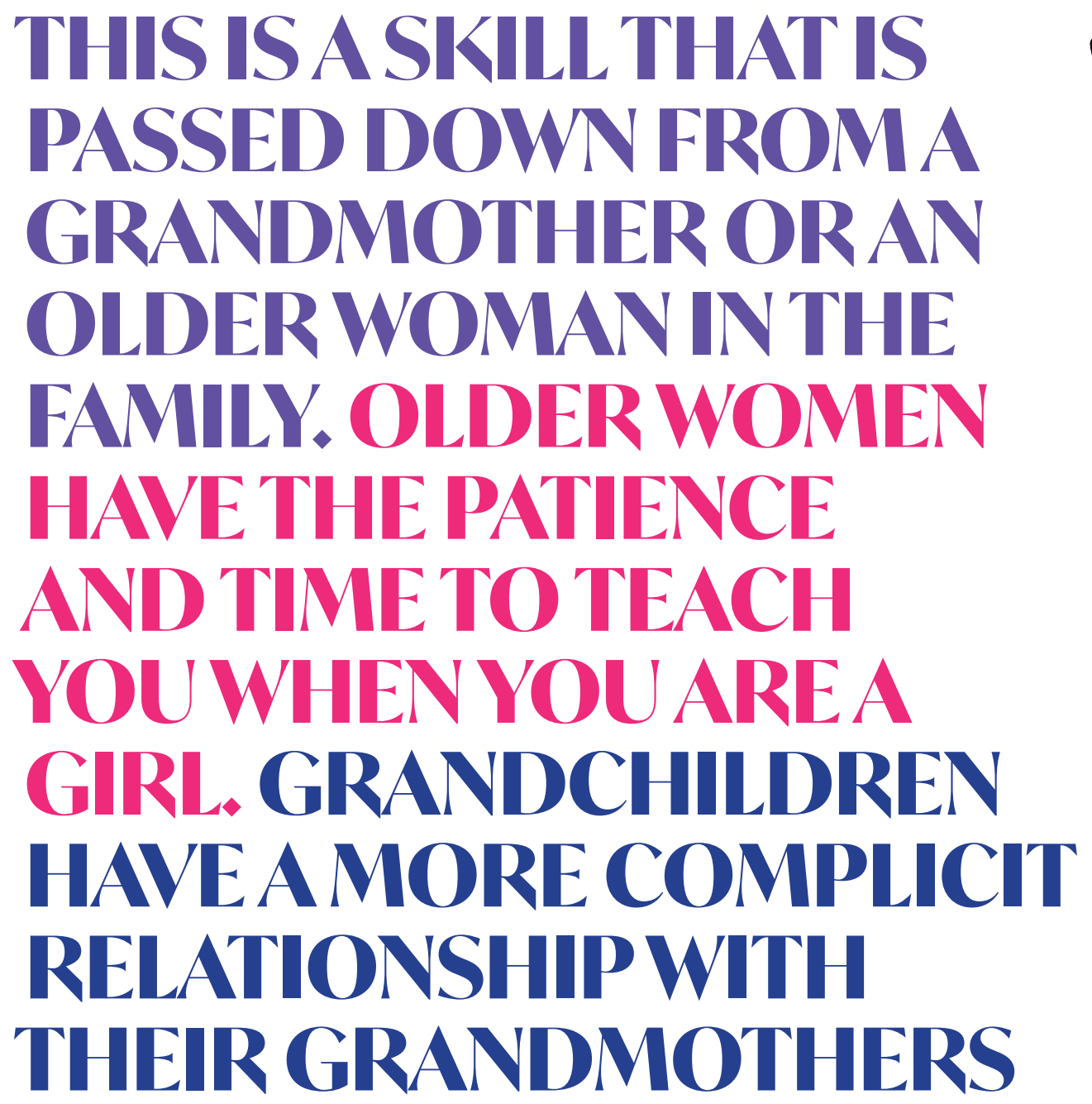

to importing ixtle together and increasing our sales with the help of Artesanias de Chile," acknowledges artisan Margarita Cabrera, 71, referring to a fair-trade, government-funded nonprofit that works to promote and disseminate traditional Chilean crafts. Cabrera is a retired accountant, mother, and grandmother who has proudly passed on her expertise to two generations. "Now we weave because we like it."

Nowadays crafting is a family and social experience that women enjoy. The older women regard getting together to weave as a chance for conversation, especially with the young. "I talk a lot with Carito, my granddaughter," says Cabrera. "She has been my darling since she was little. Weaving together is a chance to talk over ideas with other people and listen to them. In general, it is like group therapy, an opportunity to share, and you come away enriched. It helped us especially during the COVID-19 pandemic. We have shared this activity with my daughter and granddaughter. We talk and plan for hours while we work. They come up with new ideas that we incorporate, and that makes the future look brighter again."

\section{"My grandma taught me"}

Although the tradition gets passed on in several ways, it is usually the grandmothers who teach their granddaughters. Artisan Milisen Sepúlveda, 38, explains: "This is a skill that is passed down from a grandmother or an older woman in the family. Older women have the patience and time to teach you when you are a girl. Grandchildren have a more complicit relationship with their grandmothers; the mother-daughter relationship is a bit more rigid. With the grandmother, 


\section{THOUGH OLDERARTISANS}

ARE PROUD OF THEIR

MANY ACHIEVEMENTS,

THEYWORRYABOUT THE

FUTURE. "YOUNG PEOPLE

ARE NOT ASATTRACTED

TO DOING THIS WORK

ANYMORE," MARGARITA

CABRERAWORRIES. "ITIS

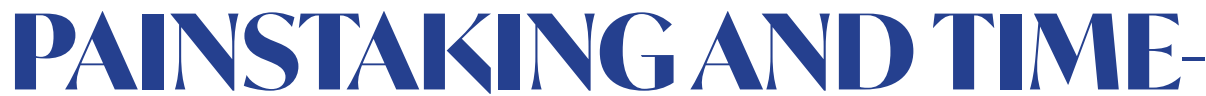

CONSUMING, AND THEY

WANT IMMEDIATE RESULTS

FOR WHAT THEY DO,"

everything is a gift. When I learned from mine, it felt like playing. She made large dolls and I made their accessories - hats, umbrellas, and baskets. We complemented each other. Similarly, my mother and her granddaughter (my daughter) are accomplices and enjoy working together while they talk."

Isabel Sepúlveda, 57, whose little horsehair animals get exported all over the world, says her children and grandchildren have been a great help to her. "They always come up with new design ideas. And they know more about how to use technology for selling," she admits.

Though older artisans are proud of their many achievements, they worry about the future. "Young people are not as attracted to doing this work anymore," Margarita Cabrera worries. "It is painstaking and time-consuming, and they want immediate results for what they do."

Professional designers from big cities represent a threat, too. "They may buy many small pieces from an artisan, rings for example, and make them into new objects, such as a lamp, and then claim authorship for themselves," says America Escobar, Regional Head from the Subdepartment of Intangible Cultural Heritage (ICH). "This is an appropriation we try to counter with education," she adds. 


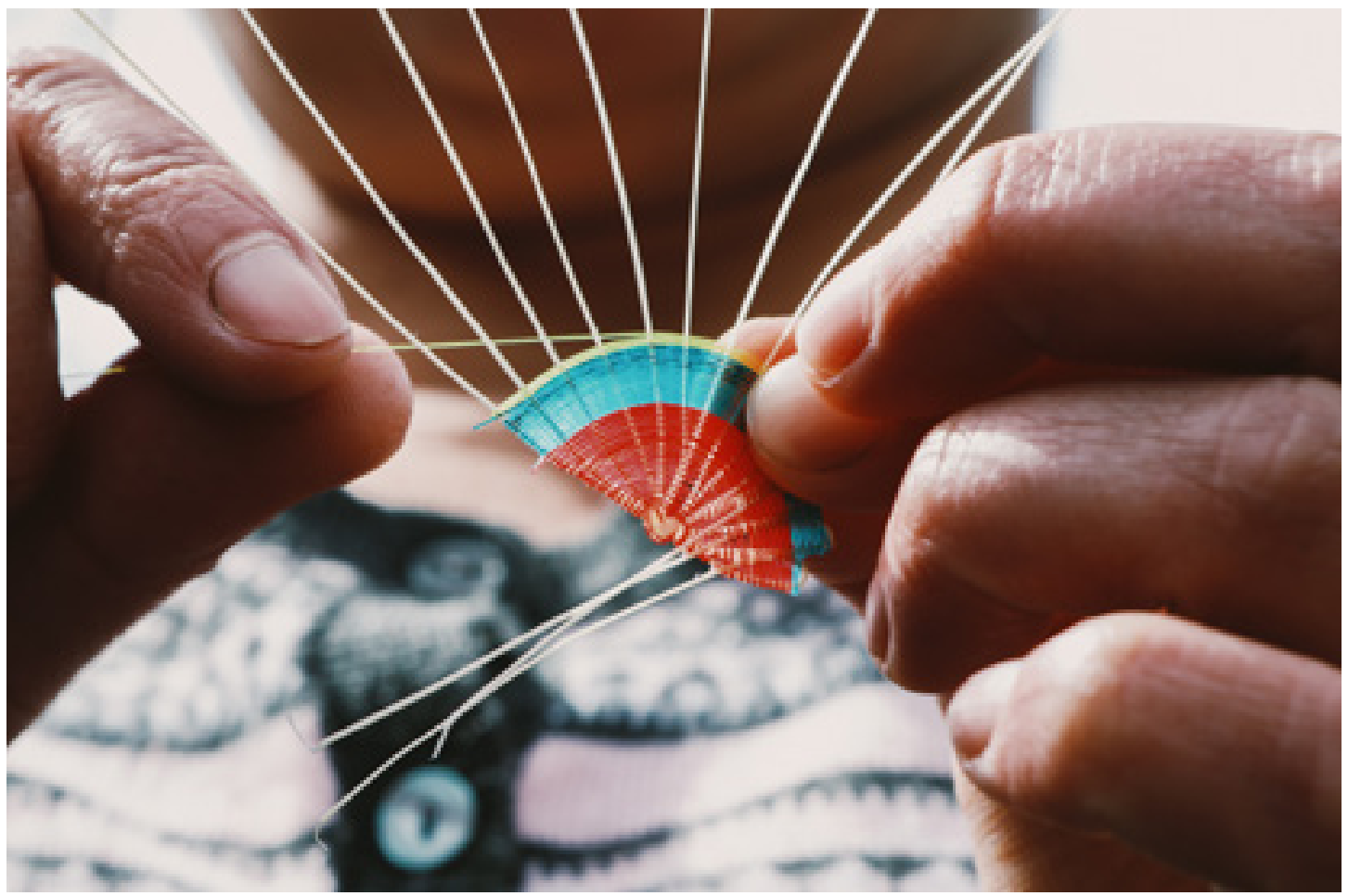

Detailed handwork, passed down through the generations

Artisan Milisen Sepúlveda, 38, and her mother Margarita Cabrera, 71, in a room attached to their home where they exhibit and sell their crafts

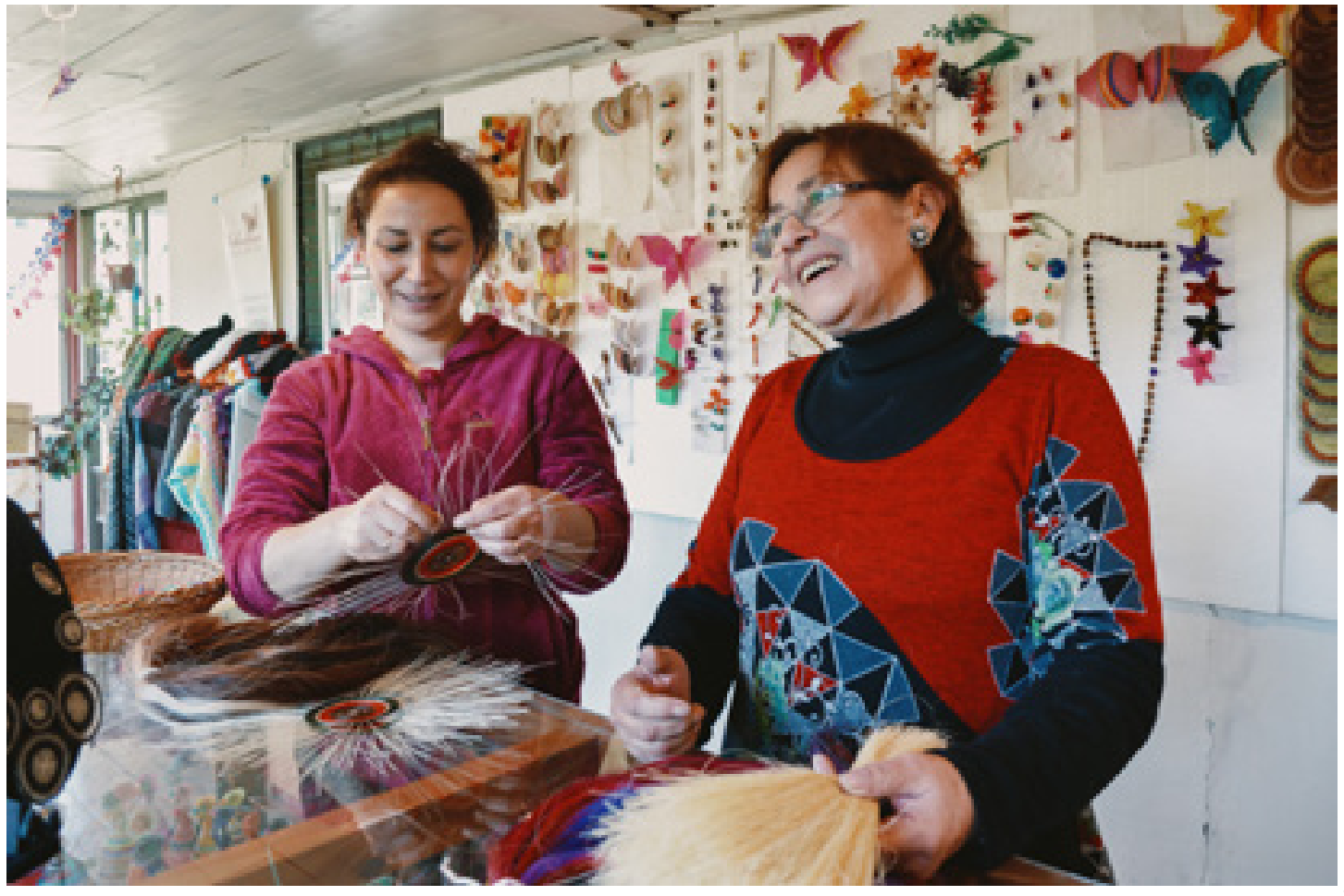




\section{Government Support}

Like Escobar, other government officials are also aware of the role of public policies to prevent the weaving tradition from disappearing. In 2010, the entire artisan community of Rari-Panimavida were recognized as "Living Human Treasures" by the National Sub-department of ICH. The acknowledgement is bestowed on individuals and communities who represent a highly significant intangible cultural heritage, and their recognition has set in motion a chain of significance both within their communities and in Chilean society as a whole. This recognition, which complies with a UNESCO convention that Chile signed, includes the incorporation of artisans into the Registry of Living Human Treasures of Chile. They are issued a public certification and given an economic incentive and government support to maintain and disseminate their tradition.

Rari's craftsmanship is permanently exhibited in a museum in the nearby city of

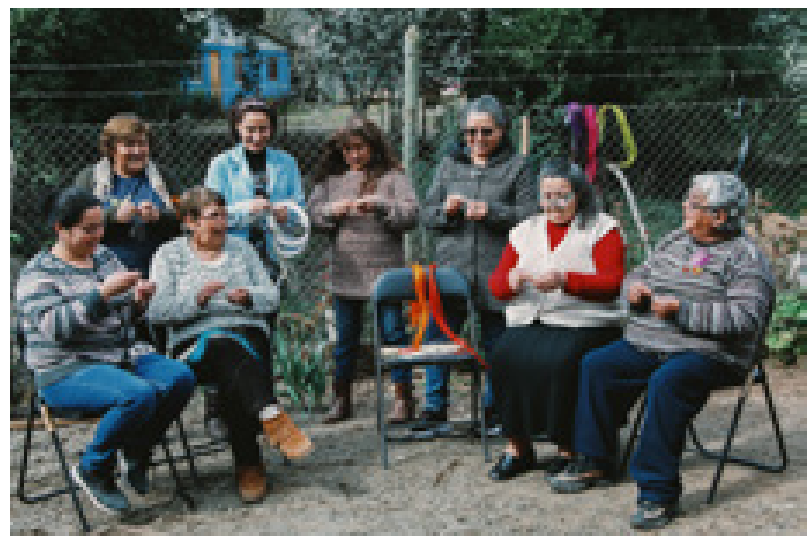

A gathering of Rari-Panimavida artisans of all ages museum next to the presidential palace. Every sale directly supports the artisan. "Artesanías de Chile has been a big help to us. They place their orders with us each month for ten months of the year. We dispatch, and they deposit the payment into our accounts. Due to the pandemic, orders were smaller in 2021, but at least they kept our business going." explains Amanda Salas, 84.

During the pandemic, Artesanías de Chile also launched an online store and campaigned through social networks to promote craft sales from Rari within Chile, especially the highly regarded "solidarity butterfly." Their platform has been successful and will soon allow international shopping. In the meantime, foreign customers can write to ventas@artesaniasdechile.cl to place orders.

According

to the authorities, targeted public policies and professional involvement have borne fruit. "Chile has made significant progress in the field of $\mathrm{ICH}$ training and education. We are also advanced in the promotion of intersectoral
Linares. The government also provided Rari with a Seal of Origin for its handicrafts and backed the community in their petition to have Rari declared a "City of the World Crafts" by the World Crafts Council. This recognition was obtained in 2015.

These distinctions, along with government-provided marketing and IT training for local artisans, as well as public spending on promotion (including road signage to facilitate tourism from outside the area), have helped to highlight the Rari-Panimavida heritage.

In addition, Artesanías de Chile certifies the delicate Rari products as genuine Chilean crafts, markets them, and sells them through its four brick-and-mortar stores. These include one shop in Santiago's international airport and another in a cultural center and strategies to provide social support to local communities that, in their great majority, are home to the most vulnerable population in the country," says Rodrigo Aravena, national undersecretary for $\mathrm{ICH}$, "especially in rural, indigenous, or traditionally feminized areas."

As the shadow of COVID-19 fades, senior artisans from Rari-Panimavida, who were all vaccinated in early 2021 and enjoy good health, are timidly allowing themselves to be hopeful. "I trust that our tradition will continue," Guadalupe Sepúlveda reflects. "As we once did, the young will find new ways of expressing themselves with our materials. We don't know what their creations are going to look like, but that's okay. We mustn't fear their creativity." 

Feature
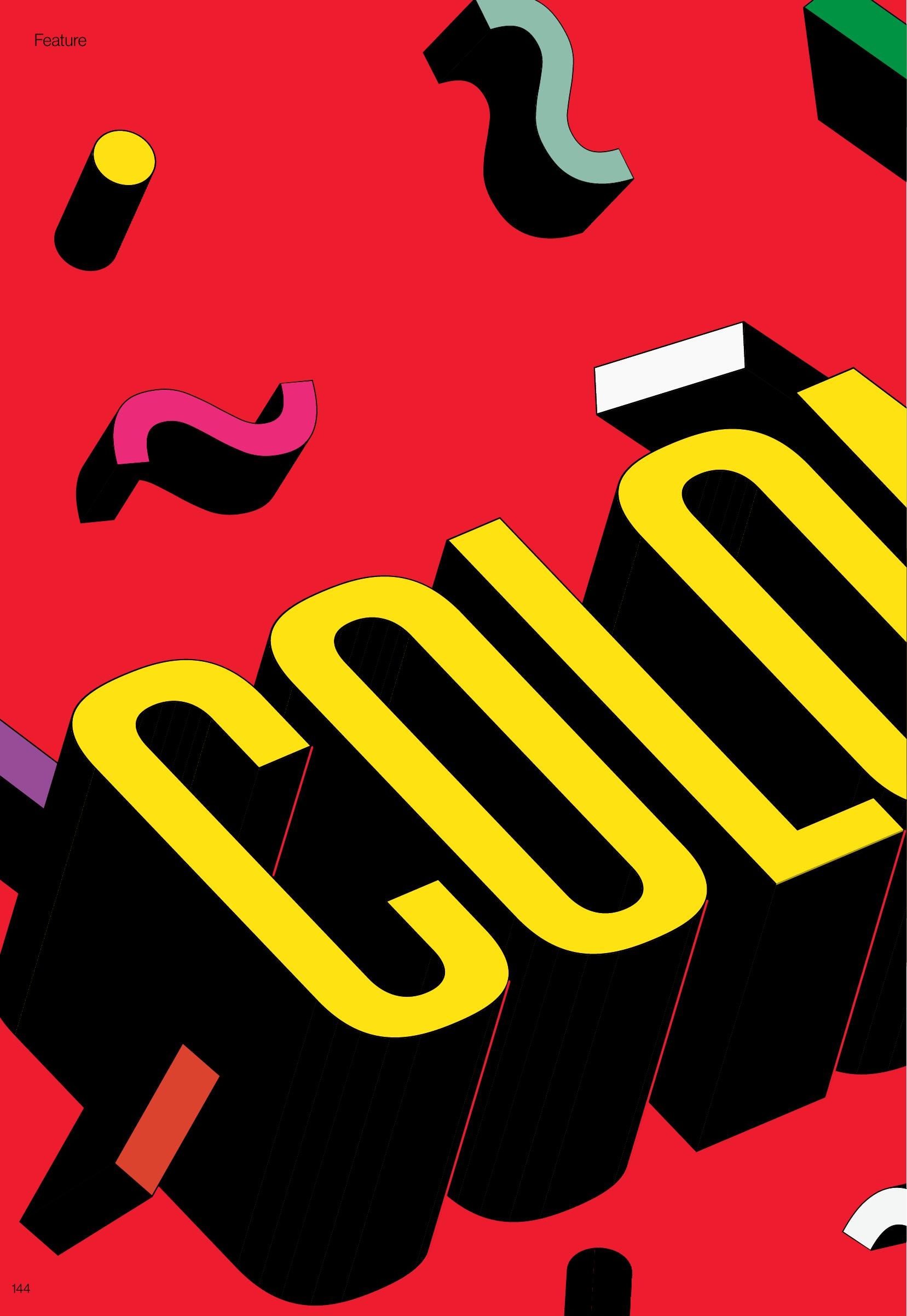
Feature

Like other countries in Latin America,

Colombia is experiencing a striking

demographic transition. By 2050,

the proportion of people age 60

and over is estimated to increase to

27.5 percent (up from 10.8 percent

in 2015) -an imminent shift that

will require the creation of a range

of policies to address their unique

needs. Although Colombia's universal

healthcare system is ranked among

the world's best and covers more than 95 percent of its population, inequality in healthcare access and delivery, particularly in rural areas, remains a challenge for those 60 -plus. The poverty rate among this group is the 
second highest in Latin America, with 40 percent of older people reporting incomes below the poverty line. A government noncontributory pension program, Colombia Mayor, launched in 2003, provides eligible low-income seniors with a monthly sum to help cover basic living needs. As Colombia continues to adapt to a changing demographic reality, both the public and private sectors have started exploring new opportunities for agefriendly programs and businesses, from apps that streamline banking and healthcare, to programs that encourage social engagement and improve quality of life. 


\section{Aging in Colombia}

\section{Demographic Profile}

1980

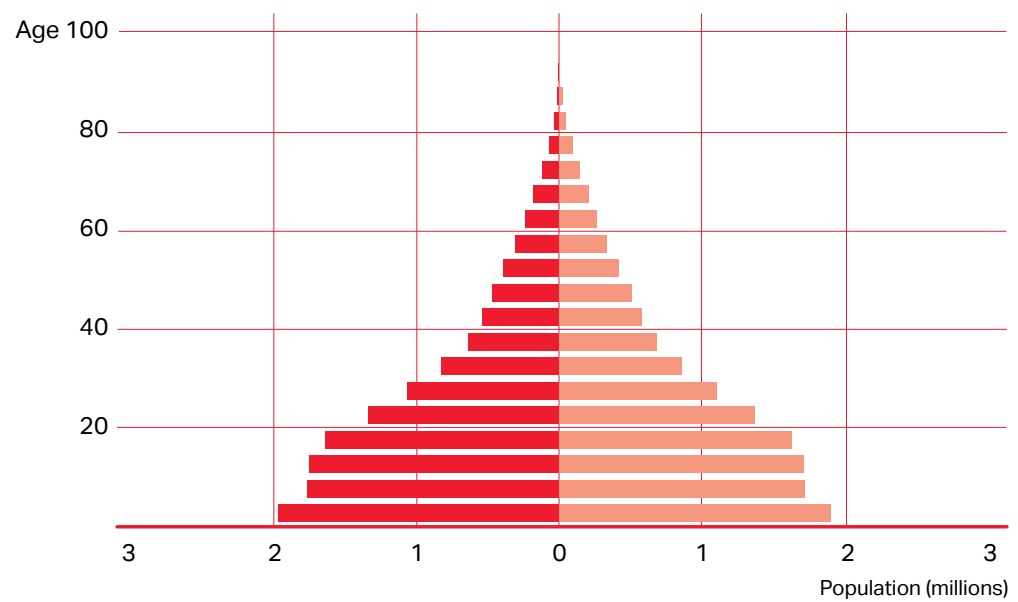

2020

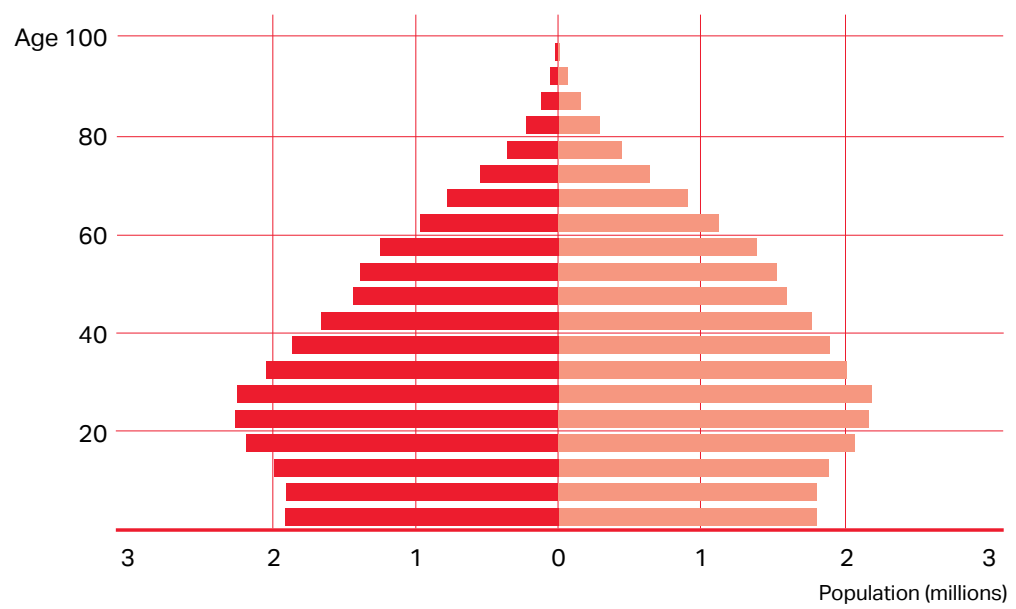

2060

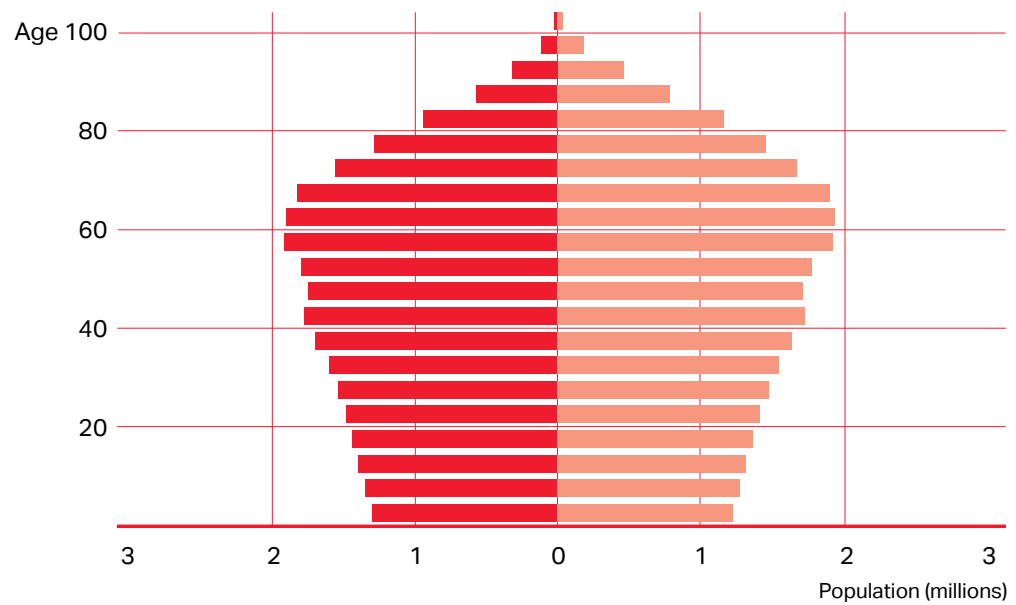



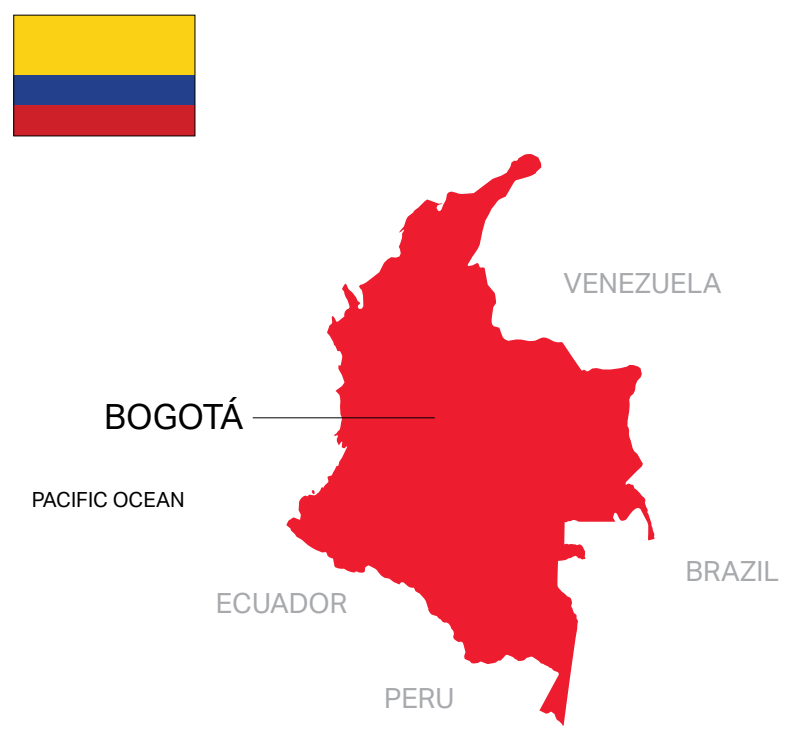

RELIGION

Roman Catholic 79\%, Protestant $14 \%$ (includes Pentecostal $6 \%$, mainline Protestant $2 \%$, other $6 \%$ ), other $2 \%$, unspecified $5 \%$ (2014 est.)

NET MIGRATION RATE -0.6 migrant(s)/1,000 population (2021 est.)

LIFE EXPECTANCY AT BIRTH

Total population: 77.3 years $\left(83^{\mathrm{RD}}\right)$

Male: 74.5 years

Female: 80.0 years (2020 est.)

BIRTH RATE

16.51 births/1,000 population (2021 est.)

MOTHER'S MEAN AGE AT FIRST BIRTH 21.7 years (2015 est.)

POPULATION GROWTH RATE

$1.07 \%$ (2020 est.)

URBAN POPULATION

$81.7 \%$ of total population (2021)

AGE STRUCTURE

$0-14$ years: $23.27 \%$

15-24 years: $16.38 \%$

25-54 years: $42.04 \%$

$55-64$ years: $9.93 \%$

65 years and over: $8.39 \%$

(2020 est.) $50.4\left(15^{\mathrm{TH}}\right)$

0.43

$7.6 \%(2018)$

OBESITY RATE

$22.3 \%(2016)$

LITERACY RATE

$95.1 \%$ Agriculture: $17 \%$

Industry: $21 \%$

PARTICIPATION RATE

$72.9 \%$ (2019 est.)

LANGUAGE

Spanish (official)
COLOMBIA

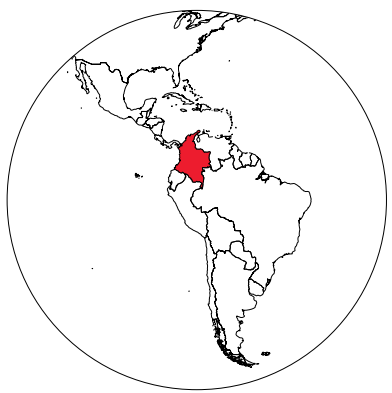

COUNTRY

Colombia

CONVENTIONAL LONGFORM NAME

Republic of Colombia

TOTAL AREA

$2,780,400 \mathrm{sq} \mathrm{km}$

$(1,073,518$ sq miles $)$

POPULATION (WORLD RANK)

$50,355,650\left(29^{\text {TH }}\right)$

POPULATION DENSITY (WORLD RANK) 44.76 per sq. $\mathrm{km}\left(166^{\mathrm{TH}}\right)$

GINI INCOME INEQUALITY INDEX (2018)

GENDER INEQUALITY INDEX (2019)

HEALTH EXPENDITURES

LABOR FORCE BY OCCUPATION

Services: 62\% (2011 est.)

RESIDENT LABOR FORCE

EXPORTS (US DOLLARS)

$\$ 61.697$ billion (2019 est.)

IMPORTS (US DOLLARS)

$\$ 87.072$ billion (2019 est.)
DEMONYM

Colombian

BUDGET (US DOLLARS)

Revenues: $\$ 83.35$ billion

Expenditures: $\$ 91.73$ billion (2017 est.)

GDP NOMINAL (US DOLLARS) \$323.26 billion (2019 est.)

MAIN INDUSTRIES

Textiles, food processing, oil, clothing and footwear, beverages, chemicals, cement; gold, coal, emeralds

NATURAL RESOURCES

Petroleum, natural gas, coal, iron ore, nickel, gold, copper emeralds, hydropower

GOVERNMENT TYPE

Presidential republic

ETHNIC GROUPS

Mestizo and White 87.6\%, AfroColombian (includes Mulatto, Raizal, and Palenquero) $6.8 \%$, Amerindian 4.3\%, unspecified $1.4 \%$ (2018 est.) 


\section{How Colombia Uses Education to}

Drive Its Healthy Longevity Work

\section{Education is a fundamental pillar of our work at Fundación Provida Colombia. As we seek to address literacy, technology adoption,} social-emotional supports, and healthy aging, we aim to educate not only older Colombians but also the entire population on the value of prioritizing longevity and framing it in a positive light. This is not without significant challenges. Discrimination, illiteracy, and isolation all threaten to upend efforts to create a society that embraces individuals at every life stage.

Fundación Provida Colombia was founded in the 1970s by visionaries Eduardo Garcia Jacome and Rita Duarte. As leaders of this organization, we strive to protect the rights of older persons in Colombia and to promote active and healthy aging in the country. These aims are not achieved overnight, and everyone shares the challenge of preparing new programs that will ensure all individuals, especially the next generations of seniors, can possess a strong sense of purpose.

To expand on this work to protect the rights and well-being of older adults, Fundación Provida Colombia hosted its first Conference on International Longevity with Purpose in October 2021. This conference identified challenges ahead and envisioned longevity as a process that is important and relevant at all stages of life.

\section{Providing Access to Education}

Older Colombians remain at a disadvantage in the field of education as a notable portion of the adult population cannot read or write. Efforts to improve literacy after the implementation of Colombia's 2016 guidelines for formal education have had little impact on older persons. Adults between 60 and 64 years old have an illiteracy rate of 10.4 percent, and, for those over the age of 85 , the rate is 30.5 percent. Illiteracy rates in the Caribbean region exceed 25 percent, while in other regions, it is between 16-18 percent, with Bogotá accounting for an illiteracy rate 


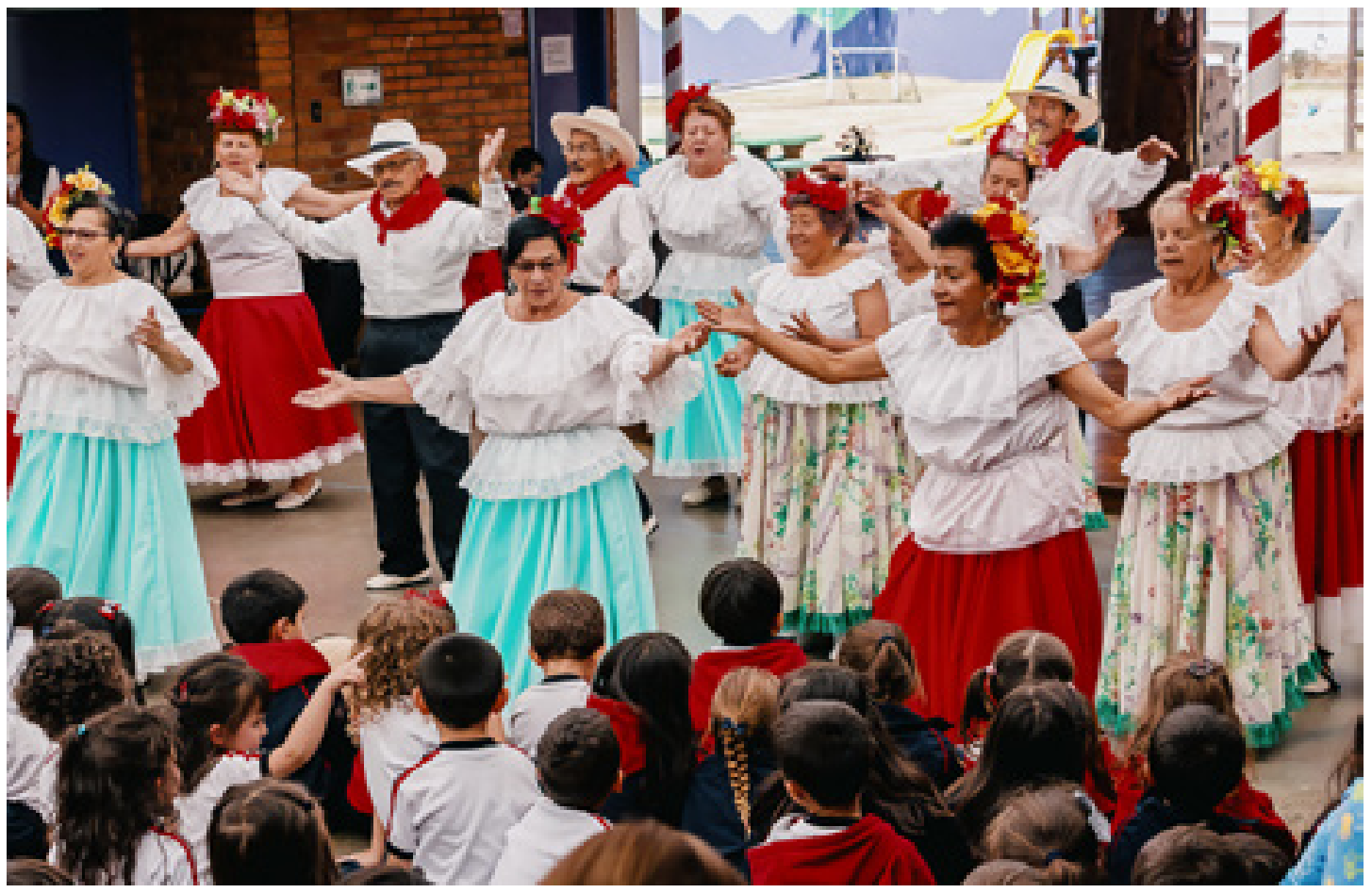

of 8.2 percent. ${ }^{1}$ Under the 2016 guidelines, the Ministry of Education's efforts focused on young people in particular areas of the country, thus deepening not only geographical gaps, but also generational ones.

On September 10, 2020, Colombia's Congress ratified the Inter-American Convention on the Protection of the Human Rights of Older Persons, which was formally adopted by the Organization of American States in June 2015. This convention highlights the concept of active and healthy aging for all individuals and recognizes education as a key component of this process - not only because access to education is a human right, but also because access to education encourages personal growth, the acquisition of new knowledge, social participation, and more.

Since the early 1990s, Fundación Provida has sought to improve education among older adults. By helping to enroll older persons in university programs of art, natural sciences, law, economics, agricultural sciences, business administration, gerontology, computer sciences, and other disciplines, we've focused on a comprehensive education program. In addition, we've helped more than 300 seniors to graduate from primary school. Through Fundación Provida's additional Dream Maker and Dream Maker Silver programs, seniors and their families have found another way to connect, learn, teach, and share. In virtual rooms, the organization 


\section{To encourage healthy longevity, we need to value a person-centric education system by prioritizing personal development in a learning environment that nourishes the mind, soul, and spirit, as well as the establishment of a community mindset.}

gathers children, young people, adults and seniors to collectively take classes about theater, cooking, creative writing, weaving, business development, empathy, history, English, and more.

\section{Creating Virtual Community}

This educational work has enabled our experts to identify tools that make learning more accessible to seniors and their families and played a critical role in our ability to respond to the severe isolation created by the COVID-19 pandemic. In 2020, we launched the Universidad de la Longevidad (University of Longevity) to provide a way for older adults to maintain connections while the world stood still. Universidad de la Longevidad provides space for virtual communication and home learning during the weekdays.

The Universidad de la Longevidad envisions education as a means for creating awareness about how present society requires learning from life experiences, transitions to new stages of life, and recognizing each of our victories, defeats, challenges, and opportunities.
We have identified four action areas as part of this initiative:

1. Longevity: the basic aspects of active and healthy aging, which allow for the improvement of older adults' quality of life and promote their independence.

2. Socio-Emotional Competencies: building skills such as empathy, independence, gratitude, self-knowledge, self-control, and collaboration to strengthen the personal development of children, young adults, and older adults and improve wellbeing.

3. Life and Spirituality: embracing spirituality as a lifestyle that balances how we think, feel, and act with being in harmony with the surrounding worldfostering connection with a sense of life and purpose.

4. Healthy Lifestyles: promoting longevity of the mind, body, and soul by redirecting our habits and beliefs to achieve a meaningful life.

These action areas inform our efforts to engage with older adults and the 
larger Colombian community, and they are especially critical in addressing some of the biggest challenges facing older adults in recent years.

Our work also confirmed that the generalization that older adults cannot manage or adapt to technology is false. Through Universidad de la Longevidad, Fundación Provida's community managed to stay connected virtually and, on average, 70 people joined virtual programs each week.

Even prior to the pandemic, older adults were navigating technology. In 2018, a Departamento Administrativo Nacional de Estadística (DANE, National Administrative Department of Statistics) survey found there were more than 6 million older adults in Colombia, and some respondents reported using new technologies. According to survey results, 30.1 percent of older adults use the Internet. Of this group of individuals, 40.9 percent used computers to access the Internet, and 95.1 percent used smartphones. ${ }^{2}$

\section{Establishing Healthy Longevity}

To encourage healthy longevity, we need to value a person-centric education system by prioritizing personal development in a learning environment that nourishes the mind, soul, and spirit, as well as the establishment of a community mindset.

Our October 2021 Conference on International Longevity with Purpose set this in motion. During the four-day event, over 2000 people visited our website, and over 400 attendees gathered online to learn from experts from Spain, Costa Rica, Mexico, Argentina, Bolivia, Colombia, Brazil, and Cuba. Older adults were included as speakers as well as attendees in discussions on intergenerational solidarity, physical activity, economic security, life-long learning and social and health services - all of which impact active and healthy aging.

As leaders of Fundación Provida Colombia, we believe healthy longevity is a matter of concern for all ages. Society must stop passing negative perceptions of old age to younger generations, because those visions inflict harm by increasing age discrimination against older and younger individuals.

\footnotetext{
EFA Global Monitoring Report 2000-2015, UNESCO

Publishing, www.efareport.unesco.org

${ }^{2}$ Encuesta SABE Colombia. Ministerio de Salud y Protección social - Departamento Administrativo de ciencia y tecnología e Innovación COLCIENCIAS Universidad del Valle de caldas (2016)
}

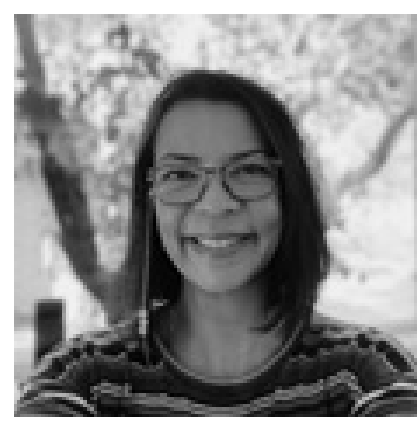

JULIETA RODRIGUEZ

President

Fundación Provida Colombia

\section{NANCY BOHORQUEZ}

Transformation and Innovation Advisor Fundación Provida Colombia 


\section{Day in the Life}

\section{Patricia ("Pati") Romero}

\section{Bogotá, Colombia}

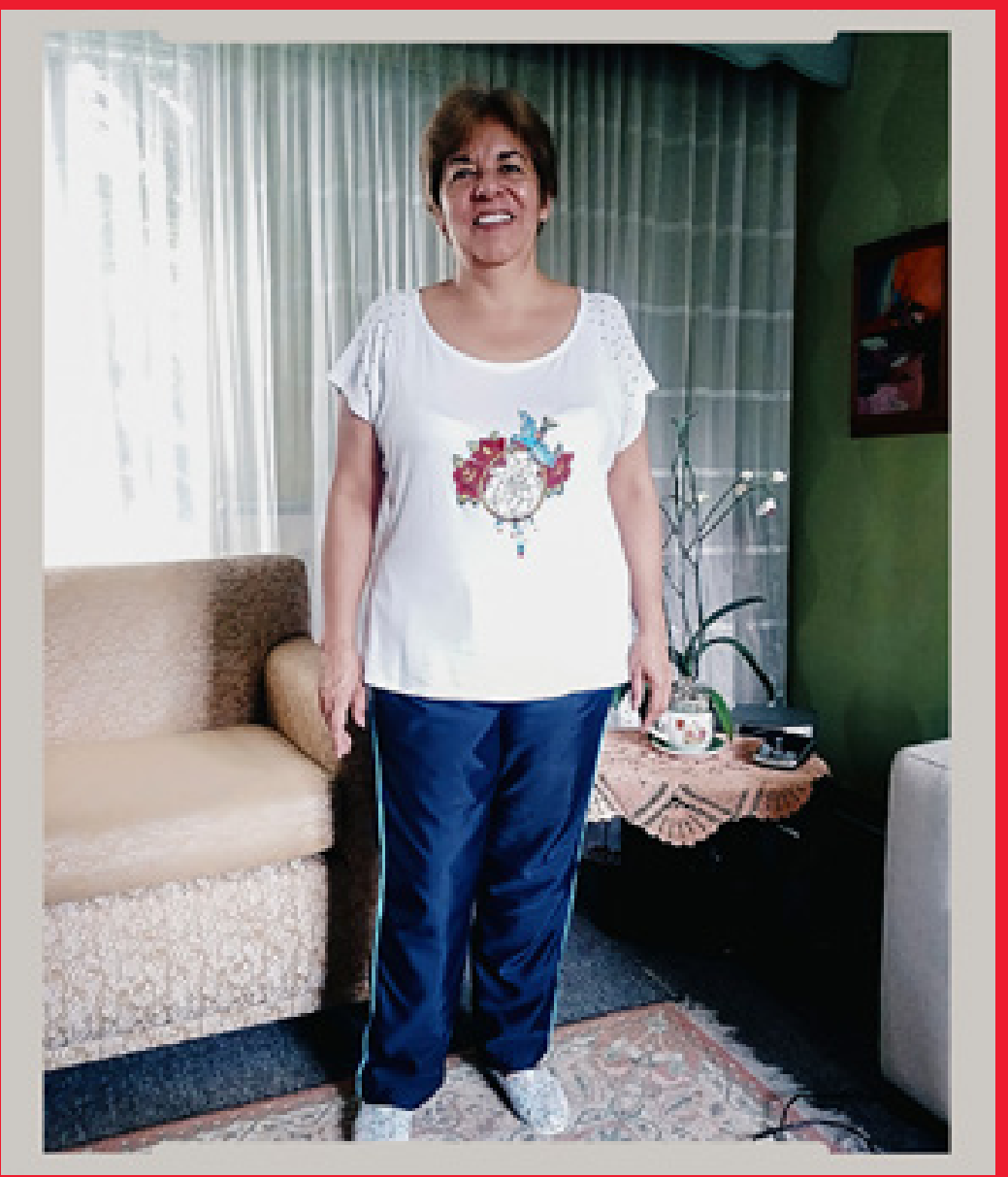

Pati is an elementary school teacher and mother of two adult daughters who lives in Bogotá. With her siblings living outside of Colombia, Pati is the primary caregiver for her parents, ages 82 and 83. 


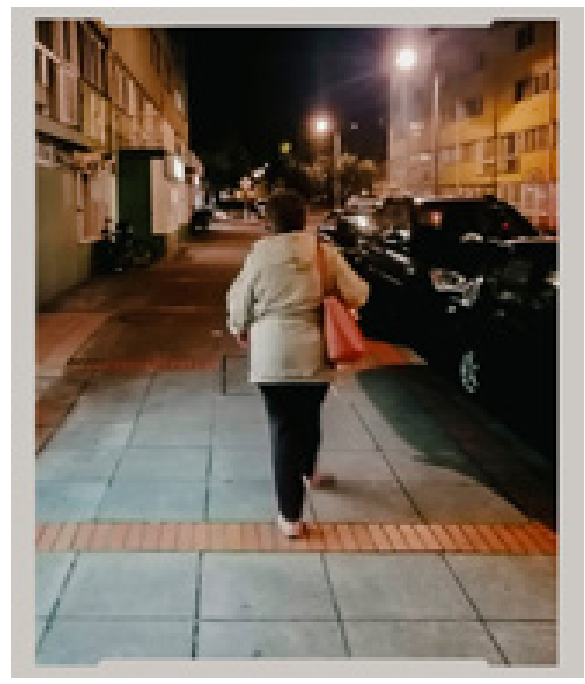

Walking to work early in the morning

\section{What is your typical day like?}

My day starts at 5:00 a.m. when I get ready and organize breakfast and lunch for my husband and my daughter and I walk the two miles to my workplace.

My work at the school begins at 7:00 a.m. when I receive the children in class until 2:00 p.m. when parents start picking them up. I am a teacher of elementary second grade. When I finish my workday, I walk to my parents' house where I usually share lunch with them, take them to medical appointments or help them with a variety of errands. I stay with my parents until 6:00 p.m., then I walk back home. I live one mile away from them. I eat dinner with my husband and my youngest daughter, who is still living at home.

I am a mother of two daughters, Diana, 25, and Fernanda, 30, and I live with my husband Jorge, 65 , and my youngest daughter. All three of us work, so the time we share is early in the morning and at night when we eat together, watch news, and get ready for the next day. I am blessed to have my parents close by because I really enjoy family life a lot. I don't dislike anything about my family situation. I do recognize that it involves effort and sacrifice but it's extremely rewarding.
What activities do you enjoy most?

I enjoy every task in my life, but especially those that have to do with my job. I have always liked to see the results of education carried out with the children, as well as their joy, their sincerity, and their ability to learn.

\section{How do you stay physically active?}

I am not a sporty type of person but frequent, long walks from home to the workplace and working with children require constant movement, so I try to compensate that way.

\section{How do you stay mentally and socially active?} Both at work as well as with the family, I am aware of everyone's needs and bring people together. I organize birthday meetings and celebrations and enjoy sharing these moments with those around me.

\section{What do you find most challenging about growing older?}

The greatest challenge of aging is to keep living, to move on with life and enjoy past accomplishments; to keep having expectations for the future without feeling burdened, nor displaced, and, on the contrary, supporting others to fulfill their own purpose.

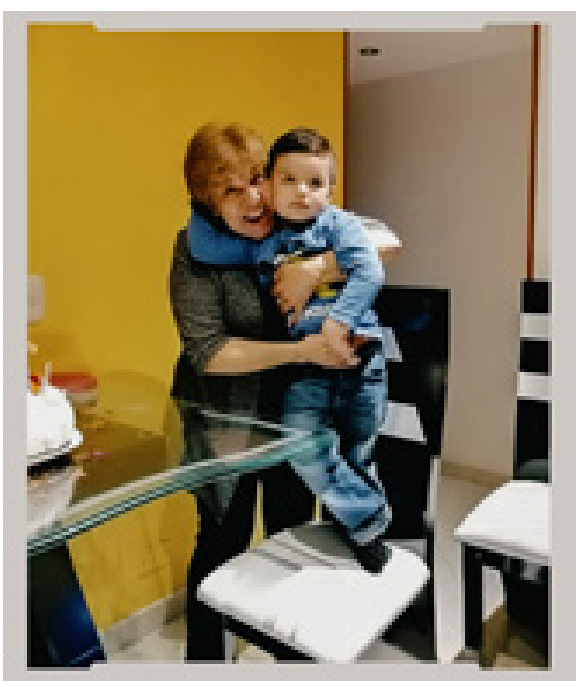

Spending time with her sister's grandson, whom she treats as her own grandchild 


\section{Day in the Life}

\section{Patricia ("Pati") Romero}

\section{Bogotá, Colombia}

\section{8 years old}

"The greatest challenge of aging is to keep living, to move on with life and enjoy past accomplishments; to keep having expectations for the future without feeling burdened, nor displaced, and, on the contrary, supporting others to fulfill their own purpose."

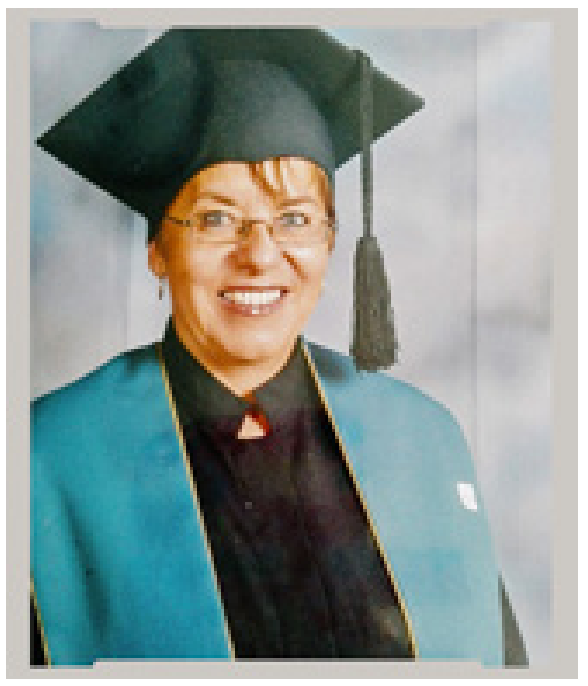

A photo commemorating her new diploma - a doctorate in education, which she earned just before the start of the pandemic

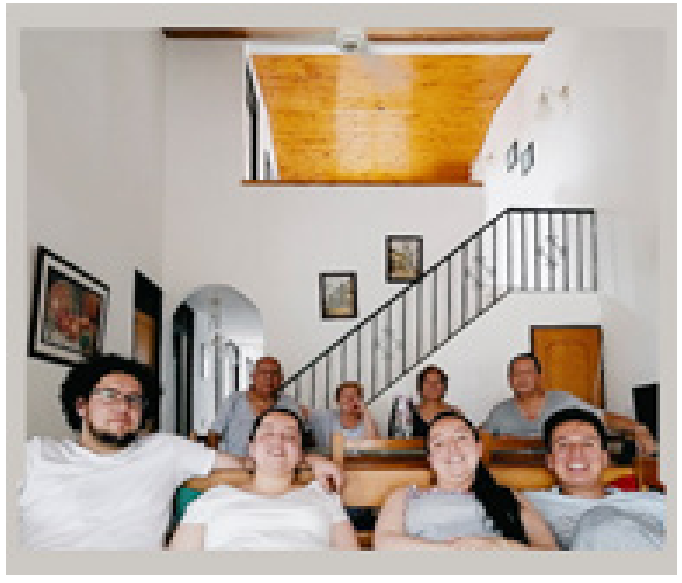

Pati, Jorge, and family in their vacation home (and future retirement residence) in the countryside

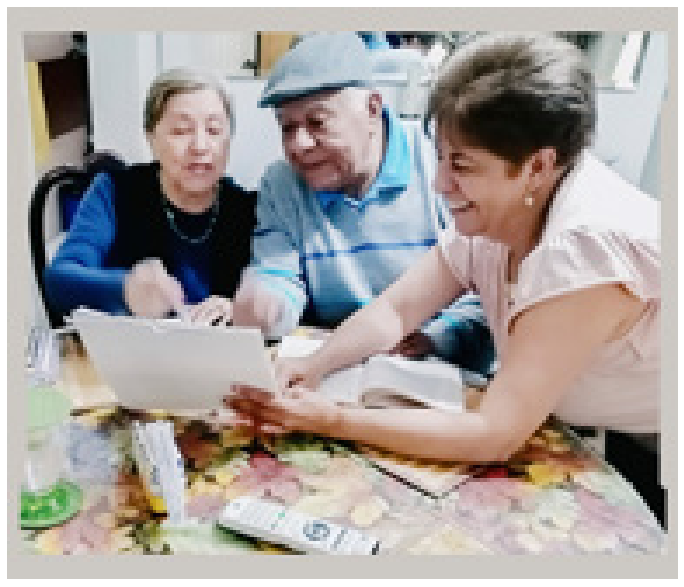

Pati reviewing the calendar with her parents, which is where she keeps track of their medications and upcoming appointments

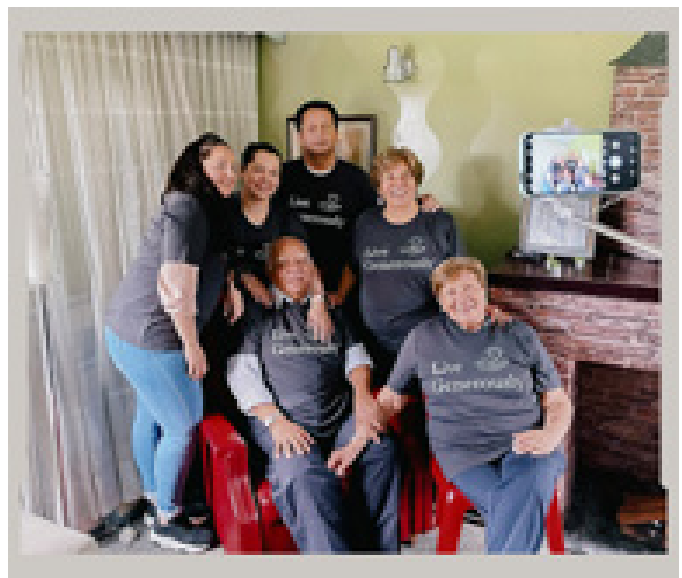

Pati, Jorge, their two daughters, and Pati's parents 


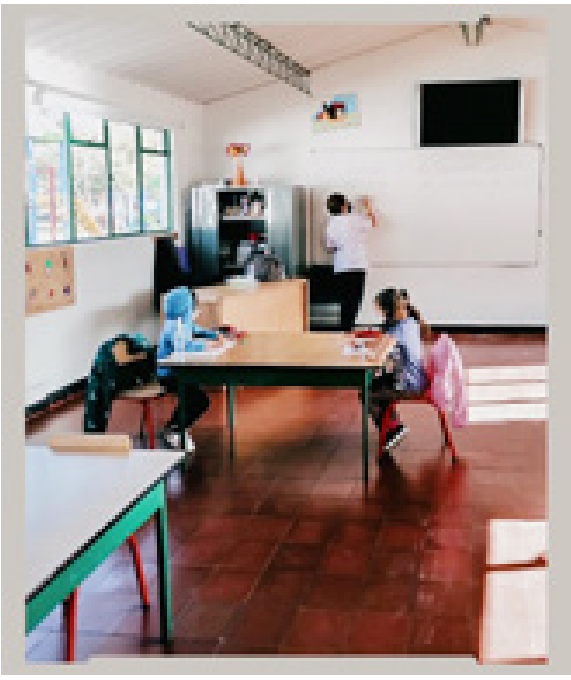

Teaching a class of elementary school students

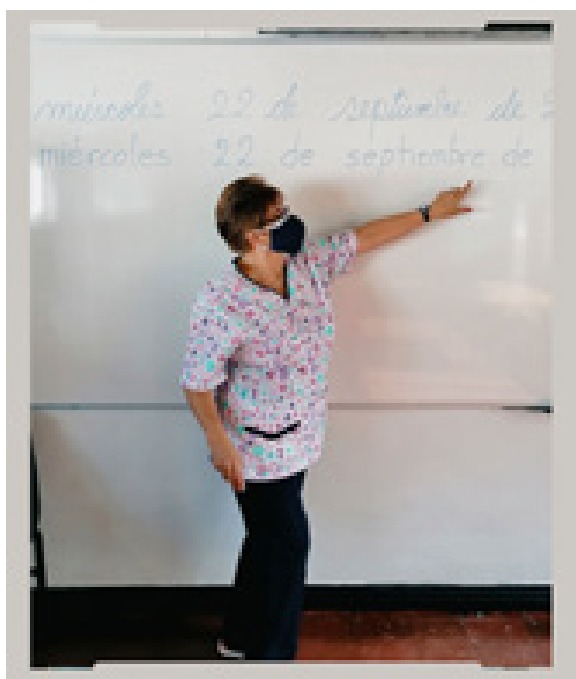

Pati in her classroom; her school resumed in-person instruction in 2021

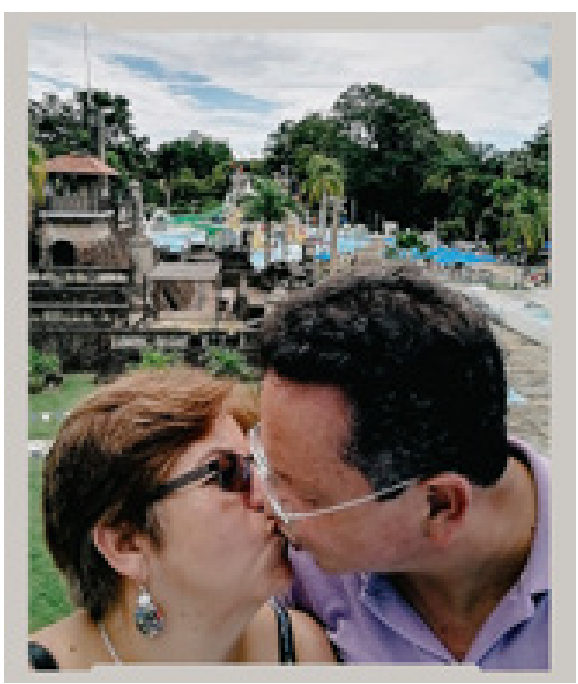

Pati and her husband of $\mathbf{4 0}$ years, Jorge

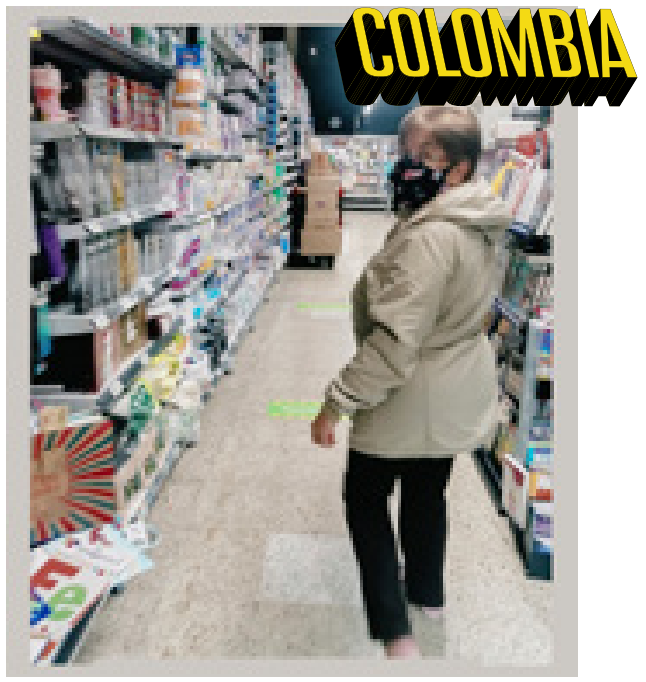

Grocery shopping

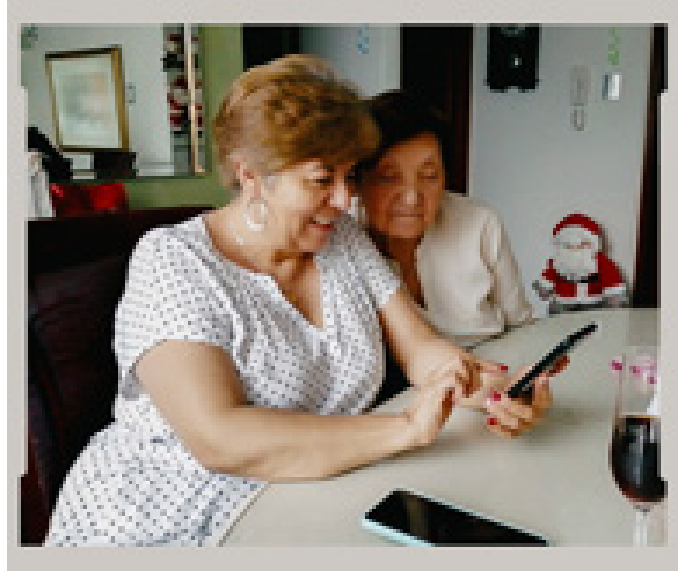

Troubleshooting a cell phone with her aunt, whom she cares for in addition to her parents

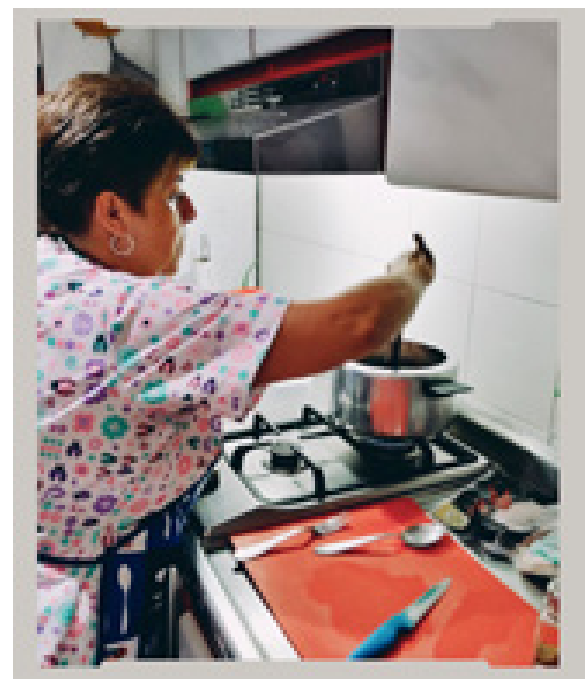

Cooking after work for her family 

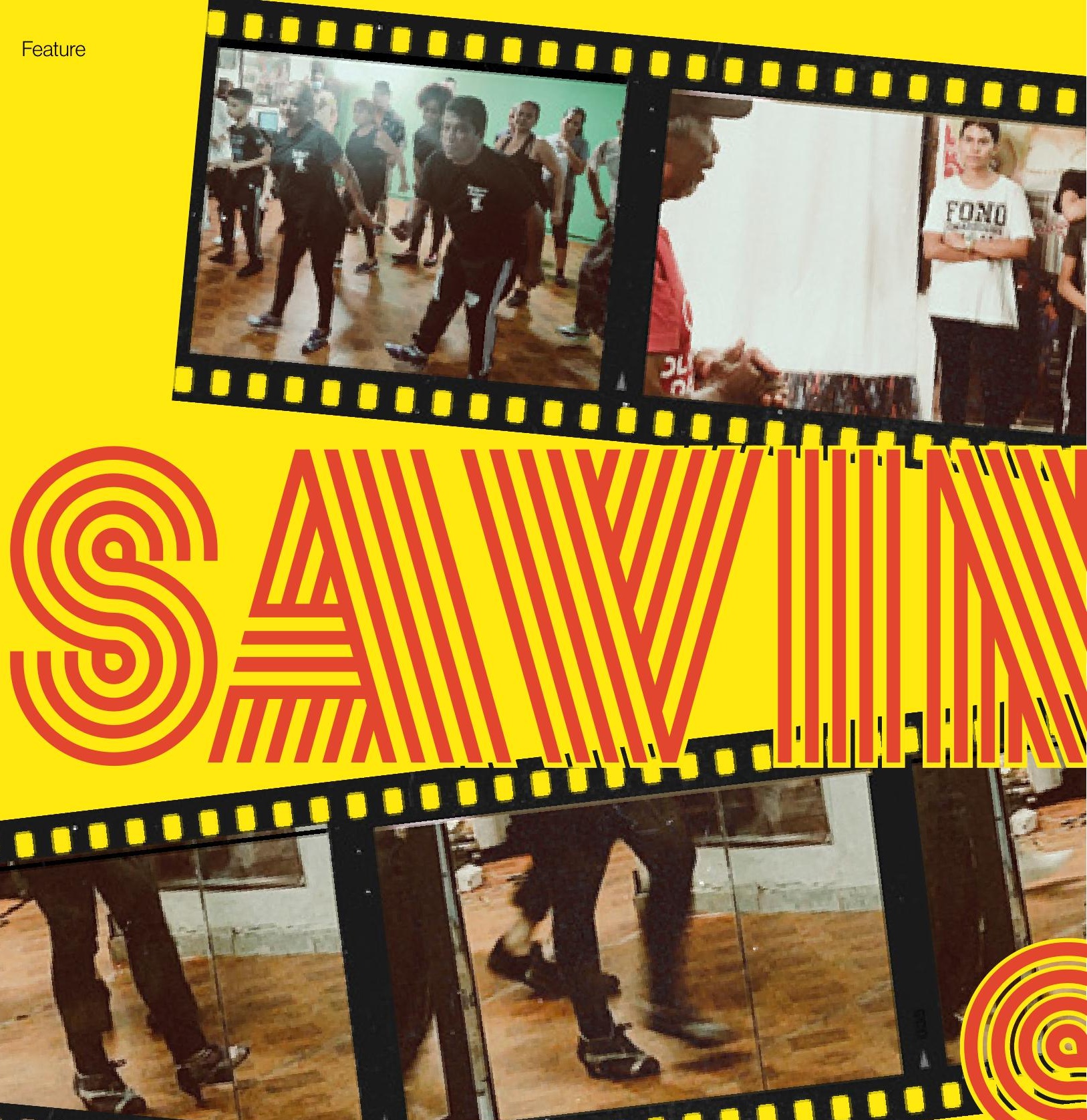

19: $\Rightarrow=0$

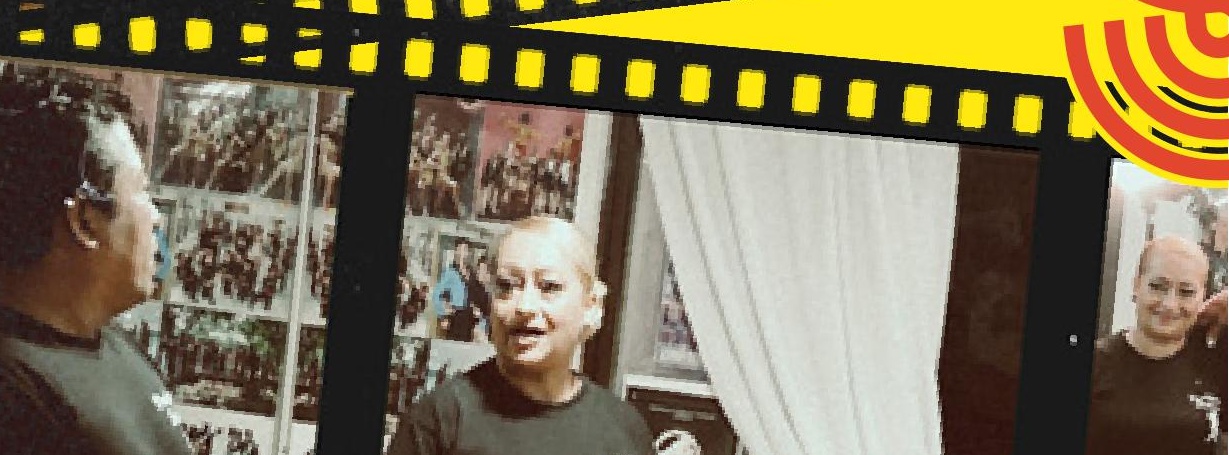

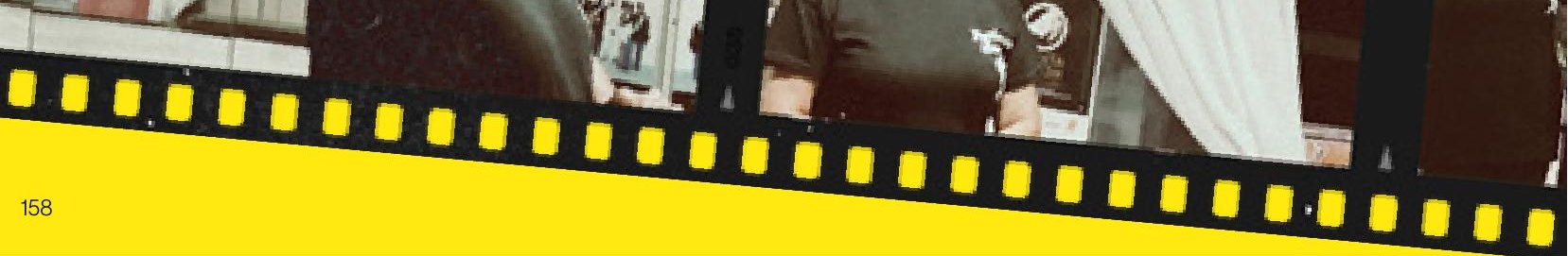


All $s$ thunder claps and rain pours outside in a working class neighborhood IItrinlllof Cali, Colombia, a pair of dancers goes through new salsa moves. These dance legends are teaching youngsters the flourishes and frenetic footwork that make up the city's unique salsa dancing style. Aceneth Ortiz, 53, and her husband Douglas Guerrero, 55, known as the "King and Queen of the Smooth Step" have nearly a century of experience between them. But they are "the babies" of a group of veteran dancers over age 50 who promote - and still dance - the world-renowned Salsa Caleña.

This dance collective, known as la vieja guardia, which literally translates as "the Old Guard," is now working with Cali's government to preserve Salsa Caleña for future generations and pass on their skills and passion through workshops, classes, and outreach around the city. 


\section{CULUVIBA}
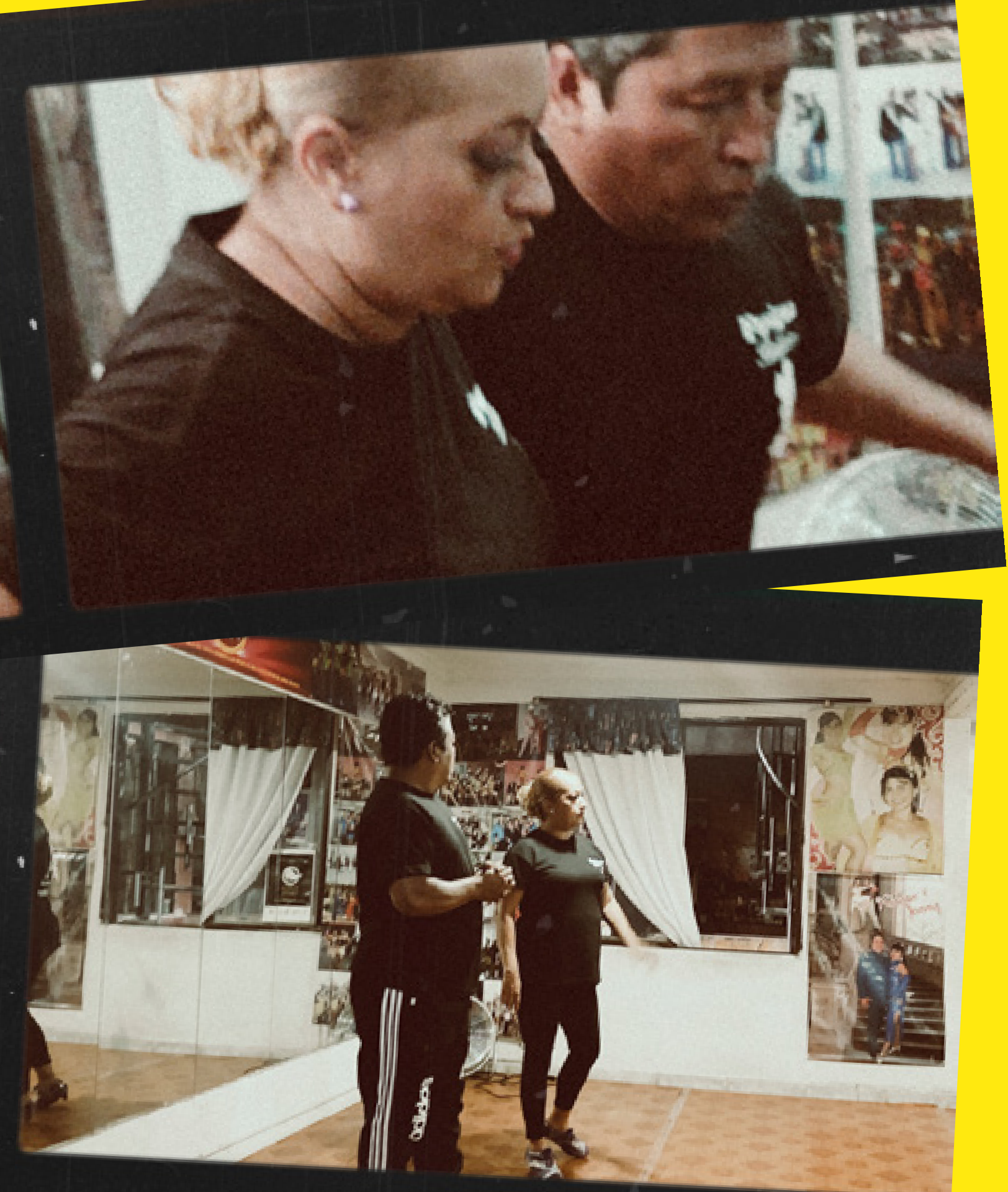
Salsa Caleña, known for the liveliness of its music and the fast, fancy footwork of its moves is now danced and taught around the globe, but changing musical tastes, the economic impact of the pandemic, and the aging population of its most ardent adherents have put Salsa Caleña at risk of extinction in its world capital.

"Salsa Caleña is the best pandemic to ever sweep the world," said Ortiz, with a cheeky smile and a flourish, showing off her across the Caribbean and then to Colombia's main Pacific port of Buenaventura in the 1960s and 70s. "In New York, the big salsa hotspots were The Palladium Ballroom, The Bronx Casino and La Campana," he said, "The sailors visited these places, bought the records and brought them to the bars and cantinas of the port of Buenaventura, a threehour drive from Cali."

But when salsa arrived in Cali, it was far from the cultural icon that it is today. "When I started to write about salsa in
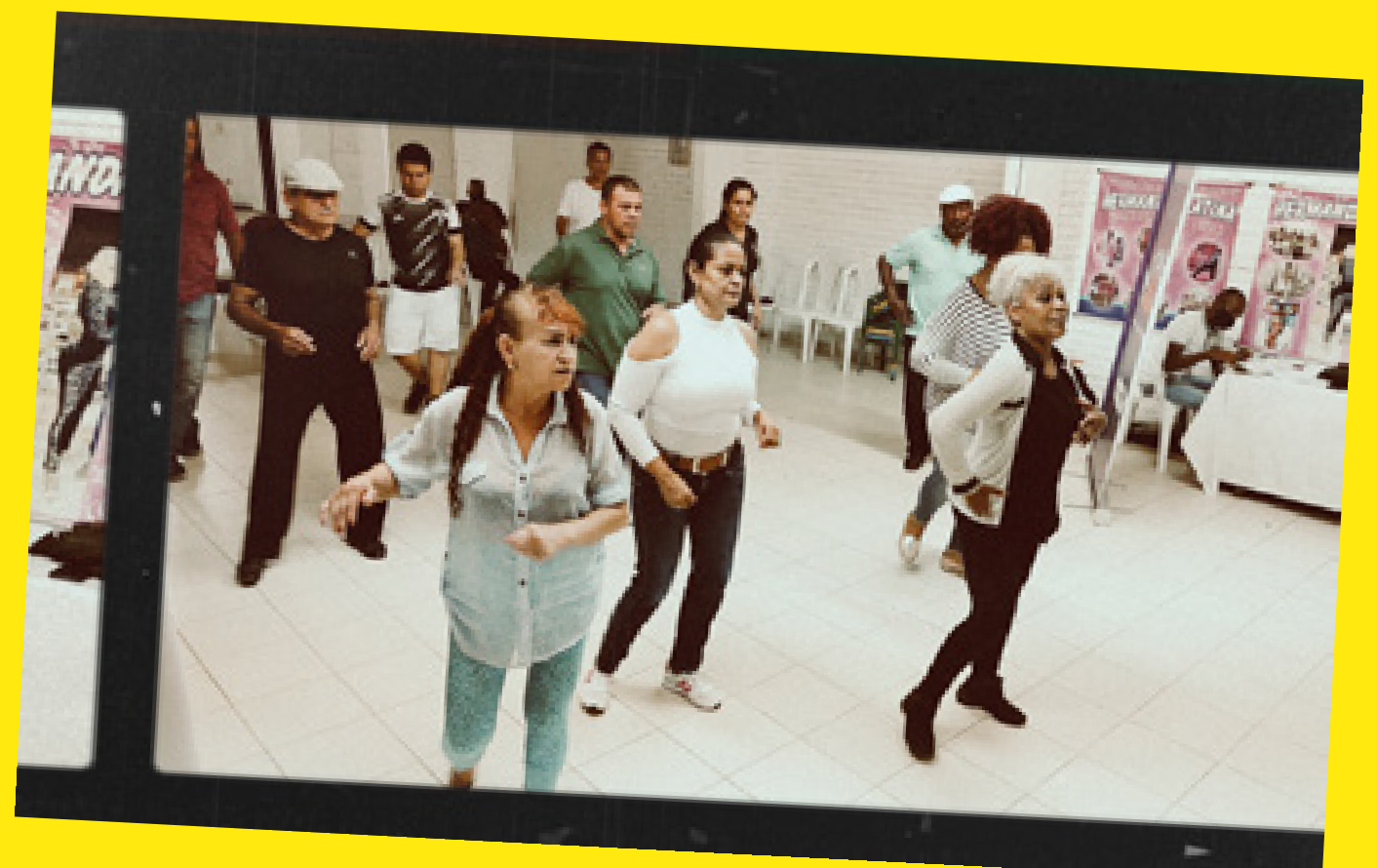

Members of the "vieja guardia", which literally translates as "the Old Guard," practice salsa dance moves at a community center in Cali, Colombia.

perfectly coiffed hair, immaculate makeup, and purple dance shoes.

\section{How Cali Became a World Capital of Salsa}

At Cali's annual book fair, Colombian journalist Merdado Arias, author of La verdadera historia de la Salsa (The True History of Salsa), sat down to explain that while salsa has Cuban and Puerto Rican roots, "without a doubt, New York was where it was truly born." He said salsa arrived in Cali with sailors working a route that ran down the east coast,
1981, it still wasn't very accepted in Colombian society," he said. "It was the music of sailors, vagabonds, and prostitutes - the down-and-outs."

It was in this era when many of Cali's Old Guard learned their moves - in the family rooms and bars of the city's working-class neighborhoods - not in the profusion of dance schools now found in the city's tourist zones.

"I grew up in a family that danced well... as 

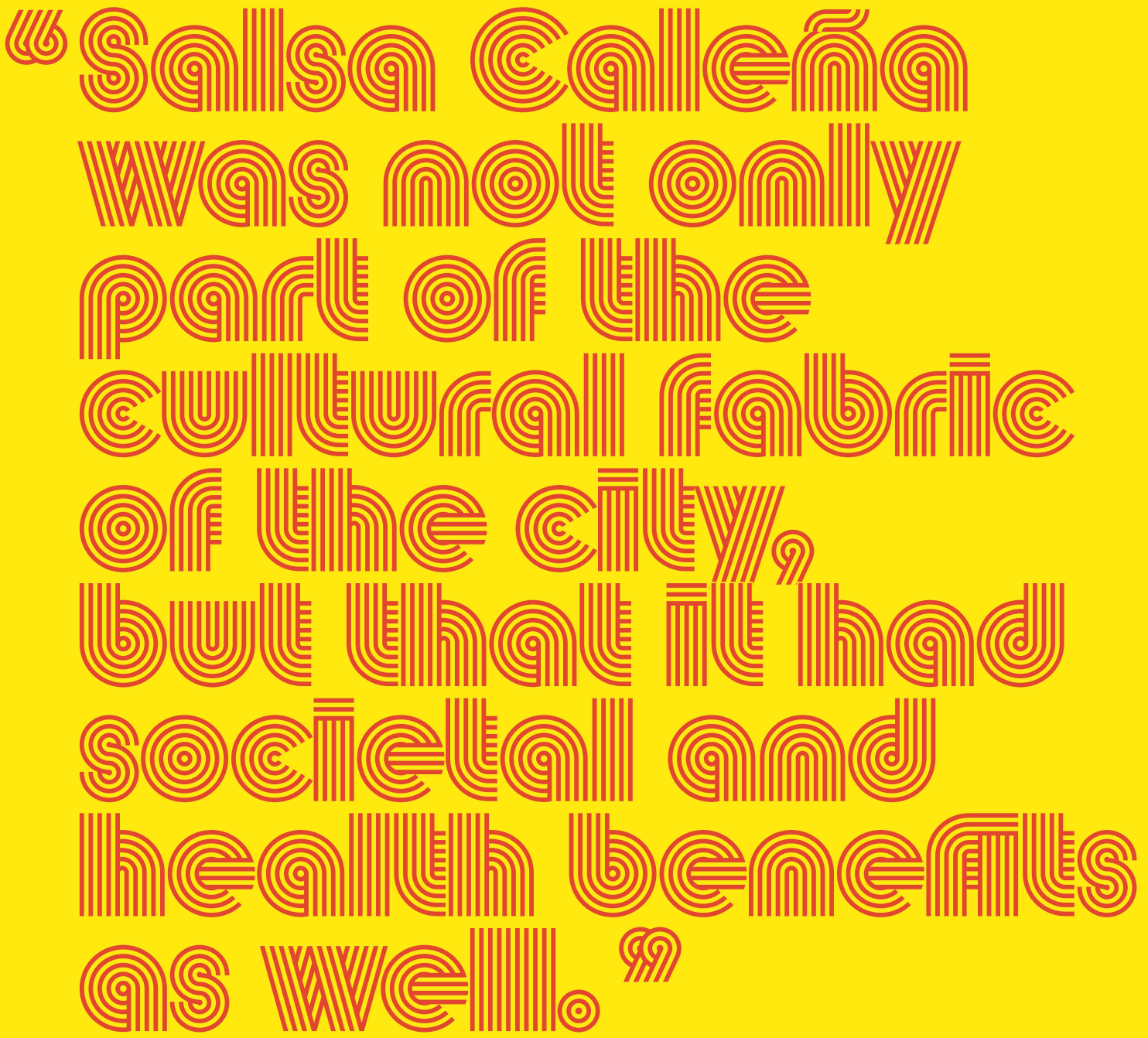

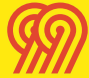

a kid we would move the family dining table aside and dance there," Ortiz said.

Salsa Caleña would slowly but surely become not just an immensely popular pastime but also an artform and iconic dance style. By December 2019, over 25,00 tourists of all stripes were visiting Cali during the Feria de Cali, the year's biggest event for Salsa Caleña.

\section{Meeting The Old Guard}

In July of 2020, Cali's city government approved what it called a "Special Safeguard" plan to save its salsa, which it aimed to get recognized as part of Colombia's national cultural heritage. This would help guarantee resources from the central government and to create cooperation agreements to help build on the existing "salsa economy."

In October 2021, a series of brainstorming sessions and dance classes began, where members of the Old Guard joined with the city's culture office, local academics, parents, and children to ask what it was about Salsa Caleña that they wanted to save.

The consensus in one of the sessions (where the discussion was written out on cards to create a collage of ideas) was that Salsa Caleña was not only part of the cultural fabric of the city, but that it had societal and health benefits as well. The hope expressed in the session was that increased awareness of these additional benefits would strengthen the impetus to preserve this cultural icon.

After that session, as people began to dance in the light of the setting sun, at the 

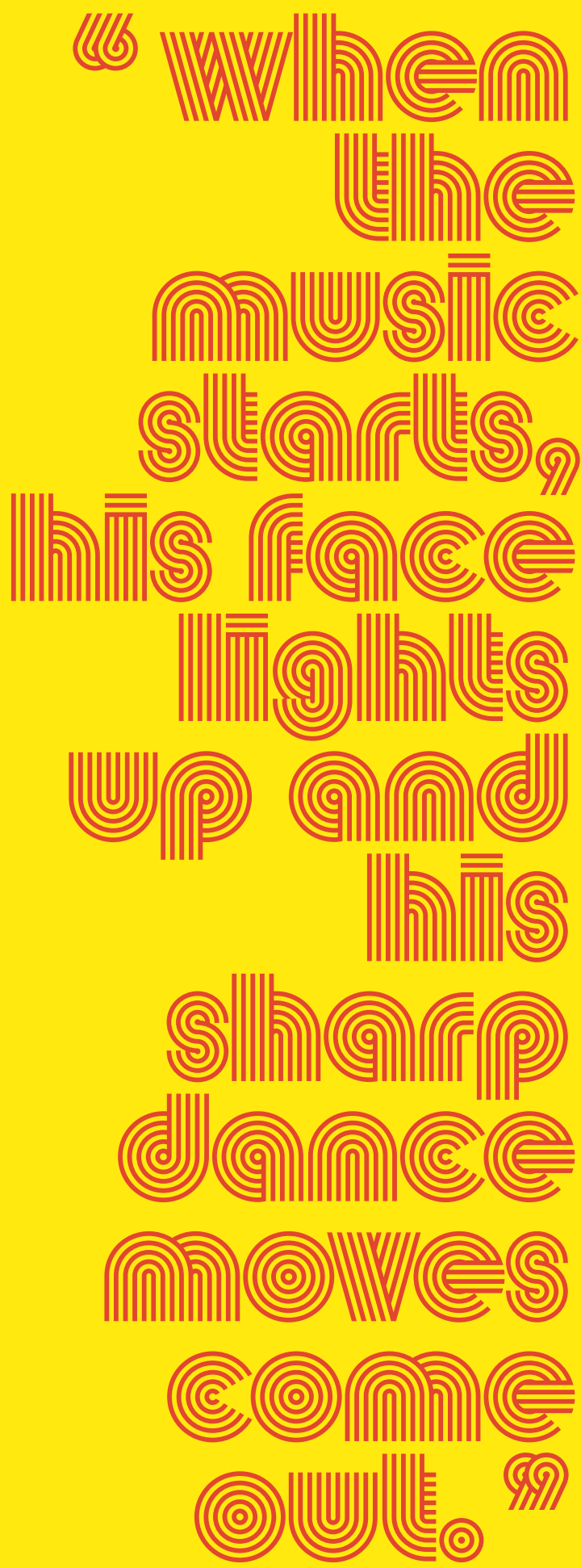

(Q) back of the crowd sat Miguel Santiago García, 78, known to everyone there as Guaracho, after Gauracha, the frenetic dance and lyrical genre that defines his personal dance style.

Dressed in a green polo and white flat cap, one might think he was ready to golf, but when the music starts, his face lights up and his sharp dance moves come out. Afterwards, parents line their children up to get their photo taken with this living legend. "We're a tropical city... Cali is where every rhythm that arrives here seems to stick," García

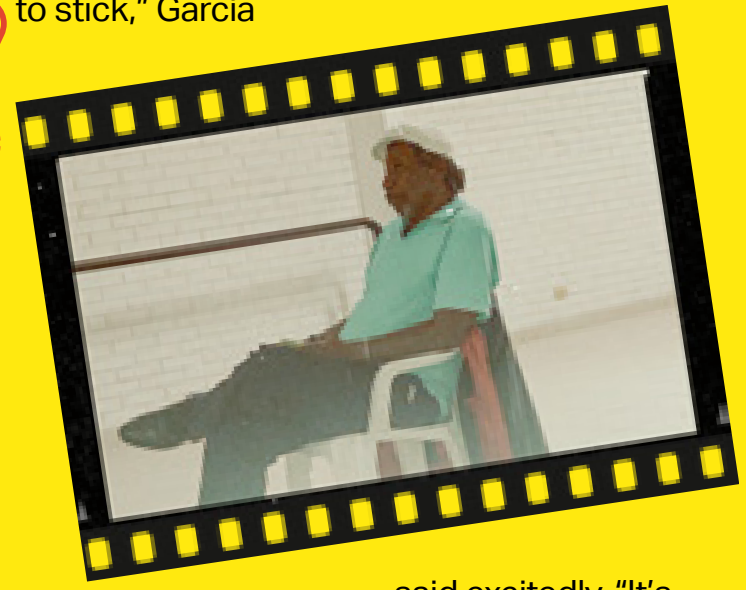
where passion builds."

But when COVID-19 struck, the city's dance economy - all the bars, schools, and hostels - ground to a halt.

"We couldn't go out to dance, we were isolated," Garcia recalled, referring to the strict lockdowns and stay-at-home orders that spanned most of 2020 and some of 2021 in Colombia. "But salsa is always in my heart and I kept practicing in front of the mirror when I couldn't go out."

Aceneth Ortiz, Garcia's fellow Old Guard dancer, explained that about half of the group, including her own husband, had caught COVID-19 at some point, often because they had to leave the house to work, even as infections raged. "My husband and I had a business making salsa costumes. But when the pandemic came, we had to let all of our 10 staff go and reinvent ourselves," 


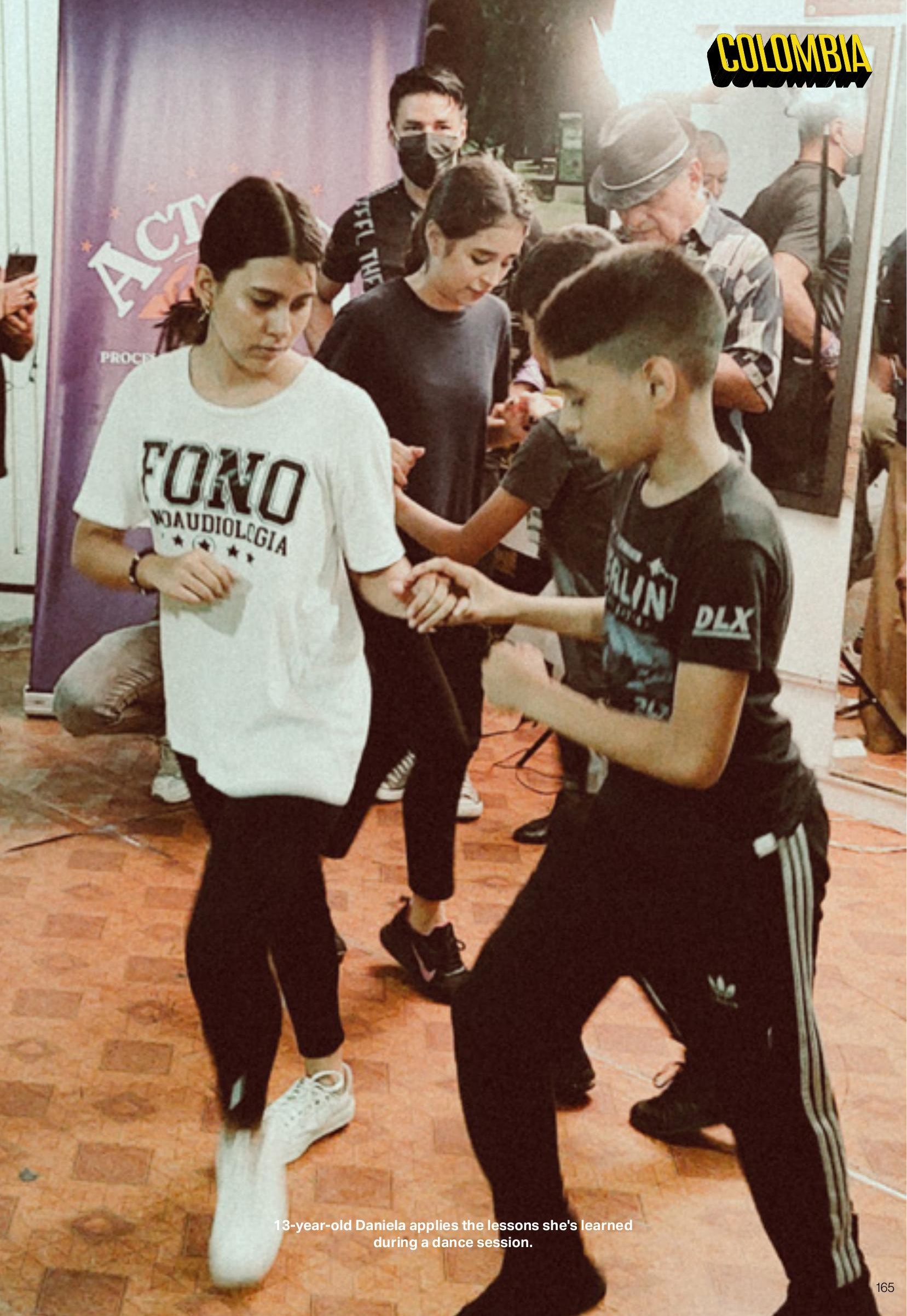




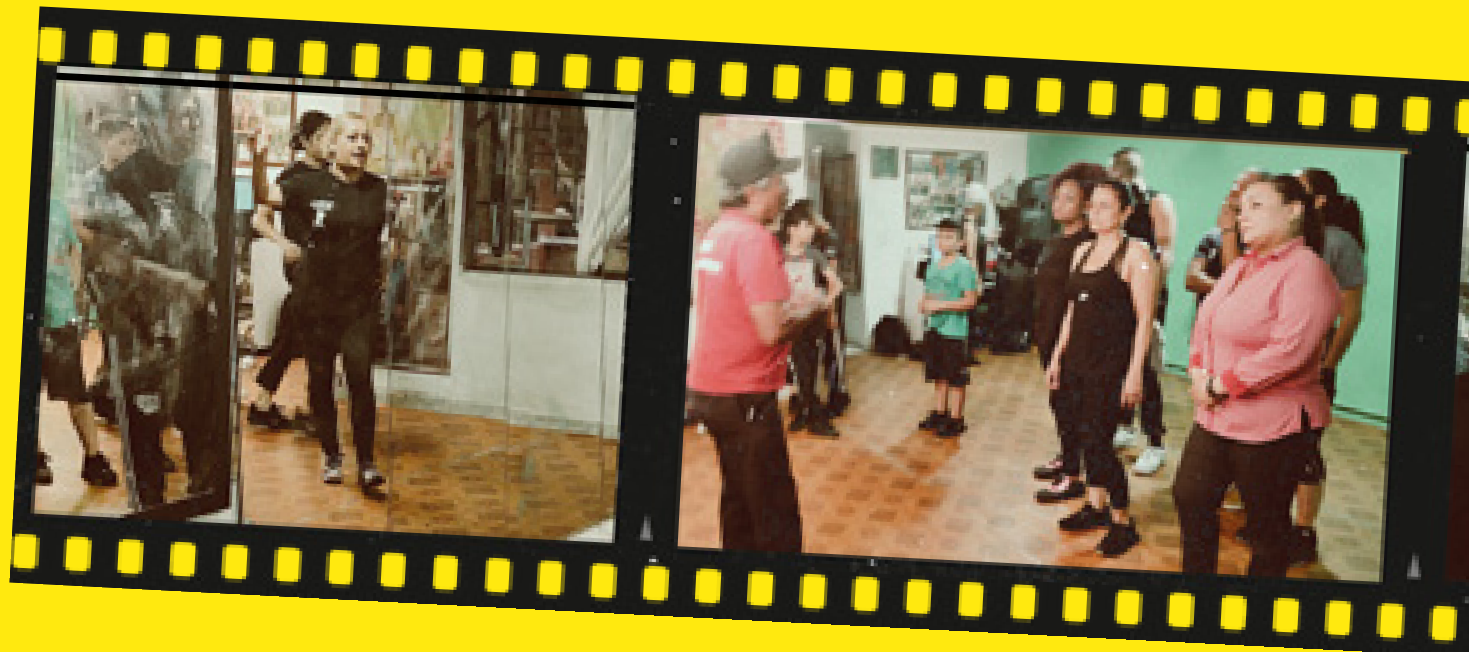

Ortiz said. She began to sew face masks using the same bright colors and patterns of her costumes.

"All through all the pandemic, my husband and I would go on to our patio and dance," Ortiz said with a tight, sad smile.

\section{The Next Generation}

Despite the challenges, Ortiz is optimistic, saying the government support for Salsa Caleña is encouraging. "With these workshops, we are finding the next generation where they live, in working-class neighborhoods all across the city," Ortiz said.

One of those next-generation dancers is Michel Ramos Casa, 14, who lives in Nueva Base, a working-class neighborhood in northwest Cali. Already sweating from the class and dressed in black sneakers, black leggings, and a simple blue t-shirt, she explained she was very happy spending time with the Old Guard. "In them you can see the true flavor of Cali... when I see them, I am very proud," she said, shouting over the strains of the music in the practice room.

She explained that although Korean pop music (K-pop) and dancehall/hip-hop inspired music (like Reggaeton) are popular among kids her age, salsa was still important to her. "If we lost salsa, maybe we would find a different dance, but salsa represents Cali, it is our dance," Ramos Casa said. "I like that salsa is passed down, generation to generation, from adult to child, and I want salsa to continue forever."

Both El Guaracho and Ortiz explained that although it is hard to transmit a lifetime of salsa learned in the street, not in the classroom, the Old Guard can still pass on the passion, music, and specific techniques to new generations. intergenerational gathering held by the Cali city government, attendees brainstormed responses to the question,"What does salsa mean to you?" and had the opportunity to learn from some of Cali's dance legends.

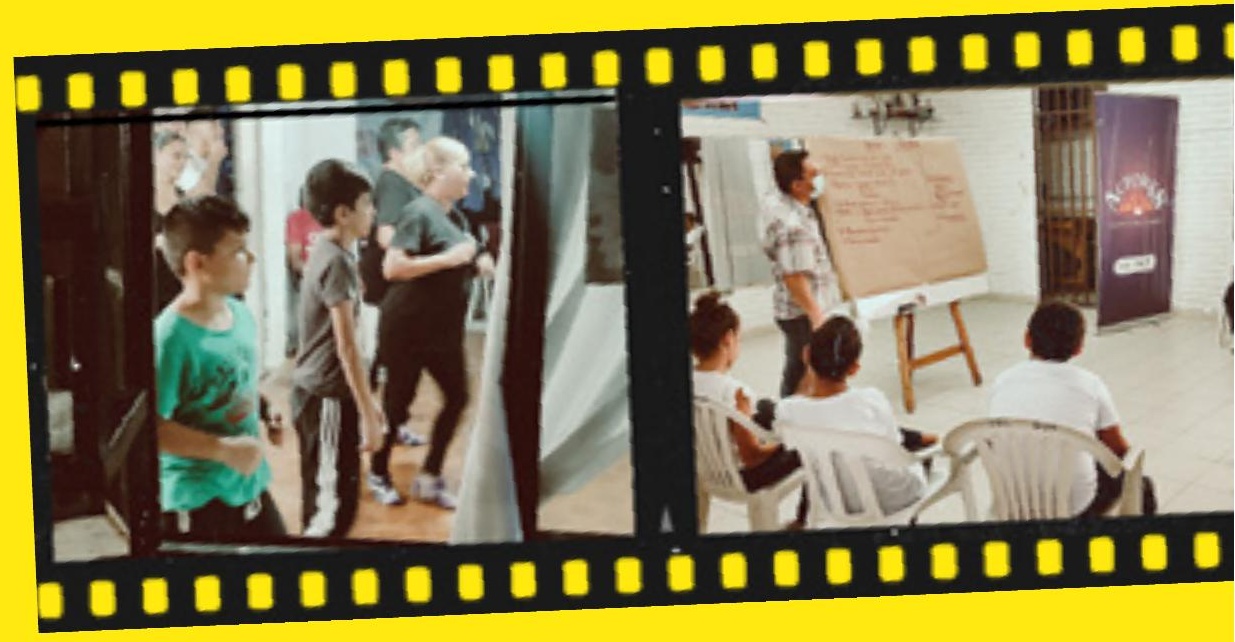




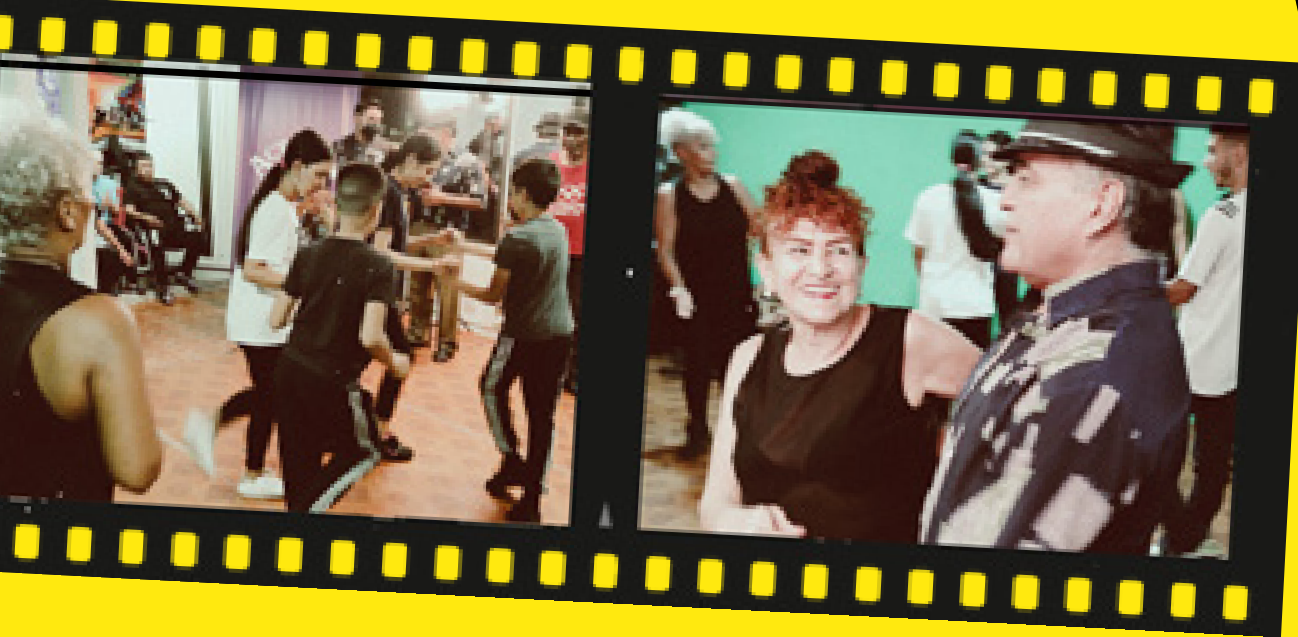

\section{The Future of Salsa}

One place this passing of the torch can be seen is the Chorrito Antillano, one of the city's iconic viejotecas (a mashup combining the Spanish words for "old" and "discoteque") in the Obrero neighborhood of Cali. Even at 7:30 p.m. on a Monday night, classic songs by Willie Colon and Celia Cruz echo off the walls covered in posters and memorabilia, as the young and the young-at-heart alternate between sipping on beer or rum and showing off their moves on the dance floor.

Merdado Arias, the author and journalist, explained the significance of the viejotecas in keeping the Salsa Caleña tradition alive.

"The viejoteca movement started in Cali in the 1990s," Arias explained, adding that this happened because the Old Guard could see that newer rhythms like salsa romantica were starting to become popular and they didn't want to lose what they had grown up with. "The people who were in their 60 s and 70 s started to open the viejotecas to listen to those original rhythms," he said.

Although some of these bars shut down for good during the pandemic, many are still going strong, with a different hotspot to be found every night of the week.

Although teenager Ramos Casas and her friends are still too young to go to a viejoteca or any club just yet, that didn't stop them from showing off their moves back at the practice session. At the end of the session, half a dozen of the kids divided into pairs, and as the Old Guard looked on, started to smoothly replicate the moves they had just learned.

Aceneth Ortiz's eyes glisten a little under the studio lights as she watches them dance. "This is the next Old Guard," she says with satisfaction.

\section{0}
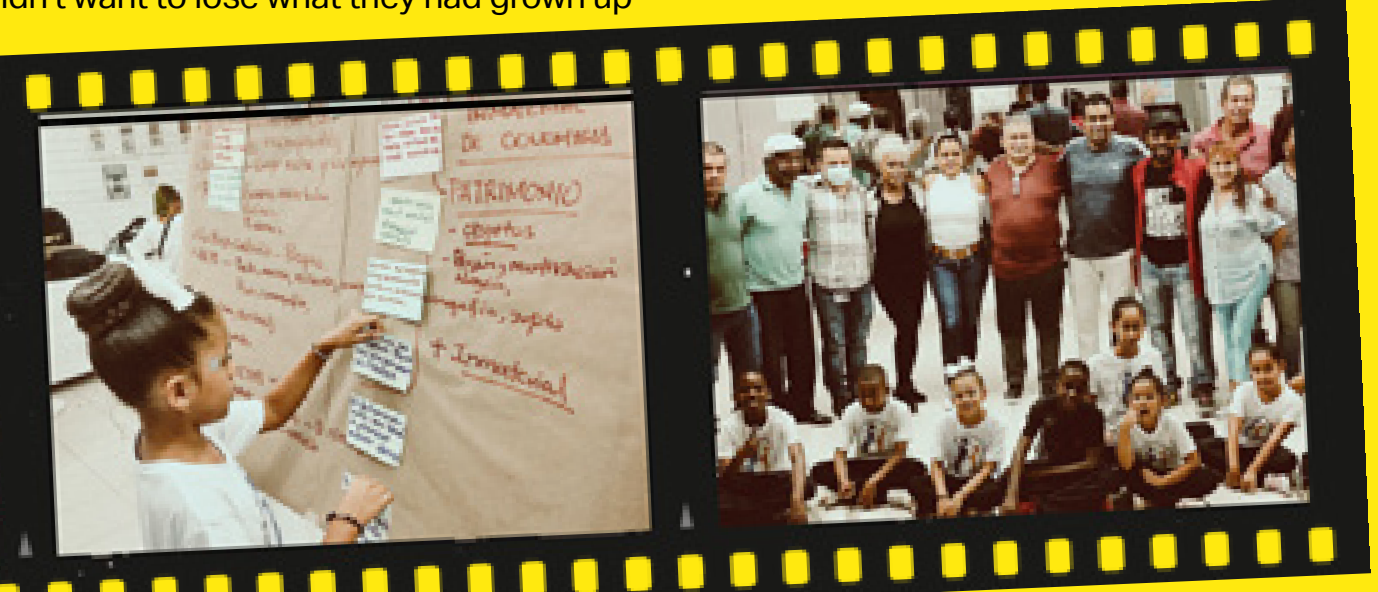

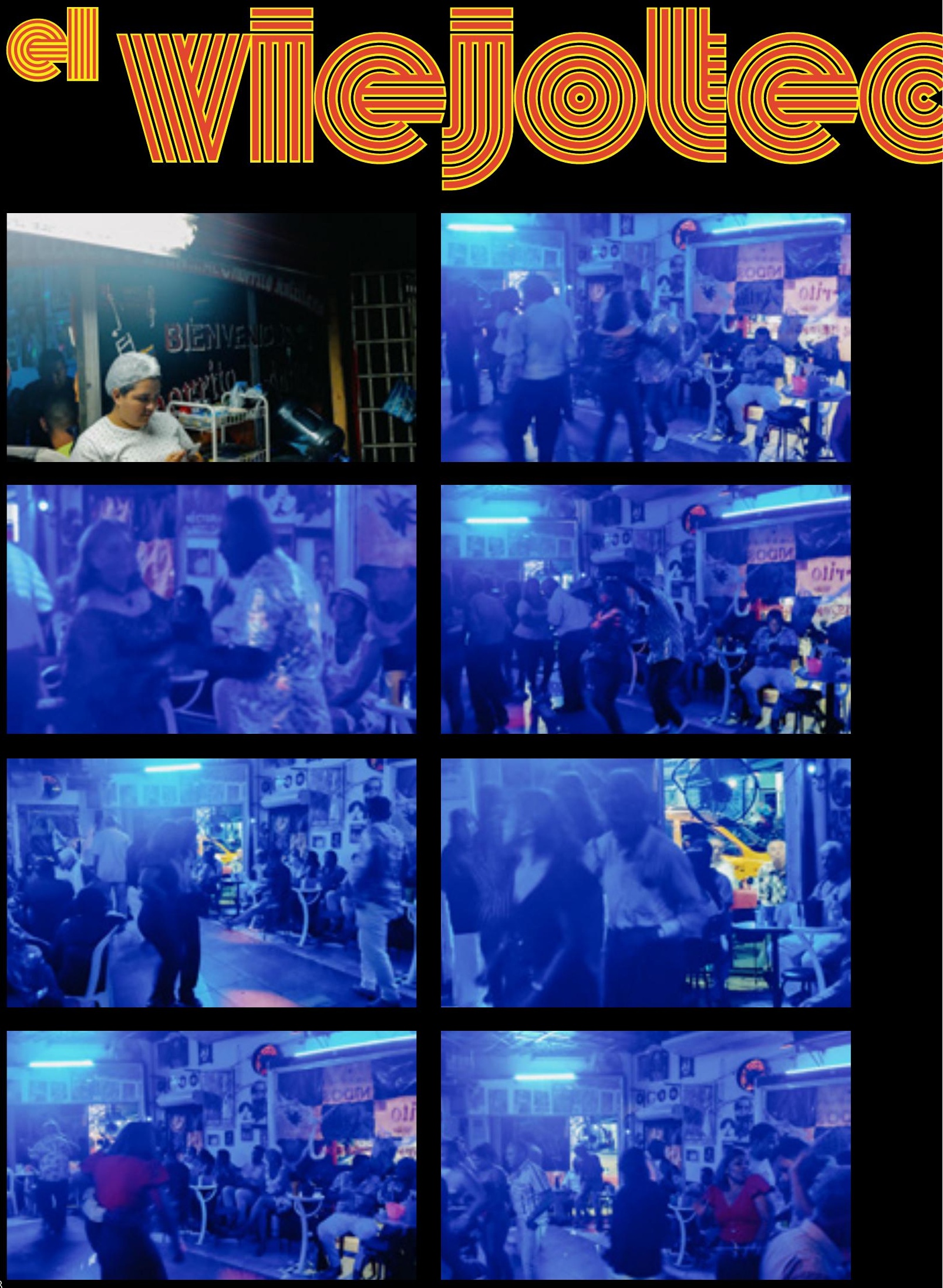


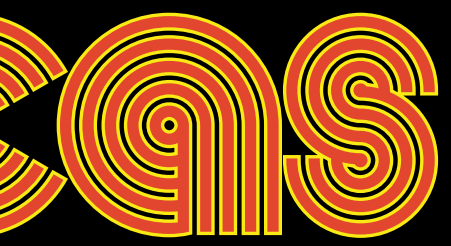

Even on a Monday night, Chorrito Antillano is filled with dancers of all ages. The iconic Cali viejoteca attracts those looking to show off their moves to the classic songs of their youth.
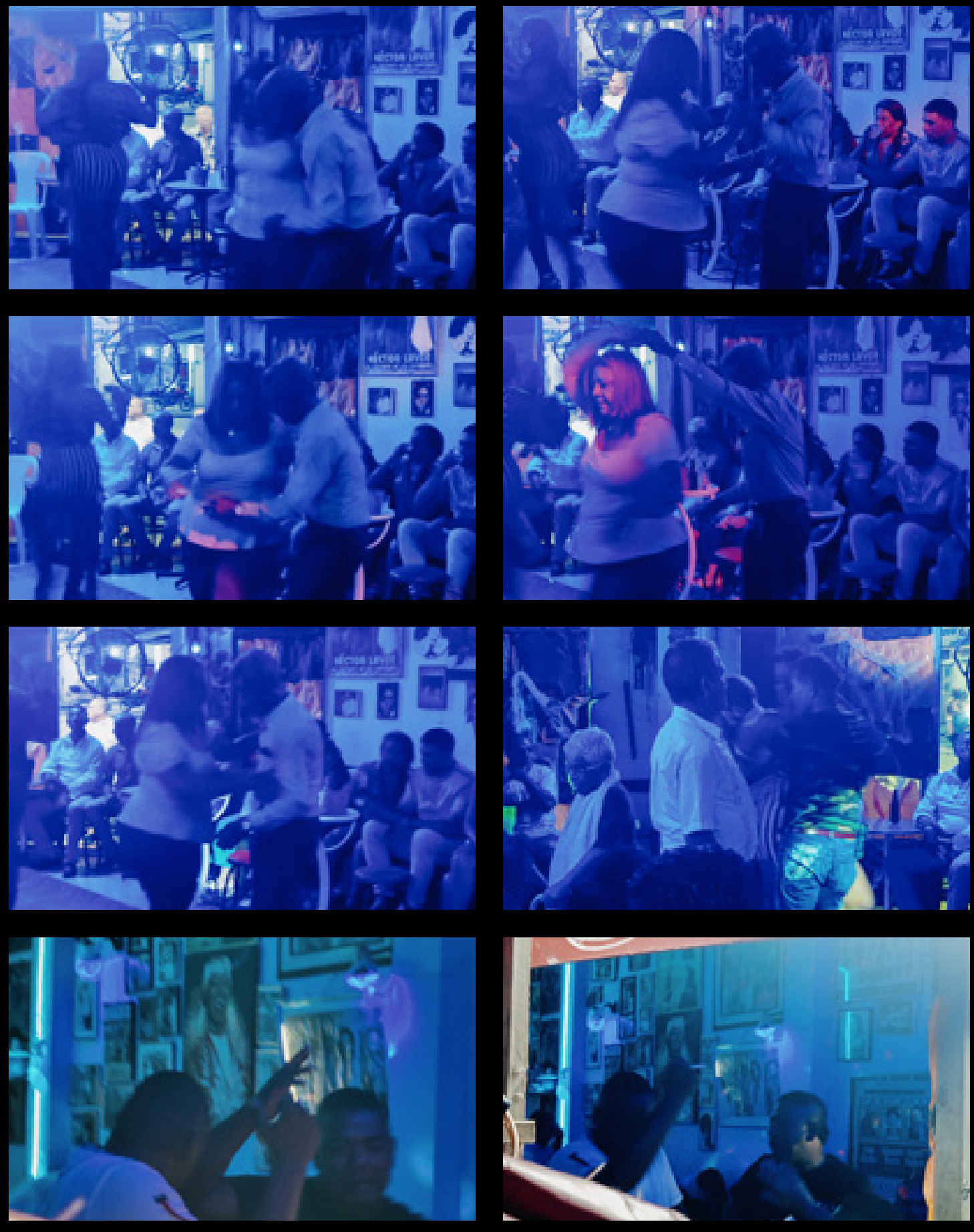
Feature
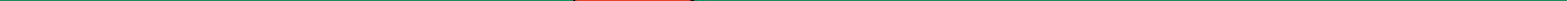


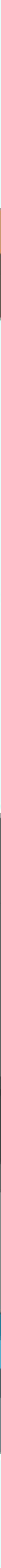


Feature

Over the past 70 years, Costa Rica has emerged as a regional leader, investing on a wide scale in its citizens' health and welfare and proactively serving the needs of its older population. The country is currently undergoing an accelerated aging process. With the highest life expectancy in Latin America, Costa Rica has a rapidly growing 65 -and-over population that is set to triple by 2050. A universal healthcare system, ranked number one in Latin America, contributes to longevity and overall enhanced quality of life. The national government has developed policies to support the rights of older 
people through the National Council for Older Adults (CONAPAM), which provides a variety of social care networks and community programs. A small population size and progressive approach to social support have made Costa Rica a testing ground for innovative aging solutions, and despite challenges like a regressive tax system and growing inequality, the country continues to expand and adapt its policies to support the changing demographics. 


\section{Aging in Costa Rica}

\section{Demographic Profile}

1980

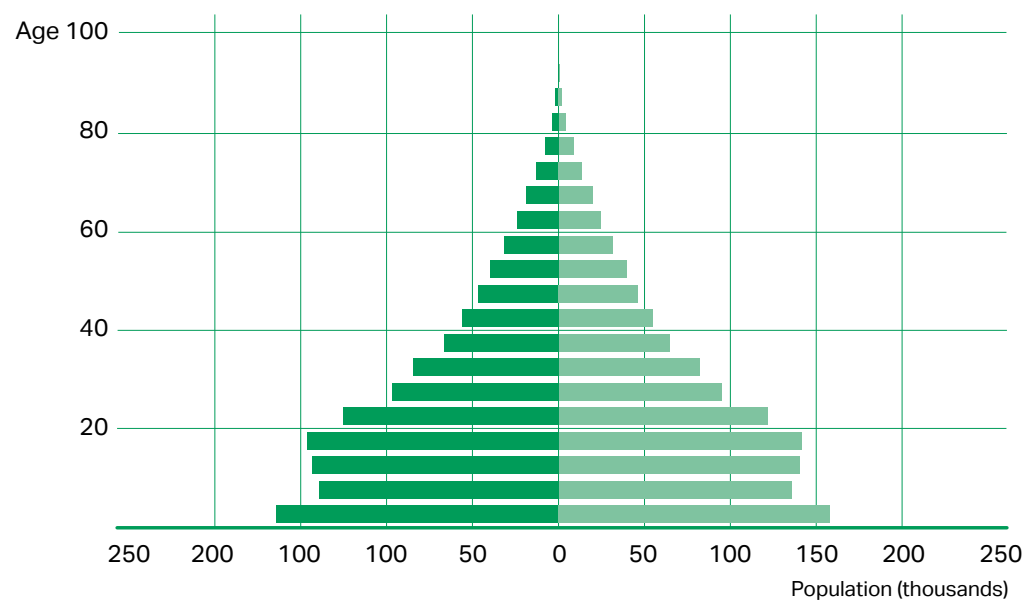

2020

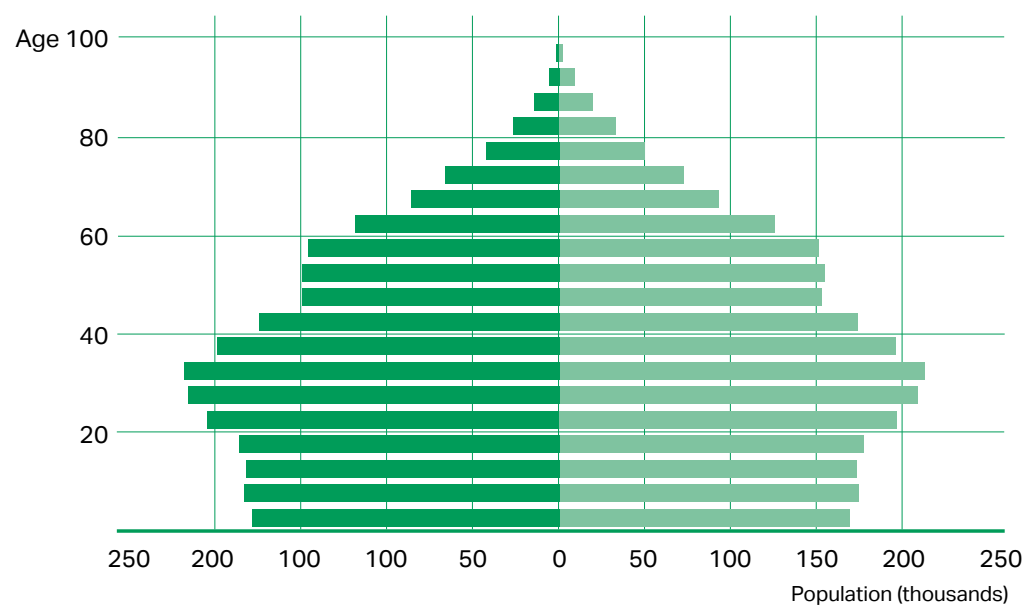

2060

Male

- Female

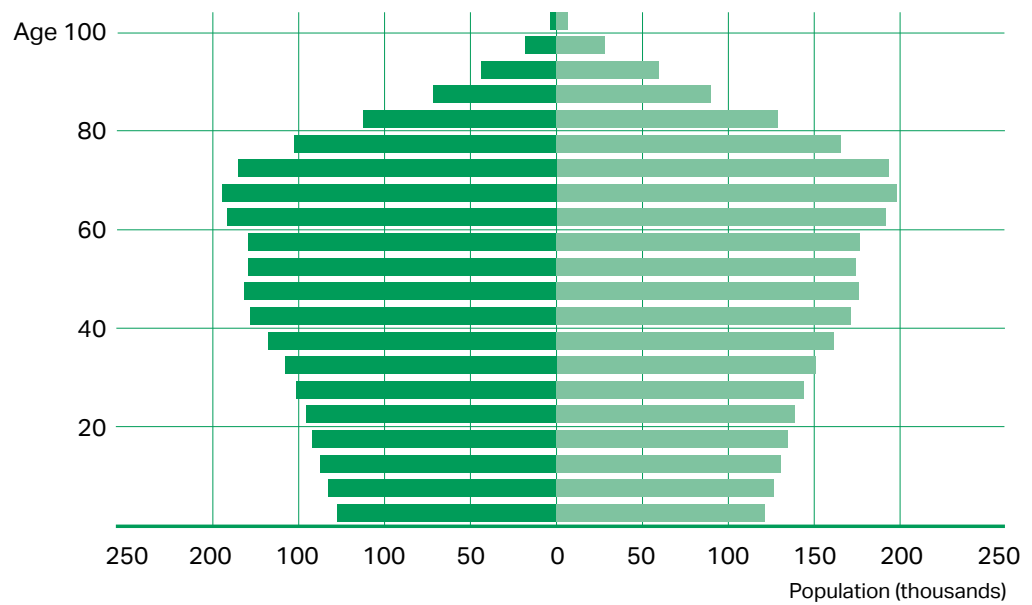



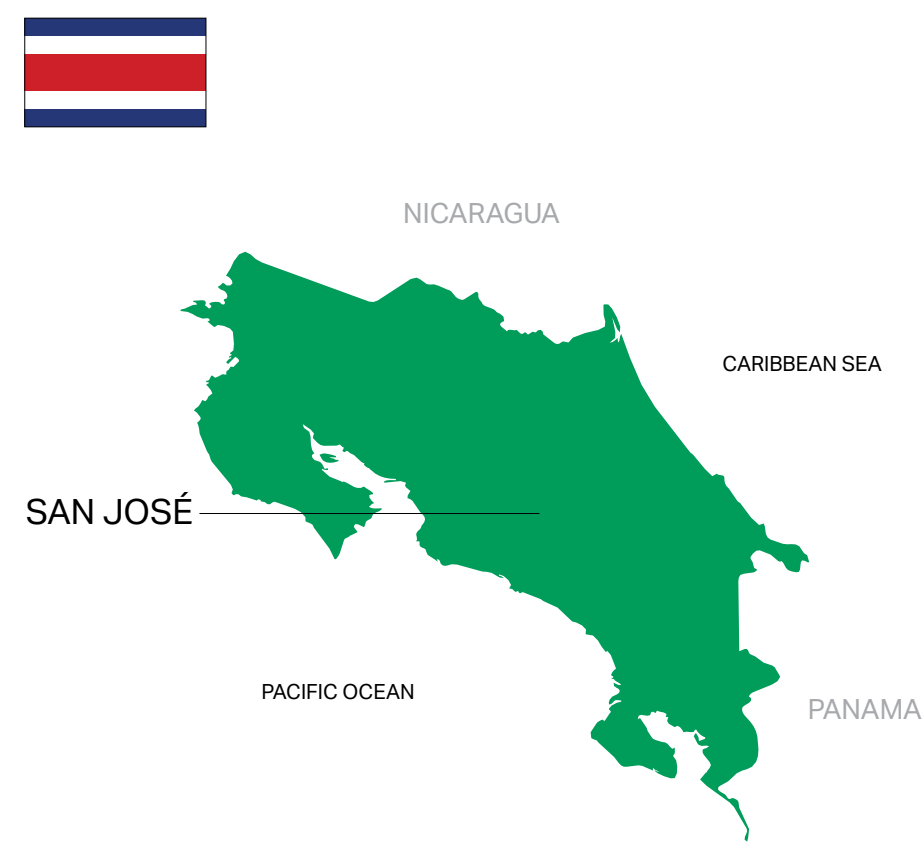

RELIGION

Roman Catholic 71.8\%, Evangelical and Pentecostal $12.3 \%$, other Protestant 2.6\%, Jehovah's Witness $0.5 \%$, other $2.4 \%$, none $10.4 \%$ (2016 est.)

NET MIGRATION RATE

0.78 migrant(s)/1,000 population (2021 est.)

LIFE EXPECTANCY AT BIRTH Total population: 79.41 years $\left(59^{\mathrm{TH}}\right)$ Male: 76.75 years Female: 82.22 years (2021 est.)

BIRTH RATE

14.53 births/1,000 population (2021 est.)

POPULATION GROWTH RATE $1.04 \%$ (2021 est.)

URBAN POPULATION $81.4 \%$ of total population (2021)

AGE STRUCTURE

0-14 years: $22.08 \%$

15-24 years: $15.19 \%$

25-54 years: $43.98 \%$

55-64 years: $9.99 \%$

65 years and over: $8.76 \%$

(2020 est.)
$8.1 \%$ (2017 est.)

GINI INCOME INEQUALITY INDEX (2018) $48\left(19^{\mathrm{TH}}\right)$

GENDER INEQUALITY INDEX (2019) 0.288

HEALTH EXPENDITURES

$7.6 \%(2018)$

OBESITY RATE

$25.7 \%$ (2016)

LITERACY RATE

97.9\% (2018)

LABOR FORCE BY OCCUPATION Agriculture: $14 \%$

Industry: $22 \%$

Services: $64 \%$ (2006 est.)

RESIDENT LABOR FORCE PARTICIPATION RATE

$71.2 \%$ (2019 est.)

EXPORTS (US DOLLARS)

$\$ 10.81$ billion (2017 est.)

IMPORTS (US DOLLARS)

$\$ 15.15$ billion (2017 est.)

LANGUAGE

Spanish (official), English

COSTA RICA

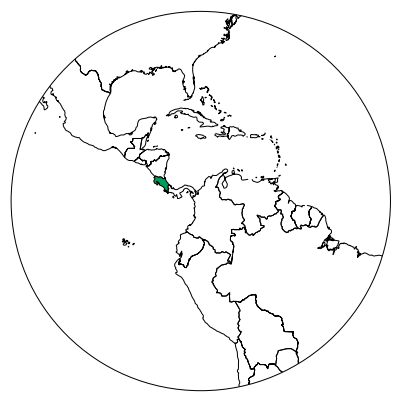

COUNTRY

Costa Rica

CONVENTIONAL LONGFORM NAME Republic of Costa Rica

TOTAL AREA

51,100 sq km (19,729.8 sq miles)

POPULATION (WORLD RANK)

$5,151,140\left(124^{\mathrm{TH}}\right)$

POPULATION DENSITY (WORLD RANK) 97.91 per sq. $\mathrm{km}\left(88^{\mathrm{TH}}\right)$

DEMONYM

Costa Rican

BUDGET (US DOLLARS)

Revenues: $\$ 8.357$ billion

Expenditures: $\$ 11.92$ billion

(2017 est.)

GDP NOMINAL (US DOLLARS)

$\$ 61.855$ billion (2019 est.)

MAIN INDUSTRIES

Medical equipment, food processing, textiles and clothing, construction materials, fertilizer, plastic products

NATURAL RESOURCES

Hydropower

GOVERNMENT TYPE

Presidential republic

ETHNIC GROUPS

White or Mestizo 83.6\%, Mulatto $6.7 \%$, Indigenous $2.4 \%$, Black of African descent $1.1 \%$, other $1.1 \%$, none $2.9 \%$, unspecified $2.2 \%$ (2011 est.) 


\section{The Aging Population in Costa Rica and the Importance of Lifelong Learning}

\section{In the Central American country of Costa Rica, individuals ages 60+}

currently represent 9 percent of the total population. By 2050, this proportion is expected to more than double, as older adults will account for approximately 20 percent of the population. ${ }^{2.3}$ Costa Rica's evident trend of accelerated aging will have diverse social, cultural, economic, health, and legal implications.

Fostering lifelong learning is a means of addressing some of those implications, and in fact Costa Rica has made strides in creating learning opportunities targeted specifically for older adults. In particular, Programa Institucional para la Persona Adulta y Adulta Mayor strives to promote older adult's right to access education as well as the development of intergenerational communities. But first, a look at certain characteristics and trends impacting the country can provide appropriate context.

\section{Costa Rica's Aging Population}

Life expectancy at birth in Costa Rica is 75.5 years for men and 81 years for women. ${ }^{13}$ However, it is relevant to analyze disability-free life expectancy as well, given that it is often a more reliable indicator of a population's health situation. A research team at the University of Costa Rica points out that at age 65, life expectancy free of disability - that is, the number of years a person lives without requiring a certain level of physically enabling services and supports - is 12.8 years for men and 10.5 years for women. In general, 35 percent of individuals over 65 report having a disability - a percentage that increases with age. ${ }^{2}$

Regarding the economic status of older Costa Ricans, in 2019, 68.2 percent had a pension and 23 percent lived in poverty. ${ }^{14}$ By 2020, poverty increased by 22 percent for metropolitan areas and by 34.3 percent for rural areas. ${ }^{3}$

In the social sphere of Costa Rican society, there are a number of concepts associated with old age and the aging process. While some positive images are linked to old 


\section{By Sofía Elena Segura}

Professor, School of Medicine and

Coordinator, Programa Institucional para la

Persona Adulta y Adulta Mayor (PIAM)

University of Costa Rica

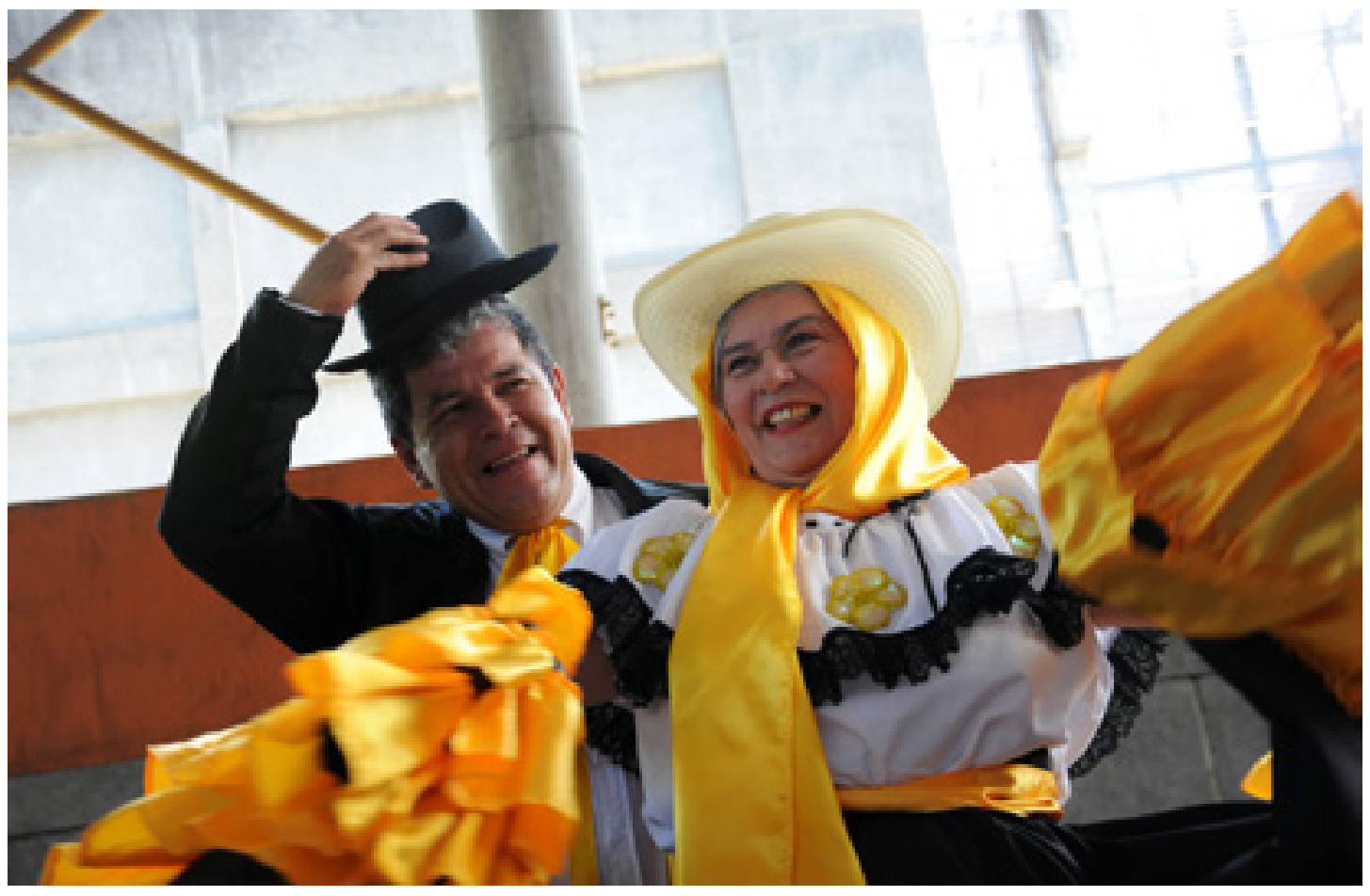

age, such as maturity and respect, there is also ageism, which leads to discrimination and the exclusion of the older population. ${ }^{2}$ Although Costa Rica's legal norms criminalize violence, abuse, exploitation, and neglect of older people, 43 percent of older persons report having suffered some form of violence ( 45 percent of men and 40 percent of women), and 9.6 percent report having suffered some form of discrimination, mainly in their family environment, their neighborhood, and public transportation. ${ }^{2}$

Nevertheless, multiple milestones have laid the groundwork for the recognition of the rights of older Costa Ricans - some of which came at the global and regional level to inspire action while others occurred at the national level.

That foundation starts with 1949's Political Constitution of Costa Rica, which established the duty of the State to seek the greatest welfare for all its inhabitants. ${ }^{4}$ In addition, since the 1982 International Plan of Action on Aging was outlined in Vienna, there has been growing interest in developing policies and strategies to respond to the needs of older people. ${ }^{5}$ In 1999, Costa Rica's Comprehensive Law for Older Adults was enacted, marking the first time that national legislation would specifically target this population with the aim of improving their quality of life. ${ }^{6}$

Next, following the creation of the Madrid International Plan of Action on Aging in 2002, the Regional Implementation Strategy for Latin America and the Caribbean (2003) was developed. This regional strategy has the goal of enhancing the protection of the human rights of older people, their economic security, social participation, 
and education. ${ }^{7}$ Then, in 2007, the Brasilia Declaration required the promotion of dialogue and strategic alliances among Latin American and Caribbean countries in order to address the regional population's aging process. ${ }^{8}$ In 2012, the San José Charter on the Rights of Older Persons in Latin America and the Caribbean further established the need to eradicate all forms of discrimination against older people and to seek ways of creating networks to augment their protection. ${ }^{9}$

Progress has continued from there. In 2016, Costa Rica ratified the InterAmerican Convention on the Protection of the Human Rights of Older Adults, which includes as some of its principles the protection of human rights, dignity, participation, self-realization, physical, economic and social security, and the respect and appreciation of cultural diversity. ${ }^{10}$

Finally, in 2020, the Law Criminalizing the Abandonment of Older Adults was passed. ${ }^{11}$ Consequences for abandonment under this law vary based on the severity of an infraction. Generally, a caregiver who commits abandonment of a vulnerable older adult will face either a fine or up to six months in jail. In the most severe cases, if death is the result of the abandonment, the prescribed penalty is six to ten years in prison.

Overall, this collective policy framework enabled the development of laws, institutions, and initiatives that aim to support and protect Costa Rica's older adult population. The National Council of the Older Adult (CONAPAM) is the governing body on aging in Costa Rica, and it leads the creation and implementation of comprehensive public policies focused on older adults. ${ }^{12}$ Simultaneously, numerous public and private organizations, institutions, and groups - including the Comprehensive Care Program for Older Adults (PAIPAM in Spanish) at Costa Rica's Universidad Nacional, the Costa Rican Gerontological Association, and the Program for Older
Adults at Costa Rica's Universidad Estatal a Distancia - also work to provide social and educational opportunities to the older adult population.

\section{PIAM: A Space for Lifelong Learning}

The Programa Institucional para la Persona Adulta y Adulta Mayor (PIAM, Institutional Program for Adults and Older Adults) was founded in 1986 and is part of the University of Costa Rica, the country's main public university. It is an informal education program for people over 50 years old. Since its inception, PIAM has aimed to foster lifelong learning and the development of intergenerational relationships by incorporating students of older age in university classrooms. ${ }^{15}$

PIAM currently offers courses under two modalities. The first refers to courses offered to matriculating students by the university where younger students share classrooms with students of other generations. By contrast, additional courses are exclusively offered to individuals over the age of 50. These 50+ specific courses are divided into eight modules: art and culture, handicrafts, general knowledge, healthy lifestyles, artistic groups, languages, human movement, and information and communication technologies. Participation in either type of course does not lead to a degree. ${ }^{16}$

In addition to offering courses, PIAM advises research projects focused on aging and educational gerontology and trains the university's professors to utilize an age-inclusive teaching approach. This has been a pioneer program in education for seniors in Latin America, and it has connected with multiple networks at the international level, including the International Association of Universities of the Third Age (AIUTA in French) and the Ibero-American Network of University Programs with Older Adults (RIPUAM in Spanish). ${ }^{16}$

Given the expected growth of Costa Rica's aging population in the coming years, 
it will remain imperative to continue PIAM, the normalization of aging as part of the life course, the promotion of healthy aging, and, above all, continuous and meaningful learning opportunities for older adults as central drivers of transforming society.
${ }^{1}$ Costa Rica | Data [Internet]. [cited 2021 Dec 2]. Available from: https://datos.bancomundial.org/pais/ costa-rica

${ }^{2}$ University of Costa Rica. Central American Population Center. II Report status of the elderly person [Internet]. San José; 2020 [cited 2020 Oct 16]. Available from: https://www.kerwa.ucr.ac.cr/ handle/10669/81562?locale-attribute=en

${ }^{3}$ National Institute of Statistics and Census. Adult Day 2021. INFOGRAPHIC [Internet]. [cited 2021 Dec 2]. Available from: https://www.inec.cr/multimedia/ dia-de-la-persona-adulta-mayor-2021-infografia

${ }^{4}$ National Constituent Assembly. Constitution of the Republic of Costa Rica [Internet]. 1949. Available from: https://www.pgrweb.go.cr/scij/Busqueda/ Normativa/Normas/nrm_texto_completo. aspx?nValor1=1\&nValor2=871

${ }^{5}$ United Nations. Report of the World Assembly on Aging [Internet]. Vienna; 1982 Aug [cited 2021 Dec 2]. Available from: https://www.un.org/esa/socdev/ ageing/documents/Resources/VIPEE-English.pdf

${ }^{6}$ Legislative Assembly of the Republic of Costa Rica. Law 7935. Comprehensive Law for the Older Adult [Internet]. 1999 [cited 2020 Aug 17]. Available from: http://www.pgrweb.go.cr/scij/Busqueda/Normativa/ Normas/nrm norma.aspx?param1=NRM\&nValor1=1\&nValor2=43655\&nValor3=95259\&strTip$\mathrm{M}=\mathrm{FN}$

${ }^{7}$ CEPAL. Regional Implementation Strategy for Latin America and the Caribbean of the Madrid International Plan of Action on Aging | Publication | Economic Commission for Latin America and the Caribbean [Internet]. Santiago; 204AD Mar [cited 2021 Dec 2]. Available from: https://www.cepal.org/ es/publicaciones/2786-estrategia-regional-implementacion-america-latina-caribe-plan-accion

${ }^{8}$ CEPAL. Brasilia Declaration: Second Regional Intergovernmental Conference on Ageing in Latin America and the Caribbean: towards a society for all ages and rights-based social protection [Internet]. Brasilia: ECLAC; 2008 Jan [cited 2021 Dec 2]. Available from: https://repositorio.cepal.org/ handle/11362/21457

${ }^{9}$ CEPAL. San Jose charter on the rights of older persons in Latin America and the Caribbean | Publication | Economic Commission for Latin America and the Caribbean [Internet]. Sam José; 2012 May [cited
2021Dec 2]. Available from: https://www.cepal.org/ en/publications/21535-san-jose-charter-rights-older-persons-latin-america-and-caribbean

${ }^{10}$ Legislative Assembly of the Republic of Costa Rica. Inter-American Convention on the Protection of the Human Rights of Older Adults [Internet]. Law 9394 Sep 8, 2016. Available from: http://www.pgrweb. go.cr/scij/Busqueda/Normativa/Normas/nrm_texto_completo.aspx?param1=NRTC\&nValor $1=1 \&$ nValor2 $=82573 \&$ nValor $3=0 \&$ strTipM $=$ TC

${ }^{11}$ Legislative Assembly of the Republic of Costa Rica. Law 9857. Law criminalizing the abandonment of older adults [Internet]. Jun 15, 2020. Available from: http://www.pgrweb.go.cr/scij/Busqueda/ Normativa/Normas/nrm_texto_completo. aspx?param1=NRTC\&nValor1=1\&nValor2=91739

${ }^{12}$ CONAPAM. CONAPAM - National Council of the Older Adult [Internet]. [cited 2021 Dec 2]. Available from: https://www.conapam.go.cr/inicio/

${ }^{13}$ Cordero M. The life expectancy of Costa Ricans was reduced by more than a year because of the impact of the pandemic. University weekly [Internet]. 2021 Sep 15 [cited 2021 Dec 2]; Available from: https:// semanariouniversidad.com/pais/la-esperanza-devida-de-los-costarricenses-se-redujo-en-mas-deun-ano-por-el-impacto-de-la-pandemia/

${ }^{14}$ National Institute of Statistics and Census. International Day of Older Adults. Elderly vs COVID-19 [Internet]. 2020 [cited 2021 Dec 2]. Available from: https://www.inec.cr/sites/default/files/infografias-pdf/imgadultomayor-2020.pdf

${ }^{15}$ PIAM. Historia|PIAM [Internet]. 2017 [cited 2021 Dec 2]. Available from: https://piam.ucr.ac.cr/ qui\%C3\%A9nes-somos/historia

${ }^{16}$ Masis Fernández K, Brenes MR. Characteristics and challenges of the Institutional Program for the Adult and Older Adult (PIAM) of the University of Costa Rica: 1-15.

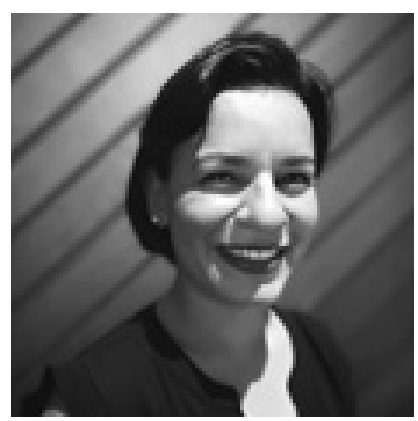

SOFÍA ELENA SEGURA

Professor, School of Medicine and Coordinator, Programa Institucional para la Persona Adulta y Adulta Mayor (PIAM) University of Costa Rica 


\section{Day in the Life}

\section{lleana Borbón}

\section{San José}

59 years old

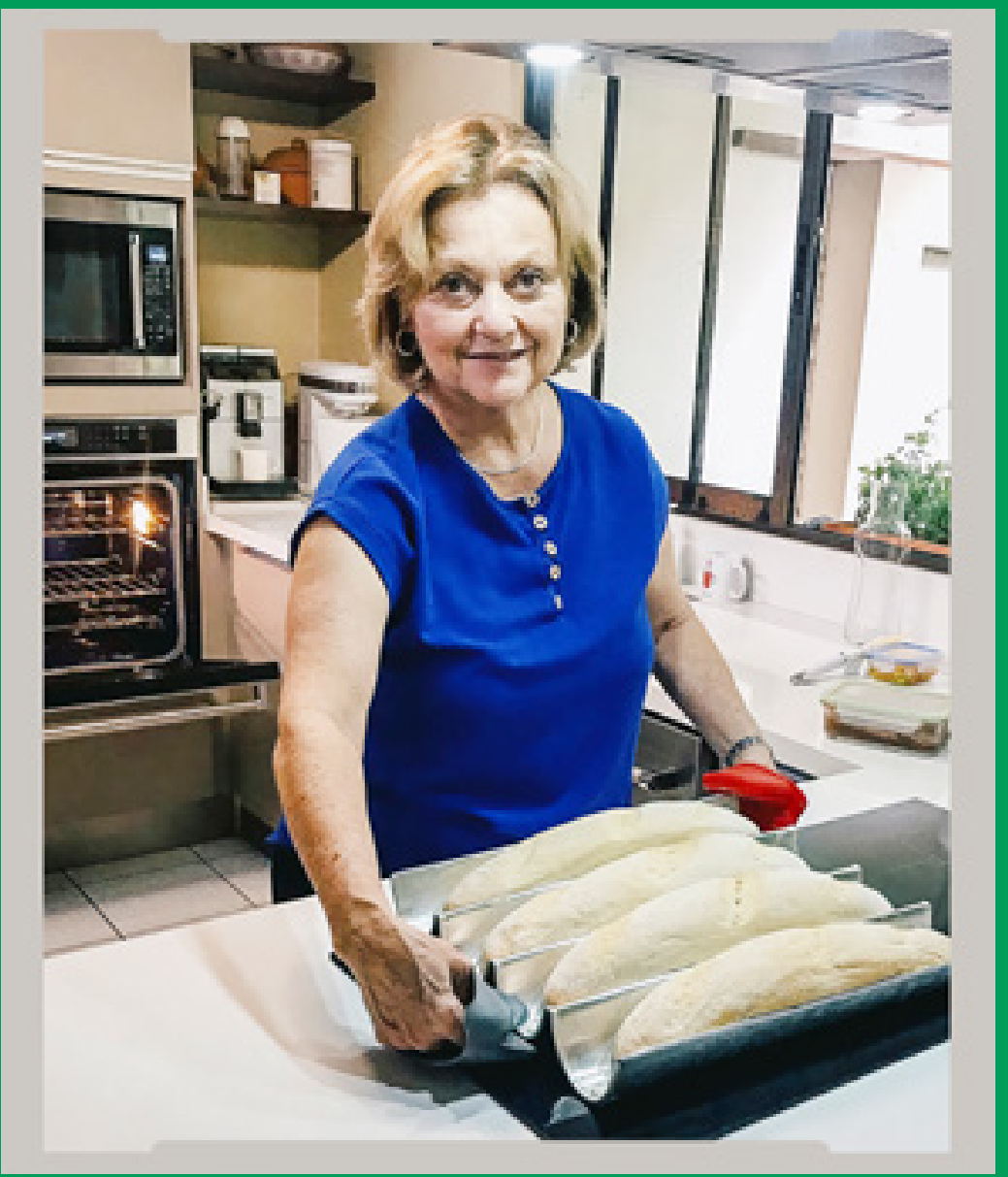

Ileana lives with her husband of 35 years and her two sons, ages 24 and 28 . She teaches foreign language classes online and visits with her parents and extended family at least once per week. 


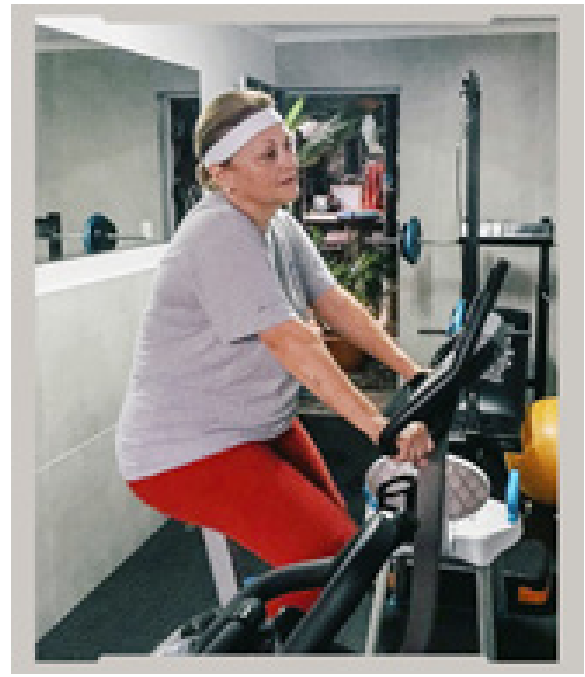

Exercising at home on the stationary bike

\section{What is your typical day like?}

I wake up at 6:30 a.m. and start teaching online at 7:30 a.m. I have breakfast around 9:00 a.m. and try to exercise on my home bike at least three or 4 times a week. I also like to watch "Body Work Out for Seniors" on YouTube and participate aactively.

At noon, I start preparing lunch. My husband and I normally eat at 1:00 p.m. In the evening, we have a snack, a refreshment or a glass of wine. Then we read together or individually or watch something - a documentary or a movie, sometimes a Netflix series.

Twice a week between 1 and 5 p.m., I work online. And I also try to exercise a bit if I haven't had time to do it in the morning. Once a week, I go to my parents' house and have "un Cafecito" (a cup of coffee) and talk about everything. I also enjoy getting together with my sisters (I have 4) and my brother and their families, but we are restricted now because of the pandemic.

\section{What activities do you enjoy most?}

I enjoy doing many things. I really enjoy teaching languages and helping students communicate in a new language. I teach Spanish, English and French online. I also love sharing time with my family. Our sons are living with us right now and are working and studying online. We are enjoying this time a lot and have gotten a lot closer.
How do you stay mentally and socially active? Things have changed with COVID, so we have been forced to socialize in a different way. I do not have "big meetings" with friends face-to-face anymore. We have Zoom meetings instead. For example, my book club and my Creative Cooking group meet once a month via Zoom now.

\section{What do you find most challenging about growing older?}

For me, growing older is a blessing! It is important to accept one's age and try to do the best with what we have. Life is always too short to be worried about looking younger. We can look and feel good according to our ages and enjoy every day as if it were the last one. Of course, we start having some aches and things but that's normal. Eating healthier food and exercising a bit every day helps. Something that I really enjoy is dancing!

What are your thoughts on aging in Costa Rica? I really like the weather here. For example, we have two seasons: the dry and the rainy one, but the temperature is always similar. In San José the average is $24-26^{\circ} \mathrm{C}$ (around $75-78^{\circ} \mathrm{F}$ ). Another advantage of living here is the beach and the mountains are just a one or two-hour drive away. I also enjoy being in the city, going to the theater or the National Symphony Orchestra, and visiting museums, galleries and different restaurants. And one of the best things about being here is that my parents and the majority of my siblings and friends live here!

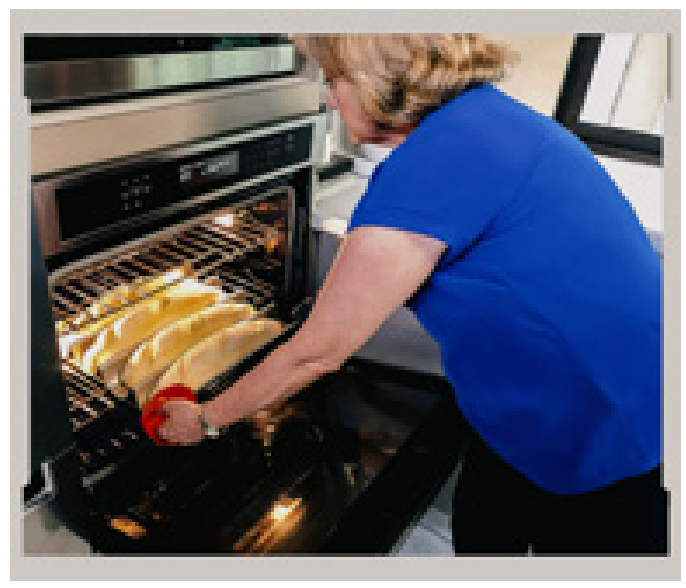

Baking bread 


\section{Day in the Life}

lleana Borbón

\section{San José}

59 years old

"It is important to accept one's age and try to do the best with what we have. Life is always too short to be worried about looking younger. We can look and feel good according to our ages and enjoy every day as if it were the last one."

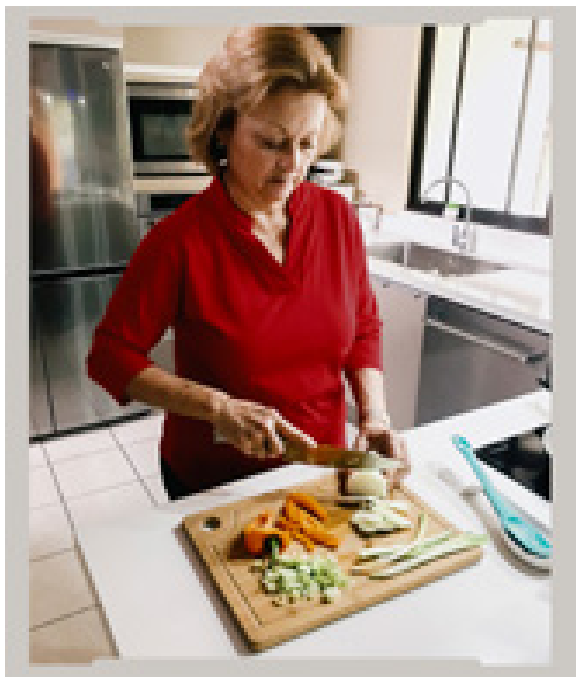

Cutting vegetables to make a "sofrito" with a bit of olive oil to be served with beef or as an antipasto with bread

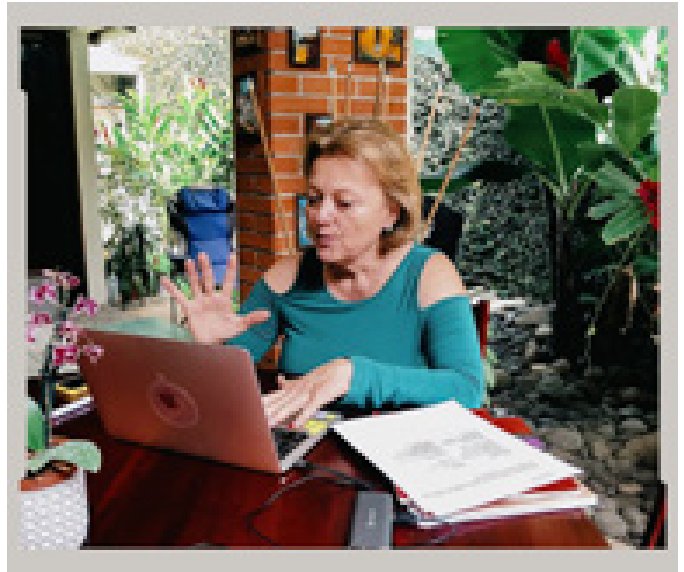

Ileana teaching a Spanish language class online

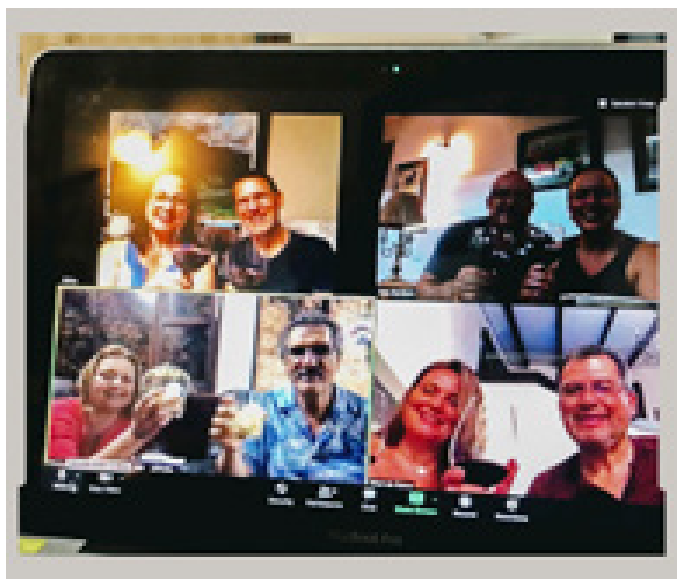

Gathering with family via Zoom for a virtual happy hour

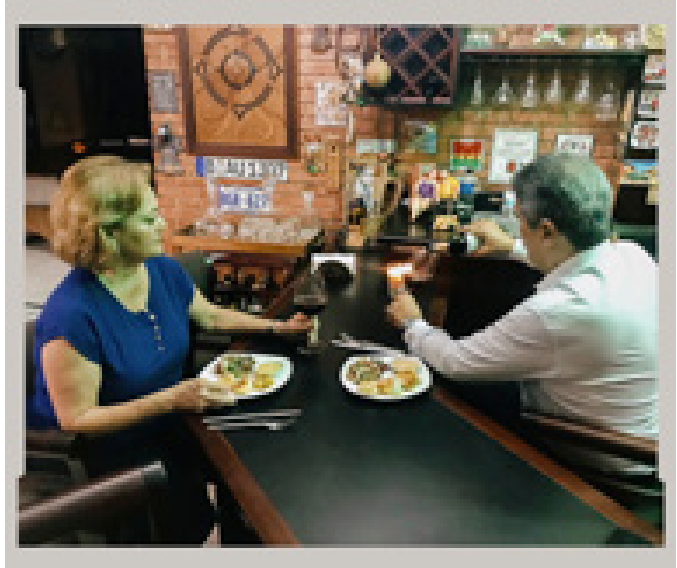

Sharing a glass of wine and snacks with husband at home 


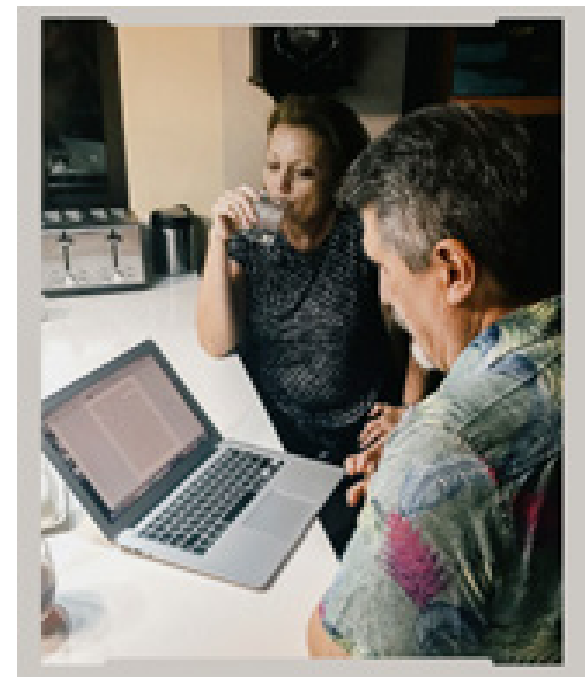

Catching up in the evening and reading online

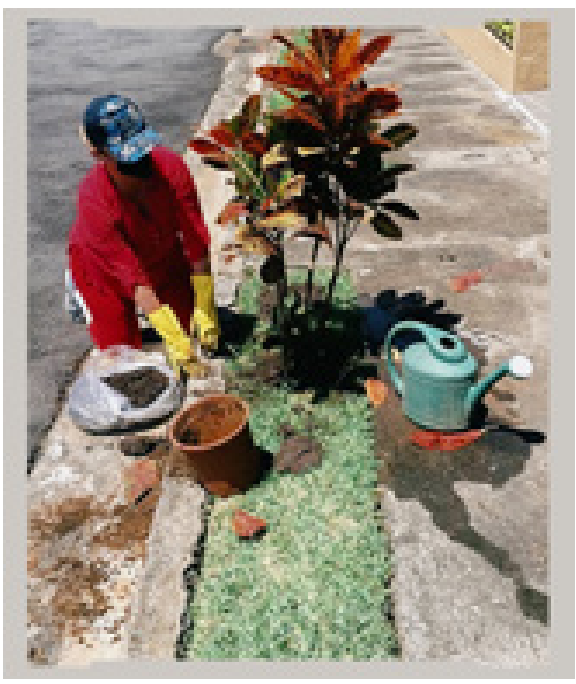

Planting trees in the front yard and gardening, a favorite pastime

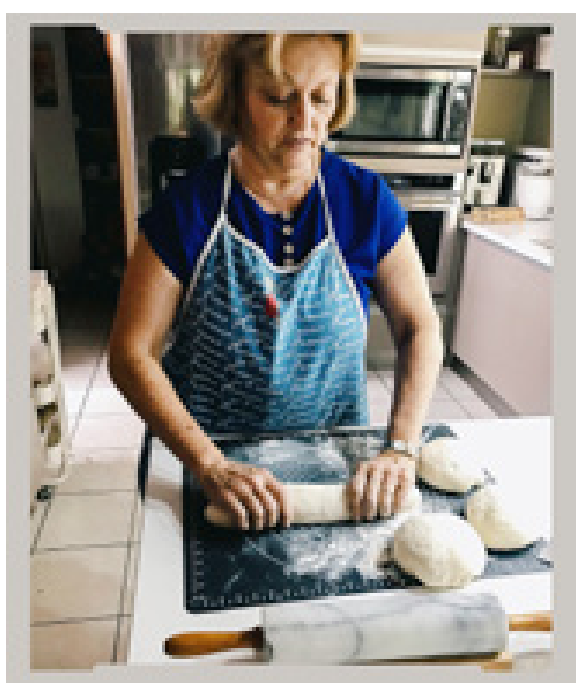

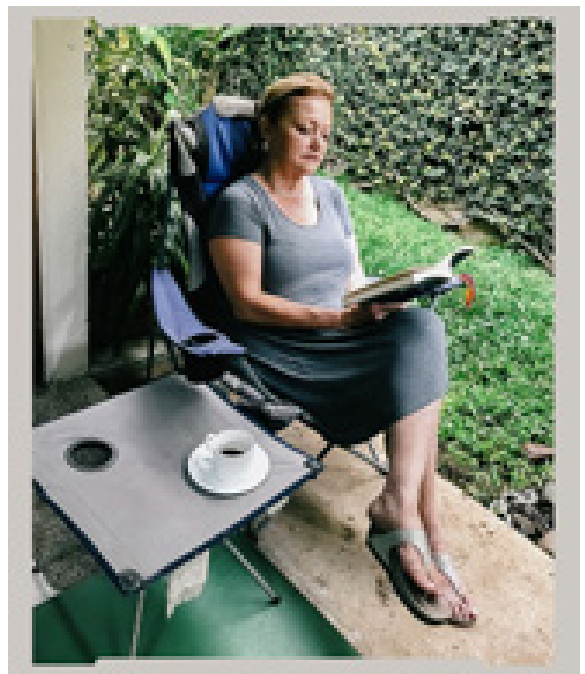

Relaxing in her small indoor patio

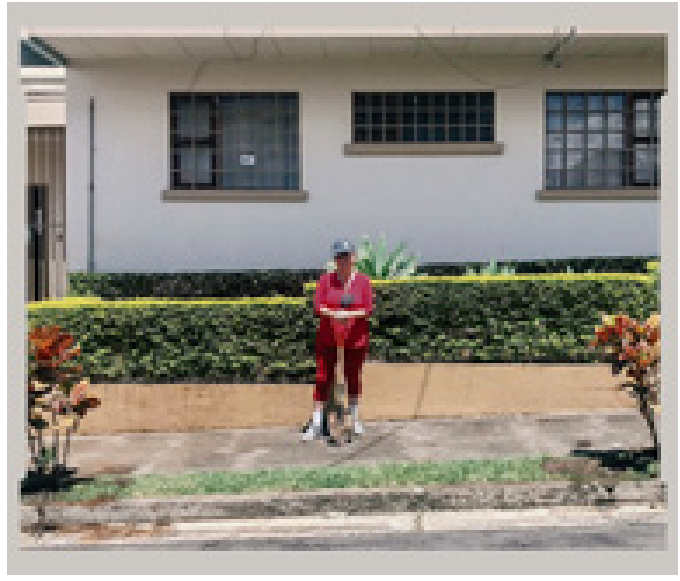

lleana in front of her home

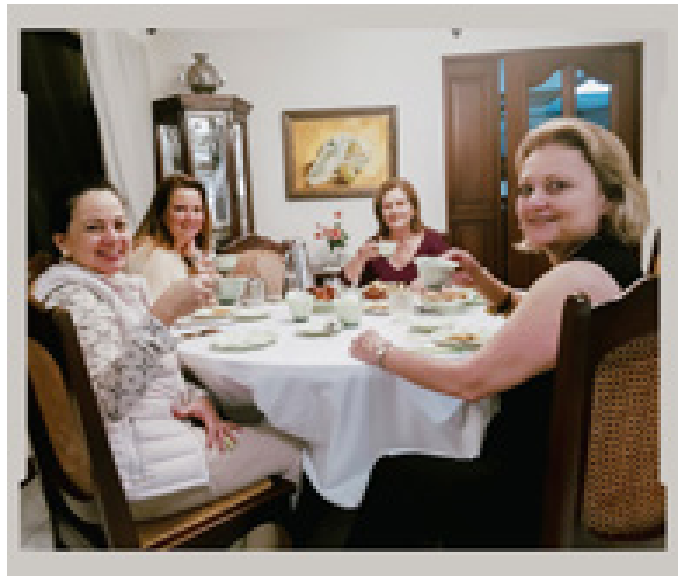

An in-person gathering at a friend's house - the first in nearly two years because of the pandemic 

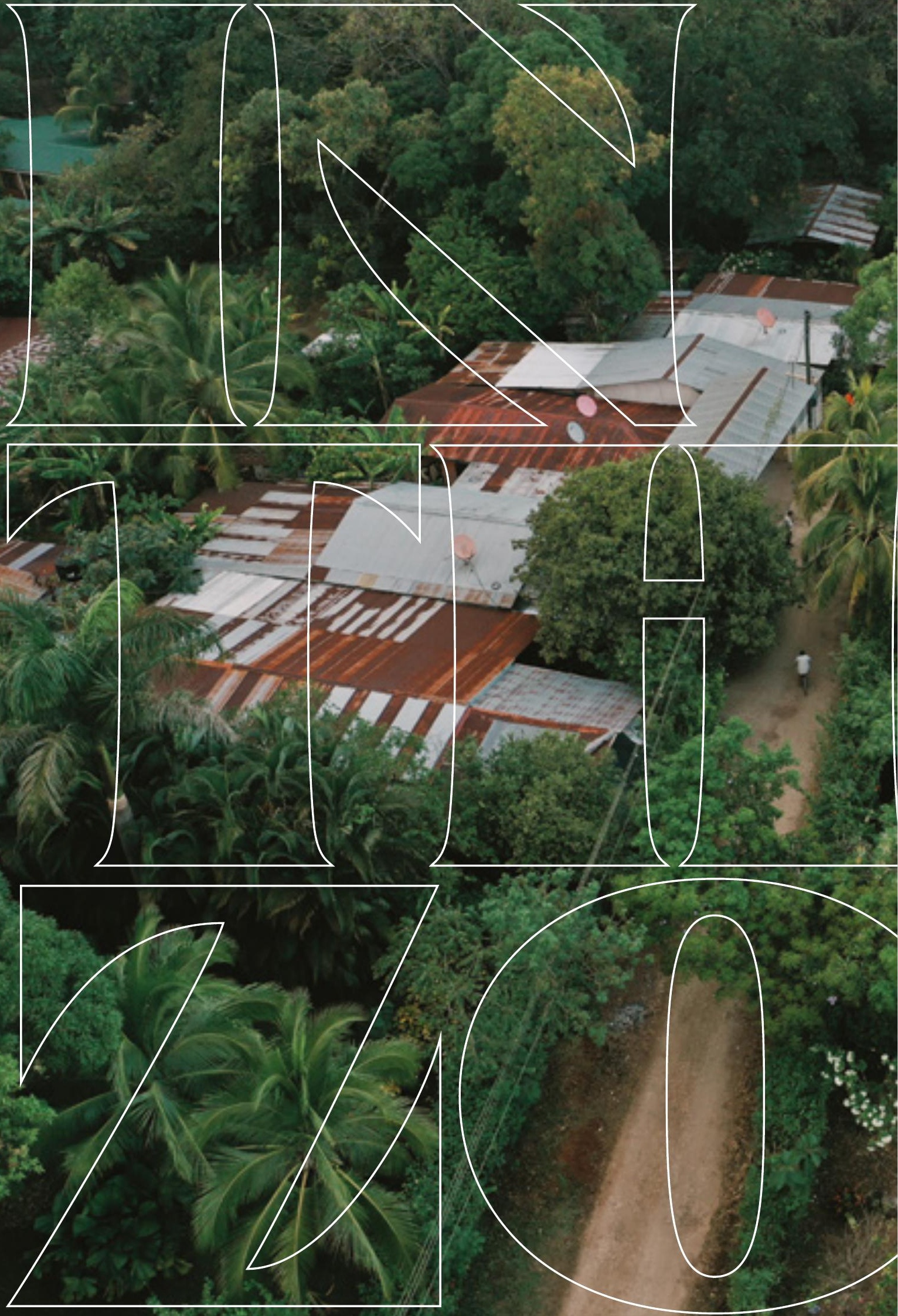
hen one thinks of the Nicoya Peninsula blue zone, located in Costa Rica (a small country on the isthmus of Central America), it is easy to imagine a single town filled with older people strolling in the parks and streets, or socializing in the "sodas" (the Costa Rican name for coffee shops). In fact, this blue zone-a concept first developed by demographers Michel Poulain and Giovanni Mario Pes and journalist Dan Buettner to refer to longevity hotspots, or areas where people live significantly longer than the general population-is quite large. $\mathrm{It}$ stretches across five jurisdictions (known as cantons in Costa Rica) on the Nicoya peninsula: Carrillo, Santa Cruz, Nicoya, Hojancha, and most of Nandayure. 
It is throughout this region where 57 centenarians live, and 1,010 nonagenarians, according to 2021 reports from Jorge Vindas López, founder of the the Asociación Península de Nicoya Zona Azul, an NGO dedicated to tracking the centenarian population. Tourist signs in Nicoya welcome passersby to one of the world's five recognized blue zones, which include Okinawa, Japan; Sardinia, Italy; Ikaria, Greece;

and Loma Linda, California. The Nicoya Peninsula blue zone is the only one located within Latin America, and it is the largest.

A cluster of towns and small cities dot the peninsula, a vast, hot region in the north of Costa Rica with a rugged terrain comprised of

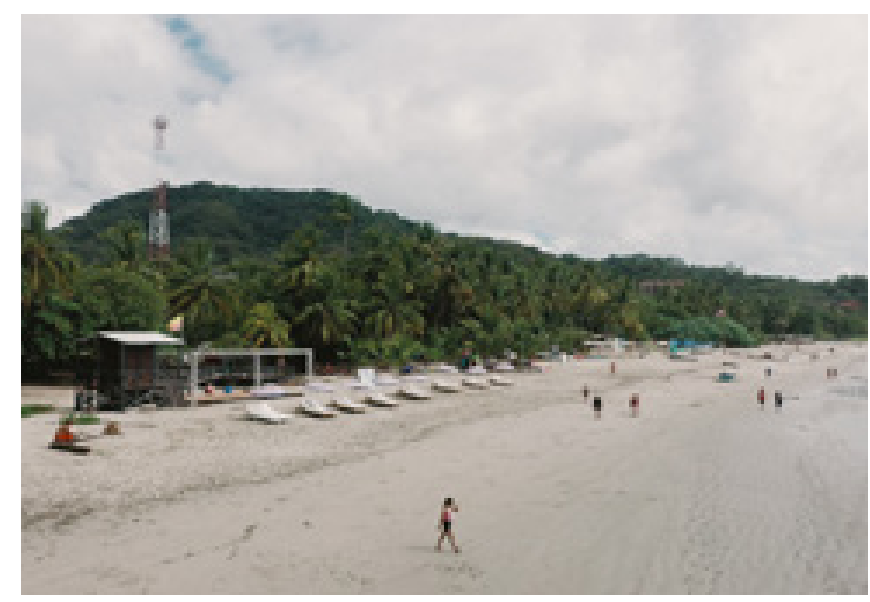

Samara Beach, located on the Nicoya Peninsula in the Guanacaste province region's oldest residents, is a mixture of both quantifiable factors and an unknown alchemy of culture and place.

Demographer Luis Rosero Bixby, of the Central American Center for Population at the University of Costa Rica (CCP-UCR), identified this blue zone in the early 2000s and is considered one of the most authoritative experts on the subject in the country.

He notes that "the number of centenarians in the peninsula is constantly fluctuating. Just as some die, others reach 100 years old each month." However, he explains, a blue zone does not differ from other regions of the world by the specific number of people over the age of 80 , mountains, farms, and beaches. Its location just north of the equator means the days are often sunny and the weather rarely dips below 70 degrees Fahrenheit. The population includes more than 5,000 adults over 75 years of age who have witnessed decades of development in their isolated locale-many of whom will likely be around to witness decades more.

For years, the media, researchers, and curious visitors alike have pondered the reasons for this unusual cluster of longevity set in the tropics. The answer, as demonstrated by the
90 or 100 who live in it at any given time, but by life expectancy. In the case of the Costa Rican blue zone, its population far exceeds the national average for life expectancy, which is 77.3 years for men and 82 years for women, according to data from the Ministry of Health.

"The metric to identify blue zones is exceptional longevity: that an adult has a very high expectation of living more years, or that they have a high probability of reaching age 90 or 100," adds Rosero Bixby.

This is precisely the case for the brothers 
Matarrita Gómez: Benedicto, who was born in 1923, and Liborio, born in 1926. They reside together in a humble home in Curime, five minutes from the city of Nicoya. And it is also the case of the sisters Lucía Villegas Cortés, 93, and Sara Villegas Cortés, 98, who live in the peaceful town of Quebrada Honda, 25 minutes from Nicoya.

All four have lived nearly a century and represent some of the faces of the autochthonous people of the Costa Rican blue zone. Their similarities attest to three factors that, according to science, may contribute to the blue zones' existence: genetics, diet, and lifestyle.

"There is probably a symbiosis of genes and environment. There is something in the genes of the Nicoyans that we do not know, possibly their Chorotega ancestry, but also the environment in which they lived. And a third element: the health system," says Rosero Bixby.

Costa Rica's public health system is universal and free for all residents. A score of national hospitals and almost a thousand health centers throughout the territory provide assistance to all populations, and all facilities respond to the call of a single institution: the Caja Costarricense de Seguro Social (CCSS). The CCSS facilitates the implementation of national plans and coordination of public health policies.

Of course, as in other countries, public care can have disadvantages, including long wait times for appointments or shortages of specialists in certain regions. However, the data overwhelmingly demonstrate the benefits to such an accessible health care system; Costa Rica now boasts the longest life expectancy in Latin America, longer even than that of the United States - by nearly two years.

Of the four nonagenarians, only Liborio Matarrita, 95, can communicate without the help of a caregiver, in his case his daughter María Matarrita, 65. A carpenter and farmer all his life, the elder Matarrita interrupted the interview several times to share artifacts and treasured objects from his later years. At the top of the list are two certificates from the municipality attesting to his participation in meetings and activities for older adults (before the pandemic). He also shows off a machete and a wooden ax that he made by hand for his great-grandchildren.

\section{There is}

something in

the genes of the

Nicoyans that

we do not know,

possibly their

Chorotega

ancestry,

but also the

environment

in which they

ved. And a

hird element:

the health

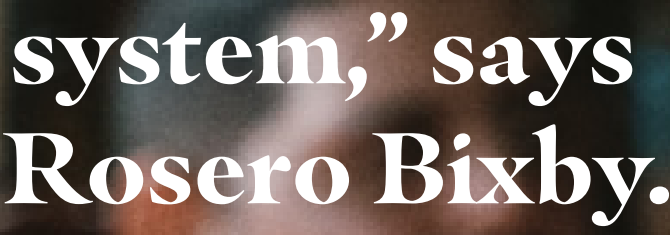




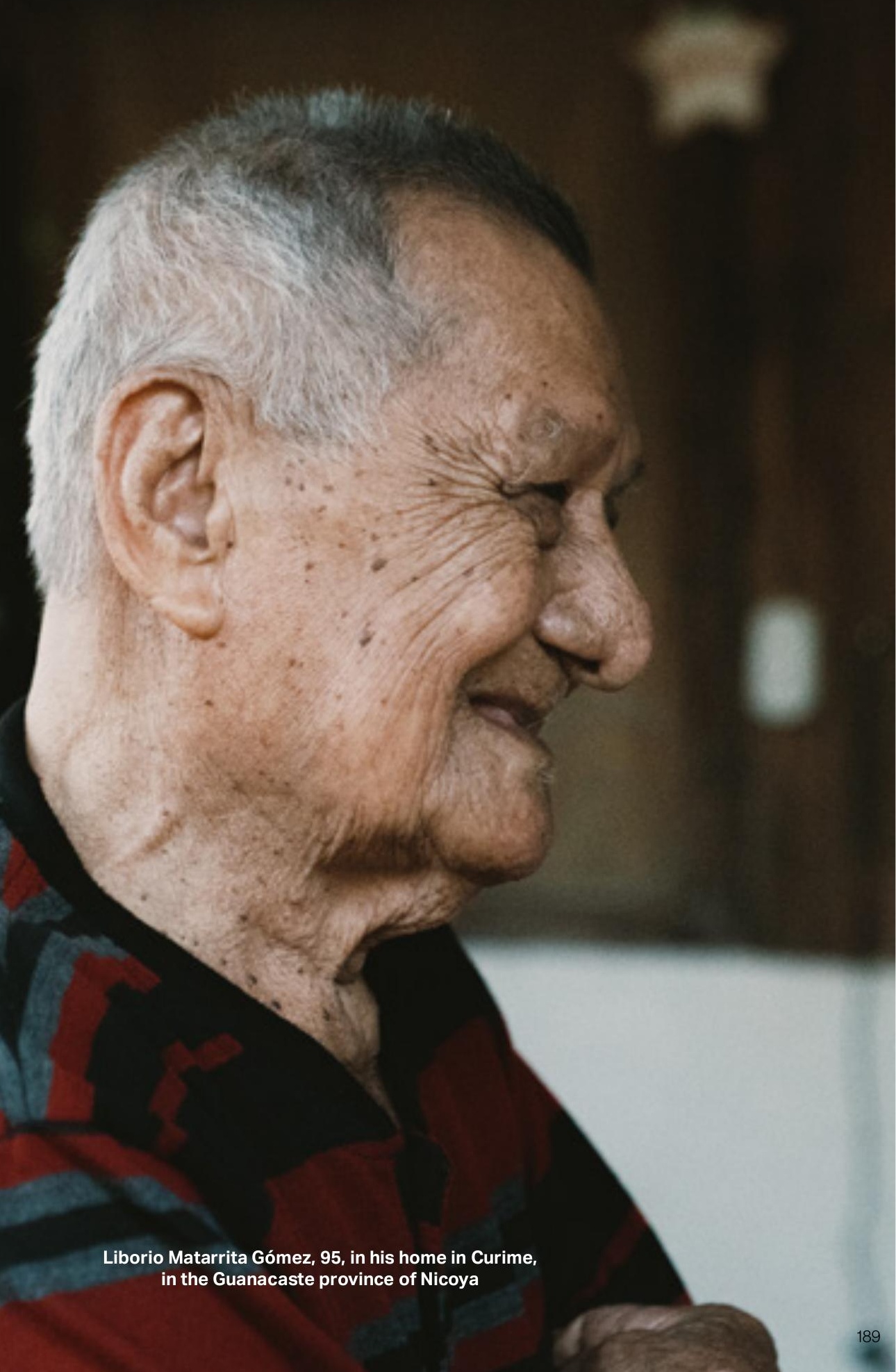




\section{Feature}

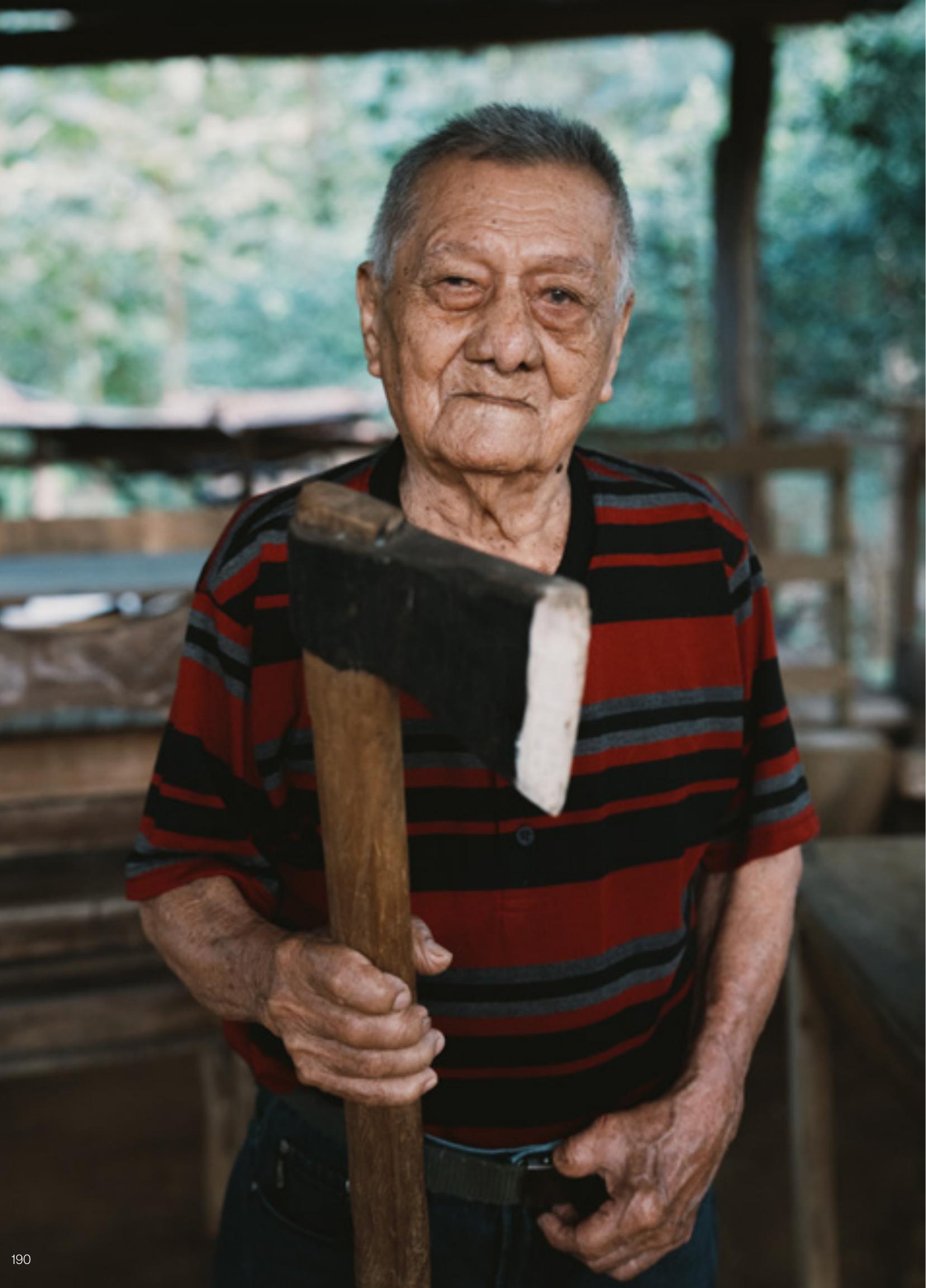




\section{COSIARIGA}
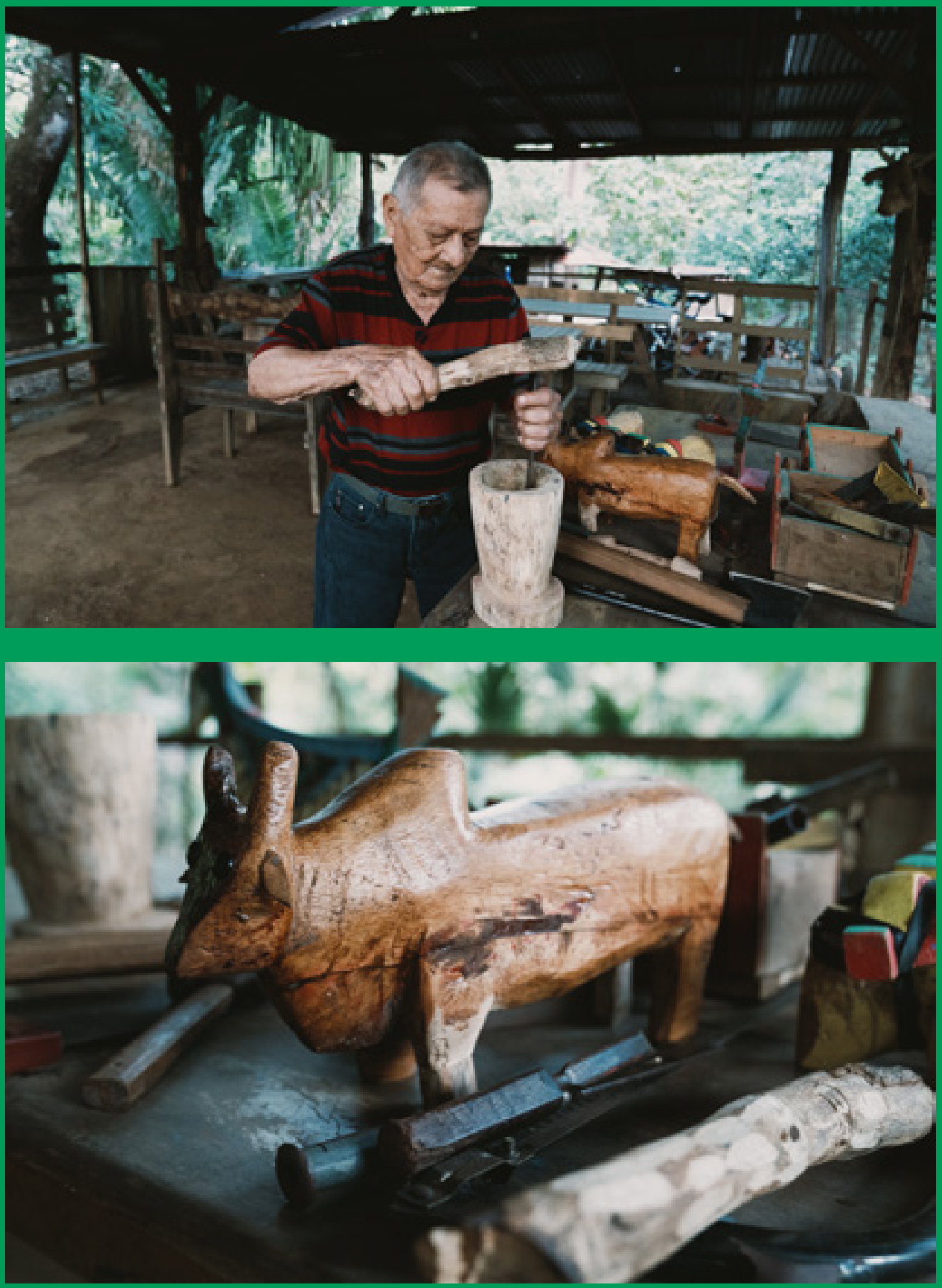

Liborio Matarrita Gómez, who worked as a carpenter and farmer for much of his life, demonstrates his wood working skills. Left, with a wooden decorative ax he made for his great-grandchildren; Above, some of his more recent wood carvings. 


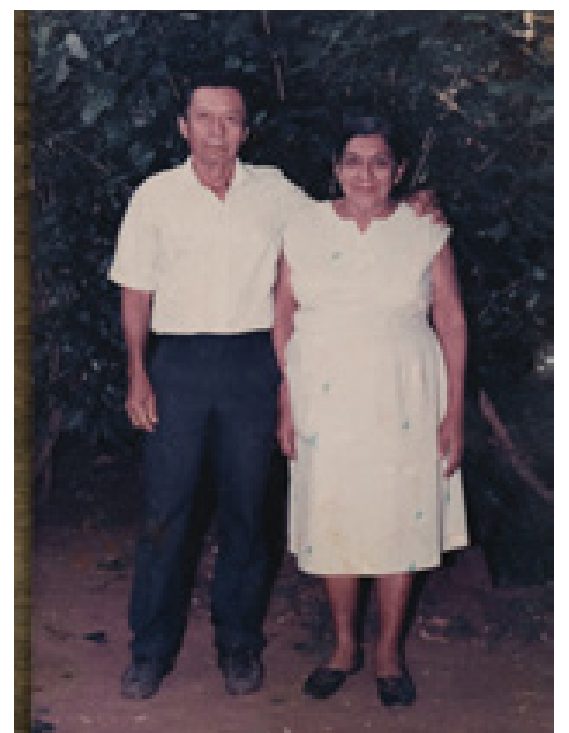

Liborio Matarrita Gómez and his wife, in a photo from several decades ago

Matarrita has short white hair and wears comfortable Crocs to keep his feet from swelling. Despite his advanced age, he possesses the strength to walk, sit, and chat quietly for almost an hour. When asked about his diet, he responds, "Rice and beans, because that's one's life." He explains that he eats small portions but is always sure to clear his plate.

And his secret for reaching 95 years of age in such good health?

"The rice and the beans," Matarrita repeats. But he also speaks in his slow, resolute way about a lifetime of physical labor. "I worked with wood. Fifteen years I spent 'flying chunches' (carrying objects, mostly wood planks)." During his youth, he often walked from Curime to San Juanillo, a journey of nearly 12 hours by foot, or 33 miles, according to Google Maps. He spent his adult life alternating between carpentry and agricultural work, all of which likely contributed to his strong constitution.

Food, too, is a crucial factor, according to Rosero Bixby and the interviewees. Rice, beans, and corn tortillas form the base of the nutritional pyramid in this region. Meals are accompanied by soft drinks flavored with fruits that sprout from trees throughout
"During his youth, he often walked from Curime to San Juanillo, a journey of nearly 12 hours by foot, or 33 miles, according to Google Maps."

Costa Rica, or with the drinking water that, by all accounts, is different in Nicoya.

"Here the water is rich in lime," says Zayda Cárdenas Villegas, 66, daughter of 98-yearold Lucía Villegas, referring to the white, calcium-laden mineral deposits that lace the Nicoyan drinking water. "Electric coffee makers don't last long here because of the lime. The same happens with the electric shower. They are a problem because water damages them quickly. But some say that it may be that which gives longevity".

Mother and daughter live together in Quebrada Honda, a small Guanacaste town with a Catholic church and school at the center of village activity, a small park, a communal hall, and sprawling houses typical of the area. During pandemic times, it is a quiet place. Saturday afternoon passes without people in the streets, with few businesses open and with a silence barely interrupted by 


\section{BUSIARILA}
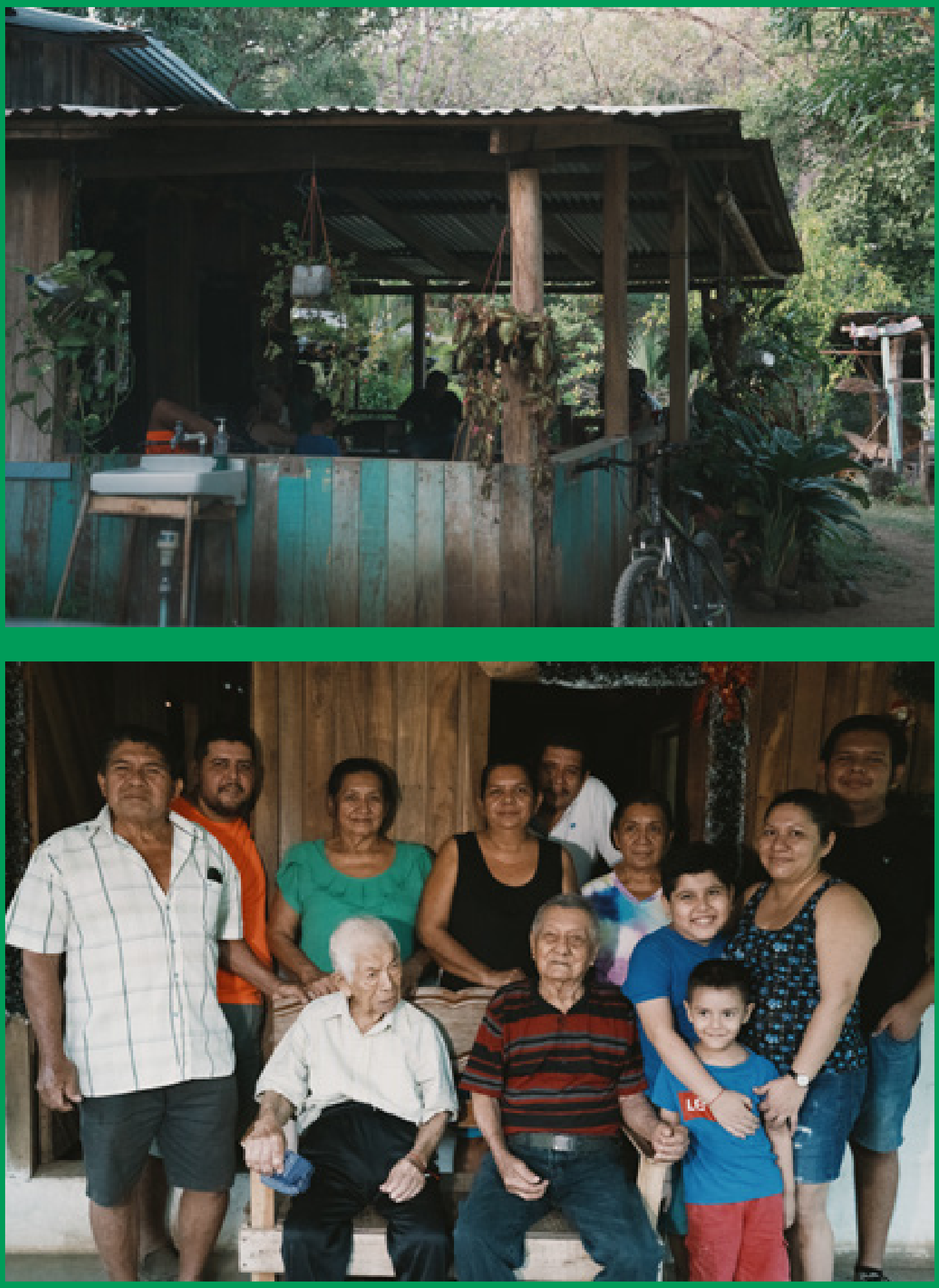

Above: The home of the brothers Liborio and Benedicto Matarrita Gómez; and a photo of the two brothers, Benedicto, 96, and Liborio, 95 (seated on bench), surrounded by their immediate family, including children, grandchildren, and great-grandchildren. 


\section{"Despite nearing 100, Villegas} has managed to overcome many challenges that come hand in hand with old age. Five years ago she suffered a fall that caused a broken hip, but thanks to Cárdenas' care, she has managed to walk again."

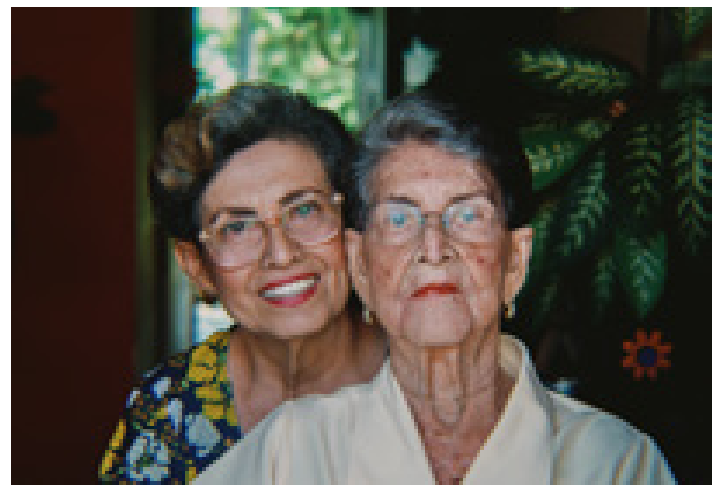

Lucía Villegas, 98, with daughter Zayda, 66

the sounds of birds or domesticated dogs barking within the houses.

Outwardly, Villegas' countenance is serene, although the recent death of her sisters, Digna, 99, and Cecilia, 95, coupled with hearing problems and the low oxygenation of her brain, keep her silent, her daughter reports. However, she never abandons her smile, which is accented by lipstick carefully applied by Cárdenas.

Despite nearing 100, Villegas has managed to overcome many challenges that come hand in hand with old age. Five years ago she suffered a fall that caused a broken hip, but thanks to Cárdenas' care, she has managed to walk again. That is a trend in the homes of the oldest people in Costa Rica. For the most part, they live with relatives, usually daughters and sons who are perhaps on their way to becoming nonagenarians or centenarians themselves.

Lucía Villegas' sister, Sara Villegas, who lives 200 meters away, is 93 years old and has suffered from Alzheimer's for just over ten years. She is also cared for by a daughter, lleana Villegas, who guides her in a wheelchair around her house.

leana Villegas explains that her mother has access to frequent and ongoing medical care. Although Alzheimer's is incurable, she 


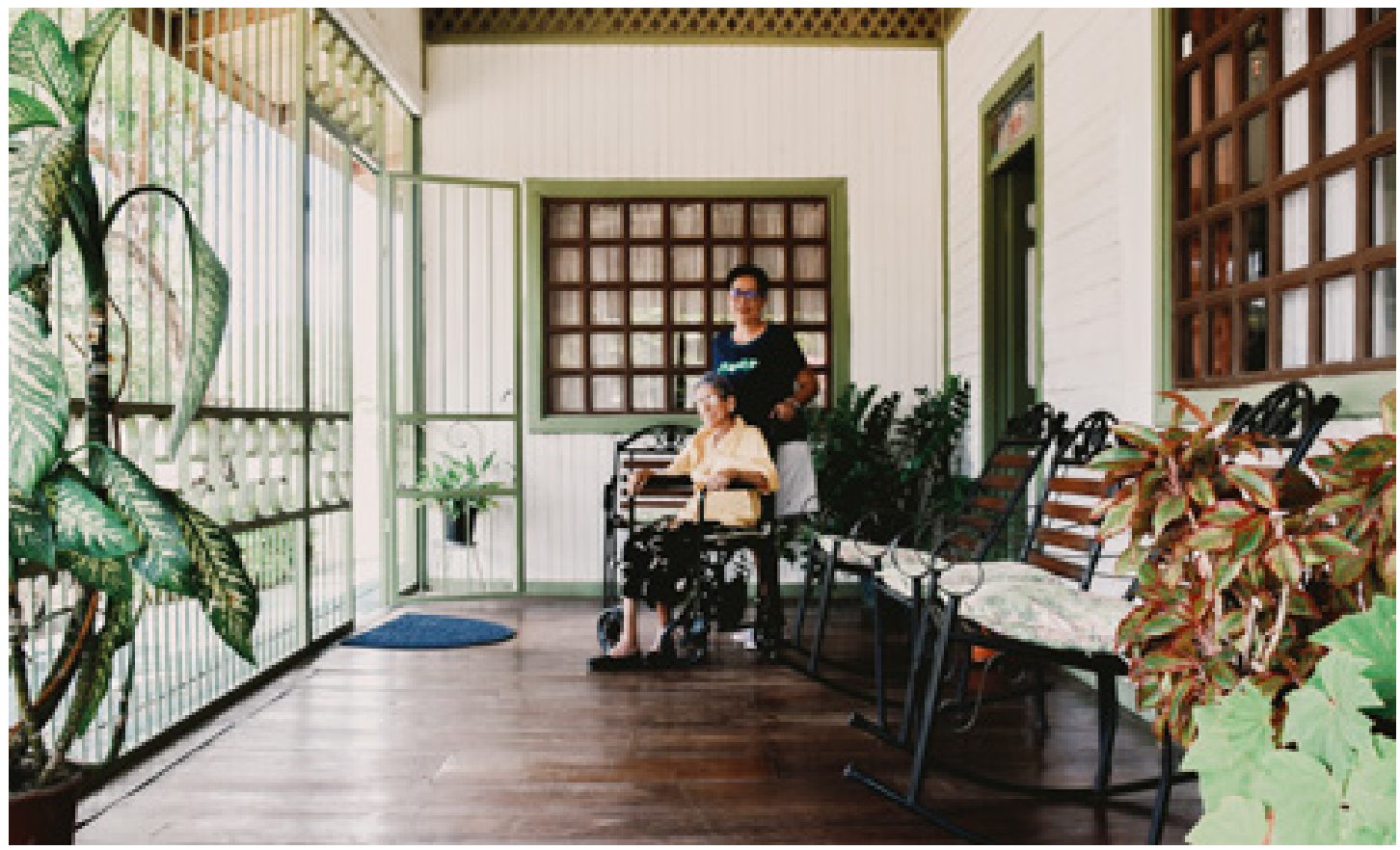

Sara Villegas, 93, with daughter lleana, in their home in Quebrada Honda

remains devoted to managing her mother's treatment plan. "As long as I live, I have to fight for her."

According to Luis Rosero Bixby, the number of adults over 65 years old will triple by 2050 . Much is due to a boom in births in Costa Rica during the 50s, 60s and 70s. Families typically had six or more children, all of whom grew up with the promise of a longer life expectancy. But those with the greatest advantage are the Nicoyans in the blue zone.

Rosero Bixby underlines the fact that one cannot simply go to Nicoya as an adult with hopes of outliving fellow Costa Ricans. In addition to inherent genetic factors, he points out the cumulative effects of other elements, including "the surroundings and the context: weather, food, water, jobs, interpersonal relationships, stress levels, and more." People keep searching for the modern-day, Nicoyan version of the philosopher's stone (a mythical substance believed by alchemists during the
Middle Ages to grant eternal life). But, Rosero Bixby says, rather than one magical key to longevity, "science suggests it's more about several small secrets, in plural."

Liborio Matarrita and his family are living proof of the combination of "small secrets."

"I planted corn, beans, and rice. Later I was a carpenter until I stopped working. My brother made baskets. He did that all his life. Baskets to coger (pick up) coffee and carry eggs."

He points to his brother Benedicto, 99, who listens silently. They come from a family of nine siblings. Of the six who are still living, their older sister Marina is 101 and the youngest, Teresita, is a mere 90 years old.

"But that's nothing!" Matarrita exclaims. "My mom lived to be 100 years old, and my great-grandmother reached 110 years old!" • 
Feature 


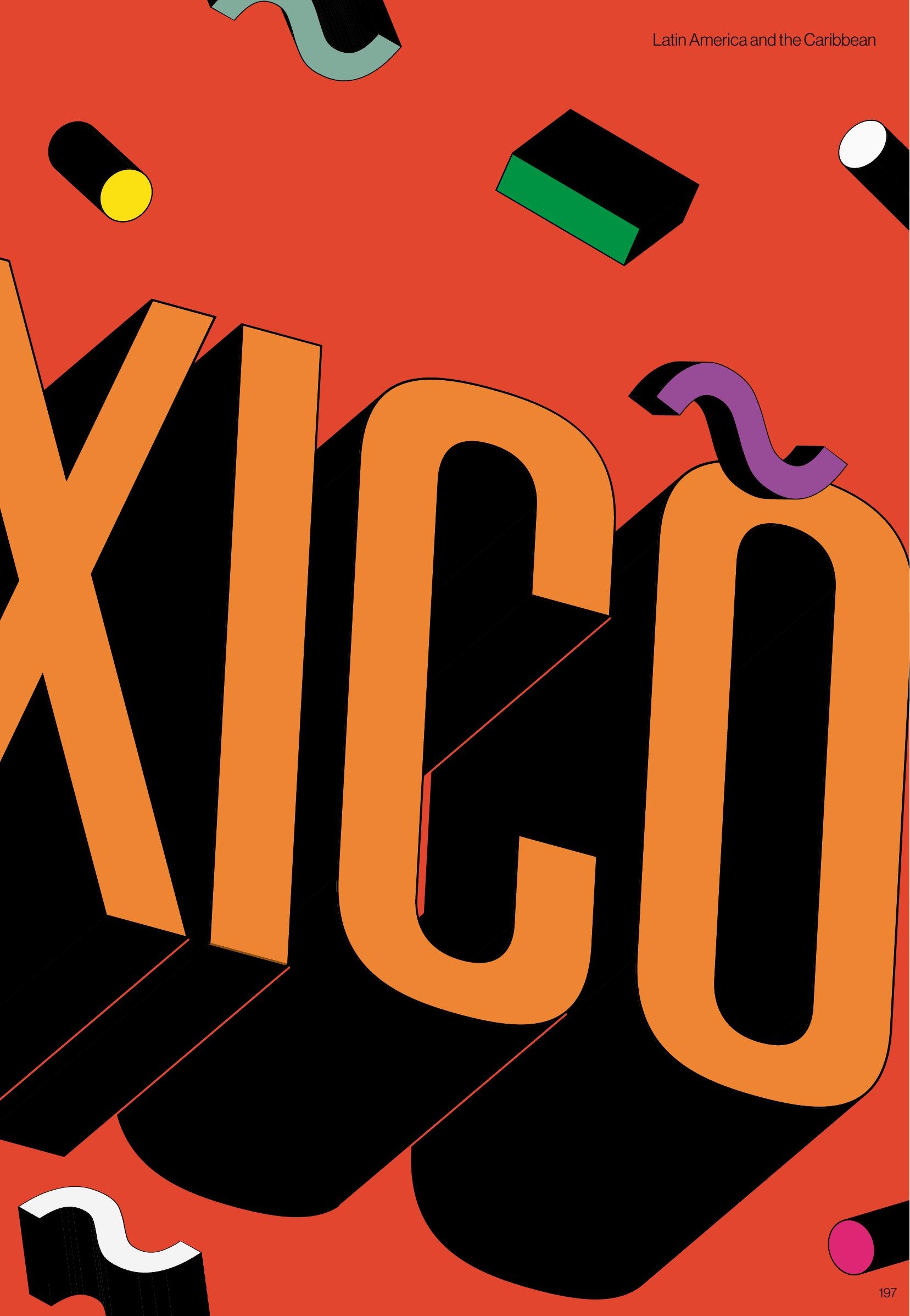


Although Mexico is still a relatively young country by OECD standards, its population of people age 65-plus is projected to more than triple by 2050, largely driven by a declining fertility rate. The government has been slow to prepare for the demographic transformation and has lagged in investing in the support systems to address the challenges of an aging society. Families are, for the most part, left to assume the responsibility for providing care and economic security for their aging family members. The country's massive informal economy has contributed to the highest poverty 
rates for older adults compared to all OECD countries; the average income for the 65-plus group is 40 percent below the relative poverty line. In recent years, the government has strengthened public policies to improve the quality of life of older adults, including creating the Program for the Well-being of the Elderly, which provides a non-contributory pension and assistance services. Other agencies, including The National Institute for the Elderly (INAPAM), seek to raise awareness about the needs of older adults in the realms of human rights, economic security, social protection, and active aging. 


\section{Aging in Mexico}

\section{Demographic Profile}

1980

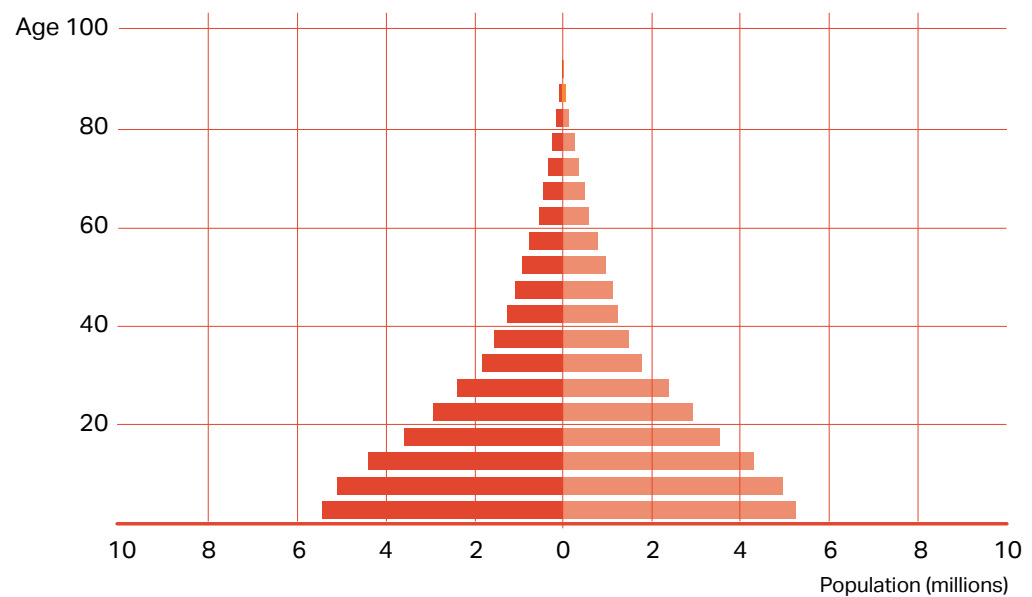

2020

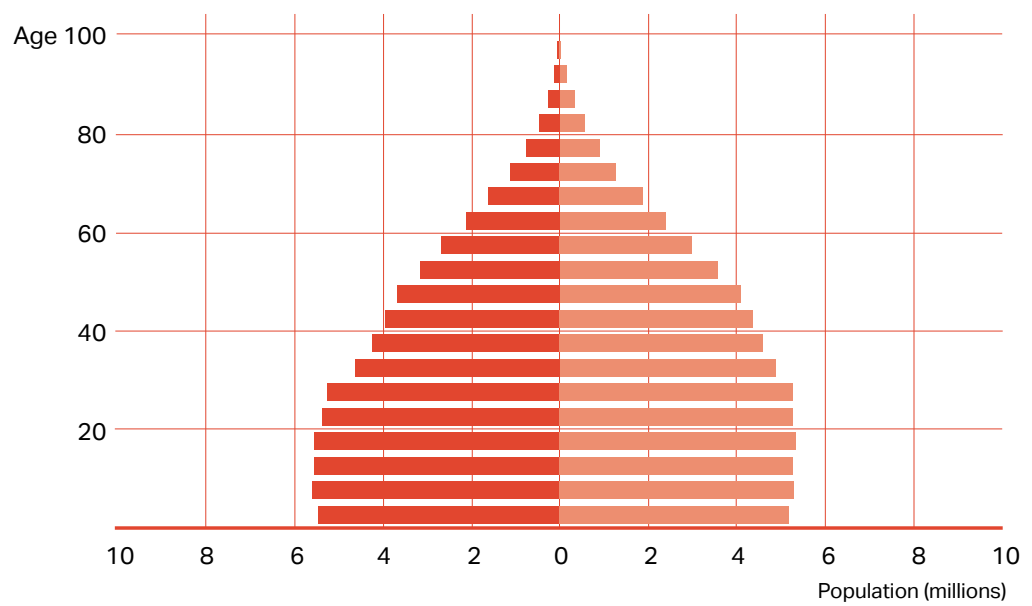

2060

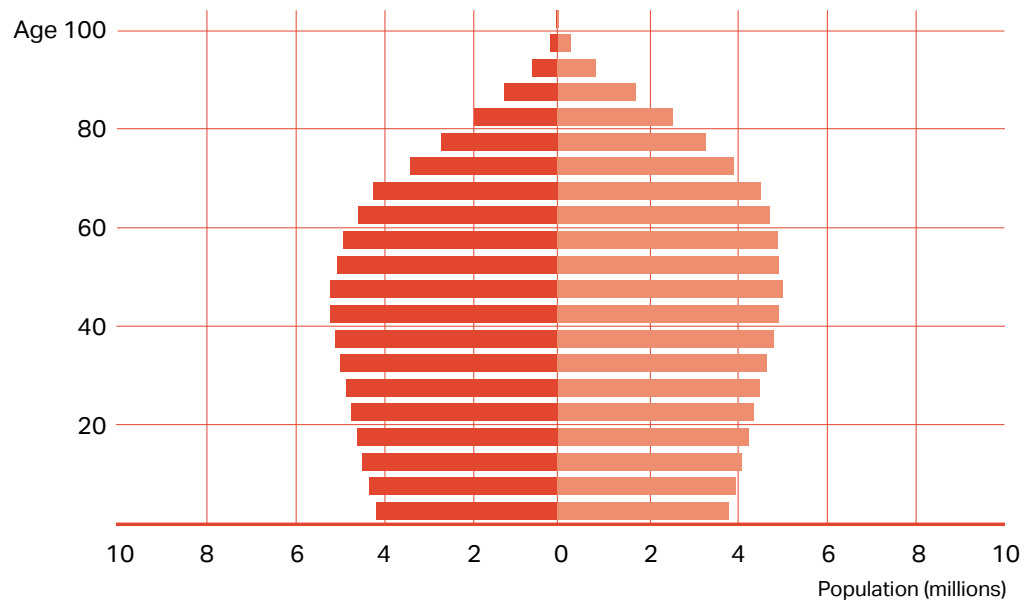



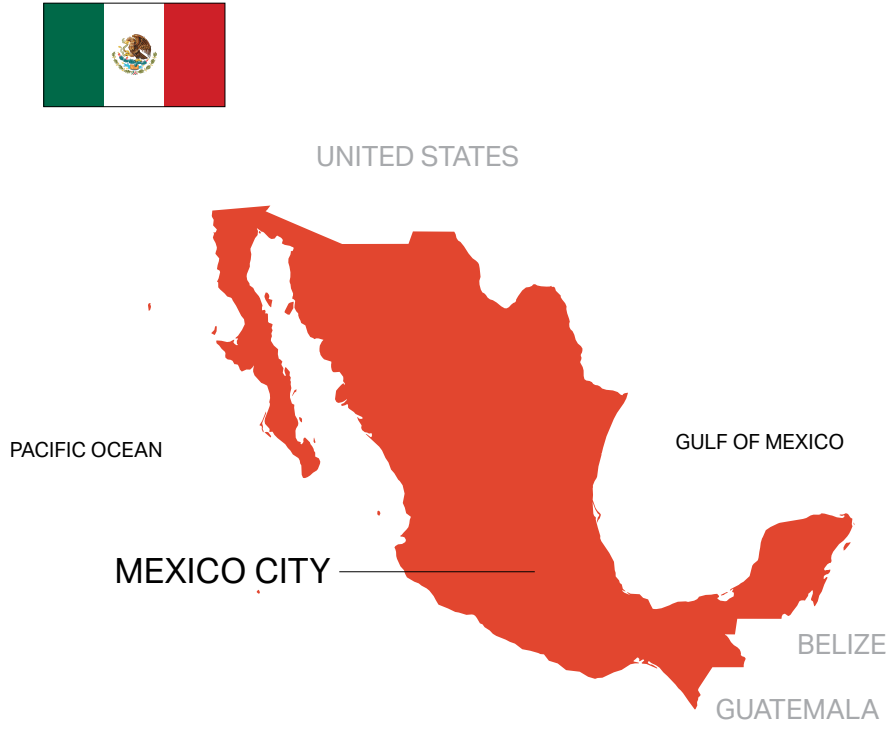

RELIGION

Roman Catholic 82.7\%, Pentecostal $1.6 \%$, Jehovah's Witness $1.4 \%$, other Evangelical Churches 5\%, other $1.9 \%$, none $4.7 \%$, unspecified $2.7 \%$ (2010 est.)

NET MIGRATION RATE

-1.46 migrant(s)/1,000 population (2021 est.)

LIFE EXPECTANCY AT BIRTH

Total population: 76.94 years (92 ${ }^{\mathrm{ND}}$ )

Male: 74.15 years

Female: 79.87 years (2021 est.)

BIRTH RATE

17.29 births $/ 1,000$ population (2021 est.)

POPULATION GROWTH RATE

$1.04 \%$ (2021 est.)

URBAN POPULATION

$81 \%$ of total population (2021)

AGE STRUCTURE (2017 EST.)

0-14 years: $26.01 \%$

15-24 years: $16.97 \%$

25-54 years: $41.06 \%$

55-64 years: $8.29 \%$

65 years and over: $7.67 \%$

UNEMPLOYMENT RATE

$3.49 \%$ (2019 est.)

0.322

HEALTH EXPENDITURES

$5.4 \%(2018)$

OBESITY RATE

$28.9 \%$ (2016)

LITERACY RATE

95.4\% (2018)

Agriculture: $13.4 \%$

Industry: $24.1 \%$

Services: $61.9 \%$ (2011)

RESIDENT LABOR FORCE

PARTICIPATION RATE

$65.3 \%$ (2019 est.)

EXPORTS (US DOLLARS)

IMPORTS (US DOLLARS)

LANGUAGES* $0.8 \%$ (2005)

\section{MEXICO}

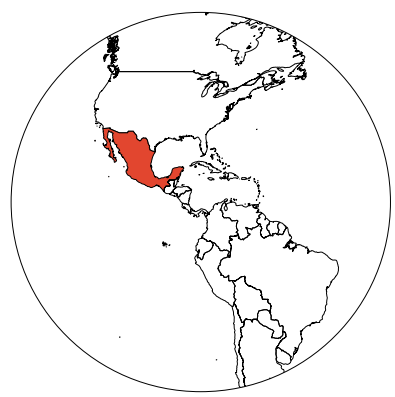

COUNTRY

Mexico

CONVENTIONAL LONGFORM NAME United Mexican States

TOTAL AREA

$1,964,375 \mathrm{sq} \mathrm{km}$

$(758,449.4$ sq miles)

POPULATION (WORLD RANK)

$126,014,024\left(10^{\text {TH }}\right)$

POPULATION DENSITY (WORLD RANK) 64.91 per sq. km (2018 est.) $\left(147^{\mathrm{TH}}\right)$

GENDER INEQUALITY INDEX (2019)

LABOR FORCE BY OCCUPATION

$\$ 491.593$ billion (2019 est.)

$\$ 480.886$ billion (2019 est.)

Spanish only $92.7 \%$, Spanish and indigenous languages $5.7 \%$, indigenous only $0.8 \%$, unspecified

*Note: indigenous languages include various Mayan, Nahuatl, and other regional languages

\section{DEMONYM}

Mexican

BUDGET (US DOLLARS) 2017 EST.

Revenues: $\$ 261.4$ billion

Expenditures: $\$ 273.8$ billion

GDP NOMINAL (US DOLLARS)

$\$ 1.269$ trillion (2019 est.)

MAIN INDUSTRIES

Food and beverages, tobacco, chemicals, iron and steel, petroleum, mining, textiles, clothing, motor vehicles, consumer durables, tourism

NATURAL RESOURCES

Petroleum, silver, antimony, copper, gold, lead, zinc, natural gas, timber

GOVERNMENT TYPE

Federal presidential republic

ETHNIC GROUPS*

Mestizo (Amerindian-Spanish) $62 \%$, predominantly Amerindian $21 \%$, Amerindian $7 \%$, other $10 \%$ (mostly European) (2012 est.)

*Note: Mexico does not collect census data on ethnicity 


\section{Turning Challenges into Opportunities:}

\section{Accelerated Aging in Mexico}

Mexico is already at an advanced stage in its demographic transition, driven by lower fertility rates coupled with lower mortality rates resulting in longer average lifespans. ${ }^{1} \mathrm{~A}$ key feature of demographic trends in Mexico is the rapid rate at which the older population is growing. According to data from the United Nations, in 2020, the population age 60 years or older reached 14.5 million, representing 11 percent of the total population. Women make up 55 percent of this group and men 45 percent. Furthermore, it is expected that in 2050, one out of four people in Mexico will be 60 and older (about 40 million people). ${ }^{2}$

Even though these demographic changes are excellent news as they represent broad socioeconomic progress, they entail challenges. Extended life expectancies impact labor market dynamics as well as the sustainability of pension systems.

They also increase the need for health care systems to prevent and manage chronic and non-communicable diseases as well as create a need to address increased demand for long-term care. Thus, in some respects, the level of impact of the demographic changes largely hinges on Mexico's capacity to respond quickly.

\section{Acknowledging and Confronting} the Challenges

An initial challenge related to a growing population of older persons is the demand for care and support services. In 2018, according to the Mexican Health and Aging Study (MHAS, or ENASEM in Spanish), 3 million individuals over 60 (21 percent of this age group) reported having experienced difficulties with performing at least one of the basic activities of daily living (ADLs) and are in a situation of functional or care dependency. This means that they need support or help from others to perform activities of daily living. Furthermore, functional dependency increases with age: the proportion of older people with difficulties in at least one activity of daily living jumps from 13 percent for those age 60-69 to 47 percent among those who are 80-plus.

The number of older people reporting 


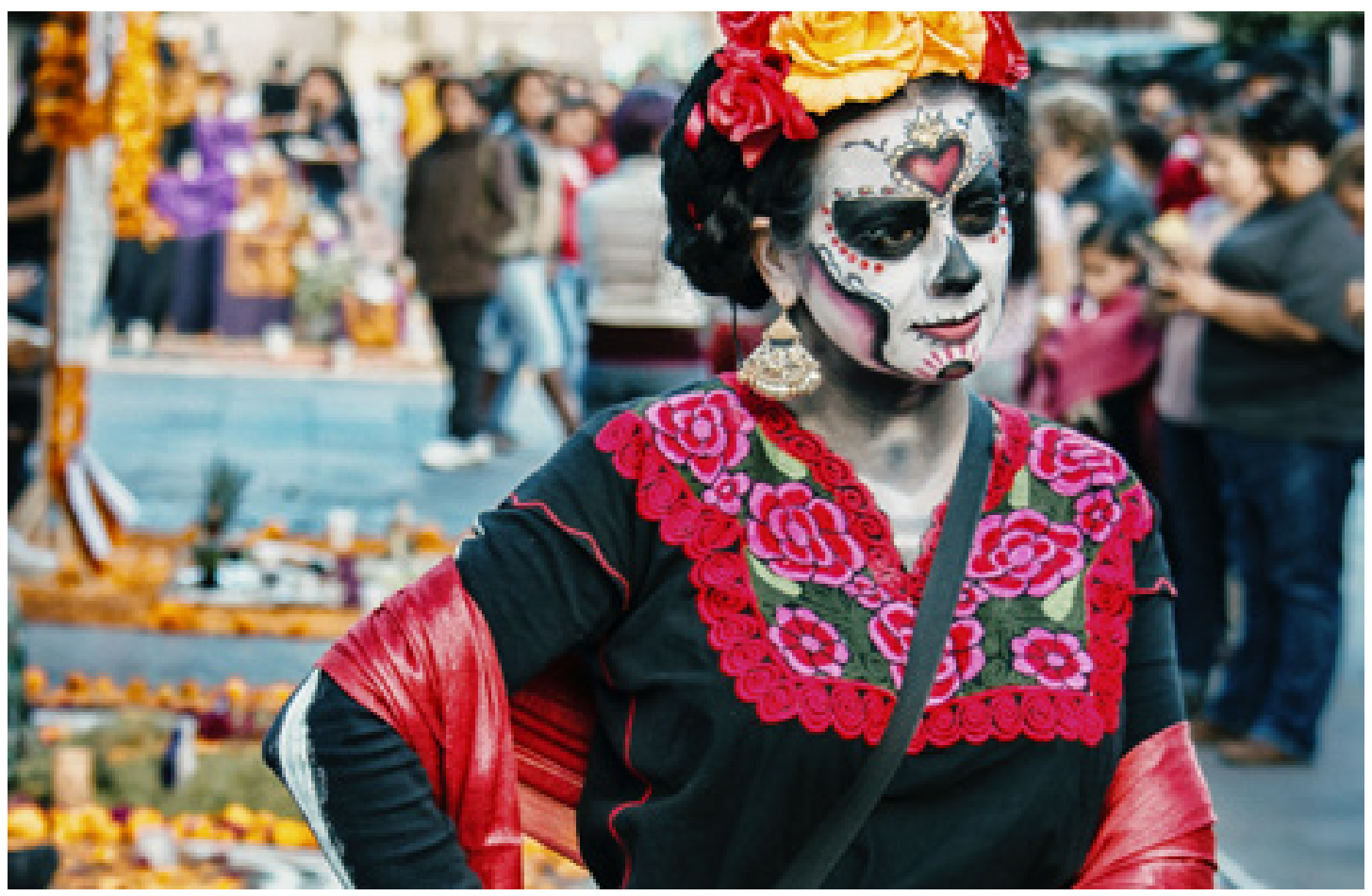

difficulties with performing activities of daily living has significantly increased since 2001 , when it totaled only $930,000(12.8$ percent of the 60-plus population). This increase of more than 2 million older persons with care dependency by 2018 is attributable both to the increase in the number of people over 60 ( 45 percent) and to the increase in the dependency rate for each age bracket (55 percent). For example, among persons aged 70 to 79 , dependency increased from 13 percent to 23 percent between 2001 and 2018. This increase is expected to continue in the coming years: by 2026 , it is projected that 19 percent of older people in Mexico will be in a situation of mild dependency and 9 percent severe dependency. ${ }^{3}$

A second challenge of accelerated aging is associated with gender, particularly regarding the provision of caregiving services for older persons with functional dependency. Similar to other countries, in Mexico women are the main contributors to the care economy. Taking a broad perspective, according to 2019 data from the National Satellite Accounts Exercise performed by the National Statistical Institute (INEGI, 2020), women contribute 75 percent of the total value of unpaid household work and 74 percent of the value of caregiving work within the family. The fact that women are overloaded with care tasks has consequences in the labor market: Mexican women between 50 and 64 years of age, who face a new need of caregiving due to the development of care dependency by a parent are less likely to work. Their probability of employment drops by 7 percent. Those who manage to stay employed, meanwhile, work 7 percent fewer hours. ${ }^{4}$ Notably, the same analysis 


\section{Women further experience higher rates of care dependency in certain age groups; for example, the dependency rate within the} 80-plus population is 53 percent for women and 41 percent for men (MHAS, 2018). In short, women are the main providers of unpaid care and the main recipients of these services. All these facts underscore the need to develop a comprehensive system of care and to rebalance the weight of care within families.

shows that there are no impacts for men who face a similar situation.

The gender dimension is further compounded by the fact that women on average live longer than men: women represent 51 percent of the general population but 55 percent of the 70-79 age group and 58 percent of the 80 -plus age group. Women further experience higher rates of care dependency in certain age groups; for example, the dependency rate within the $80+$ population is 53 percent for women and 41 percent for men (MHAS, 2018). In short, women are the main providers of unpaid care and the main recipients of these services. All these facts underscore the need to develop a comprehensive system of care and to rebalance the weight of care within families.

Another challenge is that older persons in Mexico show a high prevalence of chronic and non-communicable diseases, which are associated with higher functional dependency, decreased quality of life, and additional stress on the health system. Three-fifths of people ages 60-69 who were interviewed in the 2018 ENASEM reported having been diagnosed with at least one chronic disease. That prevalence increases with age. It jumps to 67 percent among those who are 70 and older, and for all age groups the percentage of diagnosis among women is higher. The main chronic conditions facing people ages 60-69 are hypertension (42 percent), diabetes (26 percent), and arthritis (12 percent). These values are likely underestimated since diseases such as diabetes and hypertension are often not diagnosed. The International Diabetes Federation estimates that half of those who suffer from diabetes in low- and middle-income countries do not know they have the disease. ${ }^{5}$ Finally, according to the Global Burden of Disease Study in Mexico, among people ages 70 and up, cardiovascular diseases account for the largest share of the total percentage of deaths (31 percent), followed by diabetes and other endocrine diseases (20 percent). ${ }^{6}$ Not only aging but other factors influence the appearance of chronic diseases: a more sedentary lifestyle, tobacco use, unhealthy diets, and alcohol consumption. Healthy aging requires effective and multi-sector public health approaches for identifying risk factors and mitigating long-term effects. 


\section{Opportunity and Investment}

Yet, as we know, the world's aging population presents a tremendous opportunity. For example, when older people, who typically come equipped with the benefit of experience, are in the job market, more income and tax revenue are generated. In Mexico, 40 percent of the population age 60 and over are active in the labor market. According to estimates from PwC's Golden Age Index 2018, if the labor participation rate among people over 55 years of age were to reach more than 70 percent, Mexico's GDP would increase by $\$ 52$ billion in the long term. ${ }^{7}$ And, of course, it is expected that people working longer would mean less of a strain on the pension system.

It is further important to recognize and galvanize the potential of the Silver Economy, that is the economic sector related to the needs and demands of older people. This is a growing, often overlooked, market. Major challenges associated with aging bring possibilities for economic development, new business ventures, and job opportunities. Promoting healthy aging and facilitating the growth of the Silver Economy will go a long way in turning the challenge of aging into an opportunity for sustainable, inclusive, and equitable growth.

Thus, as is the case in many countries, the rapidly aging population in Mexico demands that the nation acknowledge the challenges that lie ahead so that it can develop solutions to address them. Within both the solutions to challenges and the overall economic strength and potential of older persons lies a valuable opportunity. As with any opportunity, societies will need to invest resources, in order to benefit from it.
${ }^{2}$ López-Ortega M, Aranco N. Envejecimiento y atención a la dependencia en México [Internet]. InterAmerican Development Bank; 2019 Aug. Available from: https://publications.iadb.org/es/envejecimiento-y-atencion-la-dependencia-en-mexico

${ }^{3}$ González-González C, Cafagna G, Hernández Ruiz MC, Ibarrarán P, Stampini M. Dependencia funcional y apoyo para personas mayores de México, 2001-2026. Rev Panam Salud Publica. 2021;45:e71. Available from: https://doi.org/10.26633/ RPSP.2021.71

${ }^{4}$ Stampini M, Oliveri ML, Ibarrarán P, Londoño D, Rhee HJ (Sean), James GM. Working Less to Take Care of Parents?: Labor Market Effects of Family Long-Term Care in Latin America [Internet]. Inter-American Development Bank; 2020 Oct. Available from: https:// publications.iadb.org/en/node/29065

${ }^{5}$ Ibarraran, P. Health Challenges Facing an Aging Population. Gente Saludable. 08-19-2019.

Available from: https://blogs.iadb.org/salud/en/ health-challenges-in-aging/

${ }^{6}$ López-Ortega M, Aranco N. Envejecimiento y atención a la dependencia en México [Internet]. InterAmerican Development Bank; 2019 Aug. Available from: https://publications.iadb.org/es/envejecimiento-y-atencion-la-dependencia-en-mexico

7PWC Golden Age Index. PwC. 2018. Available from: https://www.pwc.es/es/publicaciones/economia/ assets/golden-age-index-2018.pdf

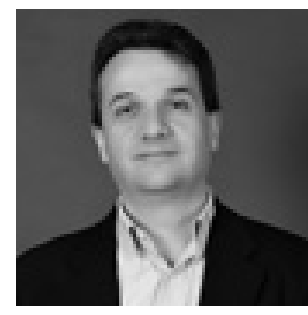

PABLO IBARRARÁN

Principal Social Protection Specialist Inter-American

Development Bank

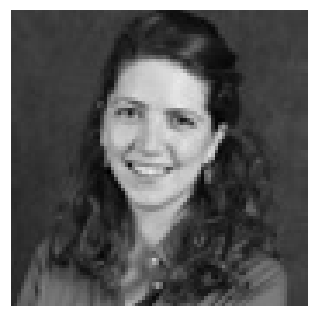

FIORELLA BENEDETTI

Undersecretary

Ministry of Social

Development

City of Buenos Aires

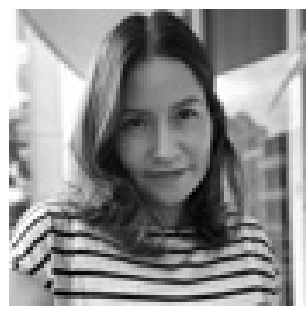

ANA MYLENA AGUILAR Senior Health Economist Inter-American Development Bank

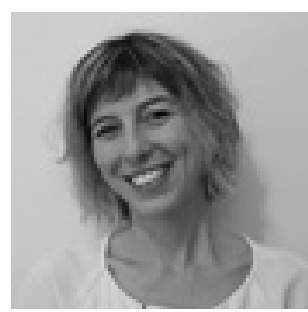

NATALIA ARANCO

Consultant

Inter-American

Development Bank 


\section{Day in the Life}

\section{Alma Julieta Juarez}

Mexico City

75 years old

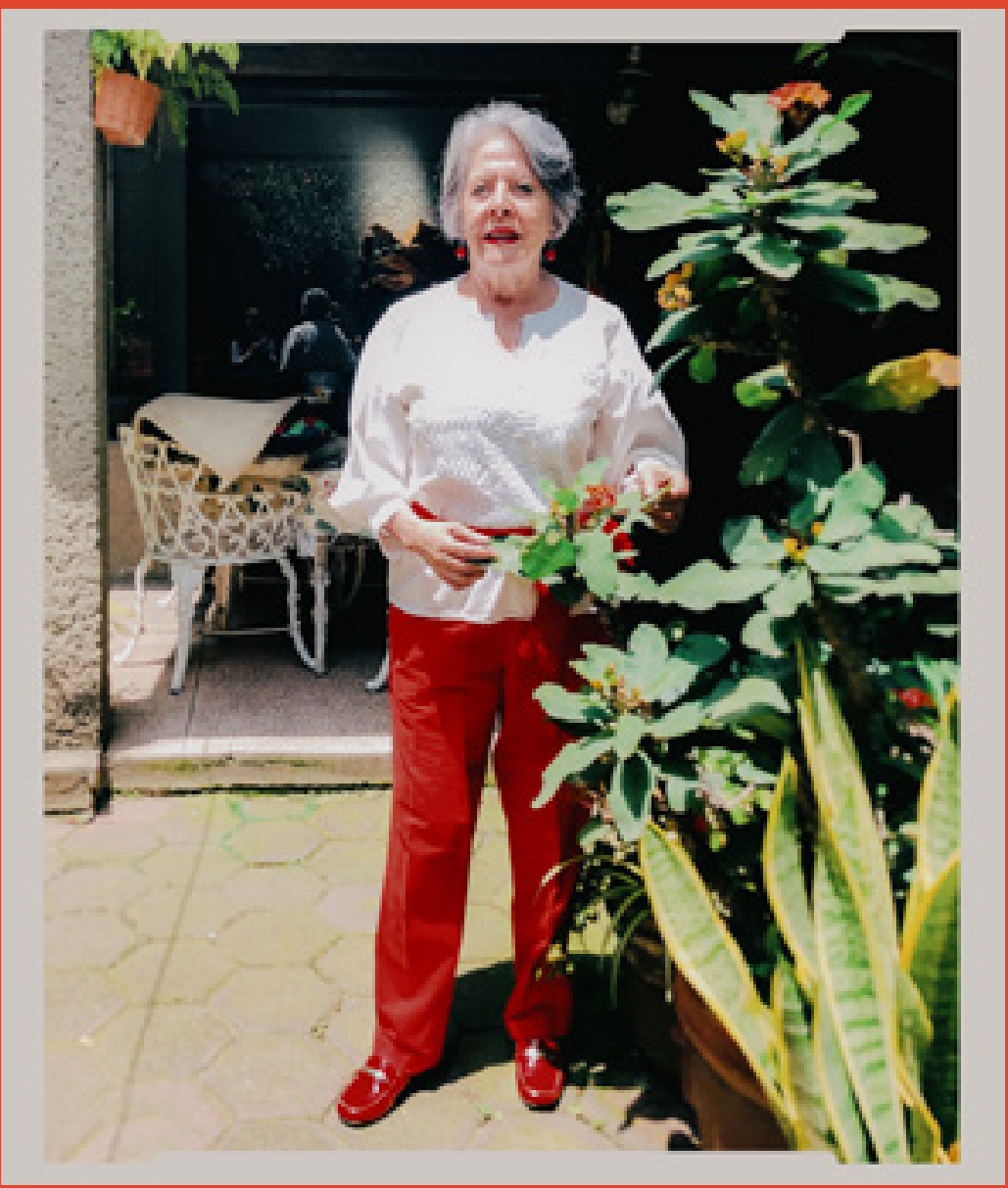

Alma lives alone in Mexico City, enjoying retired life. Although the pandemic at times made her feel isolated, she makes a conscious effort to spend time with a close-knit network of family and friends. 


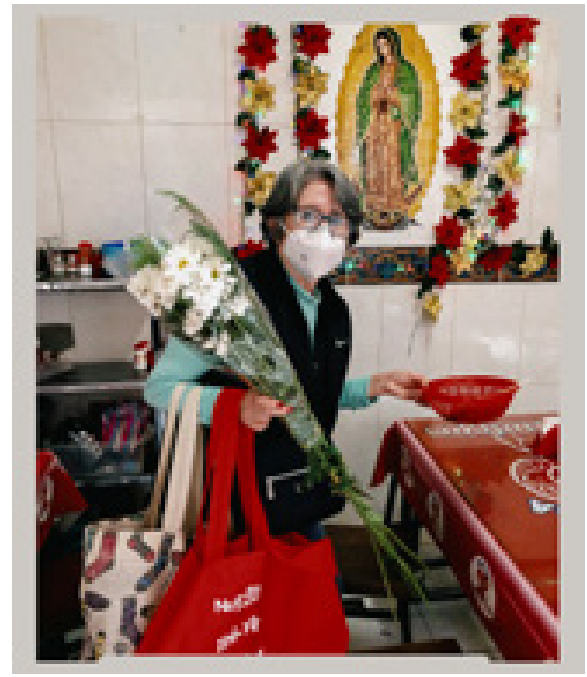

Getting ready for the Mexican Independence Day celebration

\section{What is your typical day like?}

My house is small with a garden which I greatly appreciate. In México City most people live in buildings with no gardens at all, so this is a luxury! I'm retired. Last year during the first two or three months of the pandemic, I hardly left my house and did not have visitors. I'm quite gregarious so it was a bit hard. Eventually, I started inviting one or two friends to come over. We sit outside in my small porch and are very pleased to see each other. We chat, listen to music, eat goodies, and drink Tequila. We take good care of each other.

Other days I stay here with my dog Cooper (12 years old), who is wonderful company. I'm so grateful to have him. I do a bit of house cleaning and cook a little for myself. Yoya, who has been working for my family for 62 years, comes once a week. It is a great joy receiving her and having her help me with laundry, house cleaning, and cooking (she is an extraordinary cook). I love her dearly and she is like a sister to me.

\section{How do you stay physically active?}

Every morning from Monday through Friday I walk for one hour (about $3.5 \mathrm{~km}$ ) in a lovely garden just across from my house. It is delightful. Some of my friends go out too and we walk, chat, and laugh together. It's completely therapeutic for all of us.
How do you stay mentally and socially active? During the weekends my daughter Lilly, son-inlaw Javi, and Ana Paula, my first granddaughter, usually invite me over to their place. We sit in the garden and have a lovely time. I really appreciate and love those gatherings. It is so enjoyable being with family.

\section{What do you find most challenging about growing older?}

I'm 75 years old and life has not been too difficult, although it's not as simple doing certain things now. I never want to be a burden on anybody. Being self-sufficient in every way is wonderful. I pray that I can continue this way for as long as God wills. Until then I'll continue being grateful, happy, and enjoying life.

\section{What are your thoughts on aging in Mexico?} Aging in Mexico has its pros and cons. Here, families often care for older family members rather than sending them to nursing homes. Nursing homes are generally not as expensive as in other countries. My friends and I frequently talk about what will happen to us when we are not capable of tending for ourselves. We have agreed to try going to the same nursing home, where we can keep each other company. I have lost my private health insurance because, due to my age, it is very expensive. Now I worry about having a medical emergency because the public hospitals are overloaded. Of course, private hospitals are super expensive, so I hope I keep my excellent health and never have to worry about that.

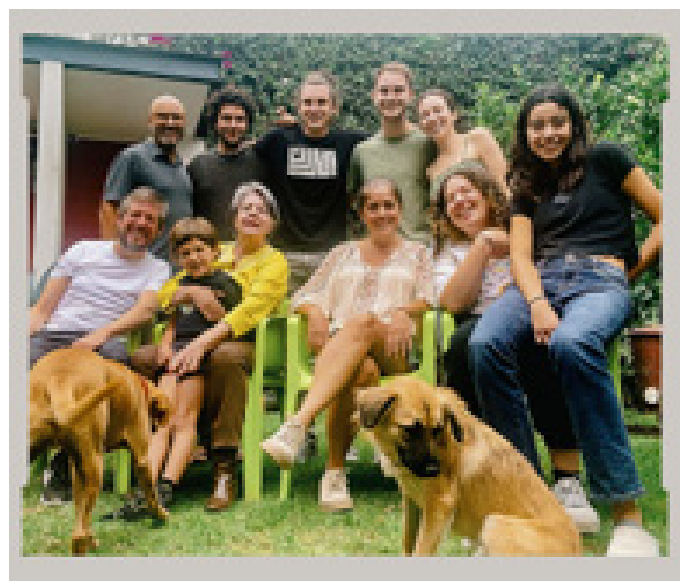

Alma with family during a gathering at her daughter's home 
Day in the Life

\section{Alma Julieta Juarez}

Mexico City

75 years old

"I'm 75 years old and life has not been too difficult, although it's not as simple doing certain things now. I never want to be a burden on anybody. Being self-sufficient in every way is wonderful. I pray that I can continue this way for as long as God wills. Until then I'll continue being grateful, happy, and enjoying life."

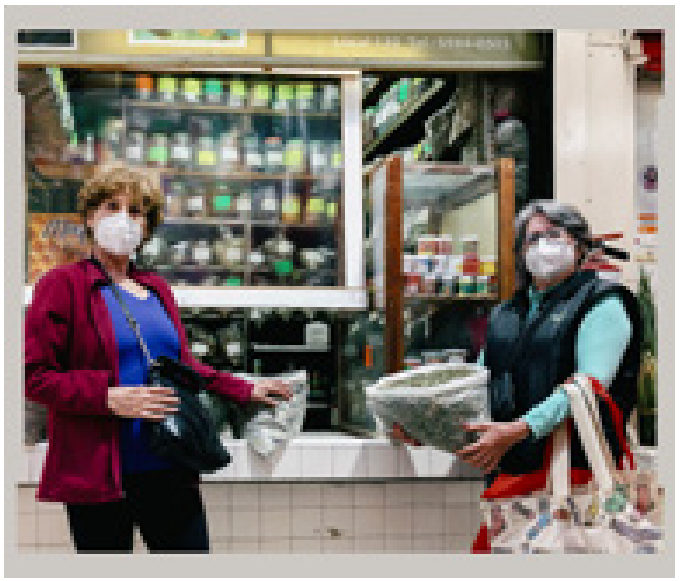

Shopping excursion with a friend in the marketplace

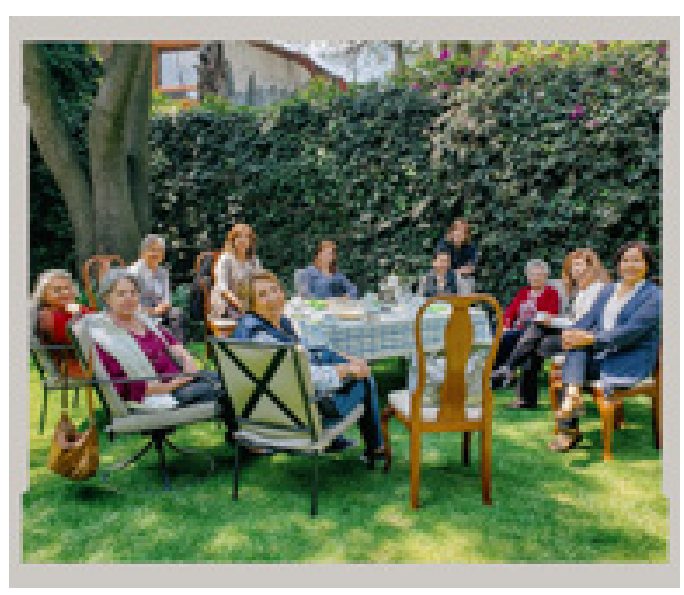

Alma with women from her "history class" group, whom she had not seen since before the pandemic

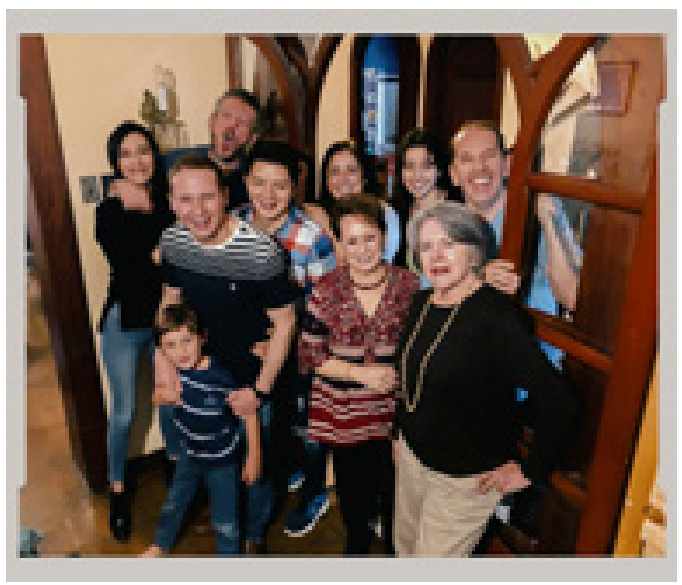

Gathering for a Sunday paella lunch with family at her son Tony's house

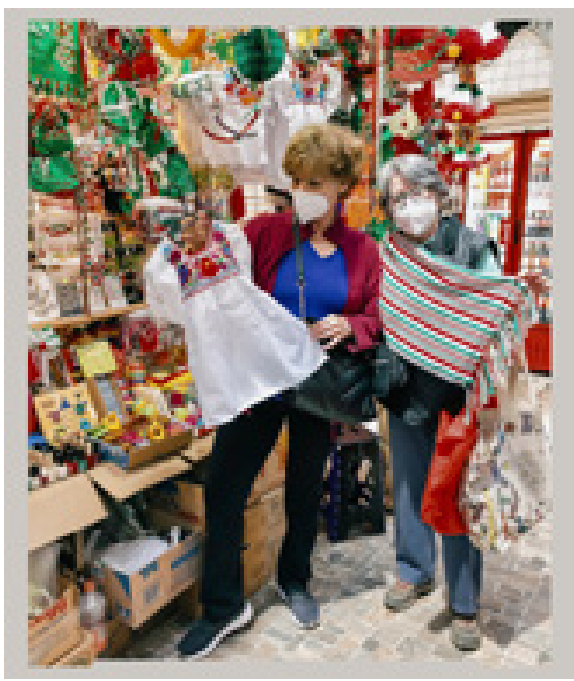

Shopping in the marketplace 


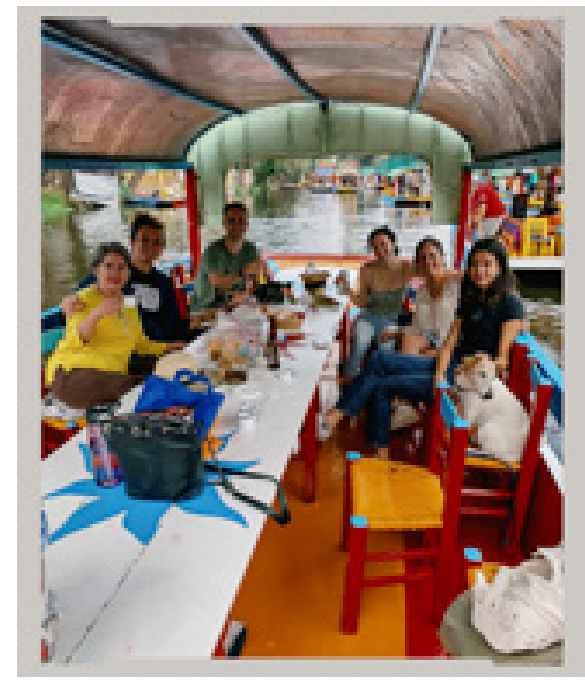

Taking a ride on a trajinera, a small flat bottomed boat, to visit the Floating Gardens in Xochimilco, México City

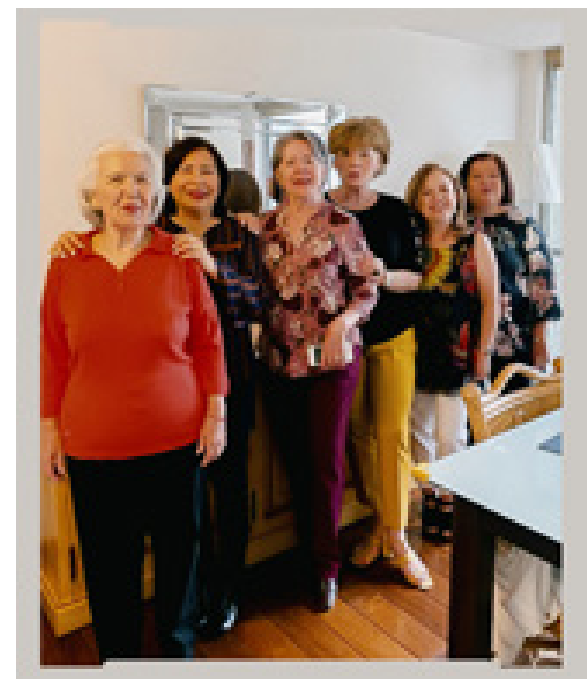

Spending time at friend Lulu's house

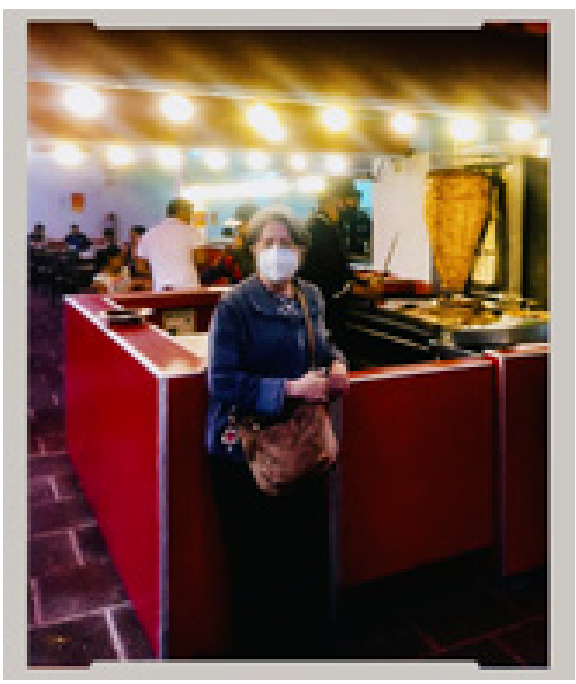

At the Copacabana, a restaurant in México City that serves delicious tacos

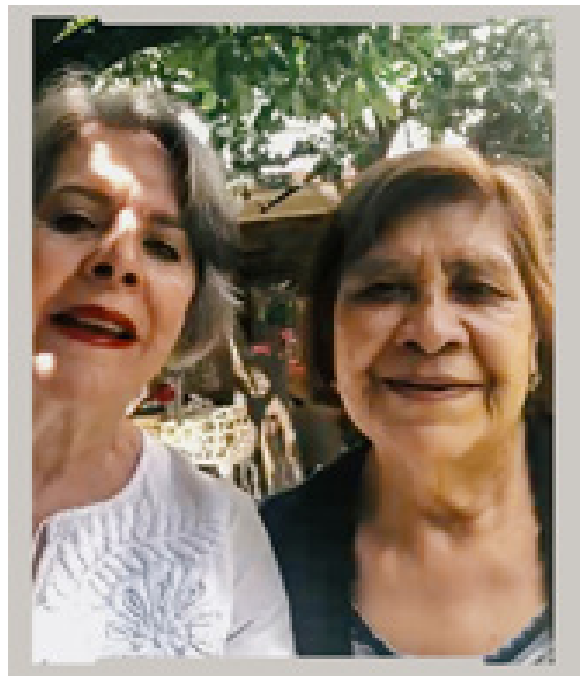

Alma (left) with friend and housekeeper Gloria, who has been with the family for 60 years and has been like a second mother to her

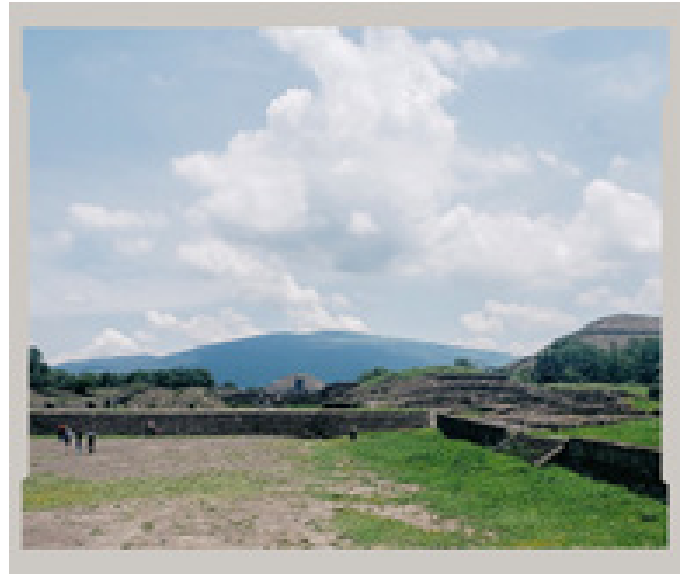

A photo from a trip with a friend to see the Teotihuacan pyramids

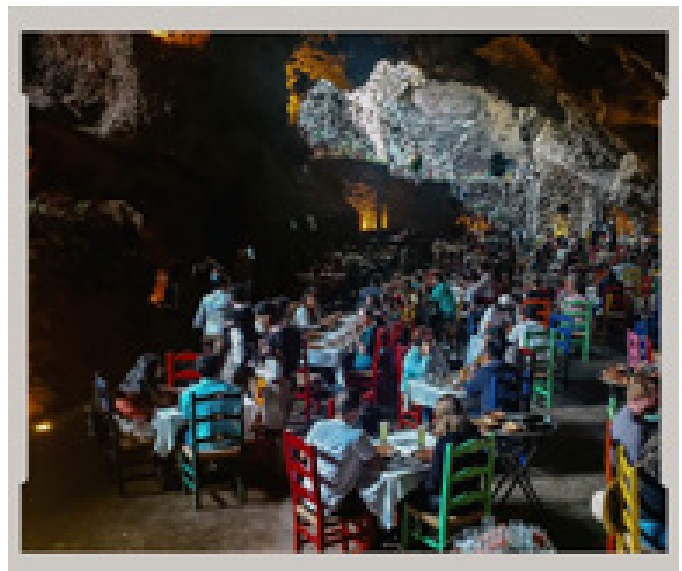

Lunch in the caves at Teotihuacan 

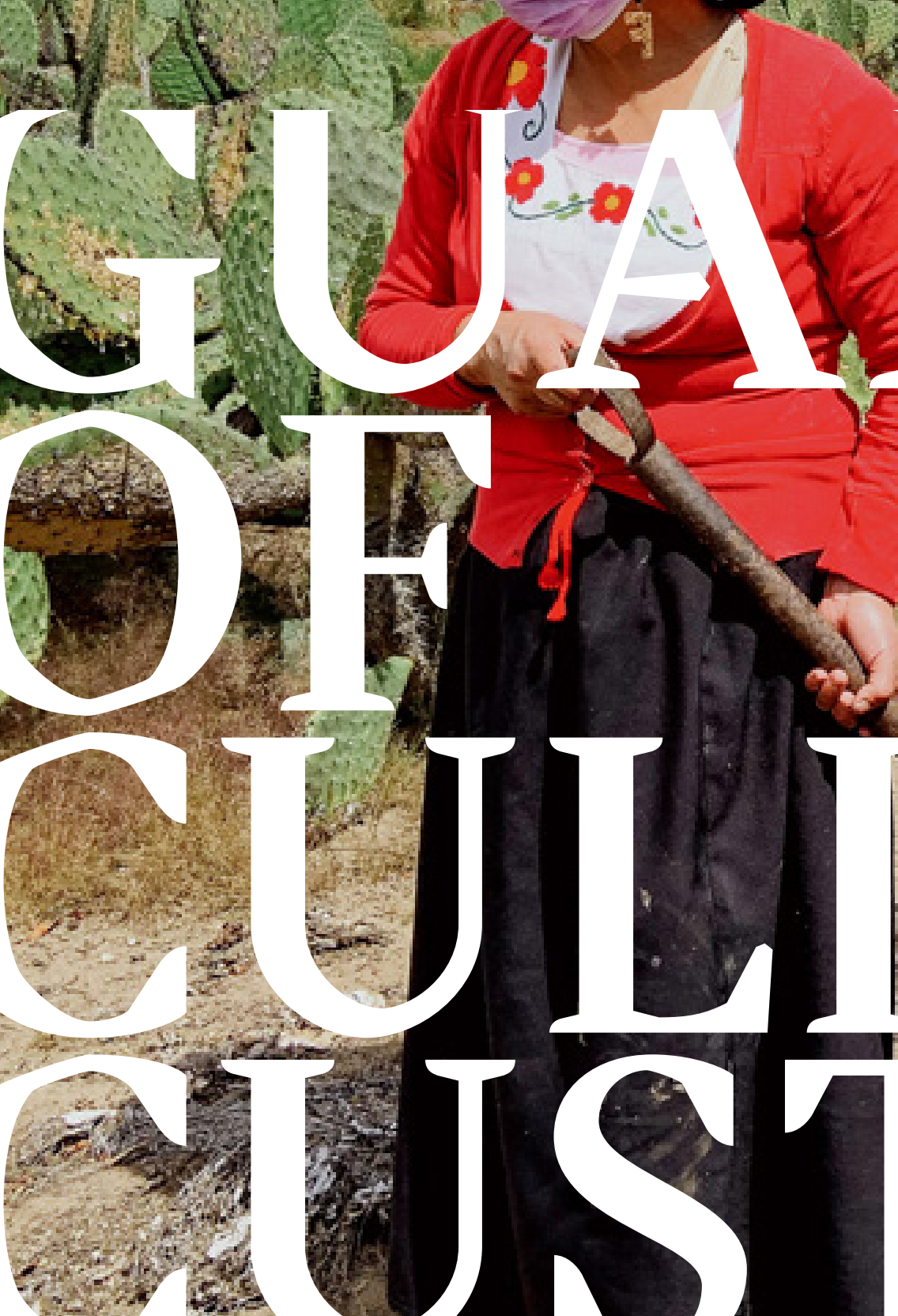

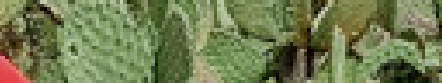

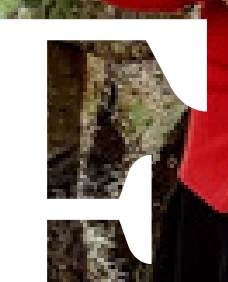




\section{Then Nicolasa Hernández \\ Muñoz was a girl, her \\ mother took her out into}

the fields of central Mexico to catch

a toad. Once she was holding the toad, she gently stroked it with one hand and then the other in an ancient ritual, before cupping it, gingerly lowering it back to the ground, and letting it go.

The ceremony, which is known as sapo rey, or toad king, marked her symbolic entry into the family kitchen. The careful mimicking of the movements used to prepare corn, shape it into a tortilla, and place it onto the griddle are confirmation that a girl has mastered the ability to handle the ingredients at the heart of Mexican cooking. 

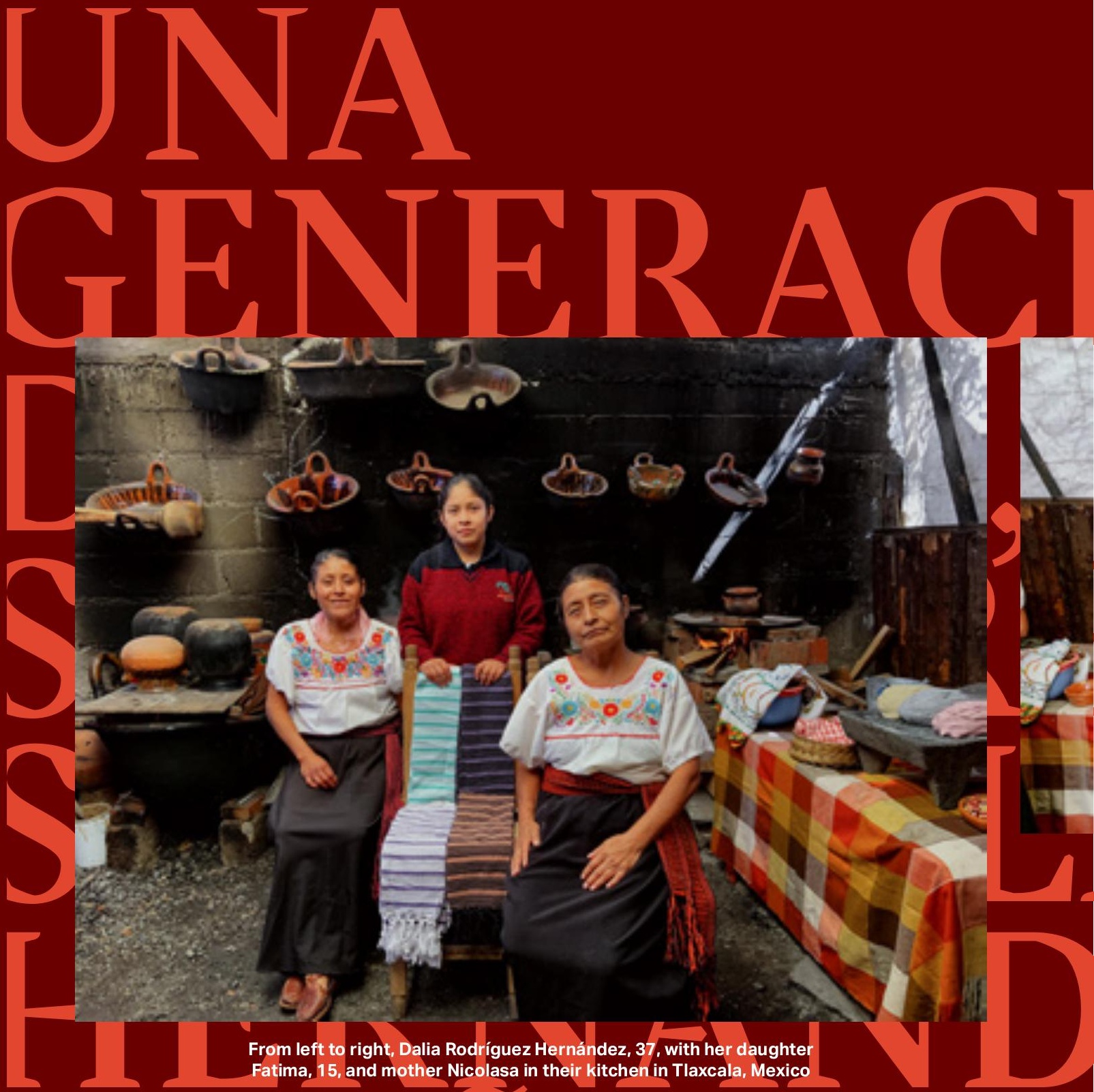
Fatima, 15, and mother Nicolasa in their kitchen in Tlaxcala, Mexico
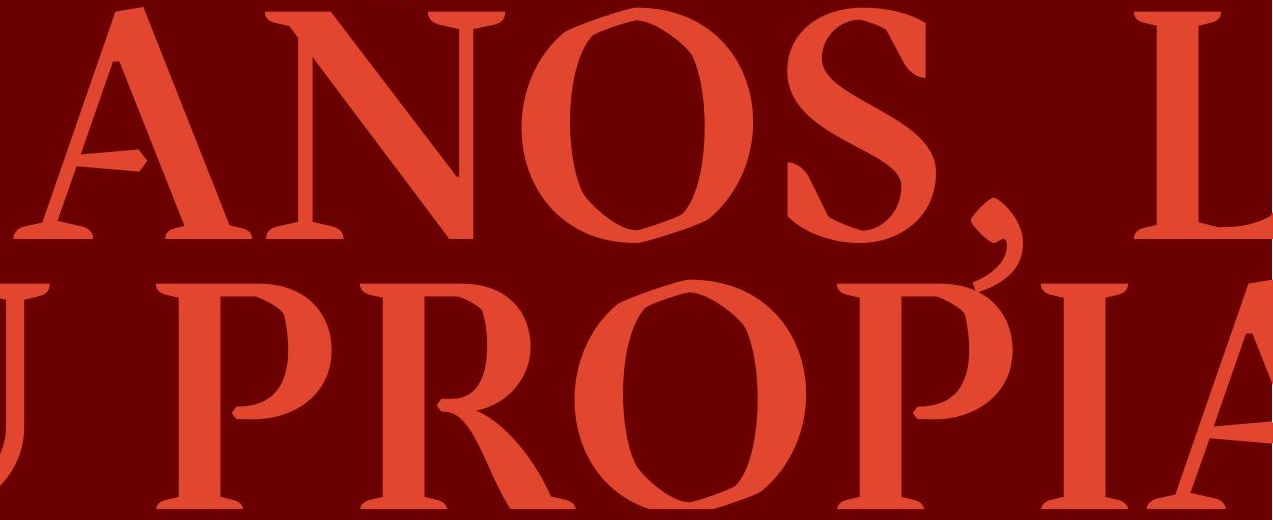


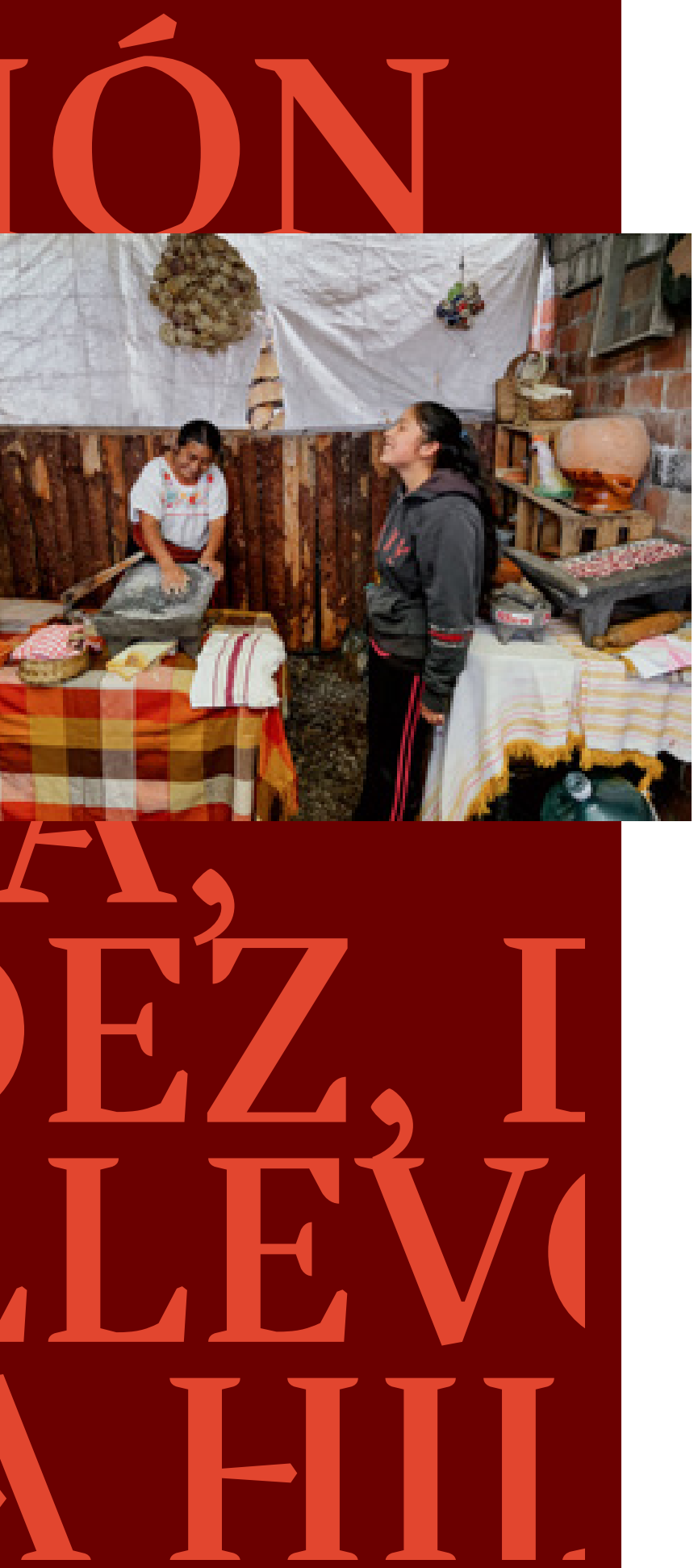

A generation later, with her mother and grandmother, Hernández, 56 , took her own daughter, Dalia, to the fields for the same sapo rey ritual. "It sensitizes the hands not to move too brusquely," said Dalia Rodríguez Hernández, 37, sitting at the long dining table at her home in the town of Contla de Juan Coamatzi.

A revival of the art of traditional cooking is under way in Mexico. Chefs are turning to ancient ingredients and trusted techniques to assemble their own versions of Mexican cuisine. Social media are filled with market tours and recipe videos while tourism boards promote their regions' local specialties.

That appreciation is giving visibility to the long-neglected caretakers of Mexico's gastronomic history, the rural women who have passed down knowledge over generations. The complex dishes that had been a source of domestic pride are now winning public admiration and generating respect for one of the country's most marginalized groups, the older women steeped in the heritage of Mexican food.

In Tlaxcala, a small state on Mexico's central plateau about two hours' drive from Mexico City, Hernández and her daughter belong to a group of traditional cooks who open their homes to visitors for workshops and demonstrations. The hope is that their growing visibility, which offers an income for what had always been unpaid work, will spur a younger generation to follow them.

Irad Santacruz Arcienaga, a Tlaxcala chef, began the group, called the Guardians of the Land of Corn, in 2009, and it has grown to more than 120 members throughout the state. "Our idea is to preserve the cooking 


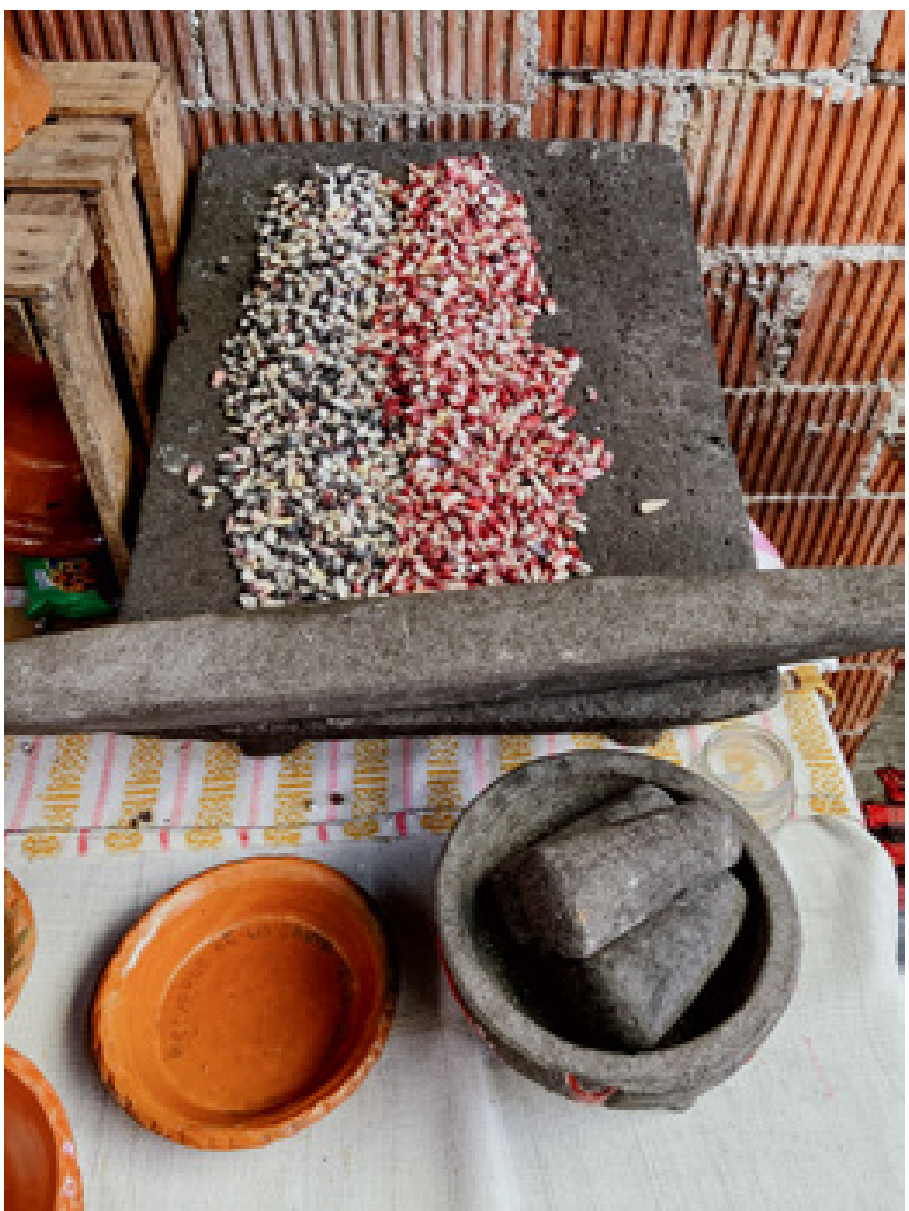

Preparing to grind the prepared corn, or nixtamal, on a base made of volcanic stone

and for the new generations to learn from the old generations," said Santacruz. "The transmission of knowledge is important." That knowledge radiates out from the kitchen to encompass much of rural life and its rhythms. The guardians are also farmers and textile artisans - heirs to the self-sufficiency that was needed for survival half a century ago, when Hernández woke up at 4 a.m. to weave on a loom or go to the river to wash clothes.

But the effort to pass on traditions constantly bumps up against modern pressures. Family bonds are fraying as people migrate to jobs in cities or to the United States. Better access to education offers the possibility of a career, an option that was closed to older women who were lucky if they finished middle school. And the history of discrimination against the speakers of Indigenous languages in Mexico means that younger generations no longer speak the same language their great-grandparents did, even if they may understand it.

Tlaxcala draws its cooking from the ingredients that flourish in its semi-arid climate, where squash, beans and the prickly pear cactus leaf, or pad, called nopal are staples alongside maíz criollo, the corn that is native to Mexico.

Corn is central to the Mexican kitchen. Believed to have been domesticated from its wild cousin teosinte about 9,000 years ago, maíz criollo is the result of many generations of seed selection. Each family chooses the seeds from its crop to plant the following year, a practice that has created a palette of 135 different colors of corn across Tlaxcala's fields.

Such small-scale cultivation doesn't pay though. Poverty forces farmers off the land and agroindustry threatens the survival of 


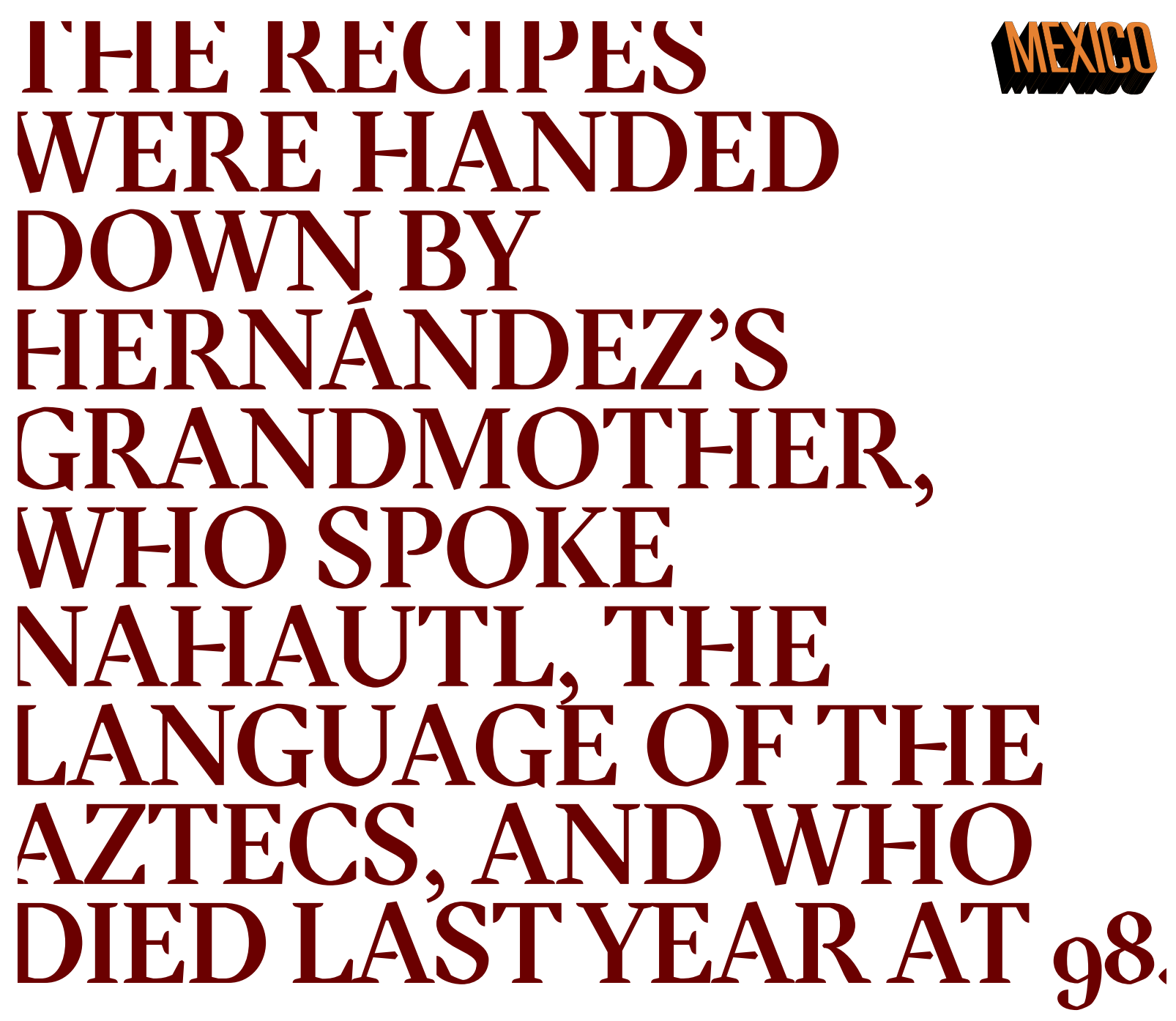

dozens of ancient varieties of maíz criollo in Mexico.

By relying on local corn, the Guardians help preserve Tlaxcala's varieties. "Through food, we can conserve ingredients, ecosystems, and the farmers' knowledge," said Santacruz. Once harvested, the dried corn kernels are first cooked and soaked in water with lime to make what is called nixtamal. The pre-Hispanic process both softens the kernels and releases their nutrients.

In their kitchen, Hernández and her daughter Rodríguez grind three different types of nixtamal by hand - white, blue and pink - on a metate, a curved base made of volcanic stone, into a dough called masa. They mold the masa into a tricolor ball that is then placed in a hand press to form a disc that they drop onto a large griddle.

They serve the tortillas for family lunch with their own pepián de venas, a fragrant sauce based on squash and sesame seeds along with seeds from four different chiles. The pepián is spooned over chicken and rice after a first course of soup made from a local legume called alberjol. The recipes were handed down by Hernández's grandmother, who spoke Nahautl, the language of the Aztecs, and who died last year at 98. She never drank water, just pulque, a pre-Hispanic drink of fermented agave sap, with Coca-Cola.

Not all traditions are worth preserving though. By bringing income into the household and traveling across Mexico and abroad to demonstrate their cooking, Hernández and Rodríguez believe they have chipped away at Mexico's entrenched machismo. "We have broken a pattern," Rodríguez said. "Now there is more priority given to food and to women." In the town of Huamantla, Flavia de Albino Ortega, 58, leads a household of three 


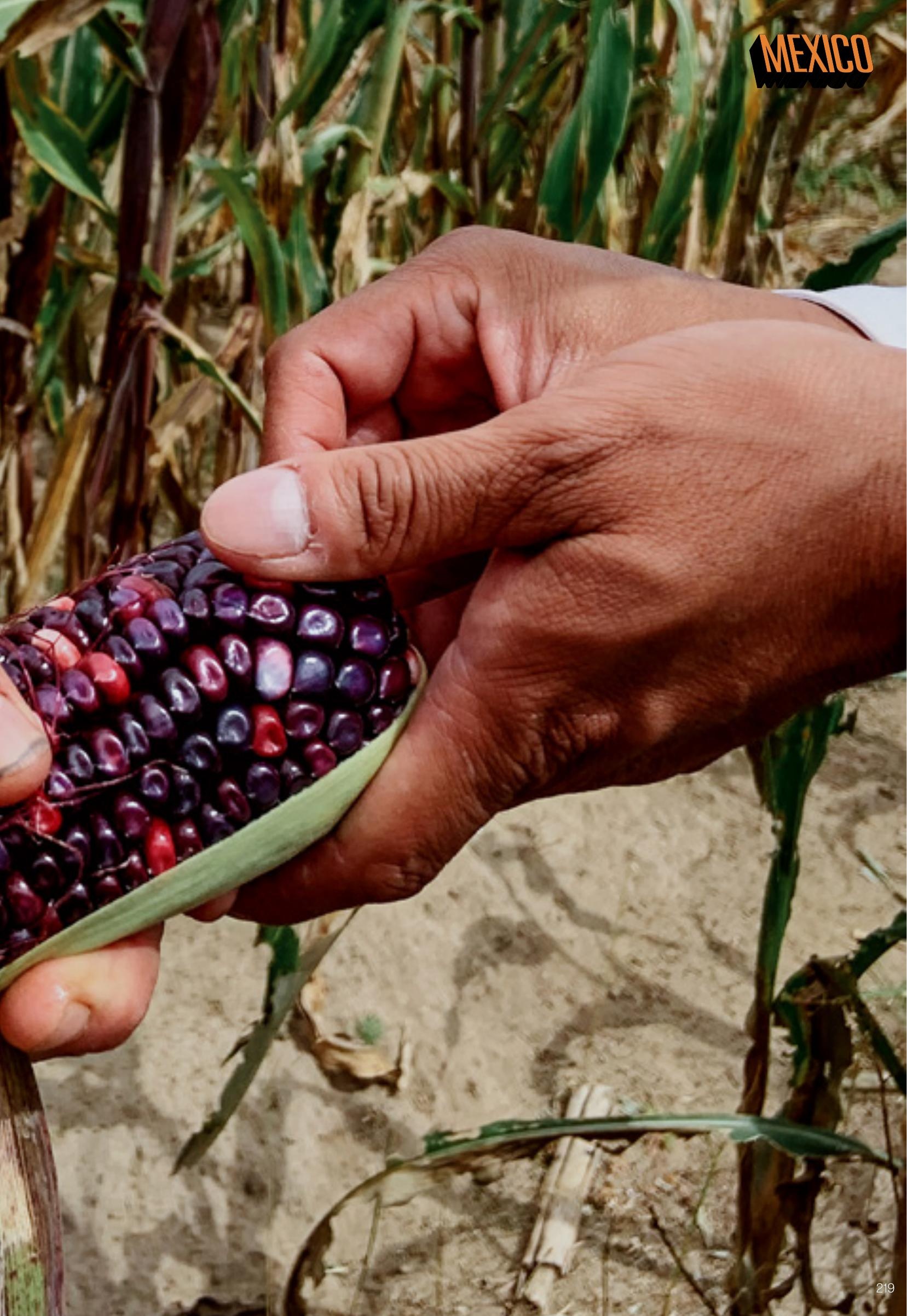


women who cultivate their own corn, nopal, squash and greens. They are also part of the Guardians, and they mix what they grow with other ingredients into what seems like an infinite array of dishes. "This is how my grandmothers did it," said de Albino, kneeling on a blanket before a ceramic griddle fueled by kindling and dried corn cobs. She spread alberjol on a tortilla made from a corn and nopal mixture and folded it into a triangle. Her tamal was filled with her family's mole, a sauce that includes almonds, chiles, and in the past, the wattle of a turkey, now replaced by lard.

Her daughter, Gloria Rodríguez de Albino, 32 , brought out a bowl filled with small, dried river fish, mixed with garlic and dried chile chipotle, which has a smoky flavor. It was her grandmother's recipe: "We don't want this to be lost. I transmit it to my daughter and my granddaughter," de Albino said.
Jacobed Martínez Rodríguez, 14, has already joined the family business, accompanying her mother and grandmother three times a week to tend to the fields. She also brings a teenage sensibility to the venture, posting photos of dishes and ingredients on Instagram.

One of 11 children, de Albino never went to school, although she learned to read when she began working as a maid and then became a nursing assistant. But access to education has expanded and now her daughter is studying for a degree in food science.

The women usually take the bus to their fields, spread over six acres off a country road. De Albino has received advice from a state agronomist on how to cultivate her crops organically, a task that requires constant work. Tiny insects called cochineals, which produce a natural crimson dye, have settled on the nopal. De Albino plucked a

Flavia de Albino Ortega preparing food at her home in the town of Huamantla

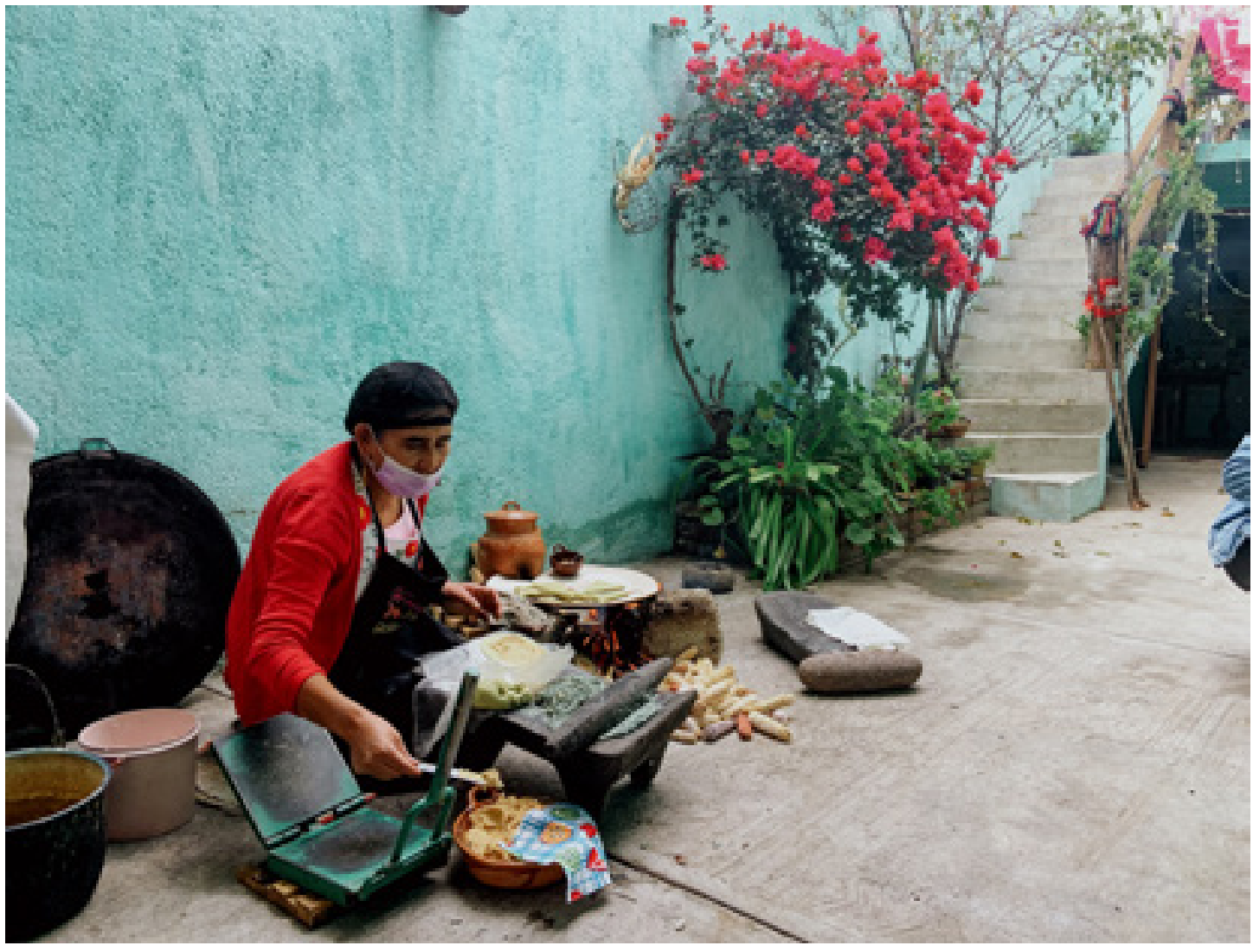




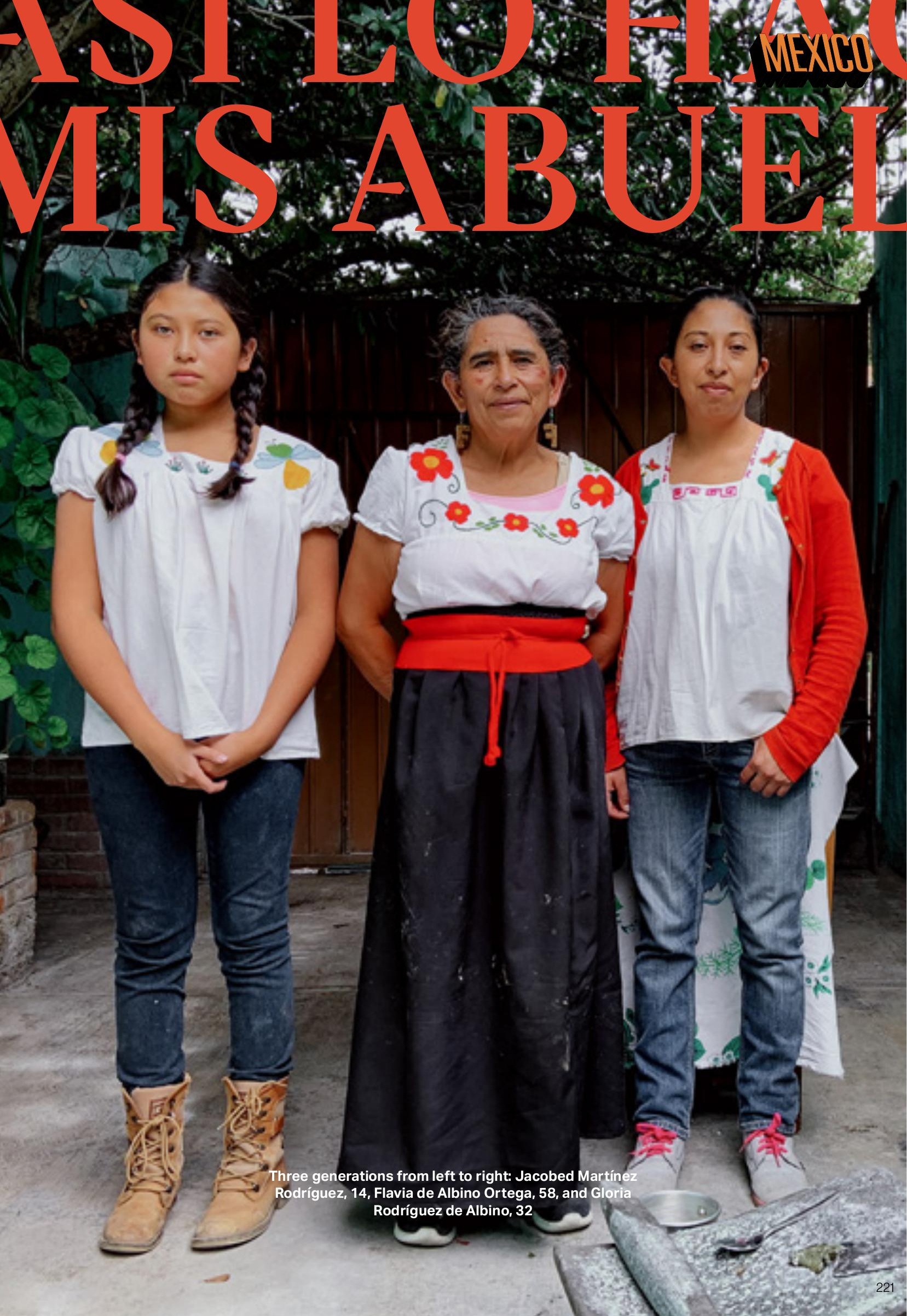




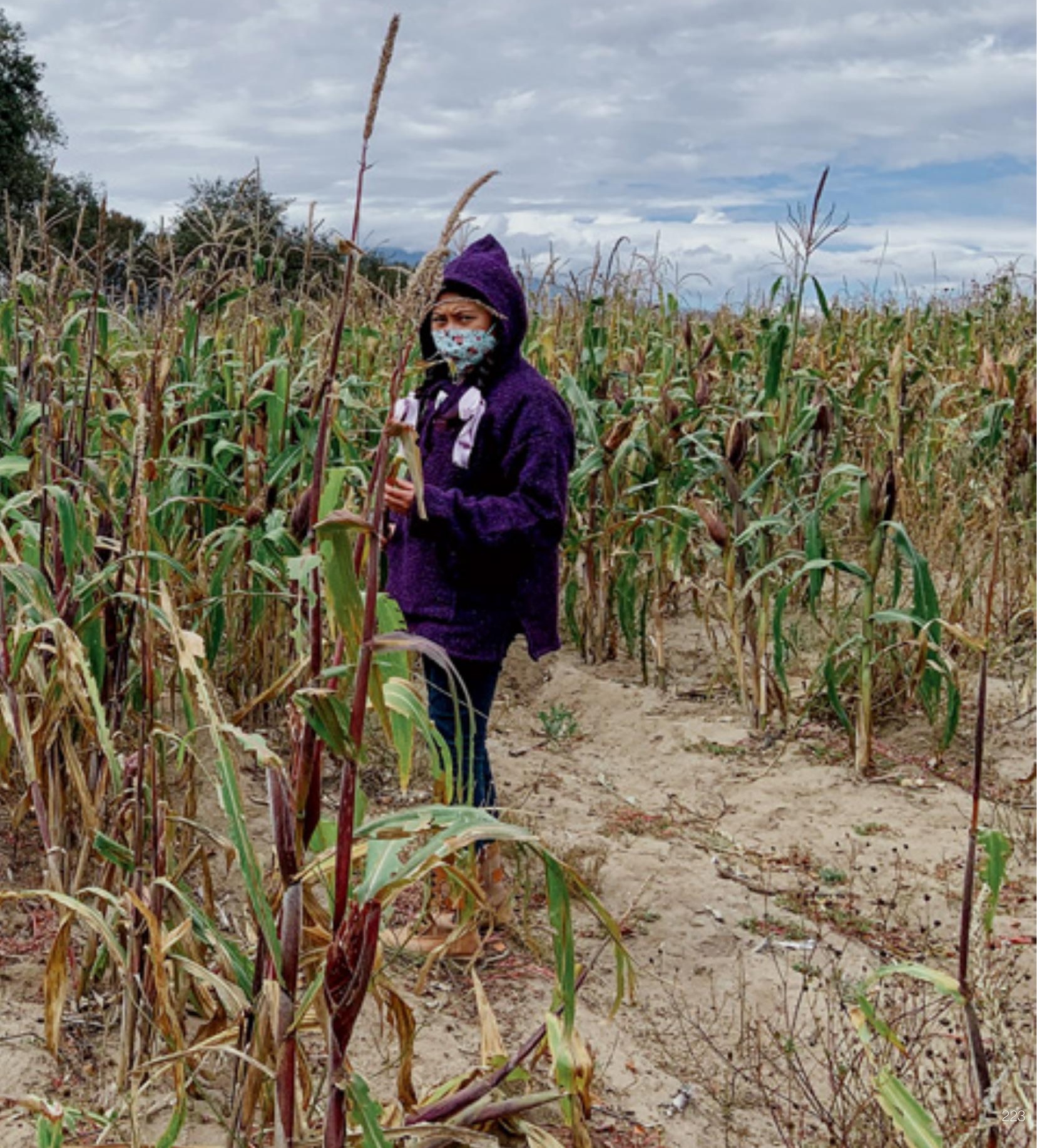


cochineal, crushed it between her fingers and brushed the color across her cheeks. She picked a wild berry. "Here in the countryside is the real food," she said.

As Tlaxcala's fragrant cooking and intricate embroidery are being celebrated, the women who preserve those traditions often describe lives of unimaginable hardship.

Juanita Márquez Solís, 94, raised her seven children alone after she was left a widow. A native speaker of the Yuhmu dialect of the Indigenous Otomí language, Ms. Márquez would walk about 6 miles from Ixtenco, where she and her family still live, to Huamantla to sell seeds. "There was no electricity, no water; we ate only vegetables," recalled Márquez. Instead of water, people drank pulque.

When outsiders came to Ixtenco, she said, she would hide because she didn't speak Spanish. But her children grew up speaking Spanish. Now, it is her great-granddaughter, Alejandra Yoell, 5, who is learning to speak Otomí again in a bilingual elementary school. Despite such poverty, Márquez passed down the knowledge she had learned from her own widowed mother. It is the turn of her daughters, Silvia and Angela Baltazar Márquez, to become the conduits for those domestic traditions.

Four generations of the Baltazar Marquez family in their Ixtenco home

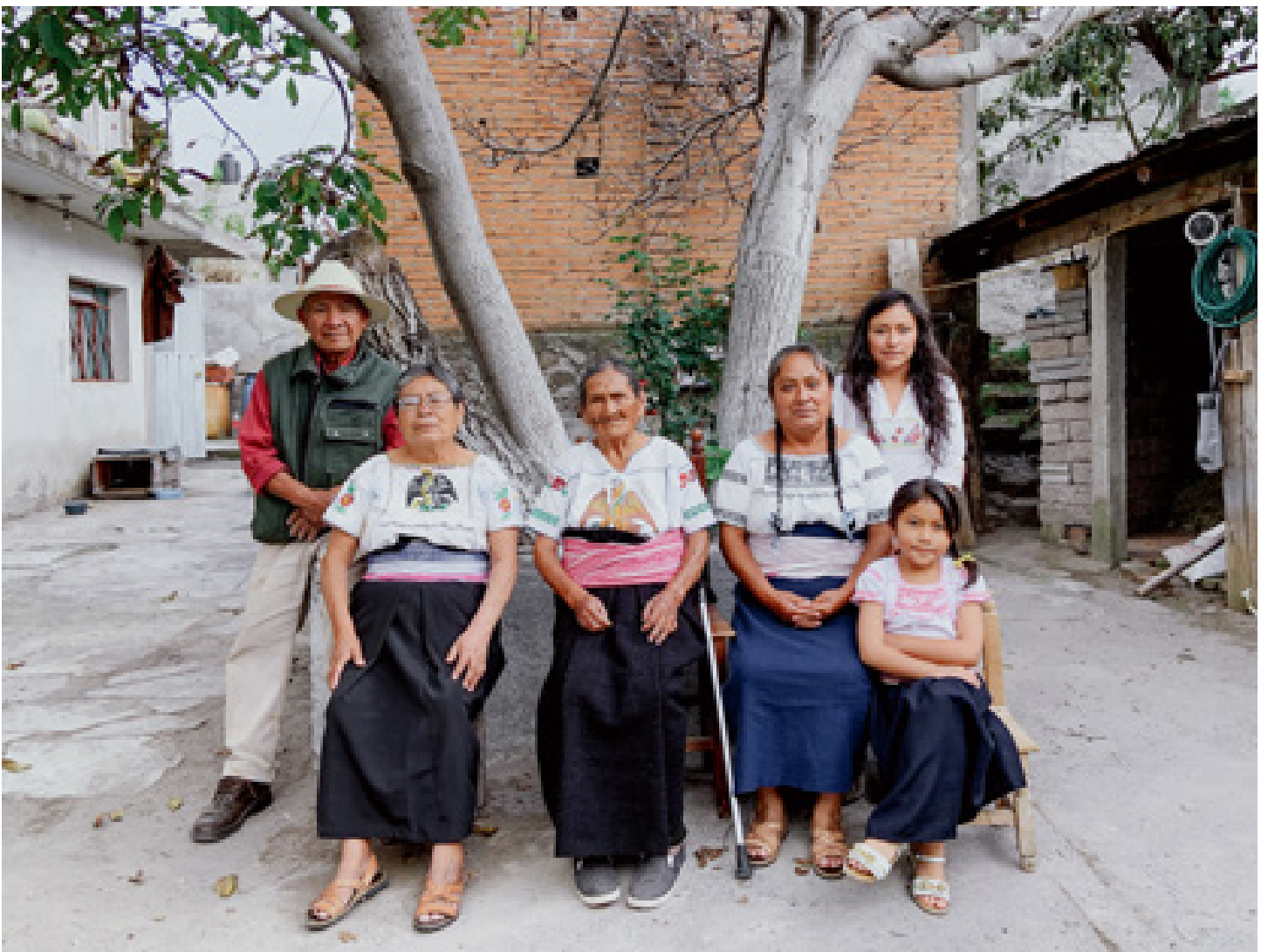




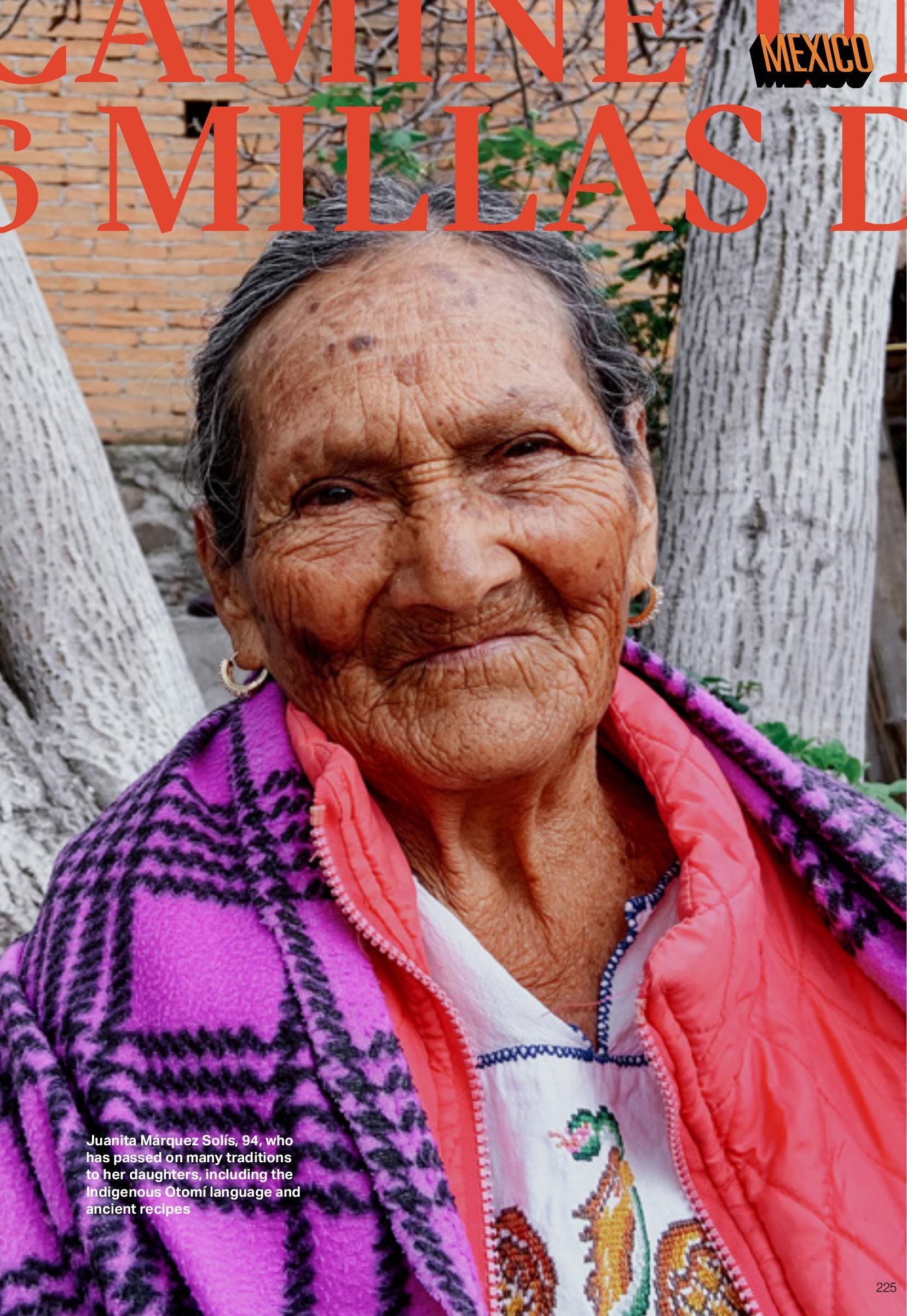


"This is our way of life," said Angela

Baltazar, 53. "Here we eat what we harvest. We have always cooked the same way. We haven't lost the essence of what we are."

Their mole de matuma is a closely held recipe, prepared for the festival celebrating the town's patron saint. Their dishes also use different native beans and an array of greens that have been grown since pre-Hispanic times. The Otomí food and traditions of Ixtenco are so distinct that anthropologists have come to the town to study them, and the Baltazar Márquez sisters, as members of the Guardians, have gone to universities to give talks about their ancient recipes.

"We're opening up spaces for people who want to learn," said Silvia Baltazar, 66. "It isn't a science, it's something we have been doing since we were young."

The interest in these local traditions has brought a change for her husband, Filomen Huerta Juárez, who has seen more demand for the multi-colored corn he harvests once a year, rotating that crop with beans and squash.

The Otomí also have a rich heritage of embroidery. After a long day in the fields, said Márquez, women would return home to embroider blouses with a technique called pepenado. The family brought out a treasured heirloom that an aunt had made and pointed to the date she had embroidered to mark a special occasion: 1928.

That tradition continues, although it adapts to modern tastes. Alejandra Baltazar, 35, Angela's daughter, likes to use beads for her embroidery. Like others of her generation, she has been able to study and has a social psychology degree - but she is pulled back to preserve her heritage. "The flavors call out to you," she said of the laborious recipes she prepares with her family.

"We all have an identity — and this is mine." •

The Baltazar Márquez women preparing Otomí dishes passed down through the generations

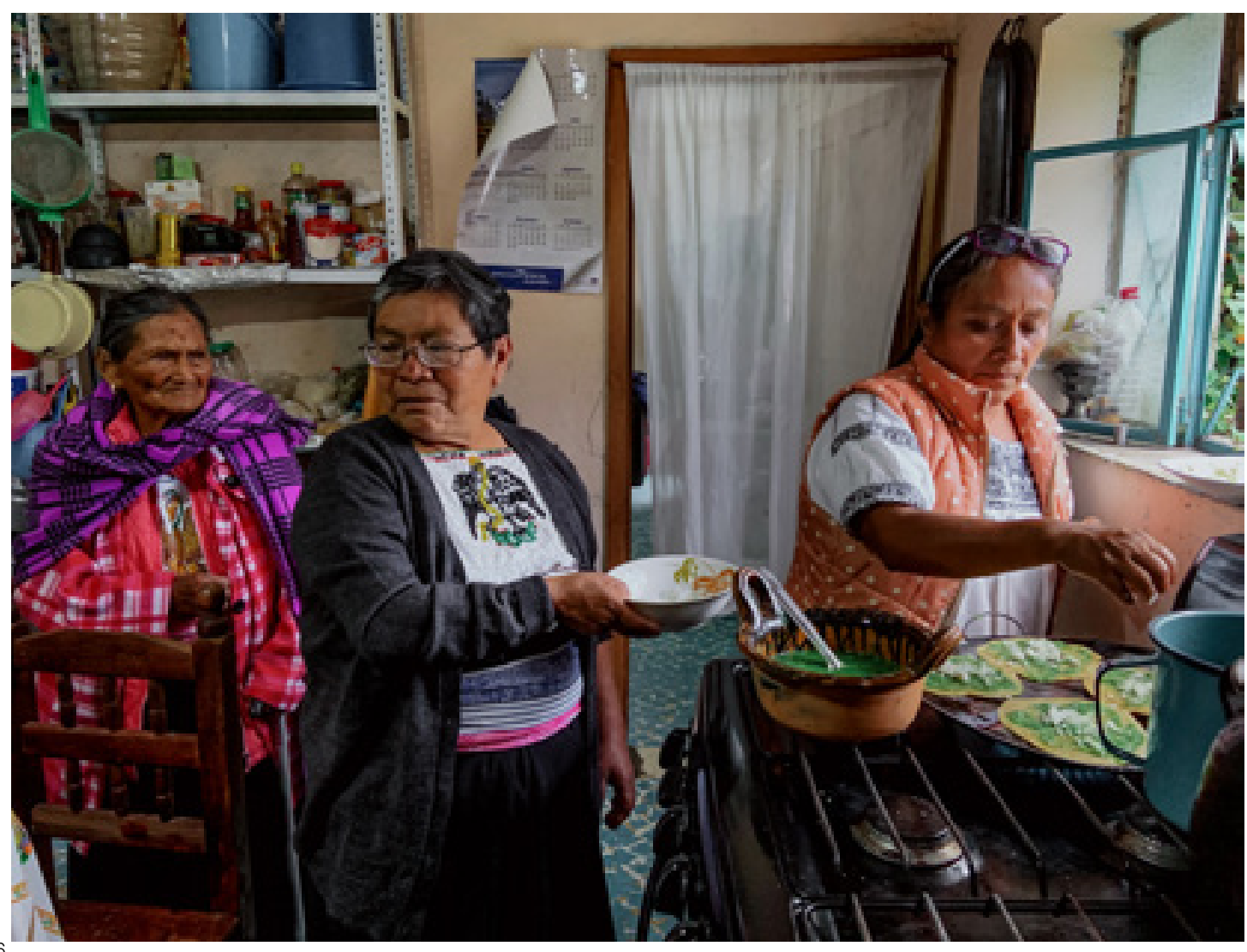


MEXIED
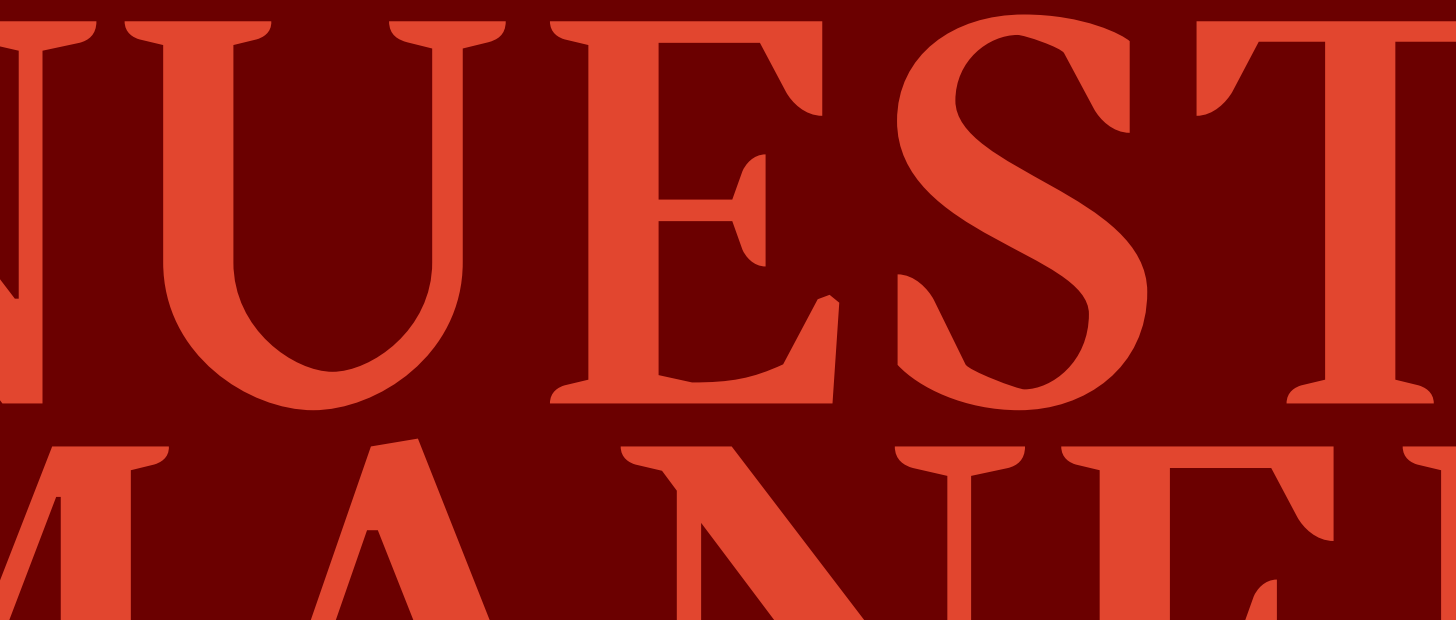

"IHIS IS UURWAY

OFIFE"SAID

ANGELA BALARAR, GTERE WVE EAT

33. FERE WE EAI

WHATWE HARVEST.

WE FAVE ALWAYS

COOKED THE SAMIE

WAY. WE HAVEN'T

LOST THE ESSENCE

DF WHANI WE ARE" 


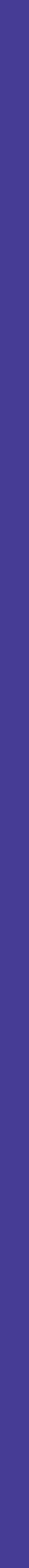




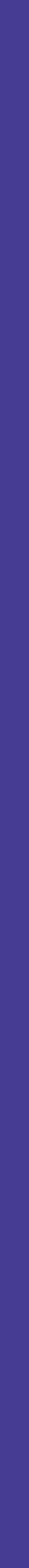




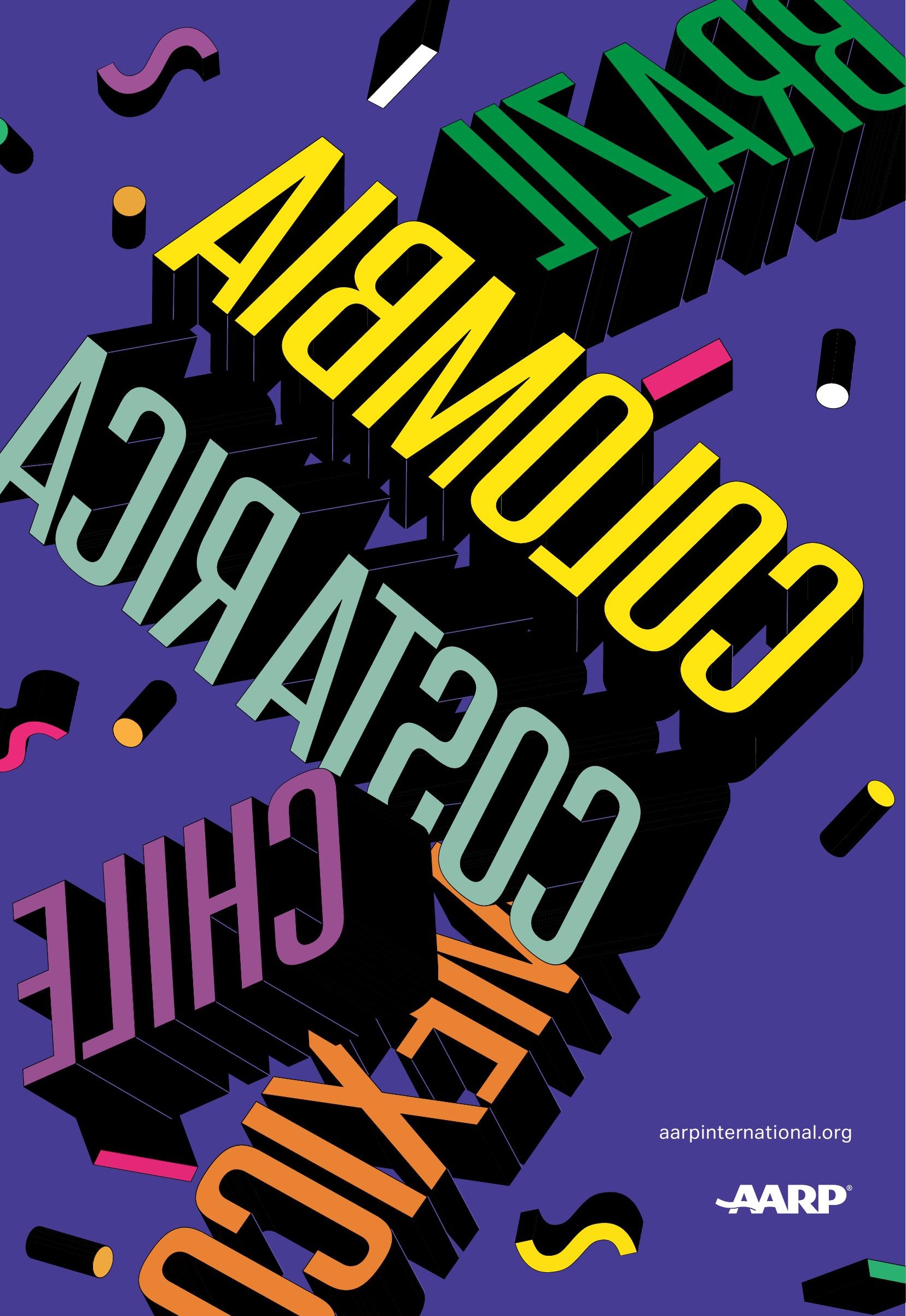

